Portland State University

PDXScholar

Spring 7-10-2019

\title{
Large-Scale DER Aggregations of Electric Water Heaters and Battery Inverter Systems
}

Kevin Marnell

Portland State University

Follow this and additional works at: https://pdxscholar.library.pdx.edu/open_access_etds

Part of the Electrical and Computer Engineering Commons Let us know how access to this document benefits you.

\section{Recommended Citation}

Marnell, Kevin, "Large-Scale DER Aggregations of Electric Water Heaters and Battery Inverter Systems" (2019). Dissertations and Theses. Paper 5097.

https://doi.org/10.15760/etd.6973

This Thesis is brought to you for free and open access. It has been accepted for inclusion in Dissertations and Theses by an authorized administrator of PDXScholar. Please contact us if we can make this document more accessible: pdxscholar@pdx.edu. 
Large-Scale DER Aggregations of Electric Water Heaters and Battery Inverter Systems

by

Kevin Marnell

A thesis submitted in partial fulfillment of the requirements for the degree of

\author{
Master of Science \\ in \\ Electrical and Computer Engineering
}

Thesis Committee:

Robert Bass, Chair

John M. Acken

Douglas V. Hall

Portland State University

2019 
(C) 2019 Kevin Marnell 


Abstract

Distributed energy resources like residential electric water heaters and residential batteryinverter systems offer a small amount of change to the grid individually. When aggregated however, these assets can cause major effects to the electric grid. Aggregating these resources allows them to take on generator-like functions with the ability to increment power and decrement power.

The Western Energy Imbalance Market is an energy market offering 15 minute and 5 minute markets for energy transactions between balancing areas. Generation assets make increment and decrement bids. Traditionally the only entrants to this market have been large scale generators and large scale assets legally designated as generators. Aggregated distributed resources could offer the same increments and decrements from managing residential assets like electric water heaters and batteries.

DERAS, a Distributed Energy Resource Aggregation System developed by the Portland State Power Lab group, is an aggregator of residential resources that could offer increment and decrement bids to an energy market, like an Energy Imbalance Market. This research models and simulates aggregations of distributed energy resources. This work analyzes the effects of 10,000 electric water heaters and 10,000 battery inverter systems. A simulation program was built to simulate regular use of these assets, and then add the additional effects of a decrement bid into the Western Energy Imbalance Market. The effects of the bids on 
energy levels inside the water heaters and batteries are examined. The power imported from the grid is also analyzed as an effect of the aggregator attempting to cover a generation decrement bid. 


\section{Acknowledgements}

Thank you to Pr. Robert Bass and the rest of the power lab researchers, Manny Obi, Tylor Slay, and Leighton Clarke. 


\section{Contents}

Abstract

Acknowledgements

List of Tables $\quad$ vi

List of Figures $\quad$ vii

1 Introduction 1

1.1 Problem Statement . . . . . . . . . . . . . . . . . . . . . 1

1.2 Objectives of Work . . . . . . . . . . . . . . . . . 1

1.3 Distributed Energy Resources (DER) . . . . . . . . . . . . . . 2

1.4 Virtual Power Plant (VPP) . . . . . . . . . . . . . . . 3

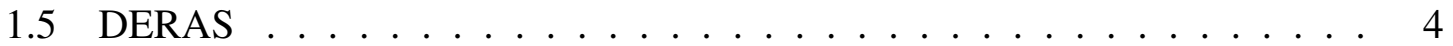

1.6 Operator Class . . . . . . . . . . . . . . . . . . . . . . 5

1.7 Balancing Area Authorities . . . . . . . . . . . . . . . 6

1.8 Energy and Imbalances Markets . . . . . . . . . . . . . . . 7

1.9 Literature Review . . . . . . . . . . . . . . . . . . . 8

2 Design Methodology 12

2.1 Modeled Aggregated Units . . . . . . . . . . . . . . . . . . . . . . . . . . . . 12

2.2 Electric Water Heaters . . . . . . . . . . . . . . . . . 13

2.3 EWH simulation in MATLAB . . . . . . . . . . . . . . . . . . . . . . .

2.3.1 Loading in the data . . . . . . . . . . . . . 16

2.3.2 Creating a look-up matrix for draw events . . . . . . . . . . . 17

2.3.3 Simulating EWH Behavior . . . . . . . . . . . . . . . . . . 17

2.3.4 Simulating Bids . . . . . . . . . . . . . . . . 21

2.4 Battery Inverter Systems . . . . . . . . . . . . . . . . 23

2.5 Battery Simulation . . . . . . . . . . . . . . . . . . 24

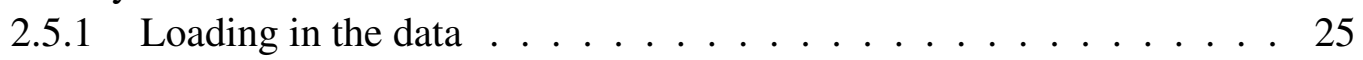

2.5.2 Simulating BIS behavior .............. 26

2.5.3 Simulating a Battery Bid ............... 29

3 Results \& Analysis

3.1 Results of simulating EWH assets without bids . . . . . . . . . . 32 
3.2 Results of the EWH on Assets with bids . . . . . . . . . . . . . . . 34

3.3 Results of Battery-Inverter Systems without bids . . . . . . . . . . . . 56

3.4 Results of Battery-Inverter Systems with EIM Bids . . . . . . . . . . . 60

4 Discussion $\quad \mathbf{7 6}$

4.1 EWH Aggregations . . . . . . . . . . . . . . . . . 76

4.2 BIS Aggregations . . . . . . . . . . . . . . . 78

5 Conclusion $\quad 82$

$\begin{array}{lr}\text { Bibliography } & 84\end{array}$

Appendix A: MATLAB Scripts $\quad 89$ 


\section{List of Tables}

2.1 Census Water Heater Makeup . . . . . . . . . . . . . . . . . . . . . . . . 14

2.2 EWH Calculations at each state . . . . . . . . . . . . . . . . 20

2.3 Statuses of EWH and BESS assets. . . . . . . . . . . . . . . . 26

2.4 Statuses of EWH and BESS assets. . . . . . . . . . . . . . . . . . . . . . 29

2.5 BIS calculations at each state $\ldots \ldots \ldots \ldots \ldots$

3.1 Maximum power of EWH aggregation . . . . . . . . . . . . . . 54 


\section{List of Figures}

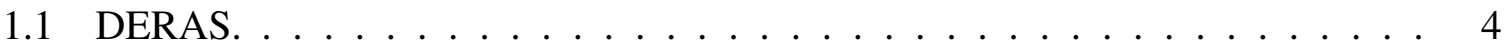

2.1 State diagram for electric water heater model. . . . . . . . . . . . . 18

2.2 Aggregator dispatch algorithm. . . . . . . . . . . . . . . 22

2.3 State diagram for battery inverter system model. . . . . . . . . . . . . . . . 28

2.4 BIS states for EIM dispatch. . . . . . . . . . . . . . . . . . 31

3.1 Simulated EWH energy take with no bids. . . . . . . . . . . . . . . . 33

3.2 Simulated EWH draws and heating. . . . . . . . . . . . . . . . . 34

3.3 Simulated EWH energy take from 5 MW bid. . . . . . . . . . . . . . 35

3.4 Simulated EWH heating from a 5 MW bid. . . . . . . . . . . . . 36

3.5 Simulated EWH energy take from a $6 \mathrm{MW}$ bid. . . . . . . . . . . . . 37

3.6 Simulated EWH heating from a $6 \mathrm{MW}$ bid. . . . . . . . . . . . . . . 38

3.7 Power absorption from 5 and $6 \mathrm{MW}, 1$ hour bids . . . . . . . . . . . . . 39

3.8 Power absorption for 2 hour bids. . . . . . . . . . . . . . . . . 40

3.9 Simulated EWH energy take from a $1.5 \mathrm{MW}, 18$ hour bid. . . . . . . . . . . . 41

3.10 Next day energy take from a $1.5 \mathrm{MW}, 18$ hour bid. . . . . . . . . . . . . . . . . 42

3.11 Simulated EWH heating from a $1.5 \mathrm{MW}, 18$ hour bid. . . . . . . . . . . . . . 43

3.12 Next day EWH heating from a $1.5 \mathrm{MW}, 18$ hour bid. . . . . . . . . . . . . . . 44

3.13 Simulated EWH energy take from a $1.6 \mathrm{MW}, 18$ hour bid. . . . . . . . . . . . . 45

3.14 Simulated EWH heating from a $1.6 \mathrm{MW}, 18$ hour bid. . . . . . . . . . . . . . 46

3.15 Simulated EWH energy take from a $2.0 \mathrm{MW}, 18$ hour bid. . . . . . . . . . . . . 47

3.16 Simulated EWH heating from a $2.0 \mathrm{MW}, 18$ hour bid. . . . . . . . . . . . . . . 48

3.17 Power absorption for 18 hour bids. . . . . . . . . . . . . . . . . . 49

3.18 Simulated EWH energy take from a 43 MW, 5 minute bid. . . . . . . . . . . 50

3.19 Simulated EWH heating from a 43 MW, 5 minute bid. . . . . . . . . . . . 51

3.20 Maximum EWH power availability across 24 hours. . . . . . . . . . . . . 52

3.21 Maximuym EWH power availability across 2 hours. . . . . . . . . . . . . 53

3.22 Maximum biddable energy up to 2 hours. . . . . . . . . . . . . . . . 54

$3.23100 \mathrm{EWH}$ aggregate energy take bidding $50 \mathrm{~kW} \ldots \ldots \ldots \ldots$

$3.24100 \mathrm{EWH}$ aggregate power absorption over 1 hour. . . . . . . . . . . . 56

3.25 State of charge for BIS aggregation with no bids . . . . . . . . . . . . 57

3.26 Logic states for BIS aggregation with no bids . . . . . . . . . . . . 58

3.27 Actions of BIS aggregation with no bids . . . . . . . . . . . . . 59 
3.28 PJM RegA signal . . . . . . . . . . . . . . . . . . . . . . . 60

3.29 BIS aggregate state of charge for 20 MW bid. . . . . . . . . . . . 61

3.30 BIS aggregate logic states for $20 \mathrm{MW}$ bid. . . . . . . . . . . . . . 62

3.31 BIS aggregate actions for $20 \mathrm{MW}$ bid. . . . . . . . . . . . . 63

3.32 BIS aggregate state of charge for $50 \mathrm{MW}$ bid. . . . . . . . . . . . . 64

3.33 BIS aggregate logic states for $50 \mathrm{MW}$ bid. . . . . . . . . . . . . 65

3.34 BIS aggregate actions for $50 \mathrm{MW}$ bid. . . . . . . . . . . . . 66

3.35 Power absorbed by BIS aggregation over 2 hours. . . . . . . . . . . . 67

3.36 BIS aggregate state of charge for $15 \mathrm{MW} 18$ hour bid. . . . . . . . . . . . 68

3.37 BIS aggregate logic states for 15 MW 18 hour bid. . . . . . . . . . . . . 69

3.38 BIS aggregate actions for $15 \mathrm{MW} 18$ hour bid. . . . . . . . . . . . . 70

3.39 BIS aggregate state of charge for 20 MW 18 hour bid. . . . . . . . . . . 71

3.40 BIS aggregate logic states for 20 MW 18 hour bid. . . . . . . . . . . 72

3.41 BIS aggregate actions for $20 \mathrm{MW} 18$ hour bid. . . . . . . . . . . . 73

3.42 BIS power absorption for $18 \mathrm{hr}$ bids. . . . . . . . . . . . . . . . 74

3.43 Maximum power output for BIS aggregation over 3 hours. . . . . . . . . 75 


\section{Introduction}

\subsection{Problem Statement}

Distributed Energy Resources Management (DERM) systems have been recognized as a means to provide energy or manage loads to better operate the power grid. By injecting power to the grid or reducing load, DERM can accomplish a number of useful grid functions. When generation is greater than load, DERM can turn on additional loads to balance the power grid. When load is greater than generation, DERM can turn off loads to balance the power grid. DERM can also provide regulation services like frequency control and reserve services like spinning and non-spinning reserves.

Portland State University's Power Lab has built a computer program to aggregate DER assets. This aggregation program, known as the Distributed Energy Resources Aggregation System (DERAS), was examined for utilization in an energy imbalance market (EIM). Simply put, DERAS is a DERM that manages DER. The current prototype of DERAS has been used to conrol 100 DER. This work examines the aggreation of 10,000 DER.

\subsection{Objectives of Work}

I aimed to test the capabilities of DERAS throug simulation. As part of this work, I spent time working with DERAS, turning on its assets both real and emulated, using an operator 
class that I developed in $\mathrm{C}++$. My goal was to take that knowlege of DERAS, and simulate it at a much larger scale capable of delivering utility scale power.

My objective was to test an aggregated system of 10,000 assets because at such a scale these assets can be useful to a public utility. DERAS in its current state can only handle 100 distinct DER assets. I aimed to simulate these 10,000 assets to examine resource at this scale.

I aimed to simulate water heaters and battery-inverter systems to see what kind of energy and power resources they could offer in the western EIM market. I simulated the large asset aggregations and then simulated the effects of making and clearing an EIM decrement bid on these system.

\subsection{Distributed Energy Resources (DER)}

DER are non-utility scale energy assets[17]. They include residential-scale distributed generation, distributed energy storage, and demand-responsive loads. These assets are connected to a distribution network, rather than to a transmission system. Alone, these assets would have a negligible effect on the power grid, but when aggregated these assets could produce major effects to the electrical grid.

Distributed generation includes small-scale generators like a fuel cell, a solar panel array, or a combustion engine. Distributed generators add additional electricity to the power grid.

Demand-response loads are electrical loads agreeing to reduce or increase their electrical usage upon request. Demand-responsive loads include loads from large power customers 
like industrial plants or commercial buildings or can also come from a residential customer, like one agreeing to turn off a water heater. Demand-responsive loads can reduce power during an emergency grid event. They can also increase power consumption when an excess of electricity is available on the grid.

Distributed energy storage includes electric vehicles and home battery energy storage units, like a Tesla Powerwall. A storage asset can act as either a generator or load, depending on whether it is charging or discharging.

\subsection{Virtual Power Plant (VPP)}

A VPP is an aggregation of DER assets that together create effects similar to that of a physical power plant connected to a transmission system work. VPPs can produce power like a traditional generator by combining distributed generation assets creating meaningful amounts of megawatts to effect the electrical grid [25]. VPPs can also reduce electrical loads to reduce the amount of power required to feed the electrical grid [22]. This reduced load is often called a "negawatt" and is legally equivalent to a megawatt for the purposes of electricity market settlements[11]. VPPs can be any mixture of these.

When a VPP injects power to the grid or reduces load, the VPP has effectively produced an increment in generation. The VPP action of increasing load has the effect of a generation decrement. This decrement action from the VPP can be an alternative to curtailing generation. 


\subsection{DERAS}

DERAS is a compilation of work by Robert Bass, Manasseh Obi, Tylor Slay, Annie Clarke, Leighton Clarke, and myself. DERAS is designed to aggregate a number of small distributed energy resources into a larger virtual power plant. In its current incarnation, DERAS has the capability to aggregate 100 individual DER units. DERAS aggregates DER assets through its VPP class (a C++ class).

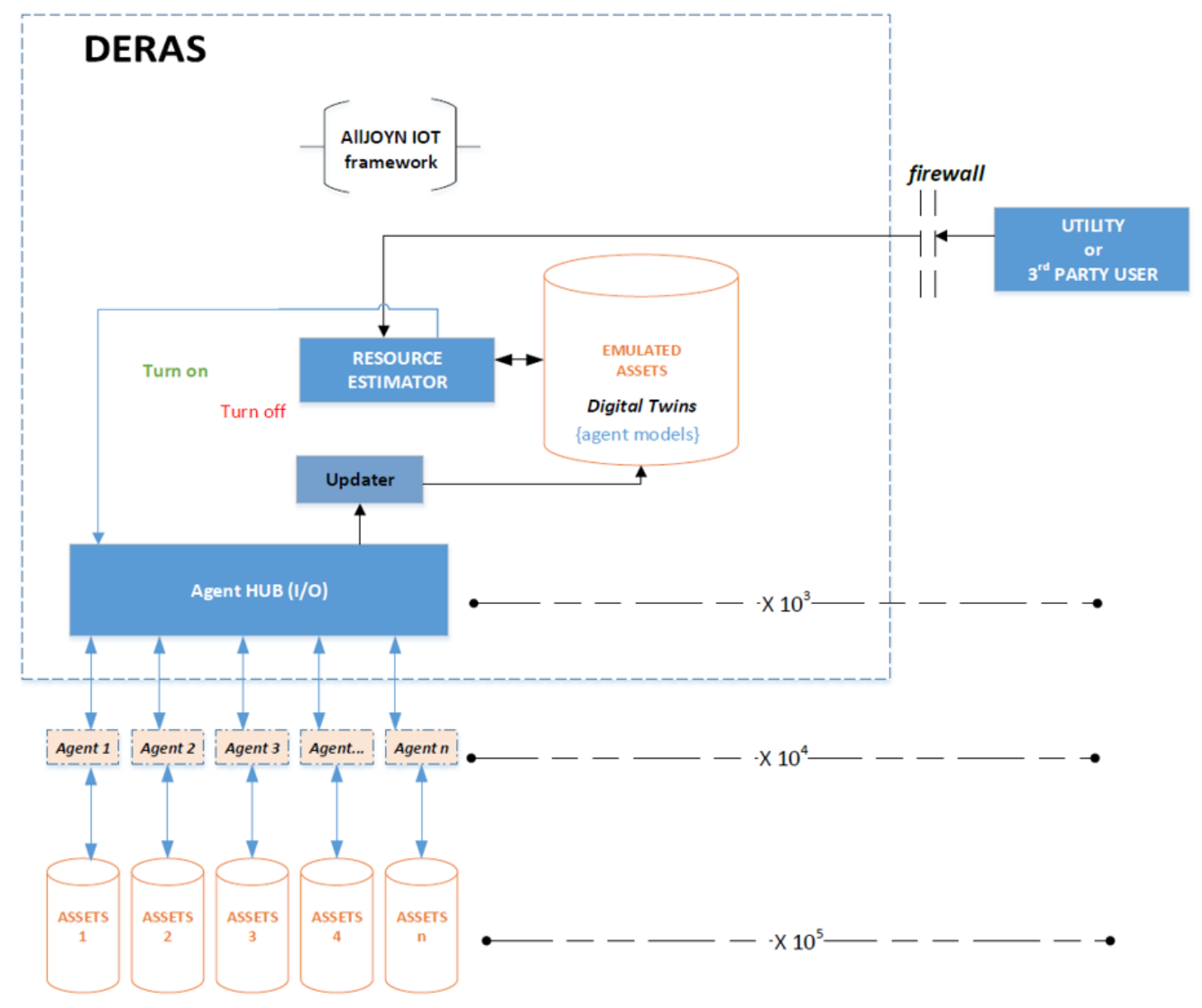

Figure 1.1: DERAS.

Figure1.1 shows DERAS as an aggregator. DERAS manages DER assets through the AllJoyn IoT framework. Assets like water heaters or batteries are monitored by agents. 
These agents talk to DERAS through an agnet hub. Digital twins (emulations of the physical assets) are created for each asset, and these predict the asset state between updates. The updater transmits the new physical states of the DER assets to the digital twins every hour or whenever a major change to the asset's physical state occurs.

The resource estimator looks at the digital twin models of the assets to predict the available resources that the aggregated assets can provide to a utility or other third party user. This paper examines resource estimation. DERAS currently cannot aggregate more than 100 assets, but this work examines how 10,000 assets could be aggregated into an energy resource. This work does not use DERAS, but rather simulates DERAS at scales relevant to electric utilities.

\subsection{Operator Class}

I created an operator class in $\mathrm{C}++$ to thread into the AllJoyn based aggregation network. This operator class contacts DER assets and gives grid commands to the assets. The operator class takes two parameters, an instantiated VPP class and a file pointer for a schedule. The instantiated DER asset can be any DER asset object in $\mathrm{C}++$, like an electric water heater, an inverter-battery system, or an HVAC system. The schedule tells the assets when to take grid actions like importing and exporting power and when to idle. The operator class determines what action to take from the schedule, and then sends the command to the DER asset. The operator class is called in a thread, allowing other computer system processes to run simultaneously. 


\subsection{Balancing Area Authorities}

The electrical grid functions on the concept that electricity produced somewhere is in balance with electricity consumed elsewhere. If a town requires $300 \mathrm{MW}$ of electricity, a group of generators somewhere will be producing that $300 \mathrm{MW}$ of electricity. Loads change frequently, and generation must balance against these new loads. Balancing areas (BAs) are sections of the power grid that are monitored for an equal amount of generation and load. A Balancing Area Authority (BAA) is an entity that manages the balancing of loads and generation in the balancing area.

BAs vary in size. At the large end, the California Independent System Operator (CAISO) manages the majority of land area in California, and the Bonneville Power Administration manages about half of the Pacific Northwest [5]. Smaller companies like Gridforce Energy Management, LLC in Oregon or Griffith Energy LLC in Arizona manage very small balancing areas for small utility districts.

Each of these Balancing Area Authorities (BAA) is responsible for ensuring that enough power is produced to cover the loads in their areas. Power can be produced within their balancing area, or they can import power from other balancing areas.

Unbalanced power has consequences to the electrical grid as a whole. When too little power is produced, frequency will sag. Frequency is affected by imbalances in load and generation. When generation is greater than load, the extra energy in the system is translated into an increase in system kinetic energy, which means the generators, primarily spinning machines, spin a little a faster. When load is greater than generation, the opposite occurs. 
The lack of power from the generators results in a decrease in kinetic energy, which means the generators will spin a little slower. These large spinning generators create a large amount of inertia on the power grid, which means changes in frequency are damped and smoothed. When non-spinning assets like solar panels and batteries are producing a large portion of the generation, the system has much less inertia from spinning machines, so changes in load or generation lead to sudden changes in frequency.

The BAA is responsible for maintaining frequency in their BA. When large amounts of renewable generation is on the grid, the BAA keeps reserve generation units to provide frequency response in the event of a sudden loss of generation or sudden spike in load.

\subsection{Energy and Imbalances Markets}

Energy Imbalances Markets (EIM) balance the short term energy needs for Balancing Area Authorities by allowing short term market transfers between balancing areas. The Western EIM is the only instance of an EIM market in the United States. Its balancing area authorities currently comprise CAISO, PacificCorp, Portland General Electric, Puget Sound Energy, Powerex, Idaho Power, and Arizona Public Service [6]. The Western EIM uses both 15 minute markets (FMM) and five minute markets, also called real time markets (RTM). These markets are managed by CAISO.

CAISO requires each BAA to have enough energy within its BA to participate in the EIM [3]. It does this through hourly resource sufficiency tests [27]. If a BA does not have sufficient generation to cover its forecasted demand, then it cannot participate in the EIM. 
This ensures that no BA in the EIM is being propped up by another BA.

Balancing areas submit bids to the EIM, and the bids are optimized for economic dispatch. The base schedules are determined based on the forecasted load demand, but when this load changes, the FMMs and RTMs cover the differences [4]. This may lead to generation being increased or decreased. CAISO manages the markets, first optimizing the FMMs and then optimizing the RTMs. Dispatch orders are then sent to the participating generators.

\subsection{Literature Review}

Many papers discuss DER asset aggregation and its relationship to the power grid. Many papers discussed aggregation of batteries or EWHs.

Laurent and Malhame built a computer aggregation model to simulate aggregations of water heaters [19]. They tested the influence of certain factors on power ratings including insulation, element power rating, and variance in water demand. Their work was targeted more for modeling the behaviors of water heater aggregations for forecasting loads, not controlling them. Later Laurent et al. created an optimization method for load management with control of electric water heaters [18]. They used a column generation method to optimize the water heaters for peak load reduction.

Fitzgerald et al. modeled 100,000 EWH assets to improve efficiency of wind generation [9]. They designed a control algorithm to improve the likelihood of water heaters being able to take on extra load during an expected peak in wind generation. Their simulation showed 
that applying their algorithm could result in electricity reduction of $25 \%$ and cost reductions of $38 \%$ (from scheduling power consumption at better times).

Kepplinger et al. tested demand side management control optimization schemes for aggregated EWHs [15]. They tested three optimization methods: a price driven optimization, an energy driven optimization, and an optimization method based on time of day. They determined that a price optimized control scheme was most cost efficient with fewer service errors.

Kapsalis and Loukas created an optimal scheduling algorithm for EWHs[13], where they used an objective function that weighed interests in keeping electrical costs low while keeping customer discomfort minimal. Their algorithm minimized both costs and discomfort based on their relative weightings. Their algorithm worked on two levels, being able to adjust customer setpoints and also having access to a direct on/off switch for the electrical coil. In a different paper, Kapsalis et al., presented a heuristic scheduling algorithm to balance decisions between cost of power and comfort of consumer hot water consumption [14]. They simulated their algorithm in a real-time market and found it performed as well as a standard optimization model with considerably less computational overhead.

Roux et al. developed a peak demand manager algorithm that focused on water heater usage. Essentially, they had EWHs compete to use the electrical grid during peak hours, and only water heaters with the most need turned on during peak hours. They tested their control method against a traditional control method, and found their algorithm could shift controlled amounts of electricity from peak times, with minimal events of user discomfort. 
Li et al. created an aggregator service for large multi-tenant buildings [20]. They built an aggregation of EWHs, solar panels, battery energy storage, and electric vehicles. Then they built a communication structure using the ZigBee protocol. They examined control algorithms for the DER assets that would allow them to minimize power costs through load shifting and energy trading of the DER units. The overall effects were lower tenant bills and shorter return on investment periods for the building.

Faika et al. proposed an Internet of Things architecture for aggregating multiple batteries over a wide area network [8]. They tested their proposal on a 5 battery test bed, and found the latencies in the network were small enough to allow for massive scaling over a cloud network.

Khalid and Savkin analyzed aggregations of batteries to smooth wind power production [16]. Essentially, they used it to compensate for the small dips and rises in wind power. They found a semi-distributed system of batteries both near the wind turbines and away from the wind turbines was most effective at smoothing wind power.

Additionally, many papers discussed battery aggregations using electric vehicles (EV). Wu et al. determined the operations scheduling of an aggregated set of EVs from cost minimization perspectives. Ortega et al. discussed the changes necessary to allow for aggregated EV dispatch in a day-ahead electricity market. Gonzalez and Andersson, Vagropoulos and Bakirtzis, and Sarker et al. investigated the optimal bidding strategies of EV aggregations $[24,28,29]$.

Asimakopoulou and Hatziargyriou modeled the economics of DER aggregation through 
a bilevel programming problem using the DER agregator's bid decisions as the upper level problem and the market clearing decisions as the lower level problem [1]. They confirmed that the addition of DER assets had a stabilizing effect on locational marginal prices (LMPs) of bulk electricity. They found that when LMPs were high, DER aggregators performed best when exporting energy to the power grid, and when LMPs were low, DER aggregators performed best when importing energy from the power grid.

Calvillo et al. built an optimization model for a variety of DER assets including photovoltaic systems, air-sourced heat pump systems, batteries, and demand response assets [2]. They optimized a system using price-maker economics, assuming that the DER aggregation was large enough to influence market clearing prices. They analyzed aggregations of residential houses running from 40 thousand to 8 million houses. Calvillo et al. found that aggregating these assets could be profitable for both aggregators and prosumers. They tested their system optimization with both price-taker and price-maker strategies, and concluded that using price-maker economics allows for significantly better optimization of the system. 


\section{Design Methodology}

\subsection{Modeled Aggregated Units}

In order to test an aggregated number of DER units for bidding into the EIM, I constructed a model of ten thousand residential aggregated DER assets. For simiplicity, I considered two types, electric water heaters and residential batteries. The aggregated assets can draw energy from the grid, inject energy into the grid, or defer drawing energy from the grid.

At any point in time, these assets have an individual power, an individual energy take, and an individual ramp rate. The model simulates expected patterns of usage for these assets and then looks at the assets in aggregate to estimate the ability of the aggregate to offer generator functions, specifically decrement and increment.

A decrement, in generator terms, means reducing the generator power output to the grid. A generator decrements because an excess of power is on the electrical grid. By drawing more power from the grid, aggregated assets effectively decrement by canceling out excess generation with additional load. The power grid retains the same amount of generation on the grid, but the load increases to balance out the excessive generation. Excessive generation frequently occurs when wind or solar produce more power than forecasted.

An increment, in generator terms, means increasing the generator's power output to the grid. A generator increment occurs when the current level of generation is unable to 
serve the required electrical load. The aggregated assets could increment in two ways. By injecting power to the grid, the assets would be acting almost exactly like generators. The aggregated assets also have the ability to defer drawing power until a later time. By choosing to defer their loads, the immediate impact would be a reduced load, which would mimic an increase in generation.

\subsection{Electric Water Heaters}

To simulate a large number of random water heaters, I used the DHW Event Schedule Generator created by Hendron et al. [10]. This program creates randomized water usage profiles for one, two, three, four and five bedroom households. It takes into account average household data and then uses a randomized clustering algorithm to approximate random, regular use patterns [23]. It then checks the randomized patterns against statistical metrics to verify that the randomly-produced schedules make sense. When parts of the schedule do not pass the statistical checks, the system is reiterated until a schedule is produced that will pass all checks.

The tool is an MS Excel workbook, which utilizes Excel's macro capability. Macros are programmable routines written in Visual Basic. The tool itself produces one annual schedule every time a button is pressed. A typical annual schedule has around 15,000 individual water draws. I reprogrammed the macro to produce many water usage schedules by inserting a for-loop. I saved three relevant pieces of information: time of event, duration, and hot water volume, to three additional spread sheets. I then ran this macro to create up to 2000 
schedules at a single button press. Using a variety of research computers available in the power lab, I produced over 10,000 random water draw schedules.

I created a set of 10,000 water heater schedules based on a guess as to the relative abundance. I used 2017 census data, showing the number of bedrooms in homes as a percentage across the United States [21]. Based on these numbers, I estimated the make up of 10,000 electric water heater units. I assumed that 0-bedroom homes would share similar water characteristics to that of a 1-bedroom home. I also assumed that four bedroom homes would be twice as common as five bedroom homes. I ignored $6+$ bedroom homes, as they were not available through the DHW Event Schedule Generator[10]. I summarized my model of 10,000 electric water heater units in Table 2.1. Each of these water heaters were modeled from individual schedules created by the DHW Event Schedule Generator[10]. I also assumed a size of water heater based on the size of the household. All models were AO Smith brand water heaters.

Table 2.1: Percent Make Up of Water Heater Units

\begin{tabular}{|c|c|c|c|c|}
\hline \# of Bedrooms & Census Makeup[21] & Model Makeup & \# of Modeled Units & Gallons \\
\hline 0 & $2.4 \%$ & $0 \%$ & 0 & 40 \\
1 & $10.9 \%$ & $13.2 \%$ & 1320 & 40 \\
2 & $26.3 \%$ & $26.3 \%$ & 2630 & 40 \\
3 & $39.6 \%$ & $39.6 \%$ & 3960 & 50 \\
4 & $16.5 \%$ & $16.5 \%$ & 1650 & 80 \\
5 & $4.4 * * \%$ & $4.4 \%$ & 440 & 80 \\
\hline
\end{tabular}

** The Census makeup showed 5+ households. 


\subsection{EWH simulation in MATLAB}

Electric water heaters with tanks heat their water to a setpoint, typically around $120^{\circ}$. The water inside the tank is insulated, but small amounts of heat slowly dissipate from the water inside the tank. When hot water is removed from the tank, it is replaced by cold water. When the tank temperature drops below a deadband temperature, heater elements turn on to increase the water in the tank back to the set point. This represents normal operation for an uncontrolled water heater.

When DERAS controls water heaters, it operates them as a controlled load. DERAS aims to maximize the amount of energy that the water heaters can absorb at any time. To do this, DERAS keeps the water heaters near the bottom of their temperature range. To do this, DERAS constantly sends out "shed" commands to the water heaters. In "shed" mode, the water heaters will not come on unless they drop below a low temperature threshold. For instance, a water heater might have a setpoint of $120^{\circ} \mathrm{F}$, a deadband of $3^{\circ} \mathrm{F}$, and a lower shed threshold of an additional $3^{\circ} \mathrm{F}$. In normal uncontrolled operation, the water heater keeps its temperature between the setpoint and deadband, or between $117^{\circ} \mathrm{F}$ and $120^{\circ} \mathrm{F}$. However, when the shed command is being called, the water heaters will continue to lose temperature until that lower threshold of $114^{\circ} \mathrm{F}$. Once they cross this threshold, the heaters ignore grid commands and heat until they reach the deadband temperature of $117^{\circ} \mathrm{F}$. Then the water heaters allow DERAS to control them once again. And again, DERAS tells them to shed. By running the water heaters between $114^{\circ} \mathrm{F}$ and $117^{\circ} \mathrm{F}$, instead of between $117^{\circ} \mathrm{F}$ and $120^{\circ} \mathrm{F}$, the water heaters will always be able to absorb energy to raise their temperatures by at least 
$3^{\circ} \mathrm{F}$ and many will be able to raise their temperatures by $4^{\circ}, 5^{\circ}$ or $6^{\circ} \mathrm{F}$.

I used MATLAB to sort through the data, simulate normal operation, and simulate a bid. I chose to track the water heater states by two variables, the energy take of the EWH and the status of the EWH. The energy take is a measurment of how much energy the water heater would need to draw to reach its setpoint temperature.

$$
Q=m c\left(T_{\text {setpoint }}-T_{\text {tank }}\right)
$$

Where $m$ is the mass of the water in the tank and $c$ is the specific heat of that water, $4180 \mathrm{~kJ} /\left(\mathrm{kg} \mathrm{C}^{\circ}\right)$. With this measurement, a water heater at its setpoint has zero energy take. The lower the temperature of the tank, the higher the energy take.

\subsubsection{Loading in the data}

Using the modified NREL program, I could produce water usage data. I needed to turn this water usage data into electrical energy use data through simulation. The first step was loading all of these data into MATLAB.

I took the hot water use data from the spread sheets, and converted them to comma separated value (csv) files. I loaded these files into MATLAB to produce simulations of the water heaters. Through an initialization procedure, I loaded in each of the csv files. I assigned each set of water heater data an identification number. I parsed through each time

and date entry for draw events, and converted them into a 5 minute time intervals. I used 5 minute time intervals, because this is how the Western EIM RTM operates, with a new 
market clearing every 5 minutes. Each day has 288 individual 5 minute intervals, which means a 365 day year contains 105,120 intervals.

I organized the data into a 9-column array with rows for each draw event. The nine column array had columns for year, month, day, hr, minute, interval number, duration of draw in seconds, gallons per minute of draw, and the identification numbers that I assigned each unit.

\subsubsection{Creating a look-up matrix for draw events}

After loading the data, assigning identification numbers to the individual water heaters, and sorting the draw events into 5 minute intervals, I created a matrix for looking up specific draws from water heaters. The rows running downward represented individual EWHs with unique identification numbers. The columns represented 105,120 time intervals over the course of the year. I sorted the individual draw events by their unit ID and the time interval in which they occurred. In a draw event, hot water is drawn from the water heater and replaced by an equal amount of cold water coming from the tap. I calculated the amount of water drawn from the water heater during each 5 minute interval, and saved that amount to the lookup table.

\subsubsection{Simulating EWH Behavior}

I next built an array to store the energy takes of the individual EWHs at each time interval. I used the columns of this array to store identifying information about the water heaters, like ID number, number of bedrooms, capacity of tank in liters, energy take at the dead 
band, energy take at the low temperature shed threshold, ambient heat losses, and power of the heating element. To start the simulation, I gave each water heater a randomized energy take between their deadband energy take and their low temperature shed threshold. I also randomized the state of the EWH, whether it was under DERAS control and shedding or whether it was under local control and heating back up to the deadband energy take.

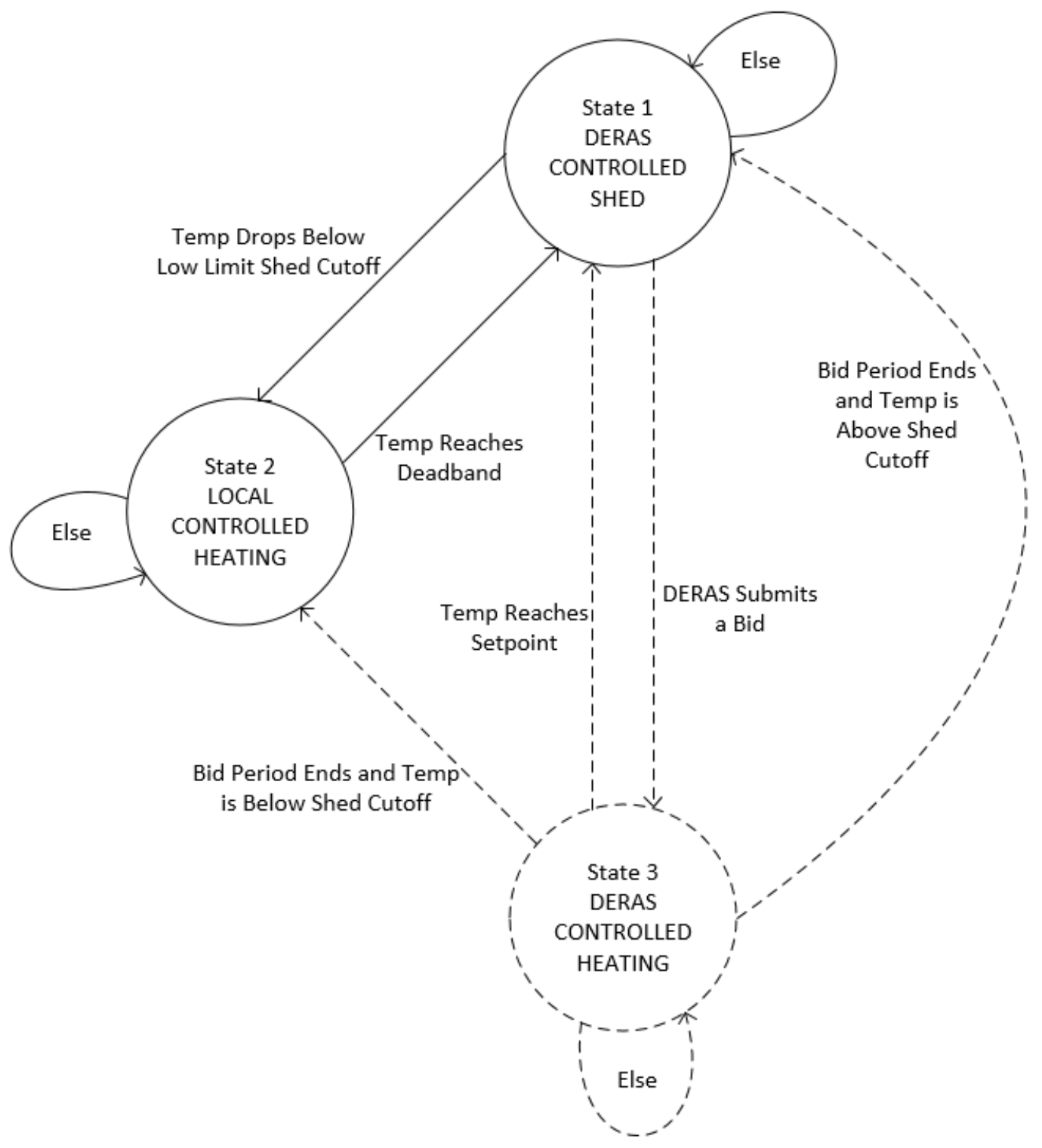

Figure 2.1: State diagram for electric water heater model. 
I used a variable to represent the states of the EWHs. When the EWH was responding to shed commands from DERAS, I gave it a state value of 1. When the EWH was heating back up to the deadband energy take because it had crossed its low temperature shed threshold, I gave it a state of 2. Additionally I used a state of 3 to represent when DERAS takes over control of the EWH, commanding it to heat to its setpoint. These states and transitions are shown in Figure 2.4.

Using nested loops, I calculated the energy take and state of the EWHs at the next time interval to compile a full year's worth of data. I assumed that ambient losses would be the same at all times, as would the heating. Draws would be found in the lookup array, and then converted into energy take.

$$
\begin{gathered}
Q_{k . d r a w}=m_{\text {draw }} c\left(T_{k, \text { tank }}-T_{a m b}\right) \\
T_{k, \text { tank }}=T_{\text {setpoint }}-\frac{Q_{k-1}}{m_{\text {tank }} c}
\end{gathered}
$$

To start the simulation, I gave each water heater a randomized energy take between their deadband and lower limit shed threshold. When left idle, the water heaters slowly lose heat to the ambient conditions. Once the water heaters drop below their lower shed threshold, the heating elements turn on and heat the water back to their deadband limits. At that point DERAS reasserts control, and the water heaters lose temperature until they reach the lower shed threshold again. This is what happens in the absence of draw events. In the presence of draw events, the units operate the same, except that at any moment, a hot water draw could lower the temperature of the tank below the lower shed threshold, at which point the unit stops shedding, turns its heating elements on, and heats until it reached the deadband 
Table 2.2: EWH Calculations at each state

\begin{tabular}{|c|c|}
\hline State 1, DERAS Controlled Shed & $\begin{array}{l}Q_{k}=Q_{k-1}+Q_{\text {amb }}+Q_{k, \text { draw }} \\
\text { if } Q_{k}<Q_{\text {LowLimit }} \\
\text { Set State }=1 \\
\text { else } \\
\\
\text { Account for Heating } \\
\text { Set State }=2\end{array}$ \\
\hline State 2, Local Controlled Heating & $\begin{array}{l}Q_{k}=Q_{k-1}+Q_{a m b}+Q_{k, \text { draw }}-Q_{\text {heat }} \\
\text { if } Q_{k}>Q_{d b} \\
\text { Set State }=2 \\
\text { else } \quad \text { Account for Shedding } \\
\text { Set State }=1\end{array}$ \\
\hline State 3, DERAS Controlled Heating & $\begin{array}{l}Q_{k}=Q_{k-1}+Q_{a m b}+Q_{k, \text { draw }}-Q_{\text {heat }} \\
\text { if } Q_{k}>Q_{\text {setpoint }} \\
\text { Set State }=3 \\
\text { else } \quad \text { Account for Shedding } \\
\text { Set State }=1\end{array}$ \\
\hline
\end{tabular}

temperature allowing DERAS to reassert control. I also randomized the current state of the water heaters. Most of the water heaters would be in DERAS's control, but some would have hit the lower shed threshold and would be heating up to their deadband temperature before DERAS took back control.

I simulated all the water heaters at each 5 minute interval. I stored two pieces of data at each interval: the energy take of the unit, and the state of the unit (DERAS controlled shed or unit controlled heating). Each new interval depended on the energy take and state of unit in the previous interval, as well as some constants specific to each EWH. I simulated the 
entire data set over the course of the year thereby establishing a bases case of uncontrolled assets.

\subsubsection{Simulating Bids}

I created a function in MATLAB to determine the effects of an EIM bid. This kind of bid would be submitted to an energy market like the Western EIM. If the market decided to clear the bid, the aggregated units, controlled by DERAS, would be dispatched to cover the bid energy. A typical EIM bid would include power and ramp rate over a given period time. Because EWH have a near instantaneous ramp rate, I assumed that bid would include two elements, amount of power and duration. The amount of power would be in megawatts (MW) and the duration would be in 5 minute intervals.

To create this bid, I imagined an energy merchant would have a forecast of expected loads. EWHs in DERAS would follow a normal trend when DERAS was not bidding their decrementing capacity into an EIM market. They would act like uncontrolled water heaters, recharging when they dropped in temperature below their lower limit threshold. The energy merchant's forecast would expect a certain amount of regular water heater use. The energy merchant would be cheated if DERAS sold that expected load back as a decrement bid. Therefore, I only wanted to sell power to the merchant that it would not expect to receive anyway.

To do this simulation, I reordered all of the water heaters from highest energy take to lowest energy take. Then I figured out how much a bid would require in energy over each 5 minute interval. I allocated the necessary number of units to meet the necessary energy, and 
changed their status to 3, a DERAS controlled import. If a unit was in state 1 , it could be shifted to state 3 , but if a unit was in state 2, the aggregator would have no control over it, so it could not be allocated for the bid. Figure 2.2 shows this visually, the aggregator skips EWHs in state 2, and allocates only those in state 1.

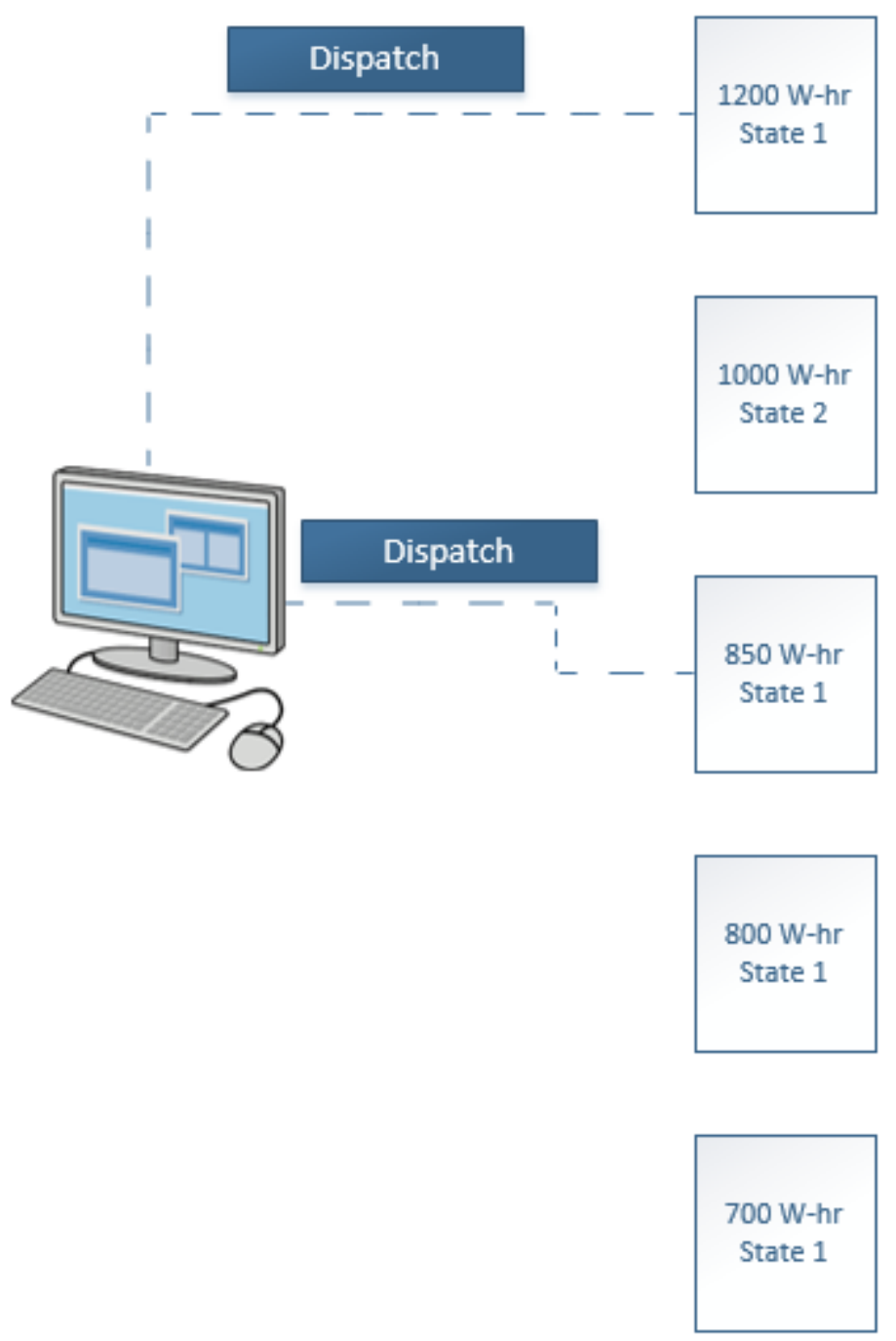

Figure 2.2: The aggregator dispatches the units with the highest energy takes, skipping those in state 2.

Then I determined whether or not a water heater would naturally turn off in a future interval due to losses. If so, then I added that amount of energy to the required energy in the 
later interval. This would ensure that my decrement bids did not artificially affect the energy merchant's forecast. I then resimulated the EWH actions at each 5 minute interval for the remainder of the day and the following day, using the calculations described in Table 2.2.

\subsection{Battery Inverter Systems}

Battery inverter systems (BIS) have two capacities, a power capacity and an energy capacity. A BIS has the ability to discharge power, which is its power capacity. This power capacity is the maximum continuous power that the BIS can discharge. The BIS also has an energy capacity. The energy capacity relates to how much energy the battery can store. Once a battery discharges all of its energy, it can no longer discharge. The power capacity is given in watts or volt-amps. The energy capacity is given in $\mathrm{W} \mathrm{hr}$.

To simulate a large number of BIS, I assumed a specific inverter type, the Outback 8048 inverter. This inverter provides a maximum continuous power of 8000 Volt-Amps. I characterized the BIS by the number of hours of rated discharge. I assumed the batteries to be randomly rated nominally at two, four, six, eight, or ten hours of full-power discharge capacity. I then assumed that the batteries could have lost up to $20 \%$ of their nominal energy capacity due to aging. I used another random number generator to assign the nominal energy capacities with roughly $20 \%$ of the batteries being assigned to each of the nominal capacities. I then used another random number generator to derate the batteries by up to $20 \%$ of their nominal energy capacities. I calculated these battery features into an array for each of the 10,000 batteries. 


\subsection{Battery Simulation}

Batteries do not have a normal usage schedule like electric water heaters. Instead, they could serve multiple purposes, and the EIM could be one of them. I assumed a second service would be frequency regulation. This would allow me to sufficiently randomize the behavior of the batteries before putting them into use.

I modeled the batteries to follow a frequency regulation profile when they were not being called on by the EIM. I use PJM's RegA profile to simulate typical battery behavior, because it is published and easily accessed [26]. PJM has two frequency regulation bids, RegA and RegD. The RegD is more dynamic than RegA and also pays better. Many battery/inverter systems can meet the requirements for RegD regulation. However, RegD, typically has a balanced amount of up and down regulation occurring across an hour. This would tend not to randomize my battery profiles. Instead, I used the RegA regulation, which is less dynamic and therefore easier for an asset to follow. It regulates both up and down regulation, but it has a particular tendency to go down. I examined the 2018 data, and found over the course of 365 days, the the RegA signal was net negative 364 days and net-positive on only 1 day [12].

Following the PJM's RegA signal, the batteries will from time to reach their limits of capacity, either upwards or downwards. I assumed that the batteries would have five states that would reflect their behavior toward the RegA signal or the EIM signal. These states are summarized in Table 2.3. I used a typical summer load profile, and assume that anytime $85 \%$ of peak load is happening, that power was expensive. In these cases a battery 
prioritizes idling over charging. When power is inexpensive, the battery prioritizes idling over discharging.

Essentially, this BIS model simulates three grid services. By default, the BIS follow the PJM Regulation A signal. When the state of charge in the batteries becomes to high or too low, the batteries participate in economic arbitrage. Finally, the BIS can bid into the Western EIM, at which point EIM bids take precedence over other actions.

\subsubsection{Loading in the data}

I used MATLAB to generate the BIS usage data. I created a vector of 10,000 empty data spaces. I used MATLAB's rand() function to generate a random number between zero and one. I used this number to assign nominal battery size to an individual data slot. I evenly weighted chances of having nominal energy capacities between 2 hours, 4 hours, 6 hours, 8 hours, and 10 hours. I then generated another random number, and used it to assign anywhere from $0 \%$ to $20 \%$ of aging loss to the nominal capacity. I cycled through the 10,000 data spaces to create 10,000 BIS energy capacities. Each of these BIS would have the same power capacity owing to their use of the same inverter.

I found the PJM RegA data from the PJM data website [12]. The data came in a zip file

for each month. The data showed the RegA signal as a percentage of an asset's bid power. The files were sorted in columns by days and in rows by 2 second intervals. I copied and pasted all the data from the individual monthly spreadsheets into a year long .csv file. I used 365 columns for each day of the year and 43200 rows for each 2 second interval in the day. I loaded these data into MATLAB using MATLAB's csvread() function. 


\subsubsection{Simulating BIS behavior}

I organized the BIS data into an array similar to my EWH array. The array shows the energy level and status of the batteries at every 5 minute interval. To get there though, I needed to simulate the battery usage based on the RegA signal data. These data occurred every 2 seconds. I built a $43200 \times 6$ array to simulate an individual battery over the course of a year. The battery's state of charge determines its behavior, with five statuses defining these behavioral strategies. These statuses are summarized in Table 2.3.

Table 2.3: Statuses of EWH and BESS assets.

\begin{tabular}{|c|c|c|c|}
\hline No. & Asset & Status & Behavior \\
\hline 1 & EWH & DERAS Shed & Respond to DERAS shed commands. \\
\hline 2 & EWH & Local Heat & Import at deadband temperature. \\
\hline 3 & EWH & DERAS Heat & Respond to DERAS import commands. \\
\hline \hline 11 & BESS & DERAS & Respond to DERAS commands. \\
\hline 12 & BESS & Charge or DERAS & Charge firsts if power is cheap, else DERAS. \\
\hline 13 & BESS & Charge & Charge if power is cheap, else idle. \\
\hline 14 & BESS & Discharge or DERAS & Discharge if power is expensive, else DERAS. \\
\hline 15 & BESS & Discharge or Idle & Discharge if power is expensive, else idle. \\
\hline
\end{tabular}

Batteries in the DERAS mode, control state 11, respond to DERAS commands exclusively, as long as they remain between their high energy and low energy thresholds. If a battery in DERAS mode drops below its low energy threshold, it turns to status 12 , charge or DERAS. In this state it prefers to discharge if power is cheap, or otherwise it follows DERAS commands. If a battery in DERAS mode, status 11, rises above its high energy threshold, it turns to the discharge or DERAS mode, status 14. Here it prefers to discharge its energy if power is expensive, or otherwise it follows DERAS commands. These states 
and transitions are shown in Figure 2.3.

I defined expensive power as power above $85 \%$ of an average summer load provided by the Florida PUC [7]. This meant power between 11:30 am and 9:30 pm would be considered expensive power. Batteries wait to discharge until power is expensive. At other times, power would be considered inexpensive. Batteries wait to charge until power is inexpensive.

I calculate the battery state of charge and new status every 2 seconds. I assume that the batteries instantly followed the RegA signal with no delay in response. I determined whether the battery would charge, discharge, or follow RegA based on the time of day and the battery's status. The calculations are summarized in Table 2.5. For an individual BIS, I calculate these at every two seconds storing it in my $43200 \times 6$ matrix. Then I would take the state of charge and status at each EIM interval change, and store it in a matrix with rows of individual battery units and columns of states of charge and statuses at each EIM interval. This data could then be stacked on top of my BIS data in a single matrix. 


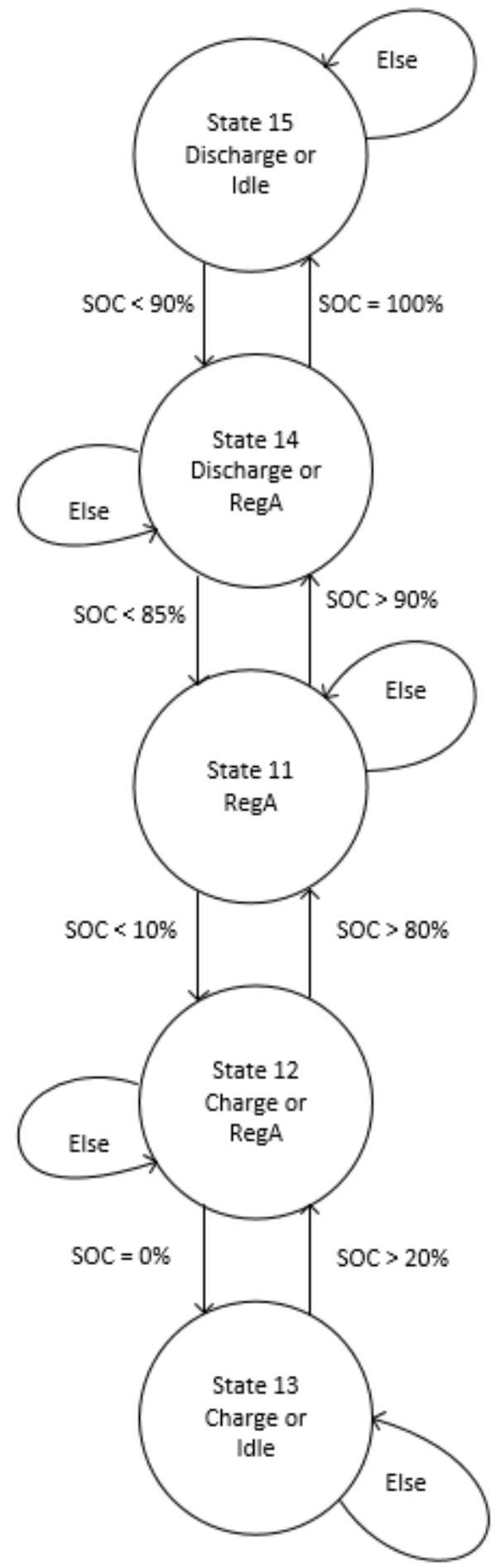

Figure 2.3: State diagram for battery inverter system model. 
I set variables based on state of charge to define when the BIS would move from one logic state to another logic state. These logic states, coupled with the time of day considerations, determine what actions the batteries take. Table 2.4 shows how batteries in one state will move to a new state based on state of charge.

Table 2.4: Statuses of EWH and BESS assets.

\begin{tabular}{|c|c|c|c|c|c|}
\hline CurrlNew & 11 & 12 & 13 & 14 & 15 \\
\hline 11 & N/A & $10 \%$ & $0 \%$ & $90 \%$ & $100 \%$ \\
\hline 12 & $80 \%$ & N/A & $0 \%$ & $90 \%$ & $100 \%$ \\
\hline 13 & $80 \%$ & $20 \%$ & N/A & $90 \%$ & $100 \%$ \\
\hline 14 & $85 \%$ & $10 \%$ & $0 \%$ & N/A & $100 \%$ \\
\hline 15 & $85 \%$ & $10 \%$ & $0 \%$ & $90 \%$ & N/A \\
\hline
\end{tabular}

\subsubsection{Simulating a Battery Bid}

To simulate a battery bid, I added another state to the battery logic, state 16 . State 16 calls on the battery to charge until completely full. This accomplishes a decrement bid, by cancelling out generation with load.

I took the aggregation of 10,000 batteries, and sorted the BIS by energy capacity from highest to lowest. Then I assigned BIS to cover parts of a bid until it is completely covered by the assets in DERAS.

I used two models. During peak hours between 11:30 and 9:30, I used the batteries from lowest to highest energy states. During non-peak hours, I assumed the batteries that were in states 12 and 13 would be charging anyway, making themselves potentially part of a forecasted load. Therefore, I ignored batteries in states 12 and 13 during off-peak hours, 
Table 2.5: BIS calculations at each state

\begin{tabular}{|c|c|}
\hline State 11, DERAS Controlled & $\begin{array}{l}E_{k}=E_{k-1}+E_{\text {RegA }} \\
\text { if } E_{k} \leq E_{\text {Low }} \\
\text { Set State }=12 \\
\text { else if } \quad E_{k} \geq E_{\text {High }} \\
\text { Set State }=14 \\
\text { else } \quad \text { Set State }=11\end{array}$ \\
\hline State 12 , Charge or DERAS & $\begin{array}{l}\text { if Power inexpensive, } E_{k}=E_{k-1}+P_{\text {Max }}(2 \mathrm{sec}) \\
\text { else, } E_{k}=E_{k-1}+E_{R e g A} \\
\text { if } E_{k} \leq E_{\text {Min }} \\
\text { else if } \quad E_{k} \leq E_{\text {Charge }} \quad \text { Set State }=13 \\
\text { else } \quad \text { Set State }=12 \\
\qquad \text { Set State }=11\end{array}$ \\
\hline State 13 , Charge or Idle & $\begin{array}{l}\text { if Power inexpensive, } E_{k}=E_{k-1}+P_{M a x}(2 \mathrm{sec}) \\
\text { else, } E_{k}=E_{k-1} \\
\text { if } \quad E_{k} \leq E_{\text {MandatoryCharge }} \\
\text { else } \quad \text { Set State }=13 \\
\quad \text { Set State }=12\end{array}$ \\
\hline State 14, Discharge or DERAS & $\begin{array}{l}\text { if Power expensive, } E_{k}=E_{k-1}-P_{\text {Max }}(2 \mathrm{sec}) \\
\text { else, } E_{k}=E_{k-1}+E_{R e g A} \\
\text { if } \quad E_{k} \leq E_{\text {Discharge }} \\
\text { else if } \quad E_{k} \leq E_{\text {Max }} \quad \text { Set State }=11 \\
\text { else } \\
\qquad \begin{array}{l}\text { Set State }=14 \\
\text { Set State }=15\end{array}\end{array}$ \\
\hline State 15, Discharge or Idle & $\begin{array}{l}\text { if Power expensive, } E_{k}=E_{k-1}-P_{\text {Max }}(2 \text { sec }) \\
\text { else, } E_{k}=E_{k-1} \\
\text { if } \quad E_{k} \leq E_{\text {MandatoryDischarge }} \\
\text { else } \quad \text { Set State }=14 \\
\text { Set State }=15\end{array}$ \\
\hline
\end{tabular}


and instead met my load by converting batteries in state 11 and also potentially state 14 as needed (state 14 can charge for a limited amount, but prefers discharge). When assigned units to a bid, I changed their status to 16.

State 16 is the aggregator controlled decrement state. In state 16 the batteries import power from the electric grid to effect a generation decrement. After each 5 minute interval, the state 16 BIS return to state 11 , and they can immediately be reassigned to state 16 for the next interval. The EIM operates on 5 minute intervals whereas the RegA and arbitrage bids operate every 2 seconds. I simulated every 2 seconds, but I only stored data every 5 minutes for energy level and state.

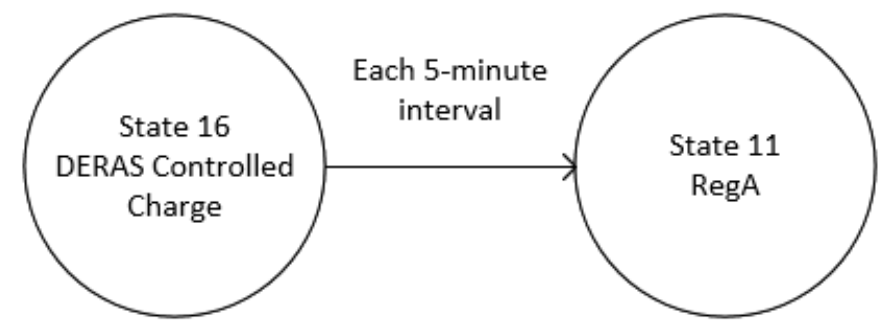

Figure 2.4: Once assigned BISs go to state 16. After each interval they revert to state 11.

After completing the bid, I resimulated the battery aggregation over the remainder of the day and into the next. By doing this, I aimed to reach a steady-state condition where the battery aggregation returns to normal after the bid. These resimulations also updated every 2 seconds and only saved data every 5 minutes. 


\section{Results \& Analysis}

\subsection{Results of simulating EWH assets without bids}

I simulated the EWH water heaters without bids as a base case. I created a plotting script in MATLAB to plot the simulated characteristics of a 10,000 unit aggregation of EWHs. Figure 3.1 shows the results for a single day, June 6th, 2007. I marked the energy takes if all units were at their deadband or at their low limit temperature point in yellow and red, respectively. I marked the median of these energy takes in purple. As expected, the energy take fluxuates around the median energy take of the units. 


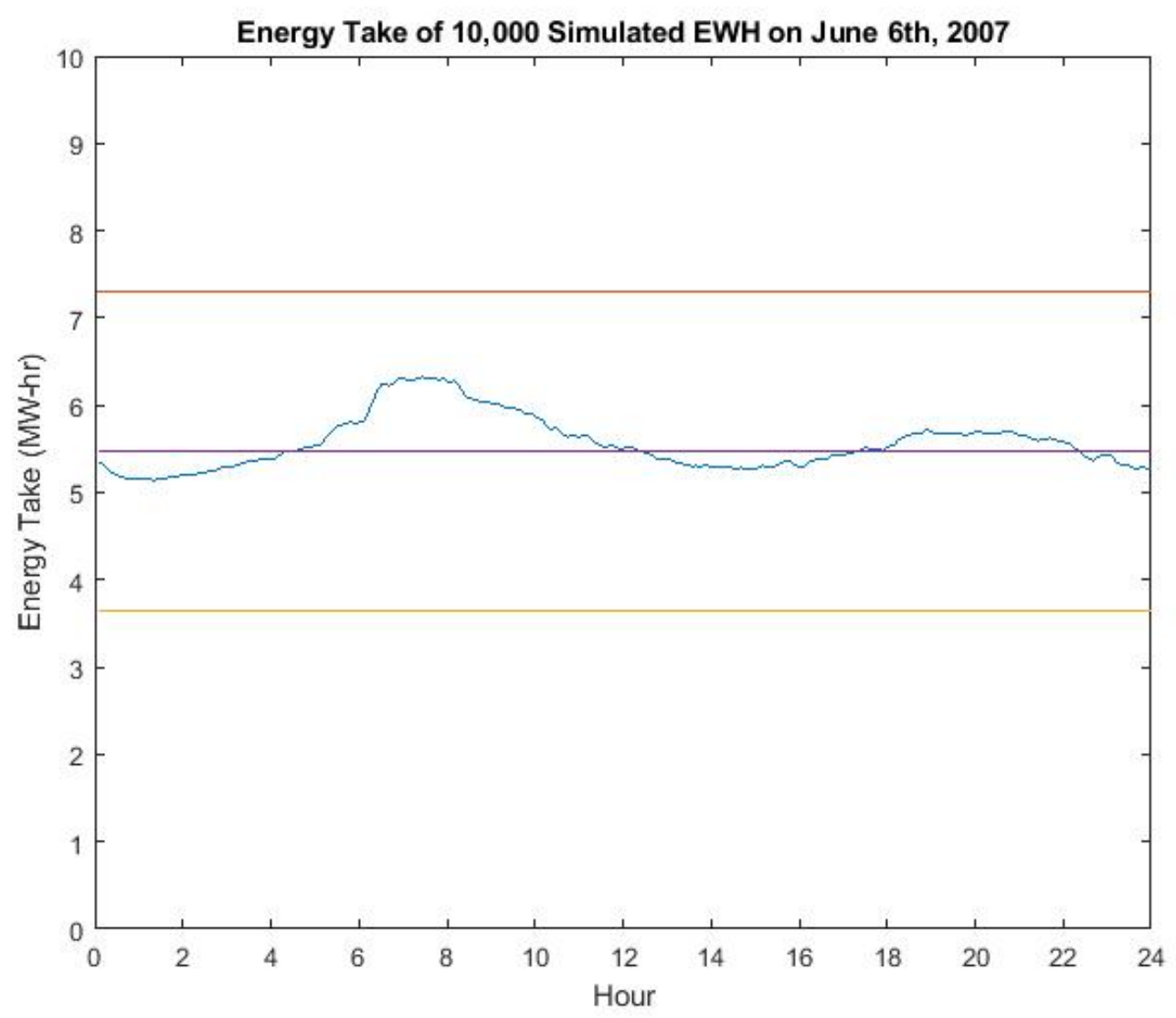

Figure 3.1: The average Energy Take hovers around the median between the dead band and the low temperature cutoff.

The percent of units on at a given time is a key metric for measuring the capacity of the aggregator, and the primary reason these units turn on is because a draw occured. Not every draw causes a water heater to turn on, and an idle water heater will turn on eventually due to thermal losses. However, we would expect to see a strong correlation between the percent of households experiencing draws and the percent of EWH assets heating. Figure 3.2 shows the percent of the units turned on coming into the 5 minute EIM market interval and the percent of units that experienced a draw during the current EIM interval. As expected, the number of units turned on slightly lags the draws. 


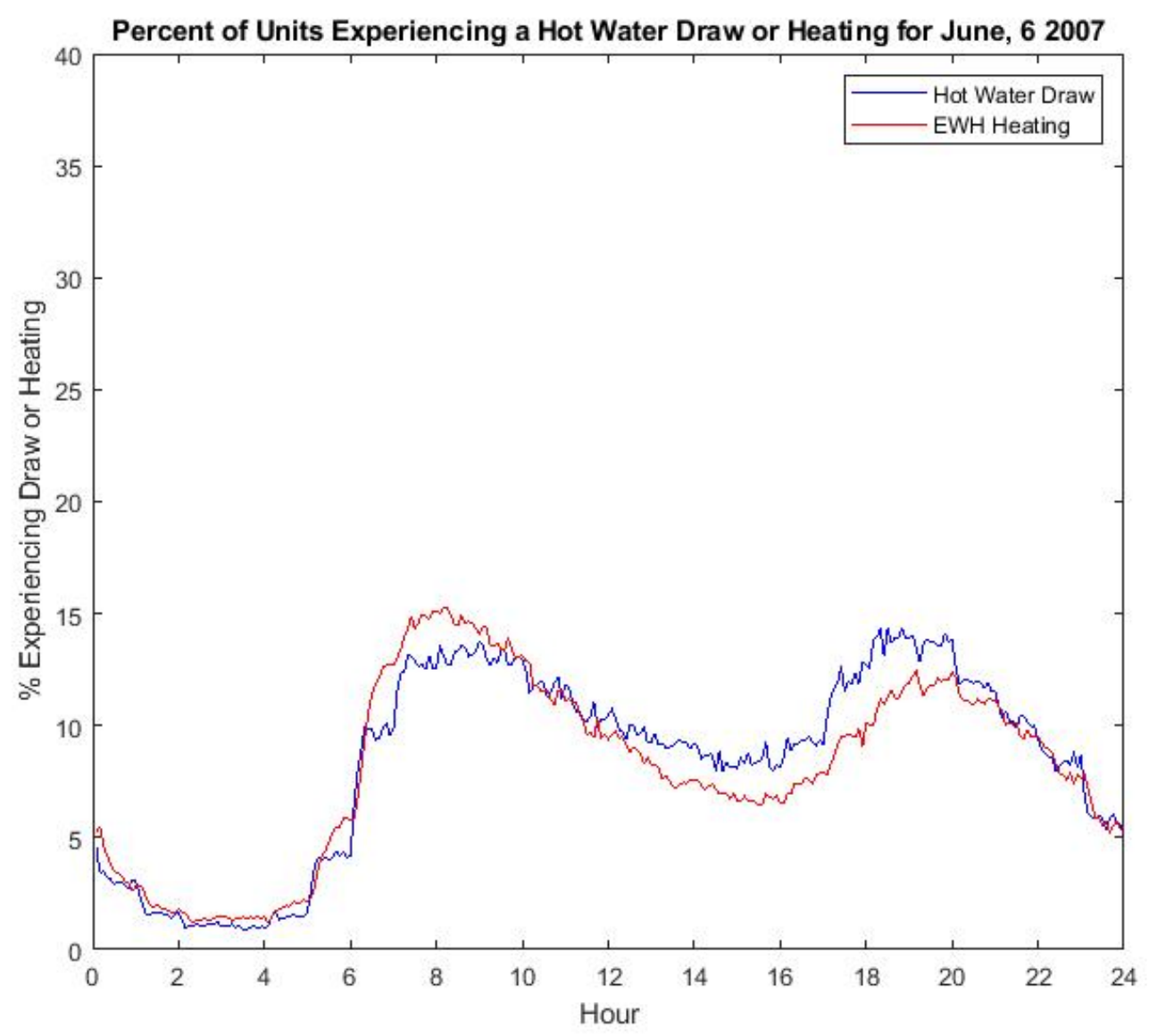

Figure 3.2: The draws lead the units heating ever so slightly.

\subsection{Results of the EWH on Assets with bids}

I simulated bids by specifying the EIM interval or intervals over which the bid was occurring and the number of megawatts I would be decrementing.

I first simulated an hour long bid from 02:00 to 03:00 of $5 \mathrm{MW}$. A bid like this could occur due to an unexpectedly gusty night, with additional wind generation that would force a decrement. The aggregator absorbs this energy into its aggregation of 10,000 EWHs. Figure 3.3 shows the overall energy take of the aggregator decreasing over this hour, and the 
system returns to normal. The blue line shows the energy take when the bid is simulated and the dotted black line shows energy take with no bid simulated. A large linear dive in energy take occurs between 0200 and 0300 . This dive in energy take comes from the units drawing $5 \mathrm{MW}$ for one hour to meet the energy requirements of the bid.

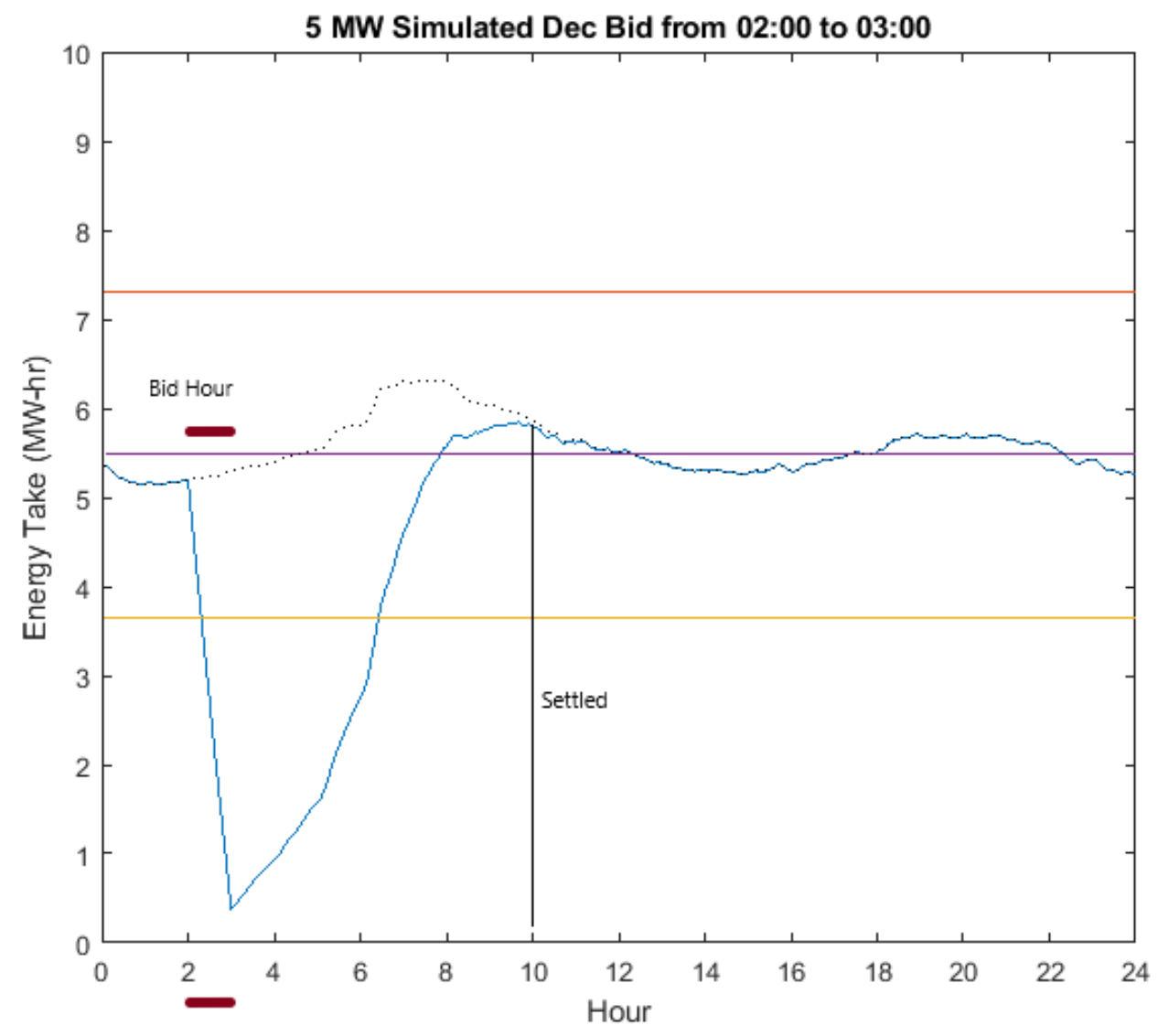

Figure 3.3: To cover the bid, extra units turn on and a drop in energy take occurs.

Figure 3.4 shows the percent of water heaters that are turned on, blue representing the bid and dotted-black representing no bid. The number of water heaters turned on spikes from 02:00 to 03:00. After this period, the number of units heating due to a bid is less than the expected number of units heating when no bid is acted upon. At 09:40, the aggregator 
energy take with bid and aggregator energy take differ by no more than $2 \%$. By 10:00 the number of units heating with bid and without bid differ by no more than $2 \%$. These can be thought of as settling times. The system takes 6 hours and 40 minutes to settle for energy take and 7 hours to settle for the number of units on.

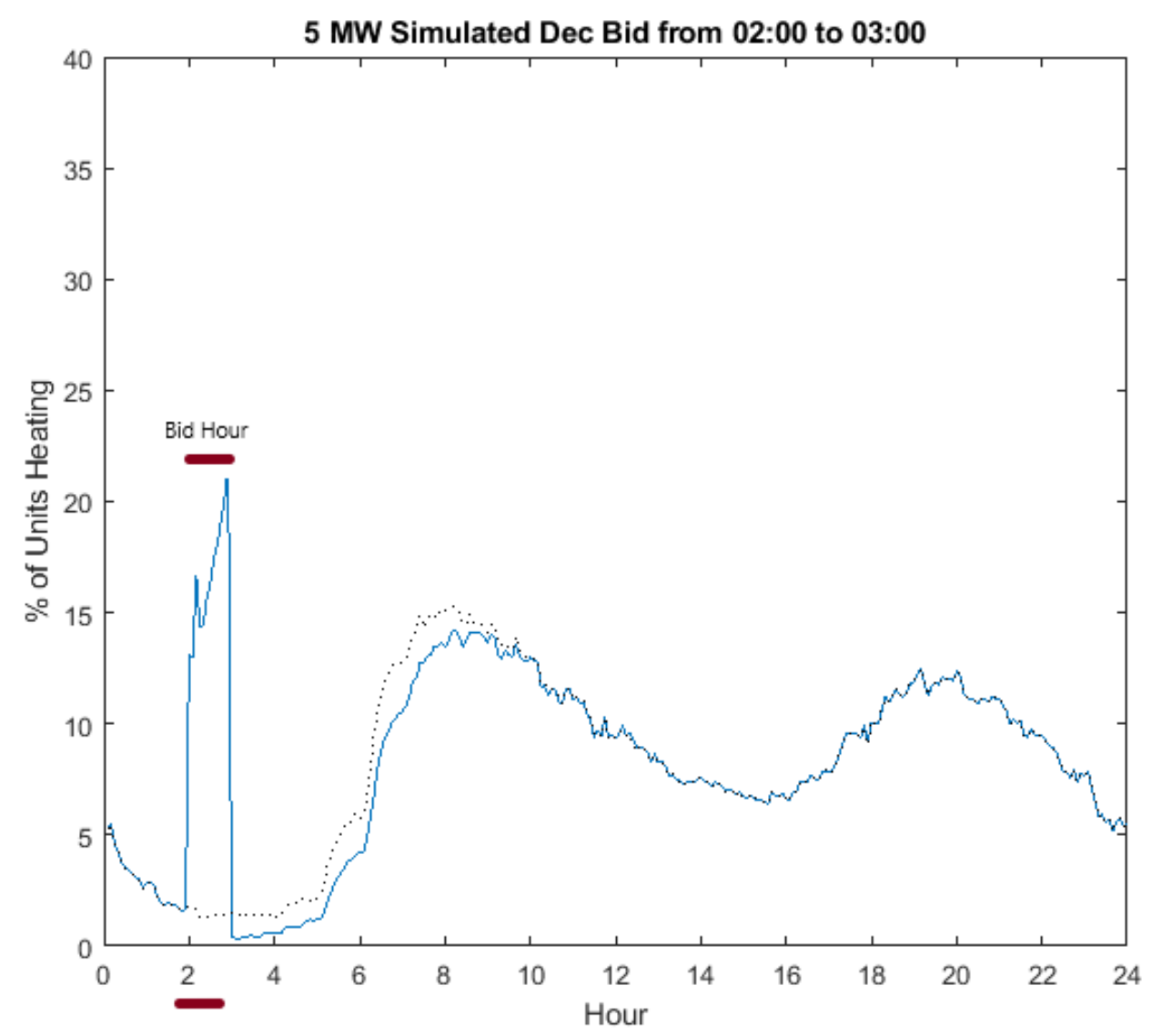

Figure 3.4: The energy take dives to nearly 0 , and it still does not cover the $6 \mathrm{MW}, 1$ hour bid

I then simulated a bid that the aggregator could not handle. I tested a $6 \mathrm{MW}$ decrement bid from 0200 to 0300 . Here the aggregator tries to assign units to get the necessary megawatts, but in the last two intervals fails to meet the bid. All units are turned on, and the aggregator still fails to meet the bid. Figure 3.5 shows the energy take falling to nearly 
zero. Figure 3.6 shows the percentage of units heating. In the last two intervals, all units are turned on, yet the aggregator still cannot meet its bid. Figure 3.7 shows the power output of the $5 \mathrm{MW}$ and $6 \mathrm{MW}$ bids.

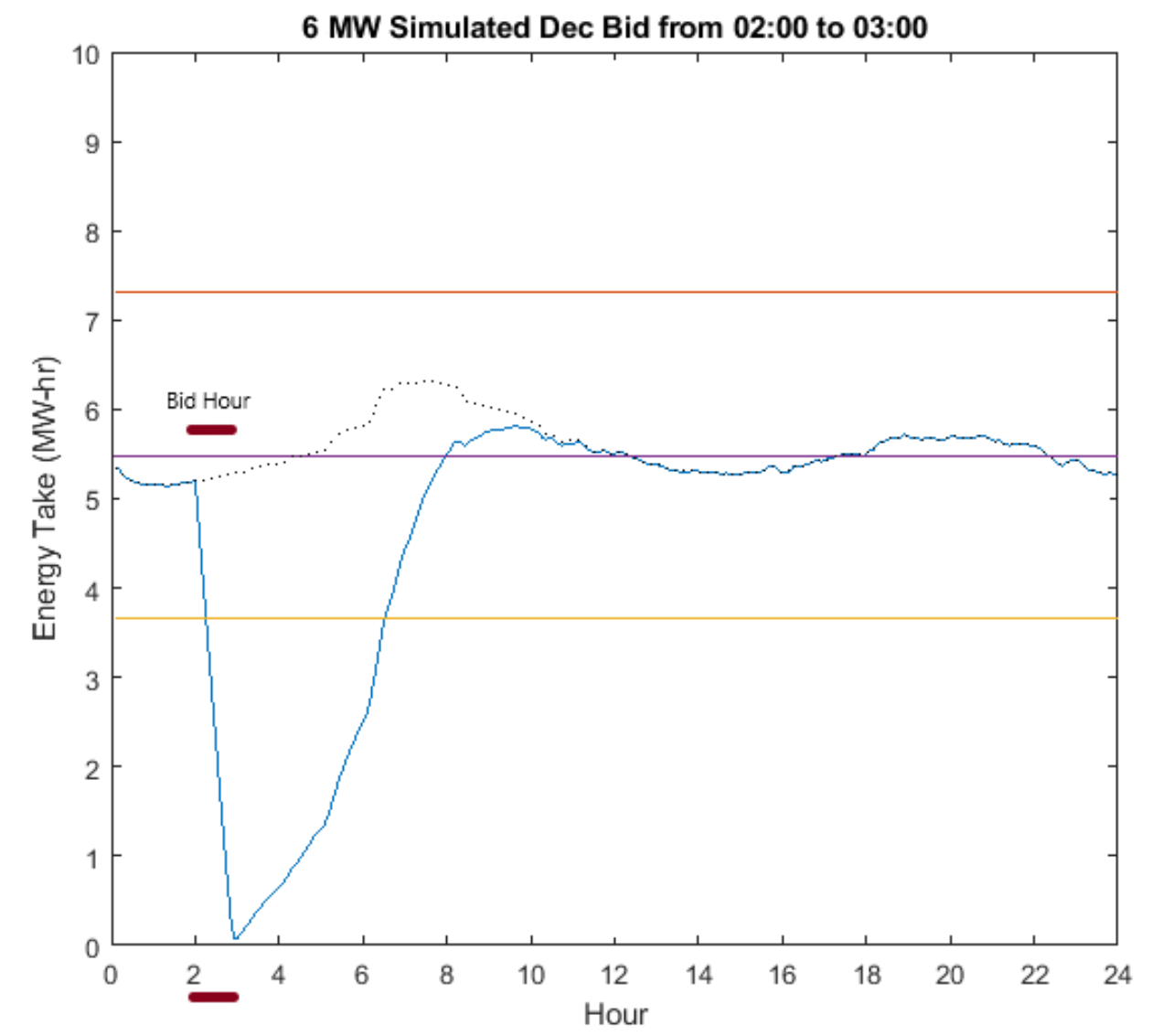

Figure 3.5: The energy take dives to nearly 0 , and it still does not cover the $6 \mathrm{MW}, 1$ hour bid. 


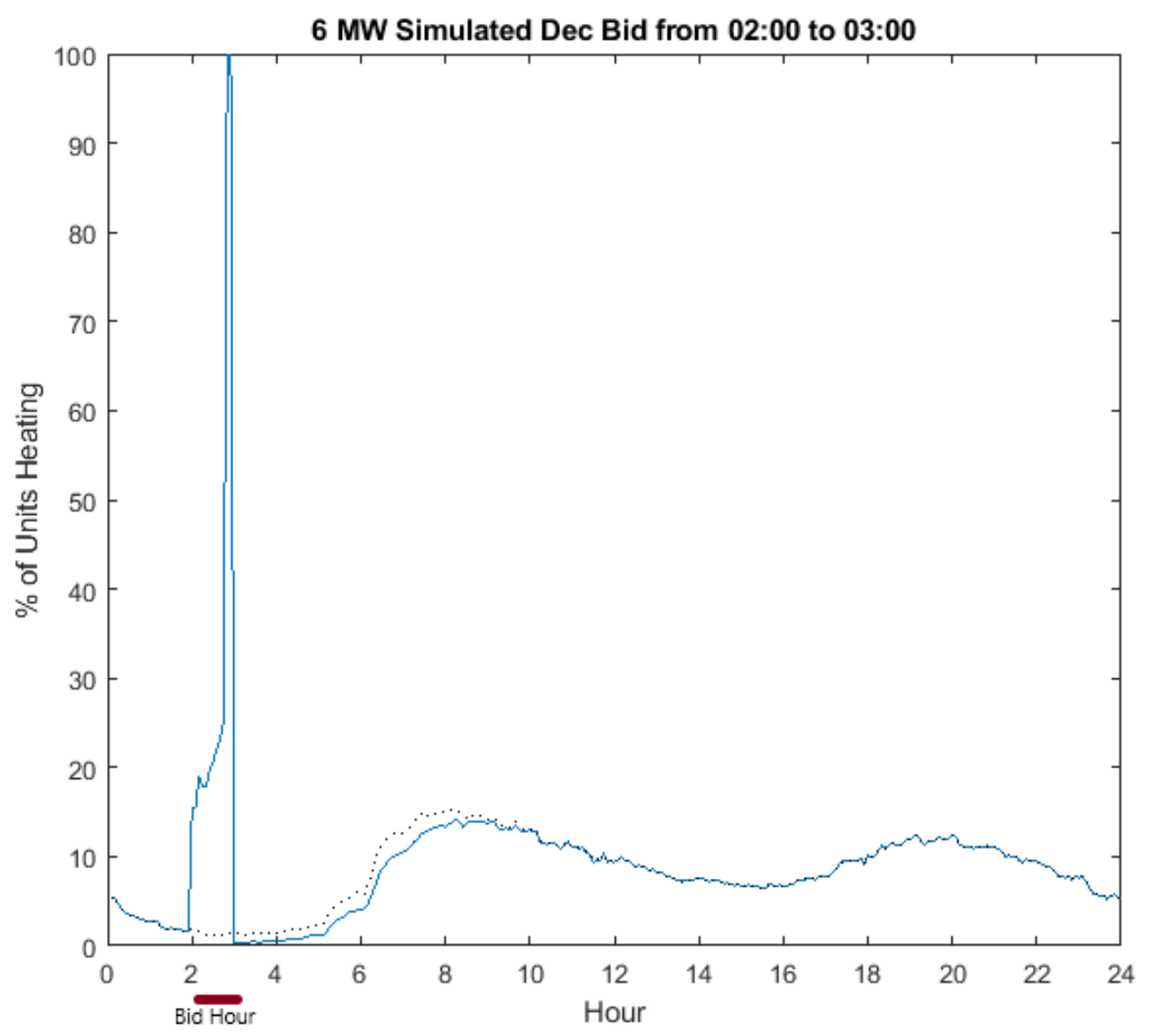

Figure 3.6: In the 2:50 and 2:55 intervals, the aggregator turns all units on, and still does not meet its bid.

Figure 3.8 shows how the aggregation handling a variety of two hour decrement bids ranging from 1 to $7 \mathrm{MW}$. Initially the aggregator provides power, and then the aggregation simply runs out of energy take. The bids do not go to zero, due to some amount of water draws and ambient losses over each interval. 


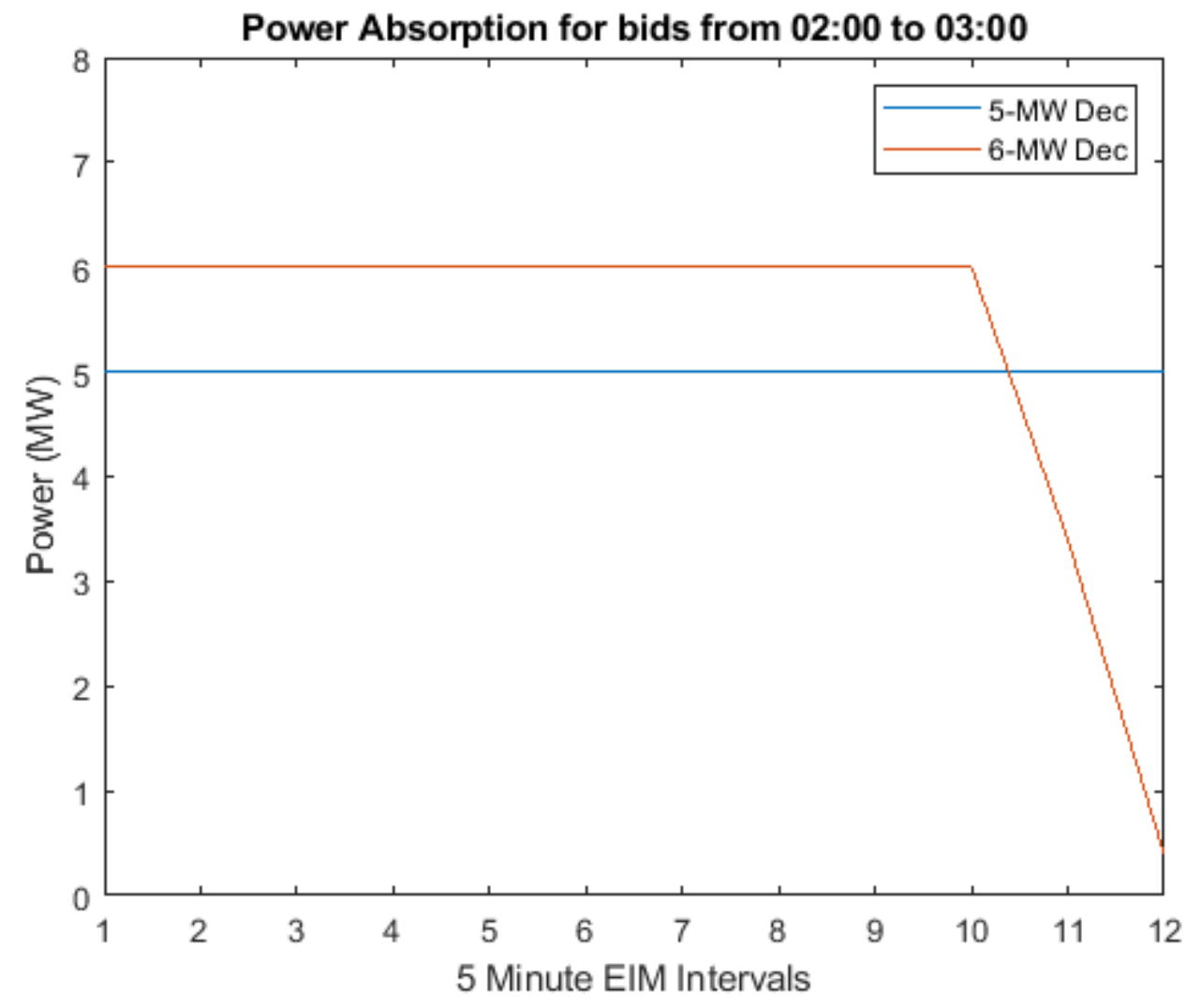

Figure 3.7: In the 2:50 and 2:55 intervals, the $6 \mathrm{MW}$ bid starts running out of energy, and fails to meet the power commitment of its bid. 


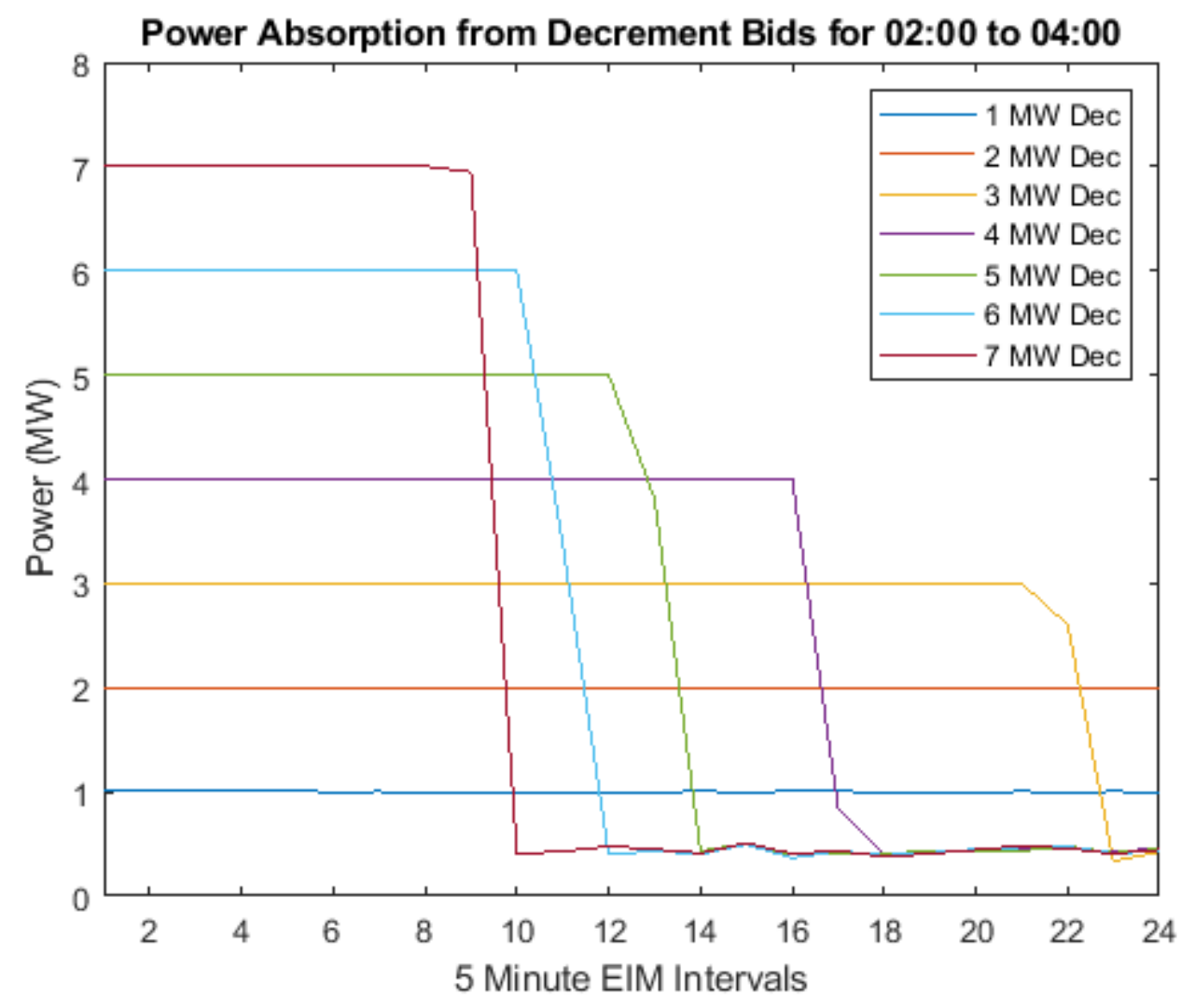

Figure 3.8: Over the 2 hour period, the 7, 6, 5, 4, and 3 MW bids eventually fail.

I tested another bid at lower power, but over a much longer time period, in order to characterize the limitations of the aggregator. Figures 3.9 and 3.10 show the effects on the energy take. The bid ends at 22:00 on the first day and the energy take settles to within $2 \%$ of the non-bid simulation by 03:00 the next day for a 5 hour settling time. Figures 3.11 and 3.12 


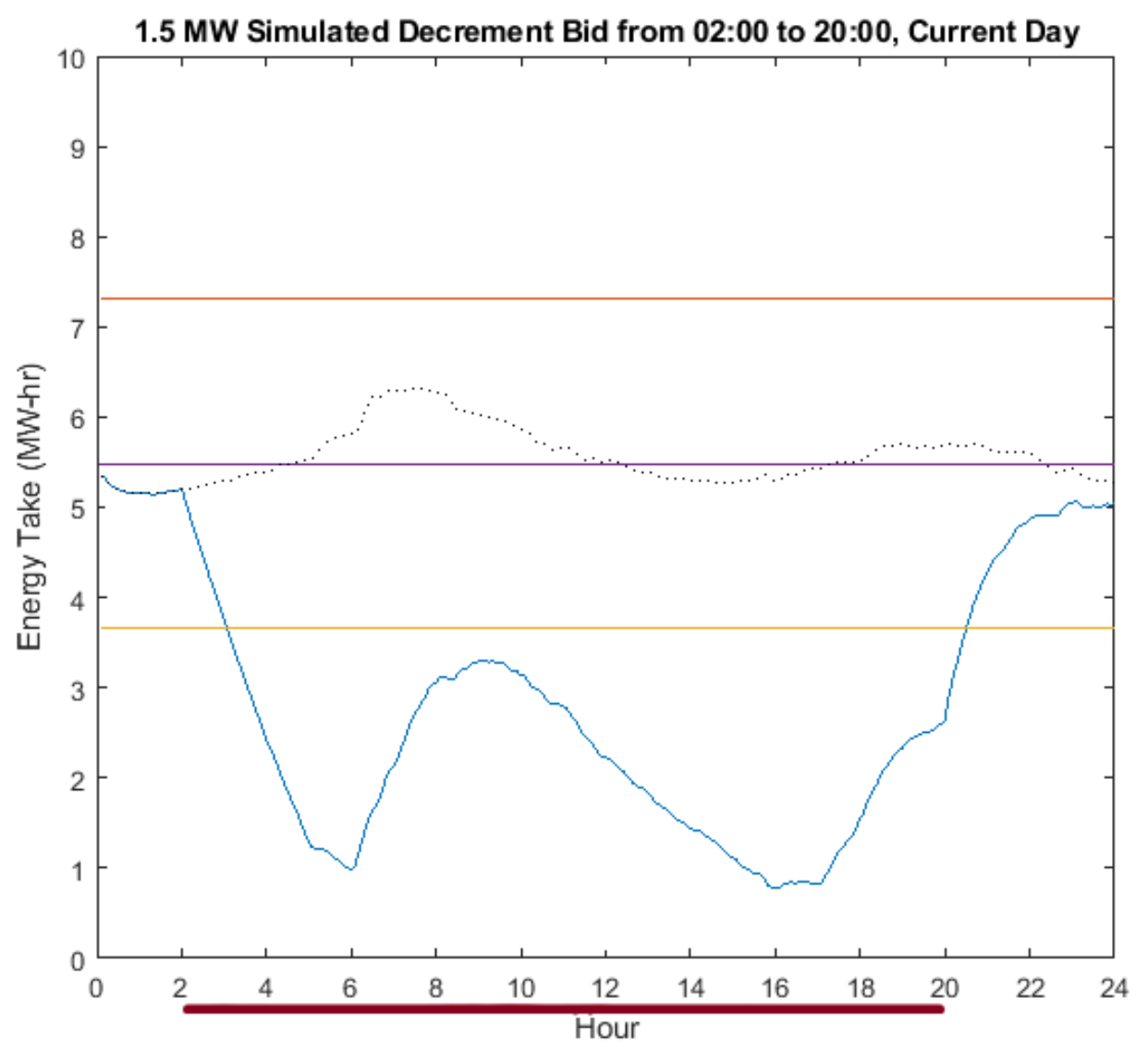

Figure 3.9: The energy take after a $1.5 \mathrm{MW}, 18$ hour bid, starting at 02:00 and ending at 20:00. 


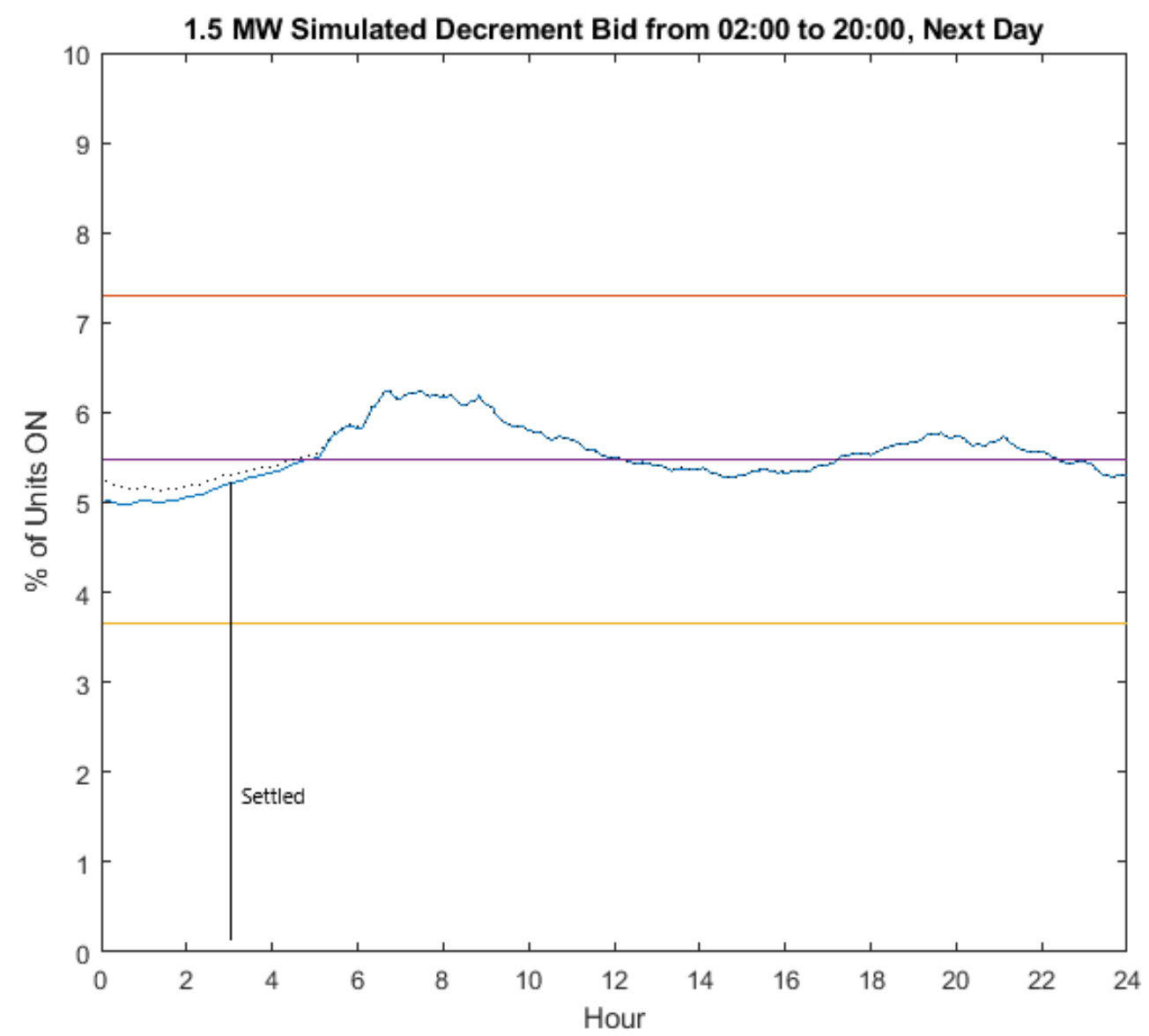

Figure 3.10: The day after energy take effects of the $1.5 \mathrm{MW}, 18$ hour bid. 


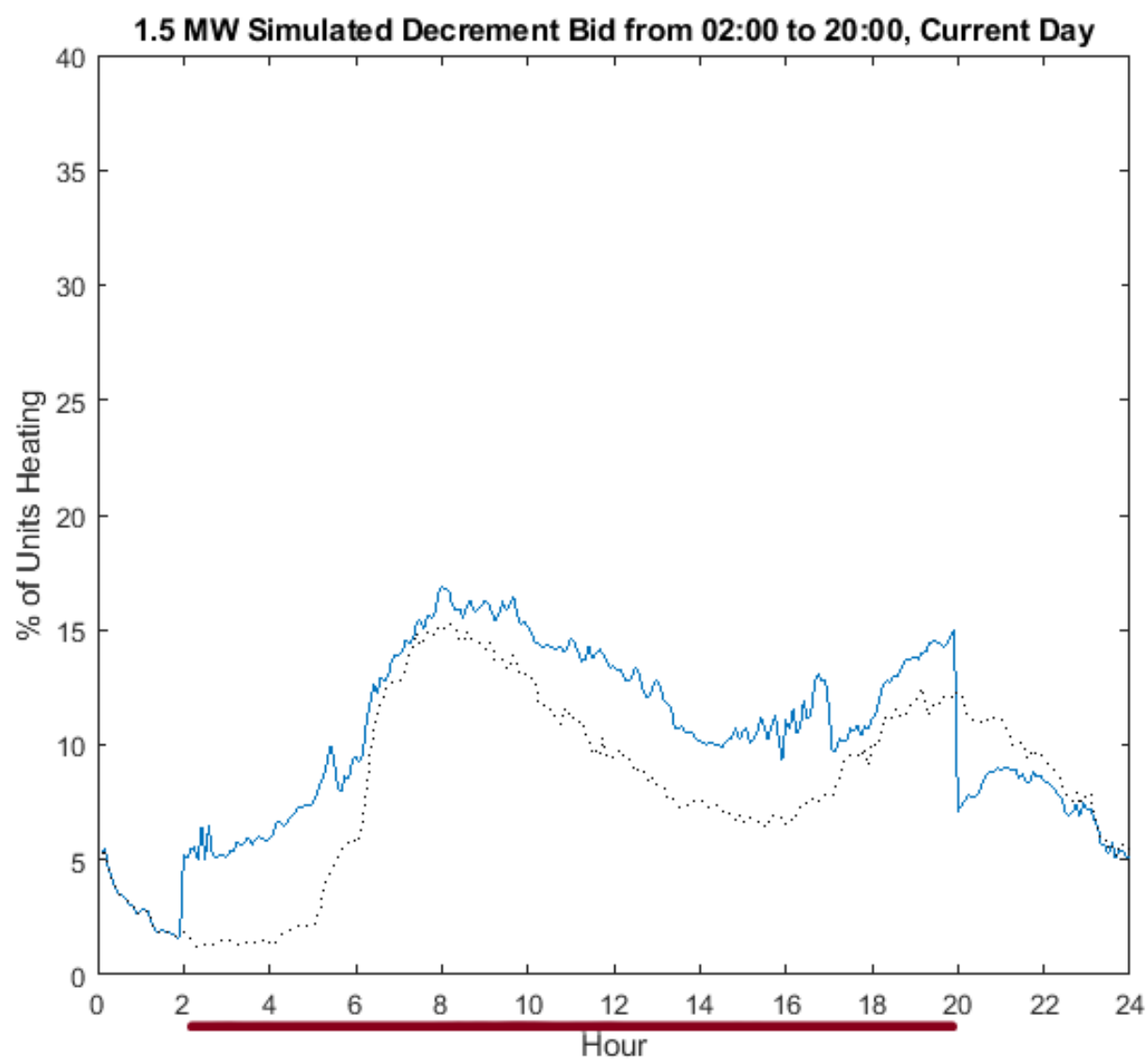

Figure 3.11: Percent of units turned on for the day the of 1.5 MW, 18 hour bid from 02:00 to 20:00. 


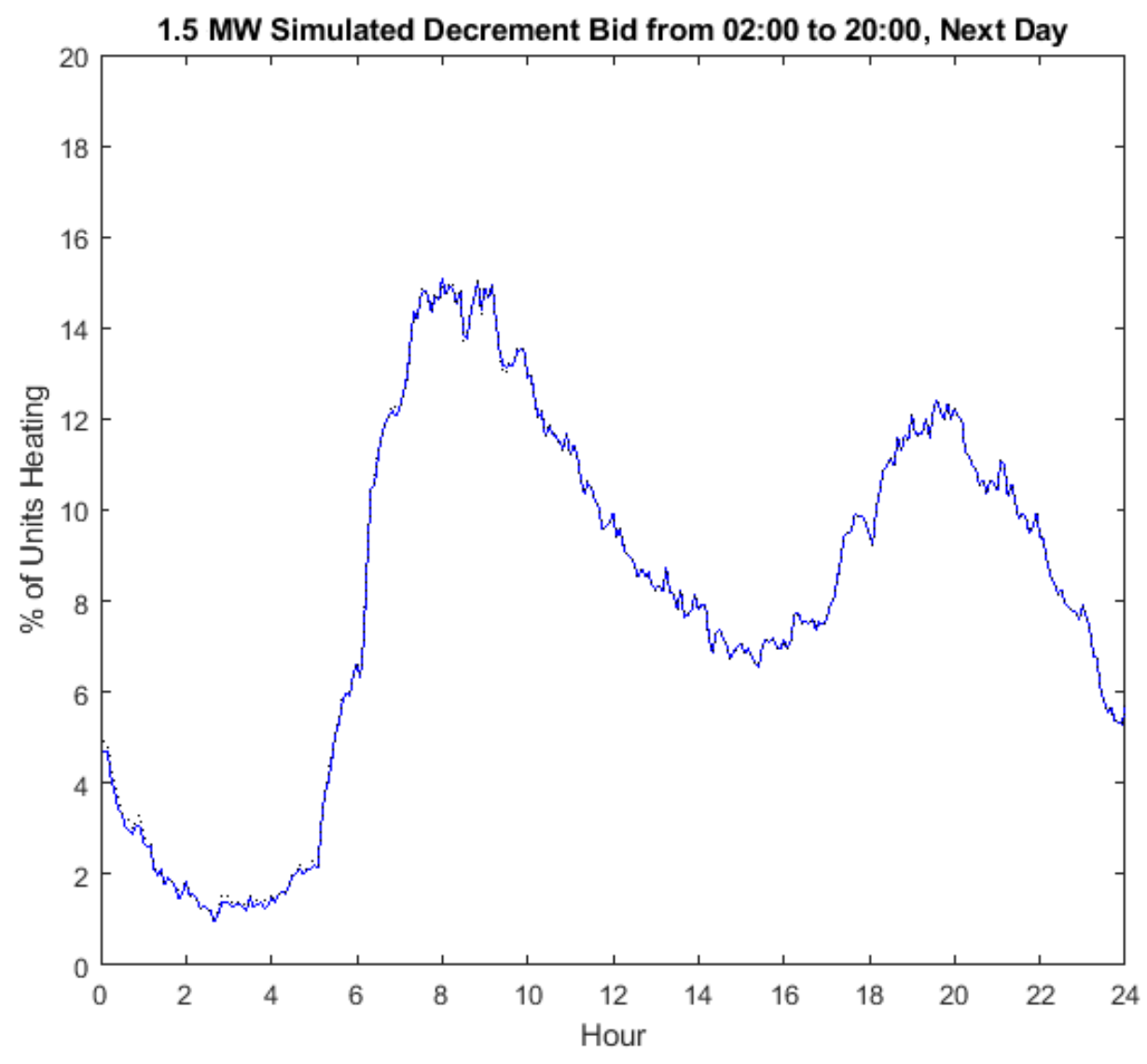

Figure 3.12: Percent of units turned on for the day after the bid.

When I raised the bid to $1.6 \mathrm{MW}$ over the same 18 hour period, the aggregator fails to meet the bid during certain intervals. Figures 3.13 and 3.14 show the energy takes and percent of units heating for the bid. Between 16:00 and 17:00, the aggregator fails to meet the bid during five of the five minute intervals. 


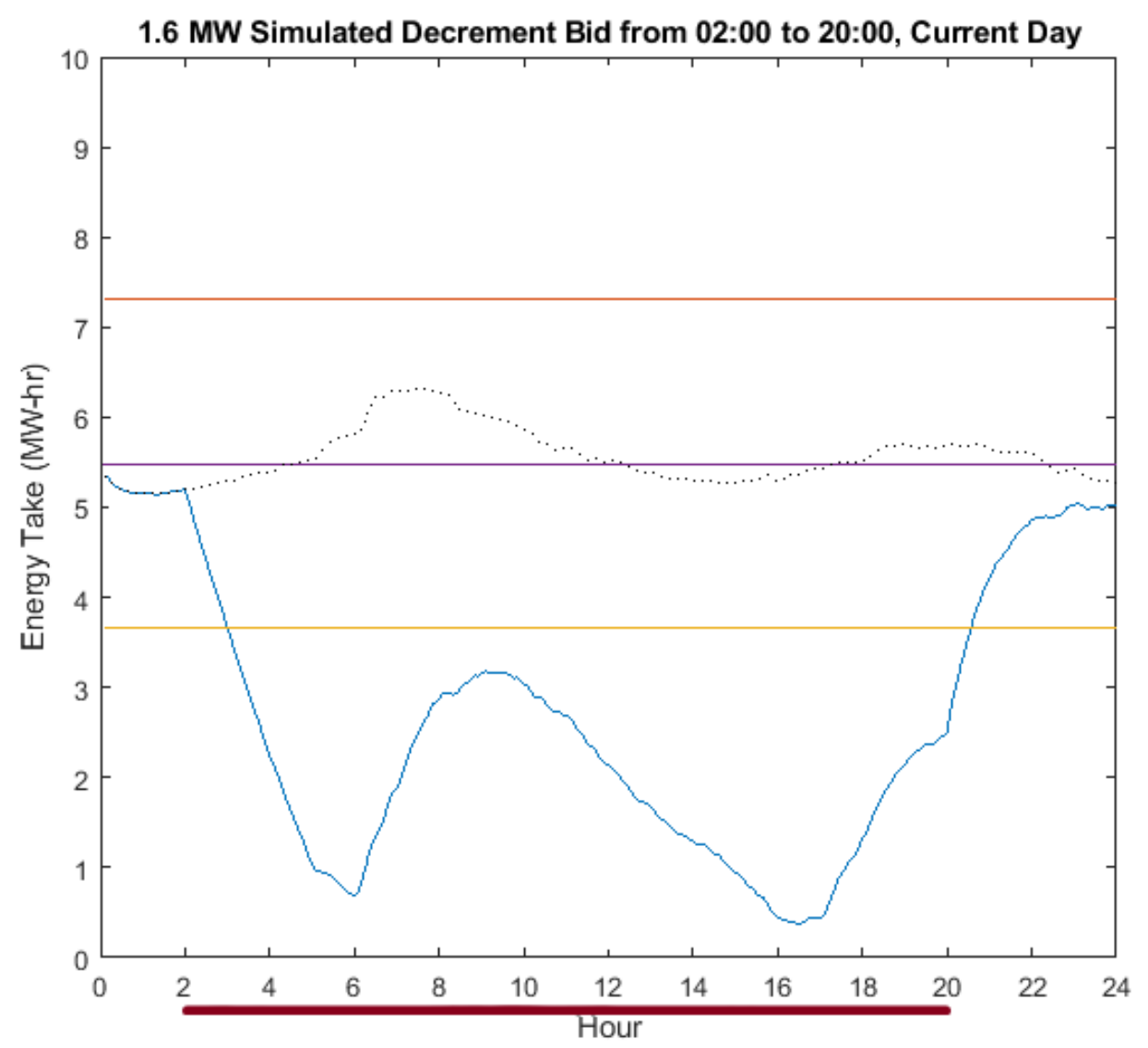

Figure 3.13: The aggregator fails to meet the bid five times between 16:00-17:00. 


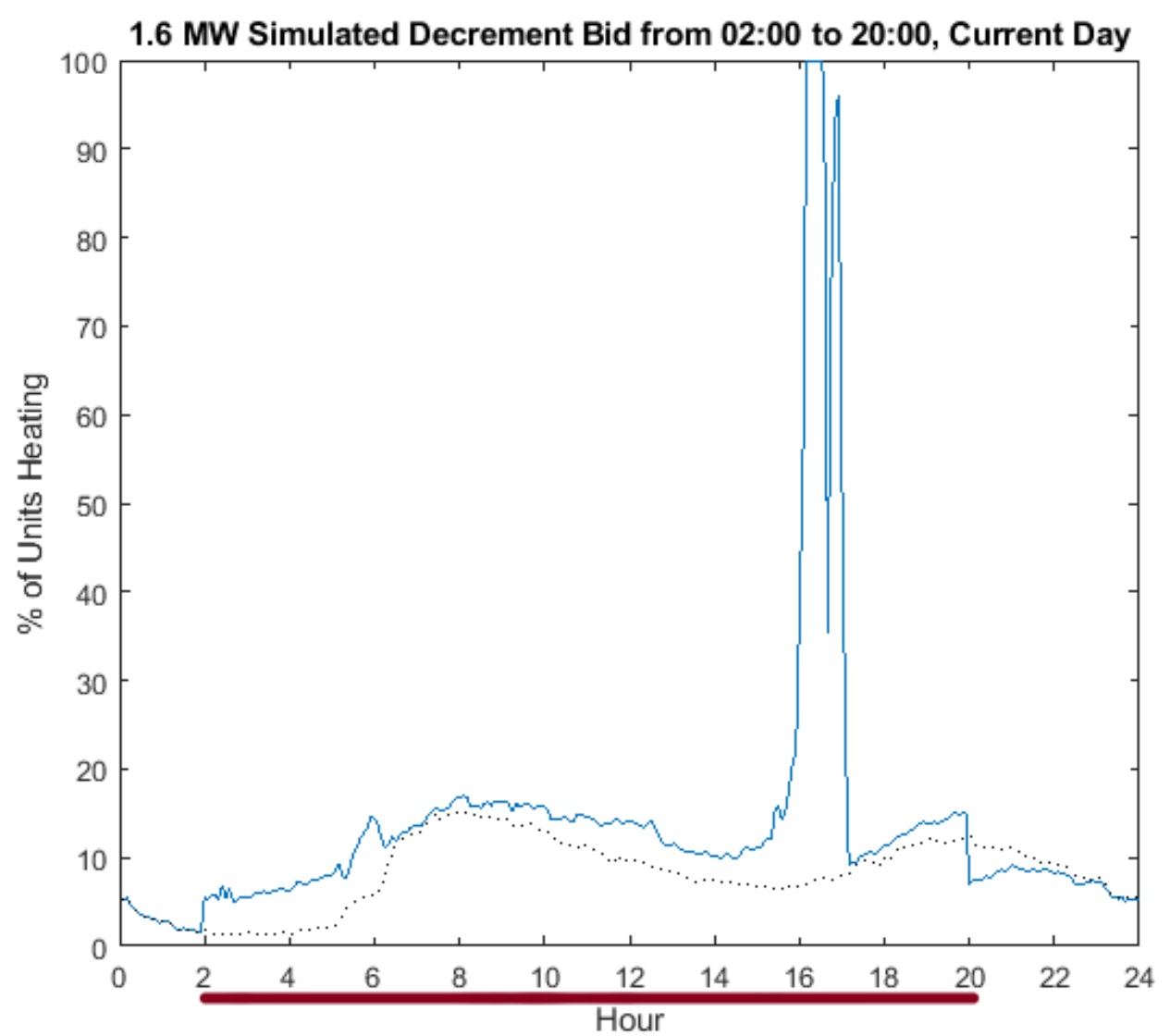

Figure 3.14: The aggregator cannot supply the necessary power across seven of the intervals from 16:00 to 17:00.

I went further to plot a 2.0 MW bid over the same 18 hour period. The aggregator fails to meet the bid across 52 intervals of the 216 total intervals. Failures now occur from about 14:00 to 18:00, and another failure period opens up from around 4:30 to 6:00. Figure 3.15 shows the energy take falling to almost nothing during this periods. Figure 3.16 shows the units heating, with spikes to $100 \%$ during these periods. 


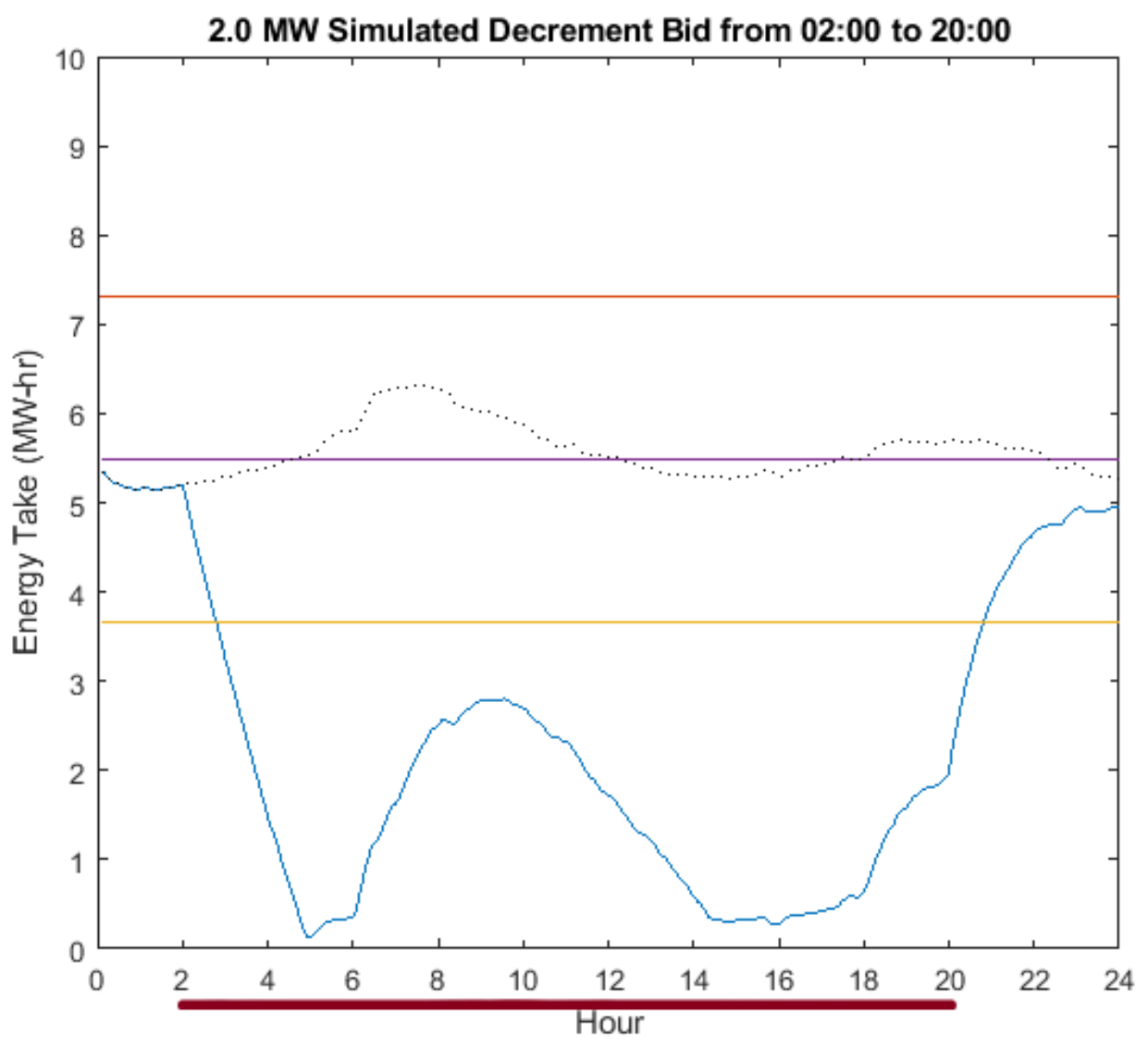

Figure 3.15: The aggregator starts failing from 4:30 to 6:00. 


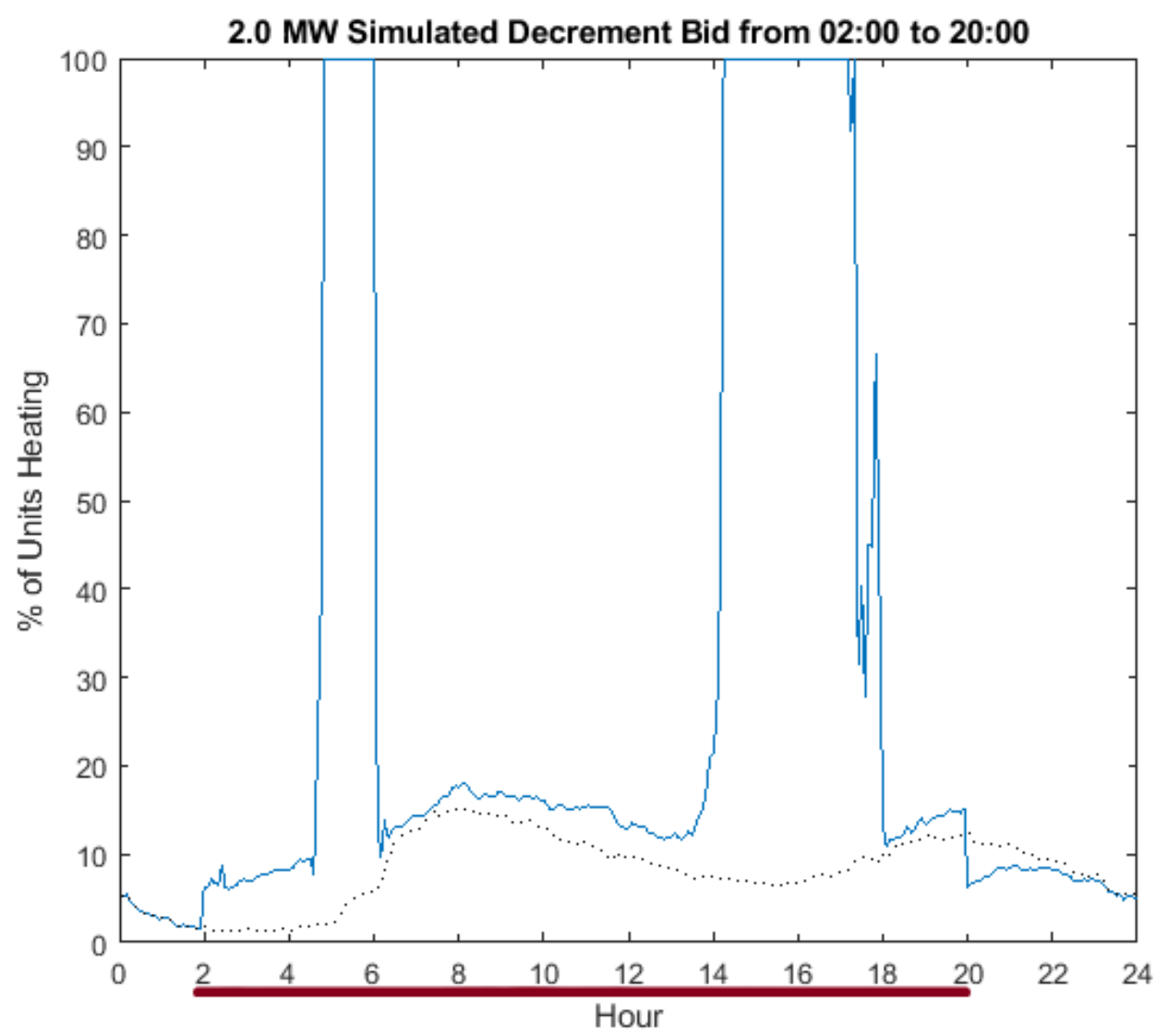

Figure 3.16: The aggregator cannot supply all the energy to meet the bids, despite all units heating.

In Figure 3.17, I plotted the power absorbed by these units for bids from 02:00 to 20:00 for bids ranging from 1.5 MW to 2.0 MW. The bids first start failing in the 16:00 to 17:00 period, then intervals around 5:00 to 6:00 starting showing deficiencies. The higher bids lead to wider spans of failed intervals as well as greater deficiencies in actual power absorbed. The aggregator recovers after these intervals of failure. Upticks in hot water draws occurring around 6:00 and around 18:00 provide the extra energy take necessary to cover future intervals. 


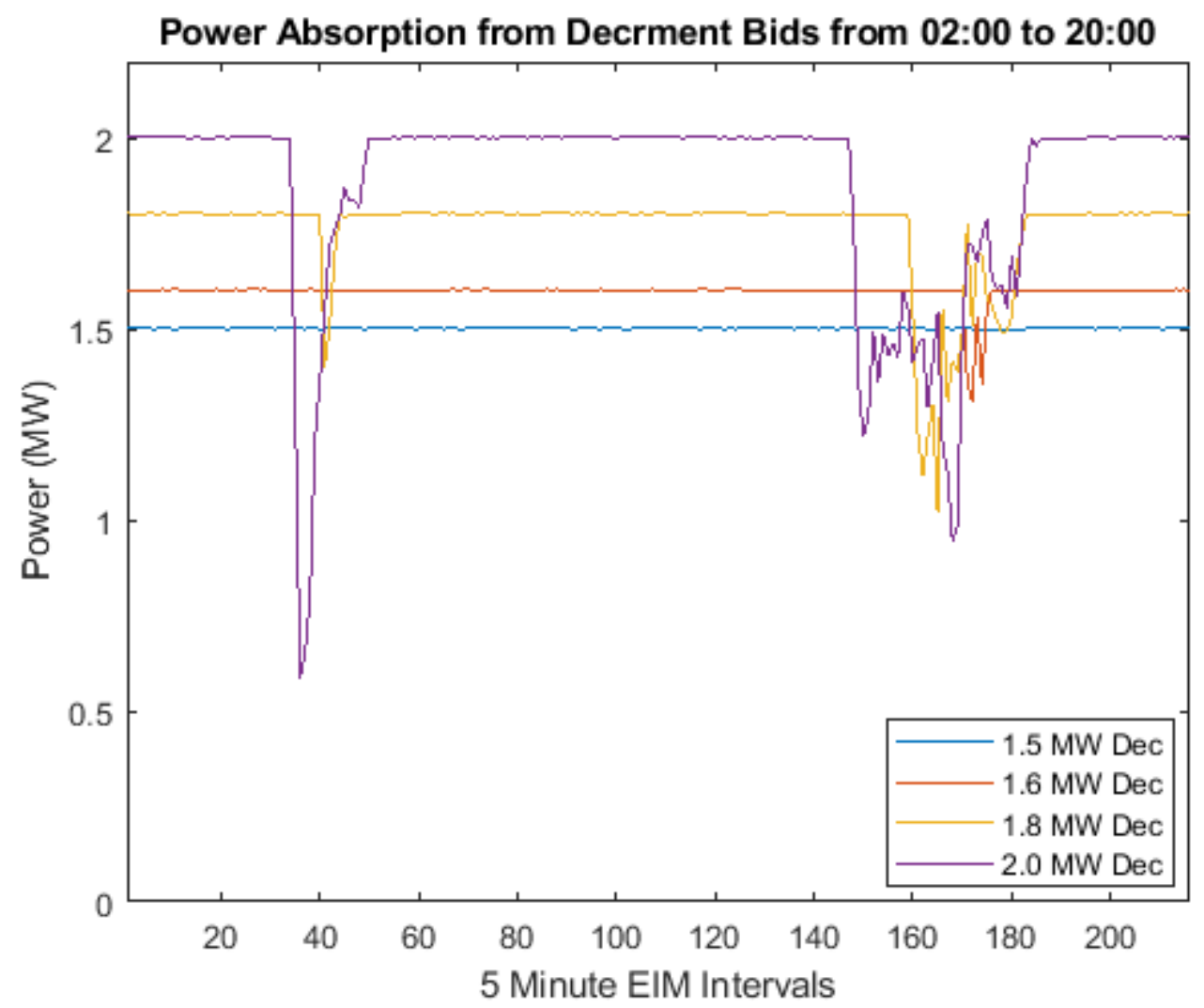

Figure 3.17: Increasing power leads to increasing number of intervals with insufficient power.

Both the 1.6 MW bid and the previous $6 \mathrm{MW}$ bid represent bids failing due to lack of energy take in the units. The electric water heaters do not have the ability to store the extra energy without going past their setpoints.

The aggregator could also fail to meet a bid due to lack of power, rather than energy. In this case a large amount of power would be called on in a short interval. To test this I tried a case of large power draw over a single 5 minute interval. Figure 3.18 shows how a $43 \mathrm{MW}$ bid over a single interval effects the energy take of the aggregator. After this bid, roughly 1.5 MWh of capacity still remain available. However, looking at Figure 3.19, we see that nearly all the units are called (99.3\%). The aggregator actually meets this bid, but increasing 
this to even $44 \mathrm{MW}$ will result in failure. Here the aggregator should have roughly $5 \mathrm{MWh}$ of energy take available. In theory it could be able to serve $60 \mathrm{MW}$ over a 5 minute period. The aggregator is limited by power here. It does not have enough power in its aggregated electric heating coils to produce $60 \mathrm{MW}$.

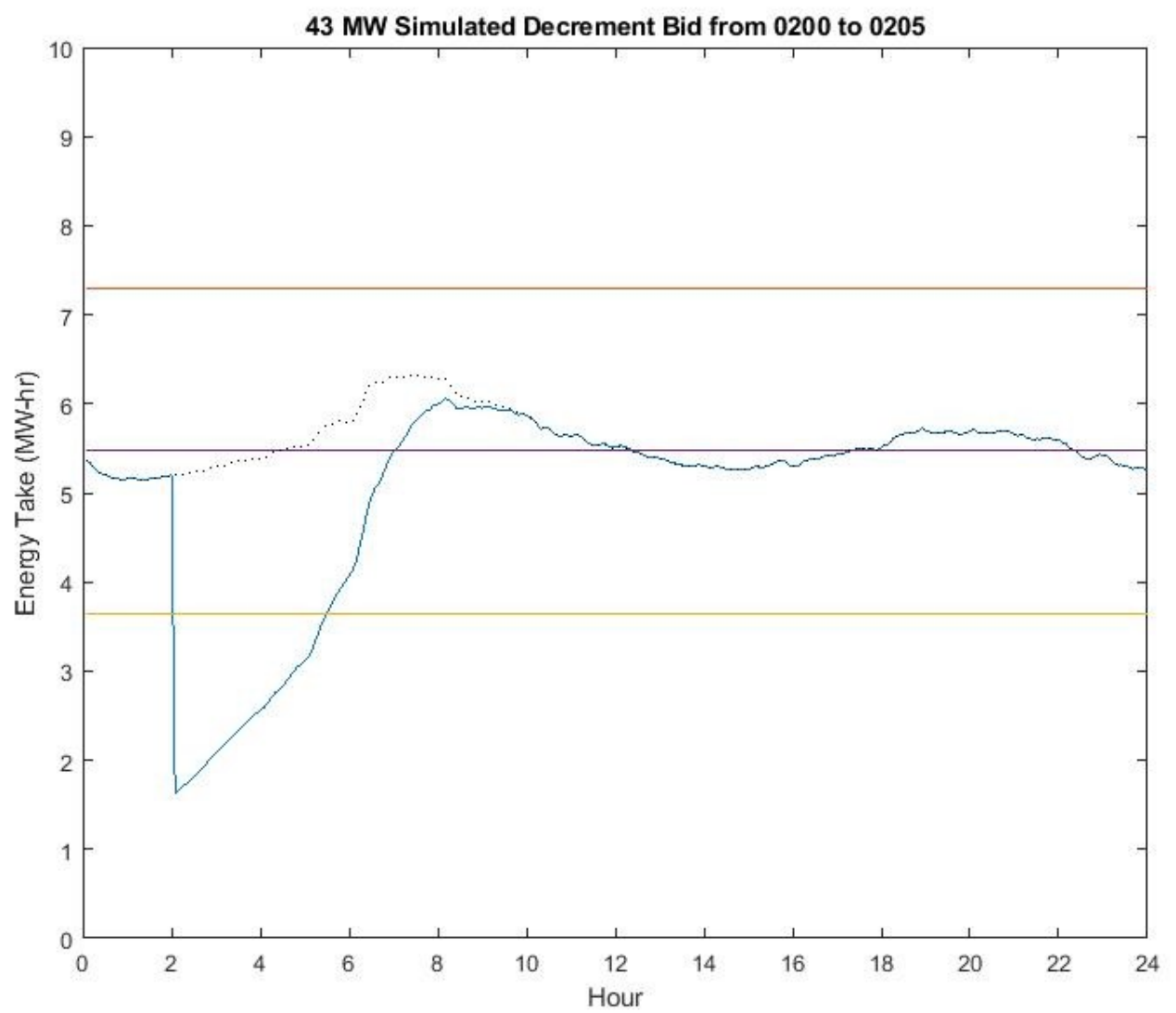

Figure 3.18: $99.7 \%$ of all units turn on, barely covering this $43 \mathrm{MW}$ bid. 


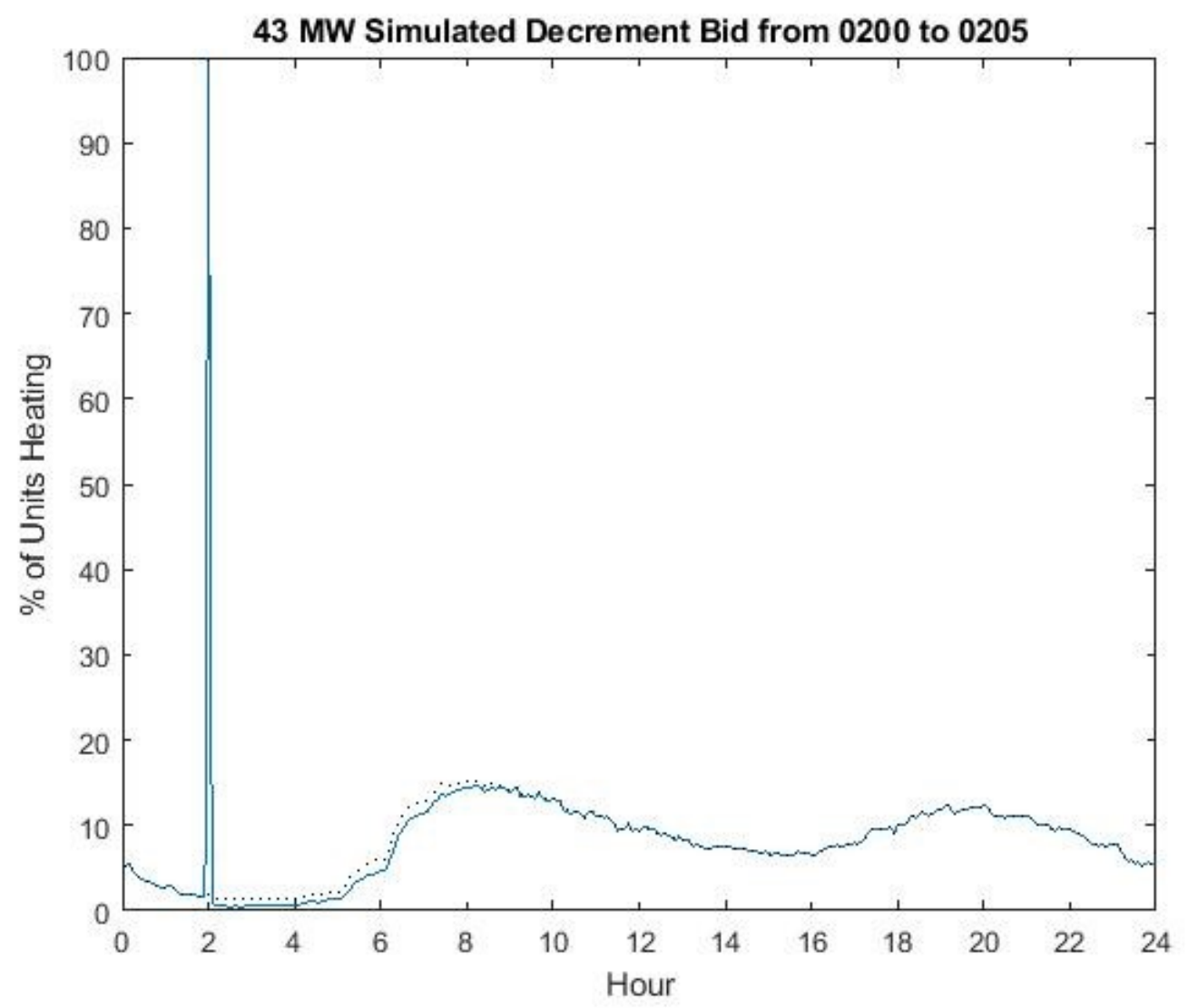

Figure 3.19: The energy take dives to nearly 0 , and it still doesn't cover the bid.

To characterize the aggregator's maximum energy, I wrote a MATLAB script simulating the aggregator's response to a bid over a number of intervals at n-amount of megawatts. With this script I can pinpoint the maximum energy the aggregator can provide over a given interval. 


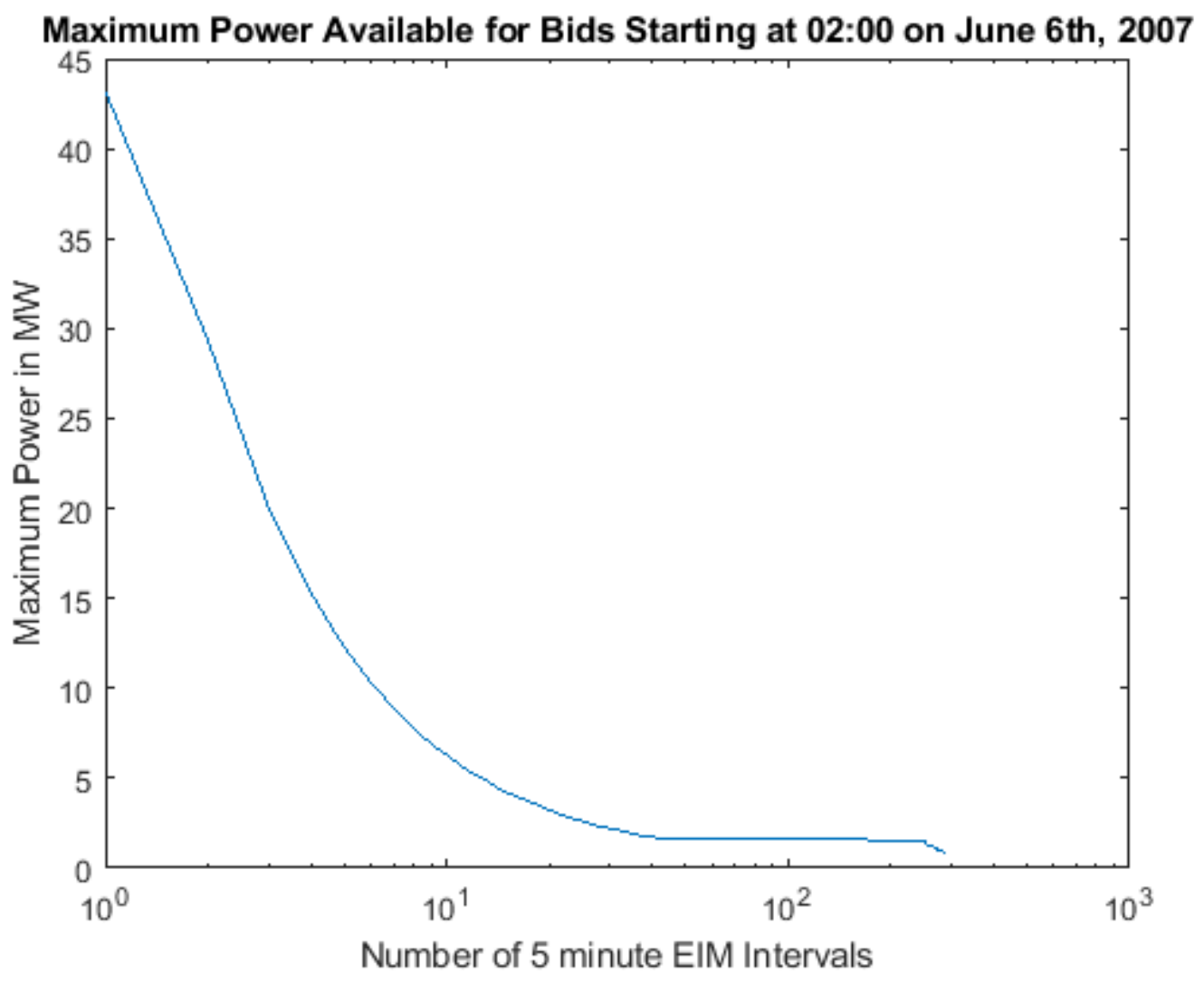

Figure 3.20: Maximum biddable megawatts up to 24 hours.

The maximum decrement bid across a number of intervals is plotted in Figure 3.20. While the lines may look continuous, the points correspond to a specific number of 5 minute EIM intervals. Figure 3.21 shows a bid from 1 to 24 EIM intervals, which corresponds to 5 minutes to 2 hours worth of resource commitment. Table 3.1 further illustrates this point with specific power levels for each of the first 12 intervals. For the 10,000 EWH aggregation, only the first interval is power limited, while the remaining intervals are all energy limited. 


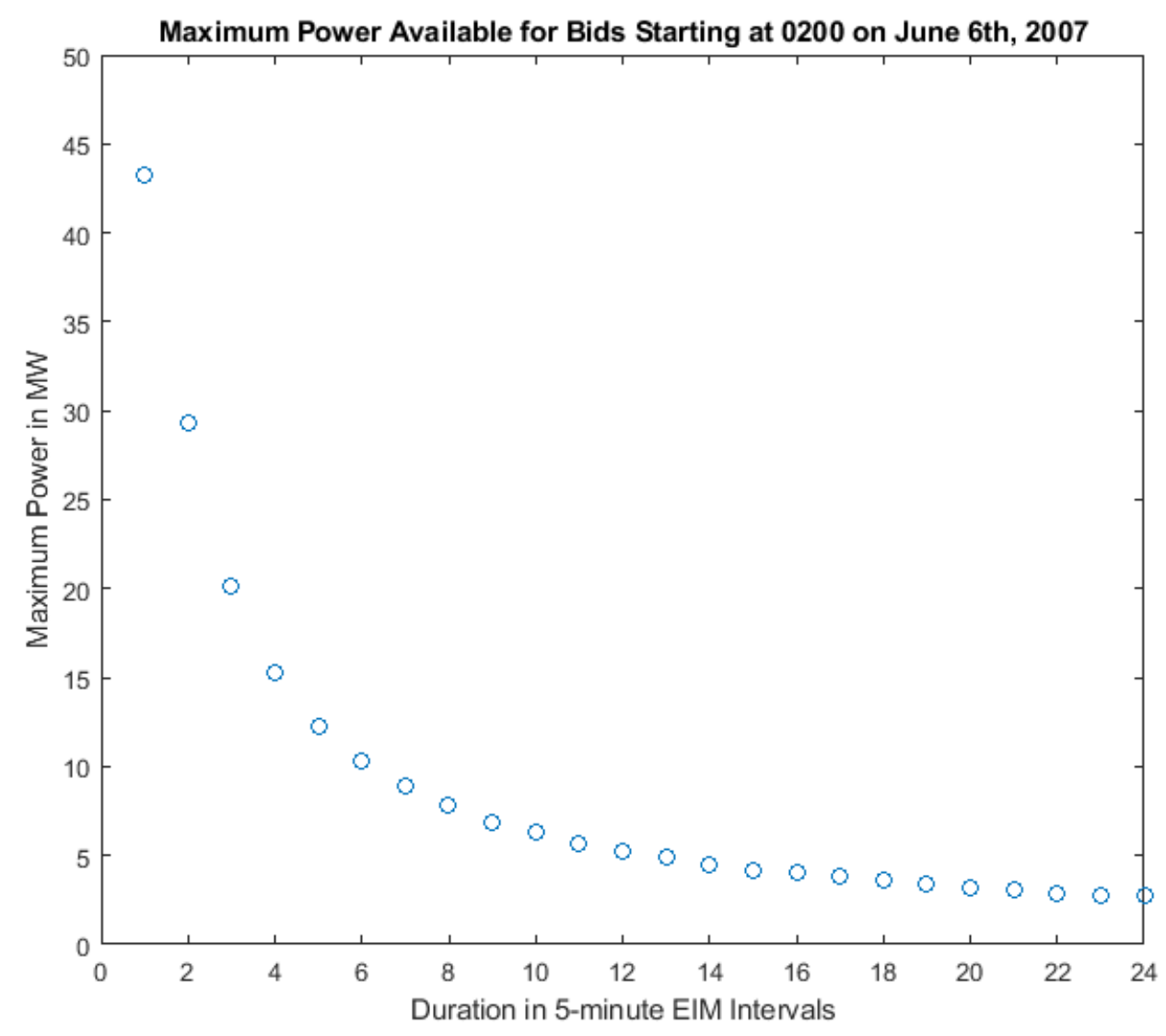

Figure 3.21: Maximum biddable megawatts up to 2 hours.

I also tested my simulation on a smaller aggregation of $100 \mathrm{EWH}$. All these EWH were from 5 bedroom households with 80 gallon water tanks. I tested a $50 \mathrm{~kW}$ decrement bid to see the similarities to the larger aggregation. Figure 3.22 shows the effects of the $50 \mathrm{~kW}$ bid on energy take. Once again the black dotted line shows the non-bid case. The bids look comparable, however the settling is considerably slower. This is due to the water heaters being either $100 \%$ on or $100 \%$ off at any given time. With greater numbers, these effects even out, but with a smaller aggregation they are more noticeable. 
Table 3.1: Maximum power the aggregator can provide across a number of intervals starting at 02:00 on June 6, 2007.

\begin{tabular}{|c|c|c|}
\hline Intervals & Max Power (MW) & Limitations \\
\hline 1 & 43.2 & Power Limited \\
2 & 29.3 & Energy Limited \\
3 & 20.1 & Energy Limited \\
4 & 15.3 & Energy Limited \\
5 & 12.3 & Energy Limited \\
6 & 10.3 & Energy Limited \\
7 & 8.9 & Energy Limited \\
8 & 7.8 & Energy Limited \\
9 & 6.9 & Energy Limited \\
10 & 6.3 & Energy Limited \\
11 & 5.7 & Energy Limited \\
12 & 5.2 & Energy Limited \\
\hline
\end{tabular}

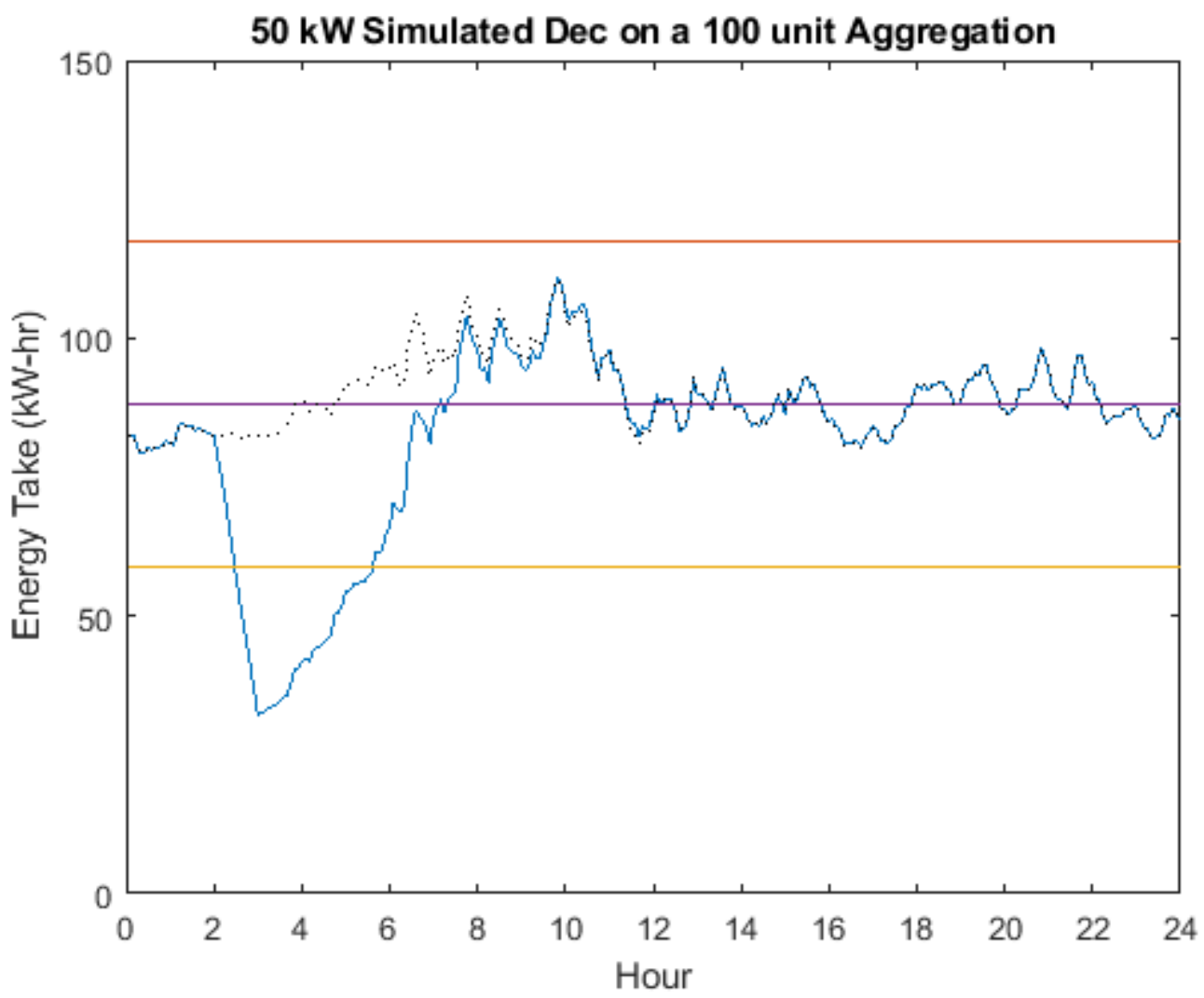

Figure 3.22: Maximum biddable energy up to 2 hours. 
Similarly Figure 3.23 shows the effects of the $50 \mathrm{~kW}$ bid on the amount of units heating. Again, slower settling is apparent.

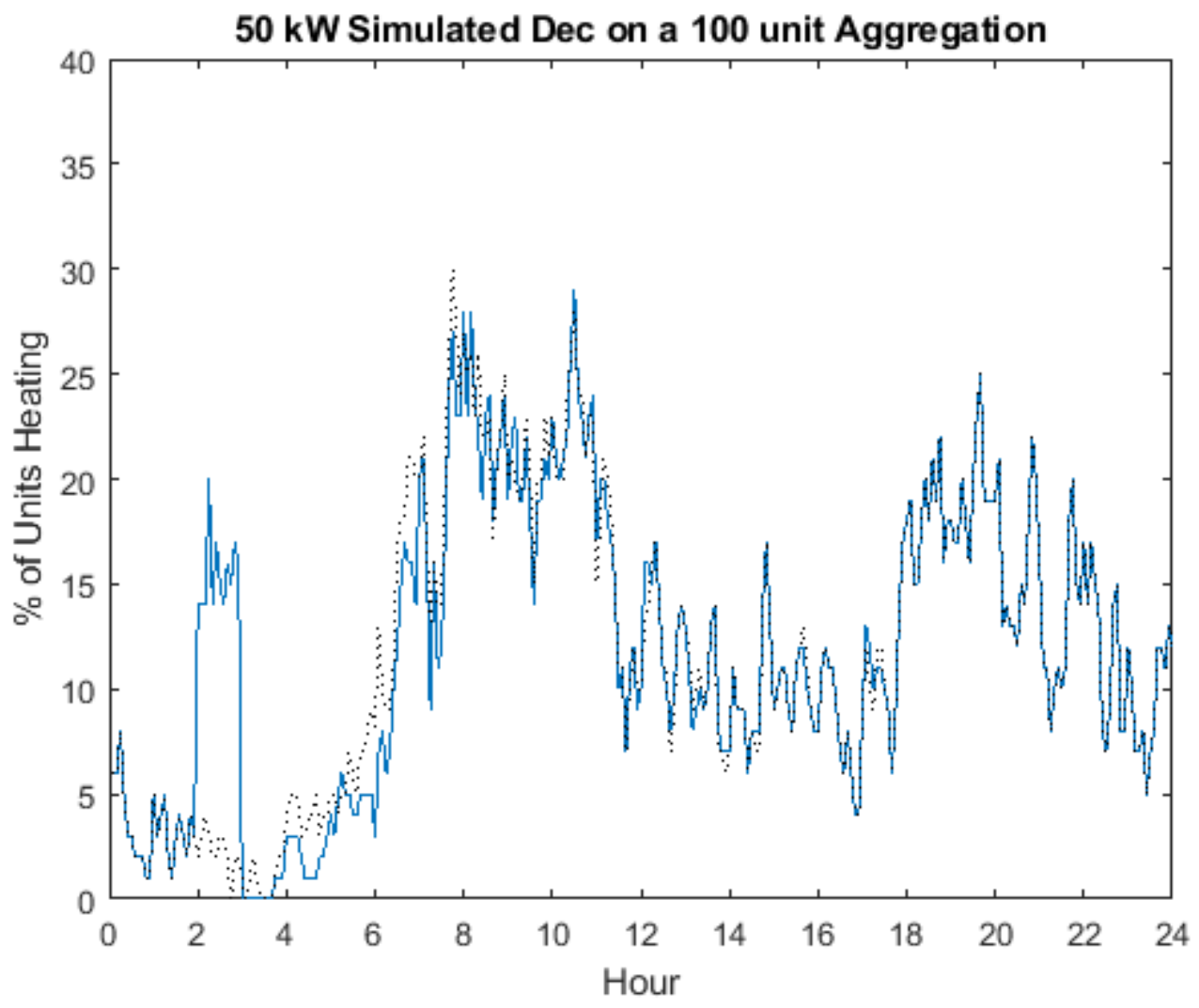

Figure 3.23: $100 \mathrm{EWH}$ aggregate energy take bidding $50 \mathrm{~kW}$.

Figure 3.24 shows the effects that bids have on power absorbed by the aggregation. Here the granularity of water heaters is most visible. The algorithm commits water heater to cover the bid by turning at $100 \%$. The units are bit until the power provided is at the bid level or higher, so with a small aggregation the power is noticeably greater than bid. Across 10,000 units this slight overage is unnoticeable on a graph, yet across only 100 units the overage can be seen on a graph. Comparing the failure of the small aggregation's $100 \mathrm{~kW}$ overbid 
to the $6 \mathrm{MW}$ overbid bid from Figure 3.7, the 10,000 unit aggregation loses power more smoothly and linearly than the 100 unit aggregation.

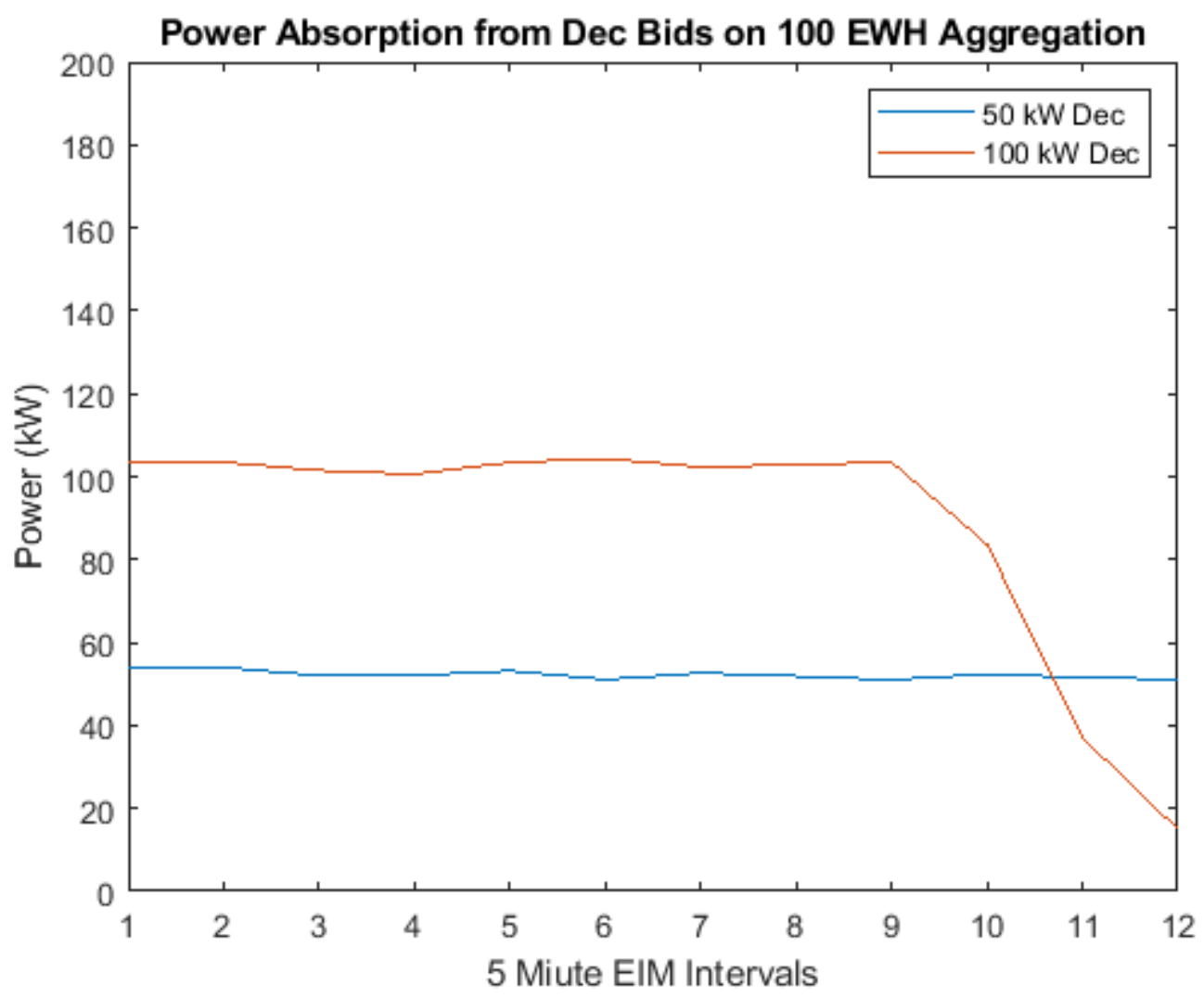

Figure 3.24: $100 \mathrm{EWH}$ aggregate power absorption over 1 hour.

\subsection{Results of Battery-Inverter Systems without bids}

I simulated 10,000 battery-inverter assets, assuming that they would follow PJM's RegA signal. The first simulation established a base case. DERAS has batteries as part of its aggregation. These batteries are likely to be doing something else when not participating with the EIM, so I modelled them to regulate frequency based on the logic in Section 2. The main purpose of this simulation is to offer a baseline for BIS use to compare against when I 
assign EIM bids later.

Figure 3.25 shows the state of charge of the batteries as a whole. The red line at the top shows the energy the batteries could store if all were fully charged. The 10,000 batteries are an amalgamation of $2,4,6,8$, and 10 hour systems, nominally rated with up to $20 \%$ of their capacity derated. Based on their state of charge, the batteries have different logic modes.

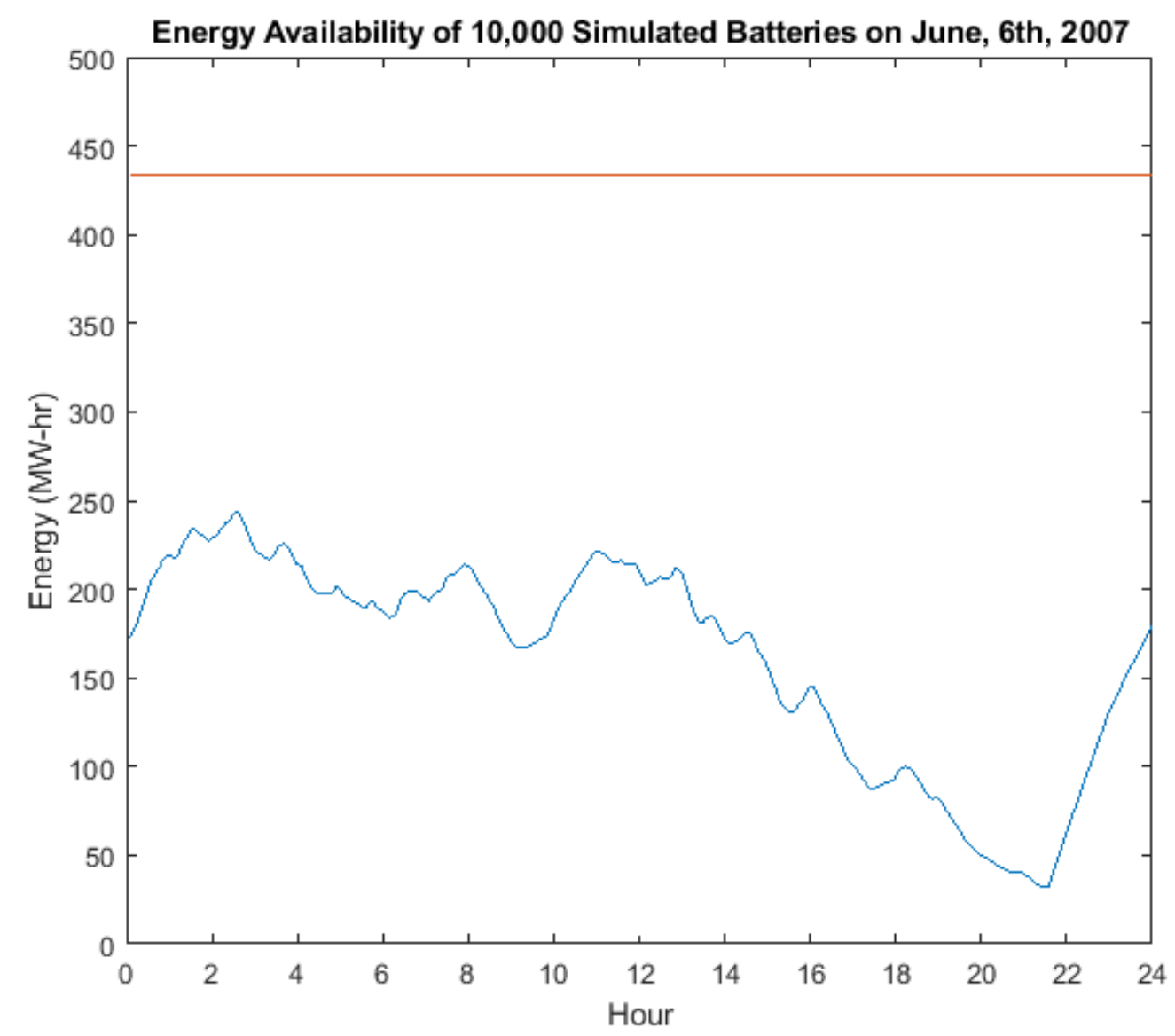

Figure 3.25: State of charge for the aggregate BIS, not bidding into EIM.

Figure 3.26 shows the logic states of the batteries. At the start of the day about half of the batteries are following the RegA signal, and the other half of batteries are in the prefer to 
charge or else follow RegA state. As the batteries start depleting over the peak hours, many of them move into the prefer to charge or else idle state.

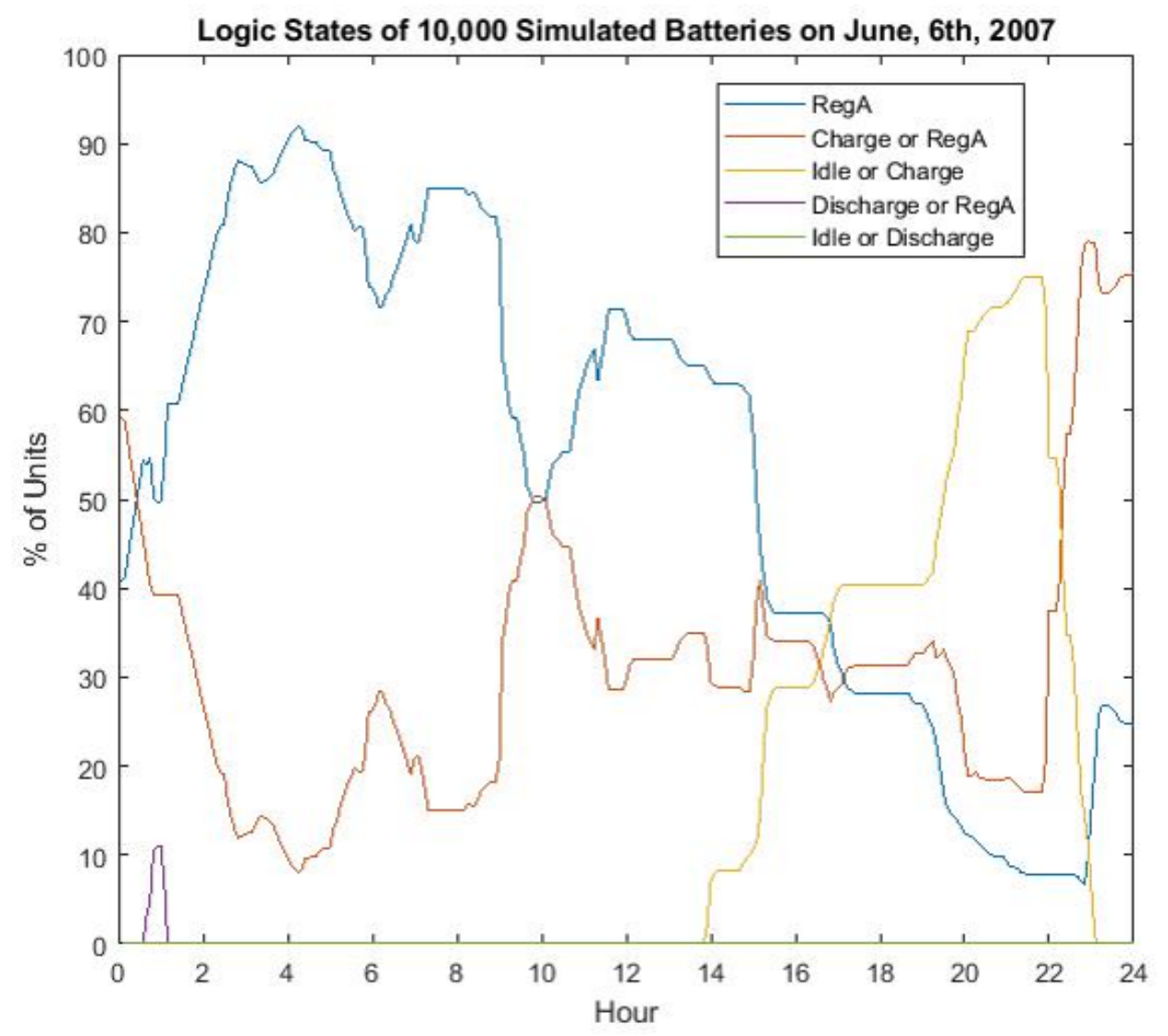

Figure 3.26: Logic states for each of the BIS not bidding into the EIM.

The logic states in Figure 3.26 manifest themselves as four actions that batteries can take: follow RegA, charge, discharge, and idle. Figure 3.27 shows the actions that the batteries are taking. In the early hours when power is cheap, the batteries choose to charge. Once sufficiently charge they again start following RegA as seen from 00:00 to 10:00. Once power becomes expensive at 11:30, the batteries all switch to follow RegA, and as time passes and more batteries deplete, they go idle rather than discharge to the grid. Once 22:30 hits, and 
power is cheap again, the batteries switch to charging.

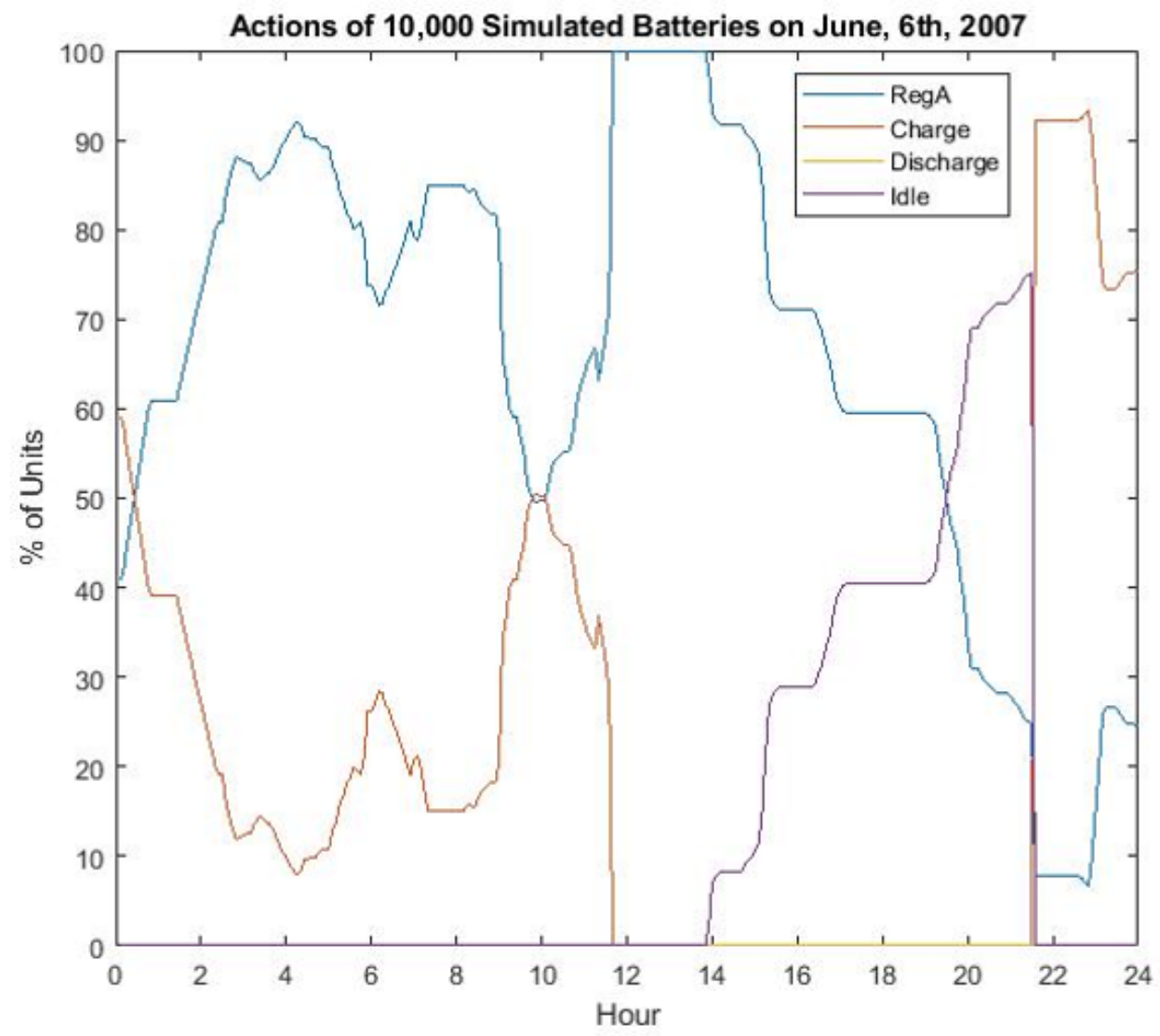

Figure 3.27: Actions the BIS take based on their logic states.

Figure 3.28 shows PJM's RegA signal that these batteries are trying to follow. The RegA signal calls for the battery-inverter systems to draw anywhere from up to $100 \%$ of the capacity as import and export power. RegA leans far more export than import, and this day is no exception. 


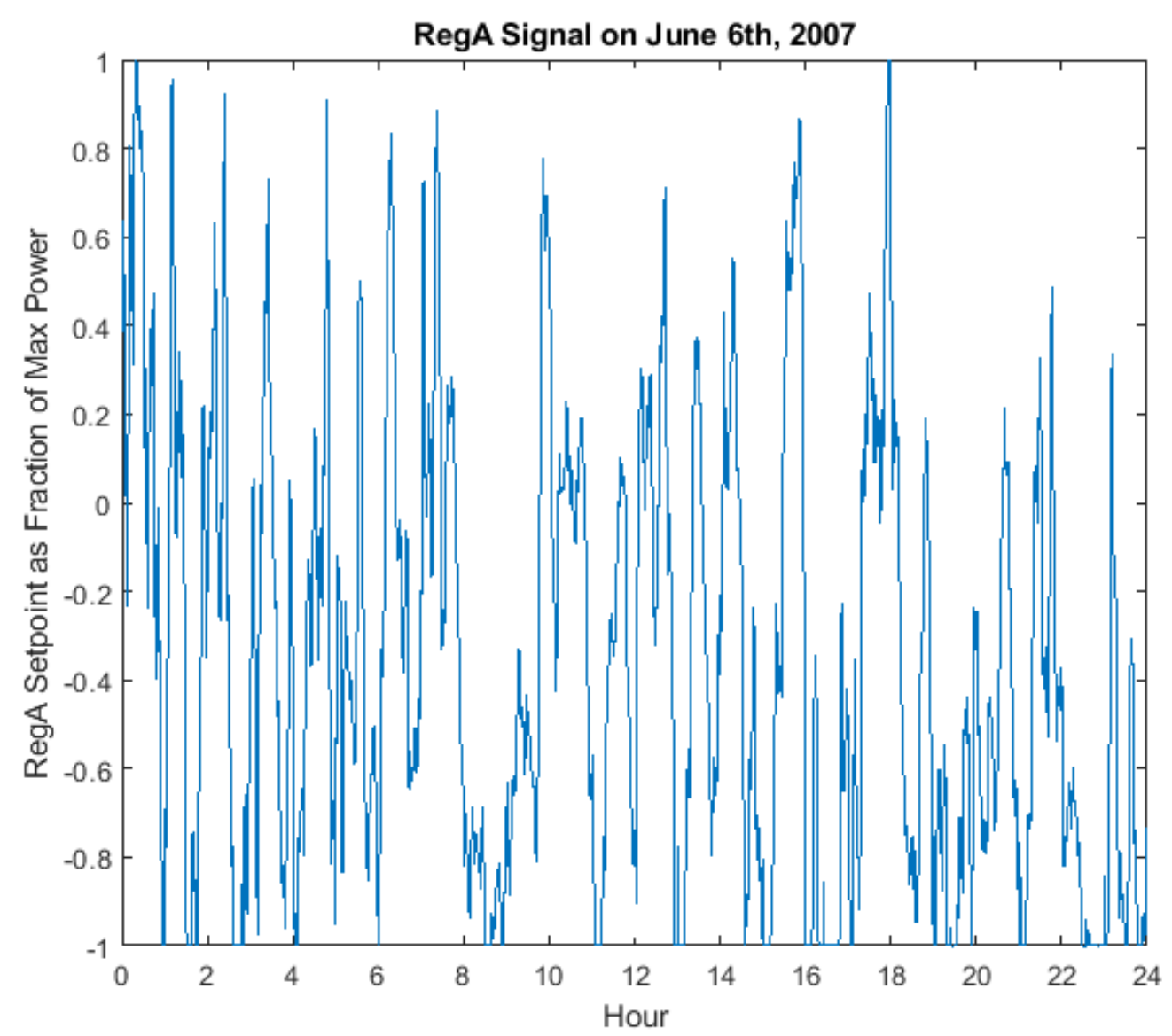

Figure 3.28: The RegA signal that the BIS are following throughout the day.

\subsection{Results of Battery-Inverter Systems with EIM Bids}

The batteries have significantly more energy that the EWHs. In this model, a $2 \mathrm{hr}$ battery (16 $\mathrm{kWh}$ ) has enough storage availability to continuously draw 8000 Watts over 2 hours, while an 80 gallon EWH at 6 degrees below setpoint can only draw 4500 Watts over 15 minutes (1.5 kWh). I tested a $20 \mathrm{MW}$ bid from 02:00 to 04:00 (40 MWh of energy). Figure 3.29 shows the energy effects of the bid. Note that here I am measuring state of charge energy, so as the battery draws power the energy should increase. From 02:00 to 04:00 additional 
batteries charge to cover the decrement bid. The energy stored in the batteries increases over this period. This would be expected from a decrement bid. The increased load that the batteries draw will cancel generation.

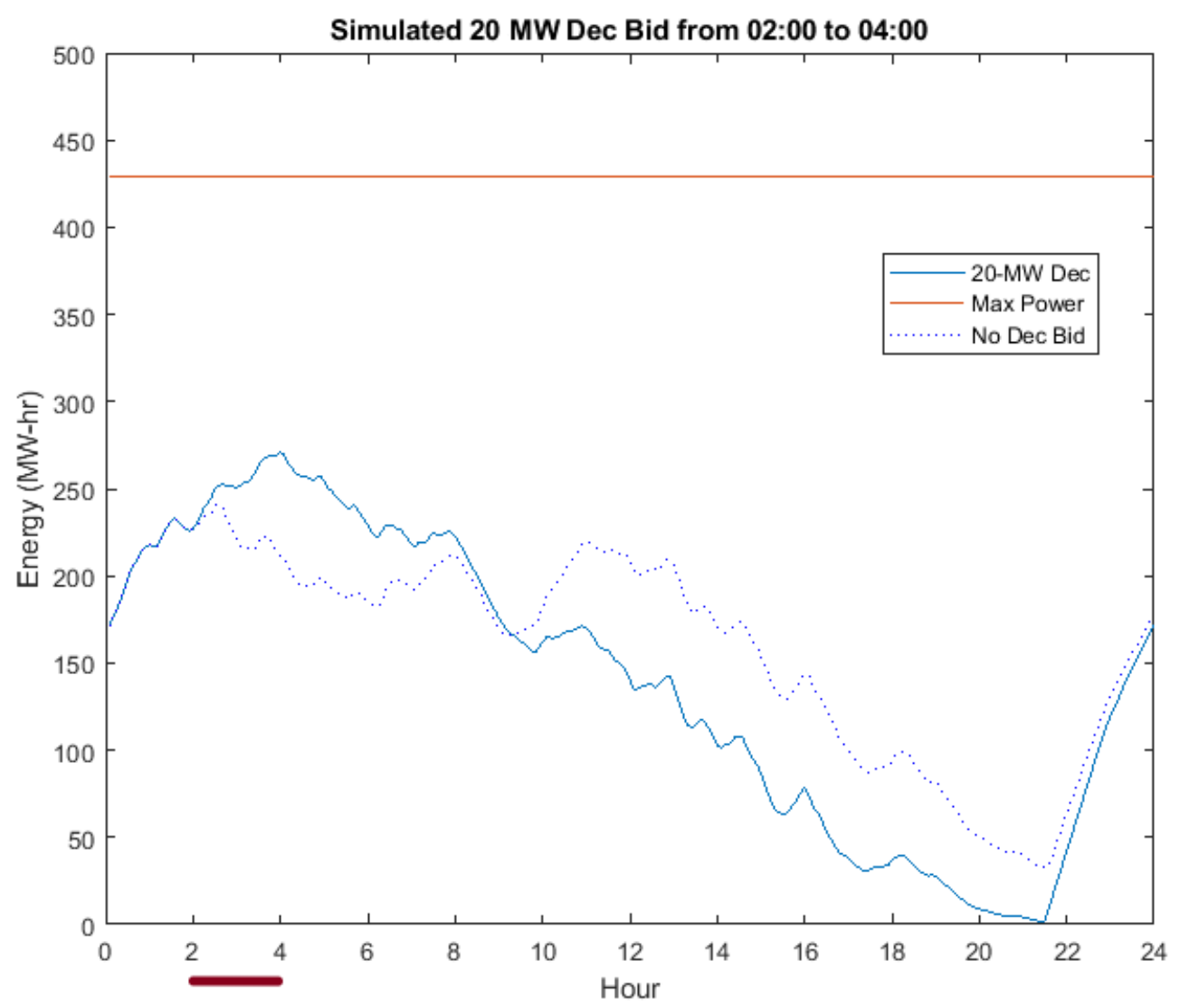

Figure 3.29: Aggregate state of charge profile after a $20 \mathrm{MW}$ bid from 02:00 to 04:00.

Figure 3.30 shows the logic states of the BIS. From 02:00 to 04:00, anywhere from 25 to $50 \%$ of the BIS charge to cover the deck the decrement bid. Figure 3.31 shows the resulting actions. 


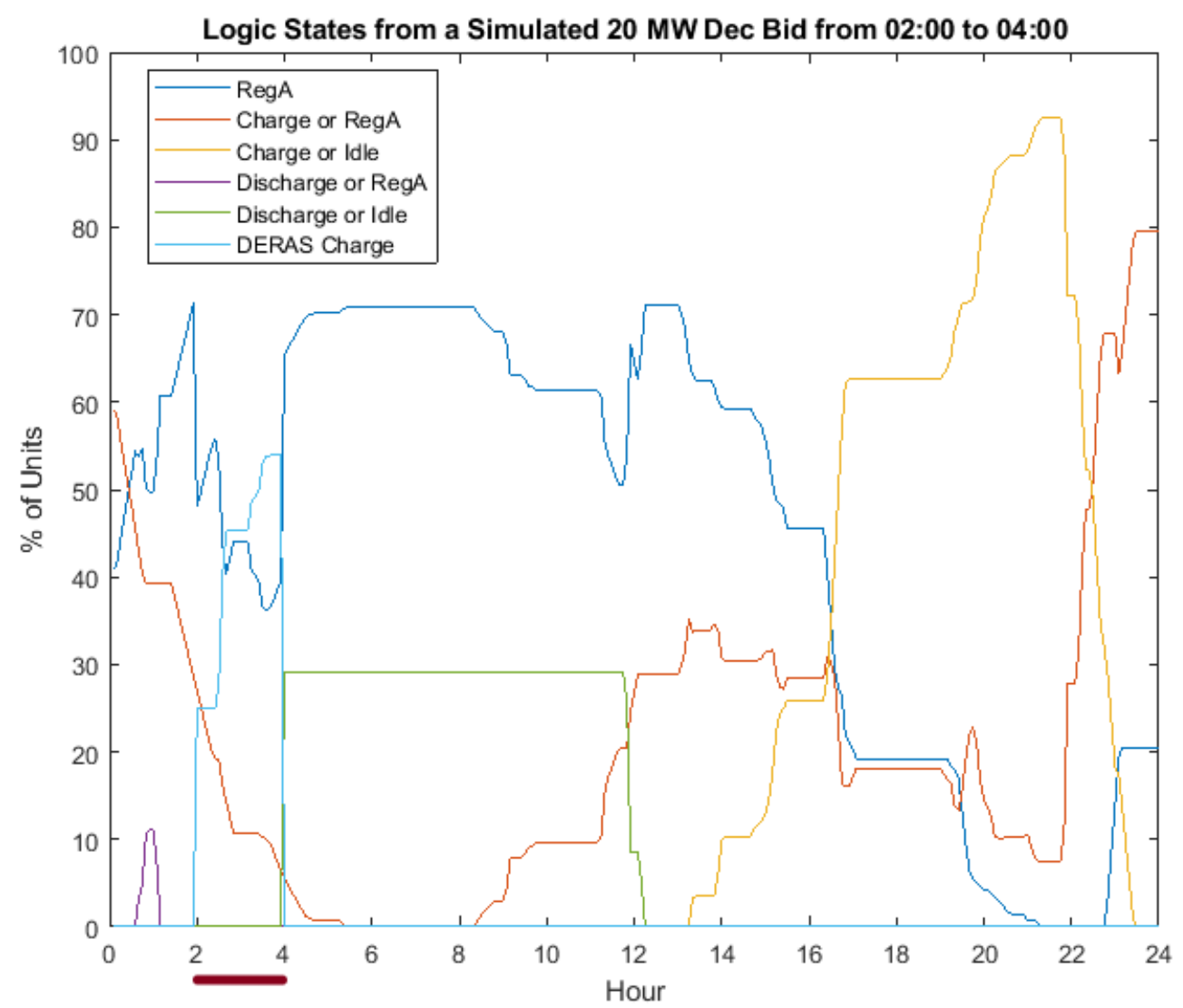

Figure 3.30: Logic states of batteries after a $20 \mathrm{MW}$ bid from 02:00 to 04:00. 


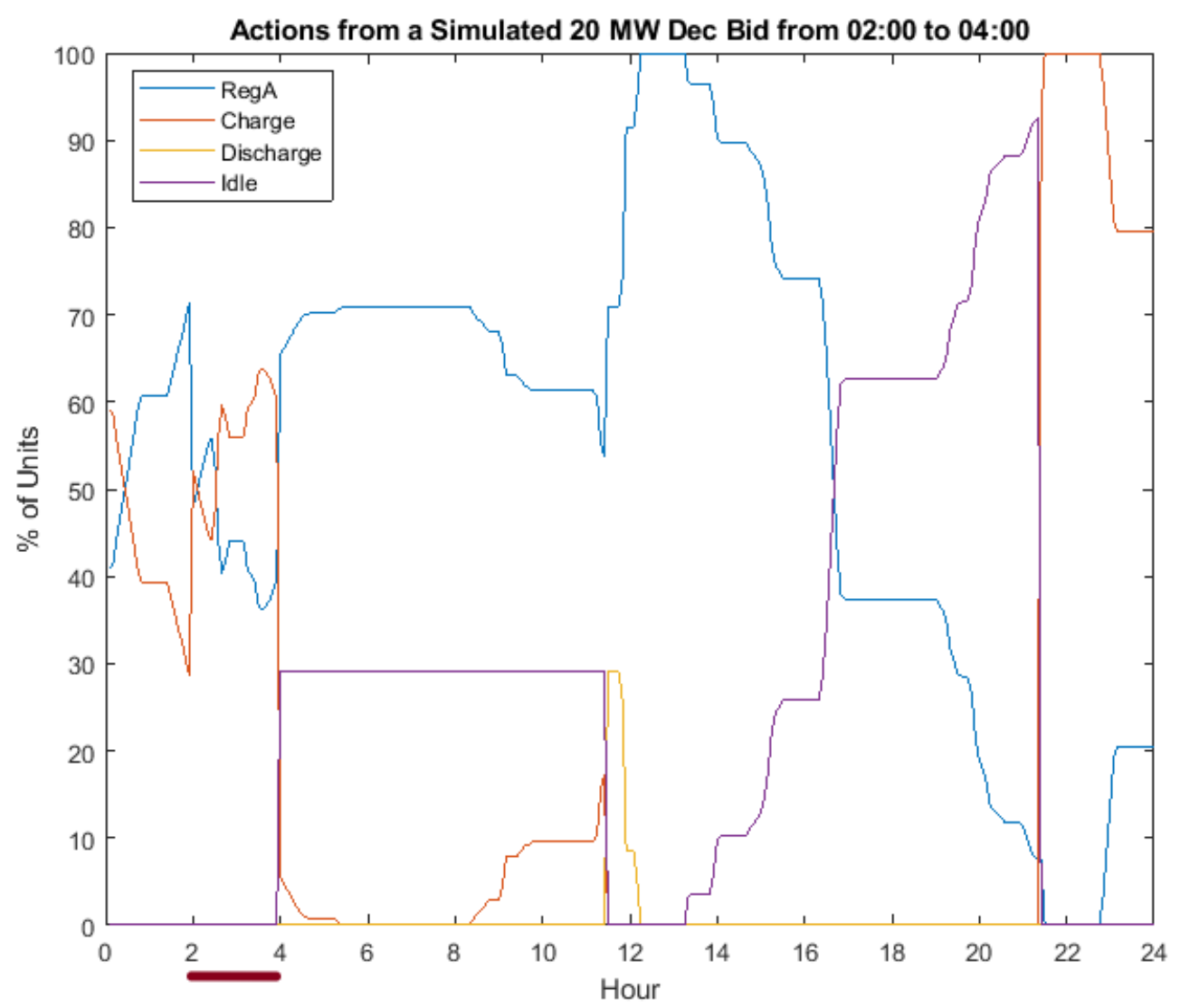

Figure 3.31: Battery actions after a $20 \mathrm{MW}$ bid from 02:00 to 04:00.

Looking closely at Figure 3.29, from 9:30 to 11:30, the bid BIS aggregation loses charge while the base case BIS aggregation gain charge. This can be understood by looking at the logic states of the batteries in the decrement bid case shown in Figure 3.30. Many of the batteries have higher energy states, which leads them to not charge before during the 09:30 to 11:30, as shown in Figure 3.31. These graphs can be contrasted against the logic and action states of the base case, Figure 3.26 and Figure 3.27 . Roughly $10 \%$ of units turn on in the bid case, while roughly $30 \%$ of the units charge in the base case. This is due to the model I used as I set logic states based on state of charge (see Section 2.5). 


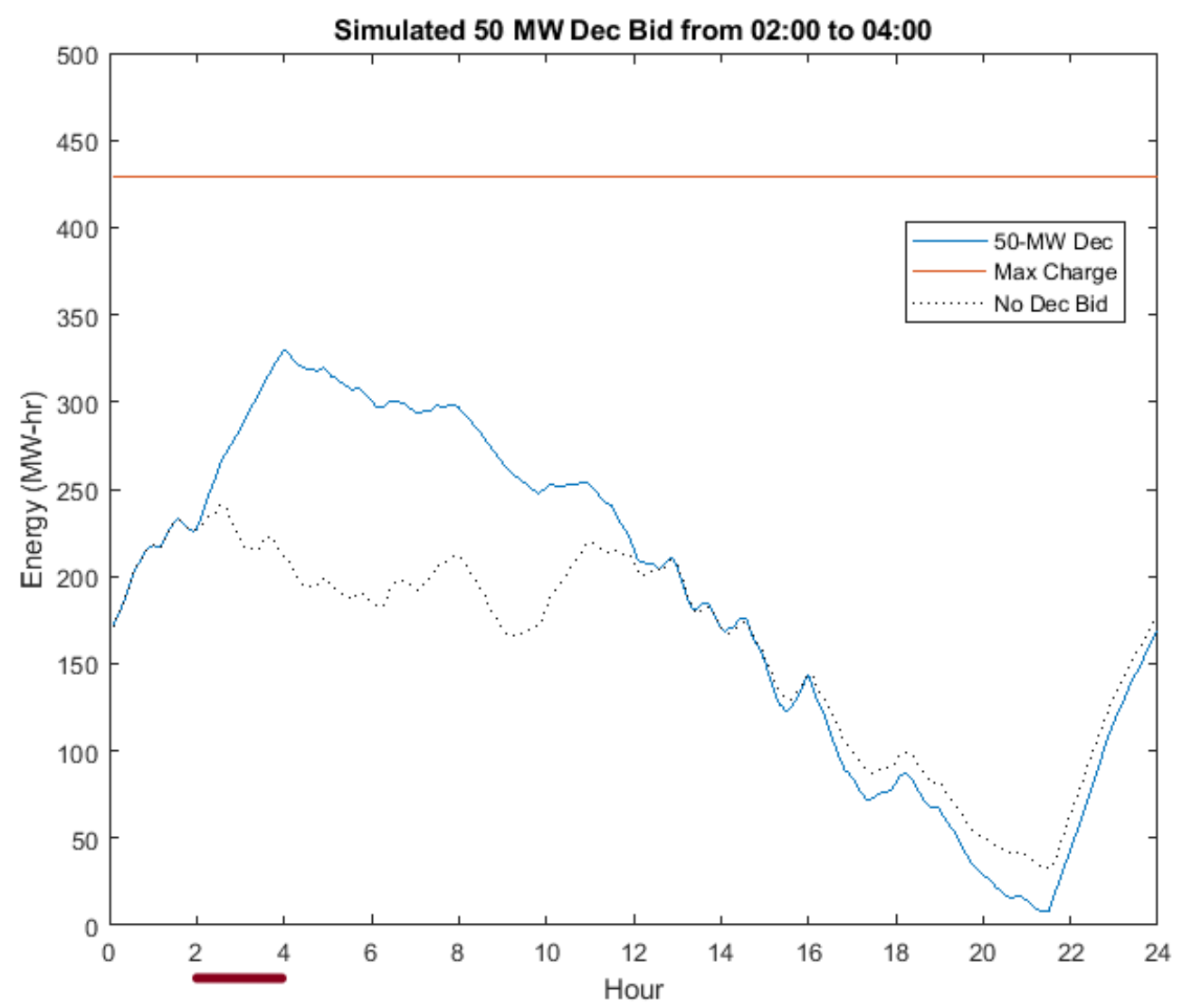

Figure 3.32: Aggregate state of charge profile after a $50 \mathrm{MW}$ bid from 02:00 to 04:00.

I also tested a $50 \mathrm{MW}$ overbid for the period from 02:00 to 04:00 (100 MWh). Figure 3.32 shows the state of charge of the battery aggregation. Over the first hour, DERAS supplies the $50 \mathrm{MW}$ decrement bid. This can be seen in the logic states of the aggregation in Figure 3.33. Between 03:00 and 4:00, all batteries switch to charging mode, but the batteries cannot cover the bid. Figure 3.34 shows the BIS actions for the aggregation. 


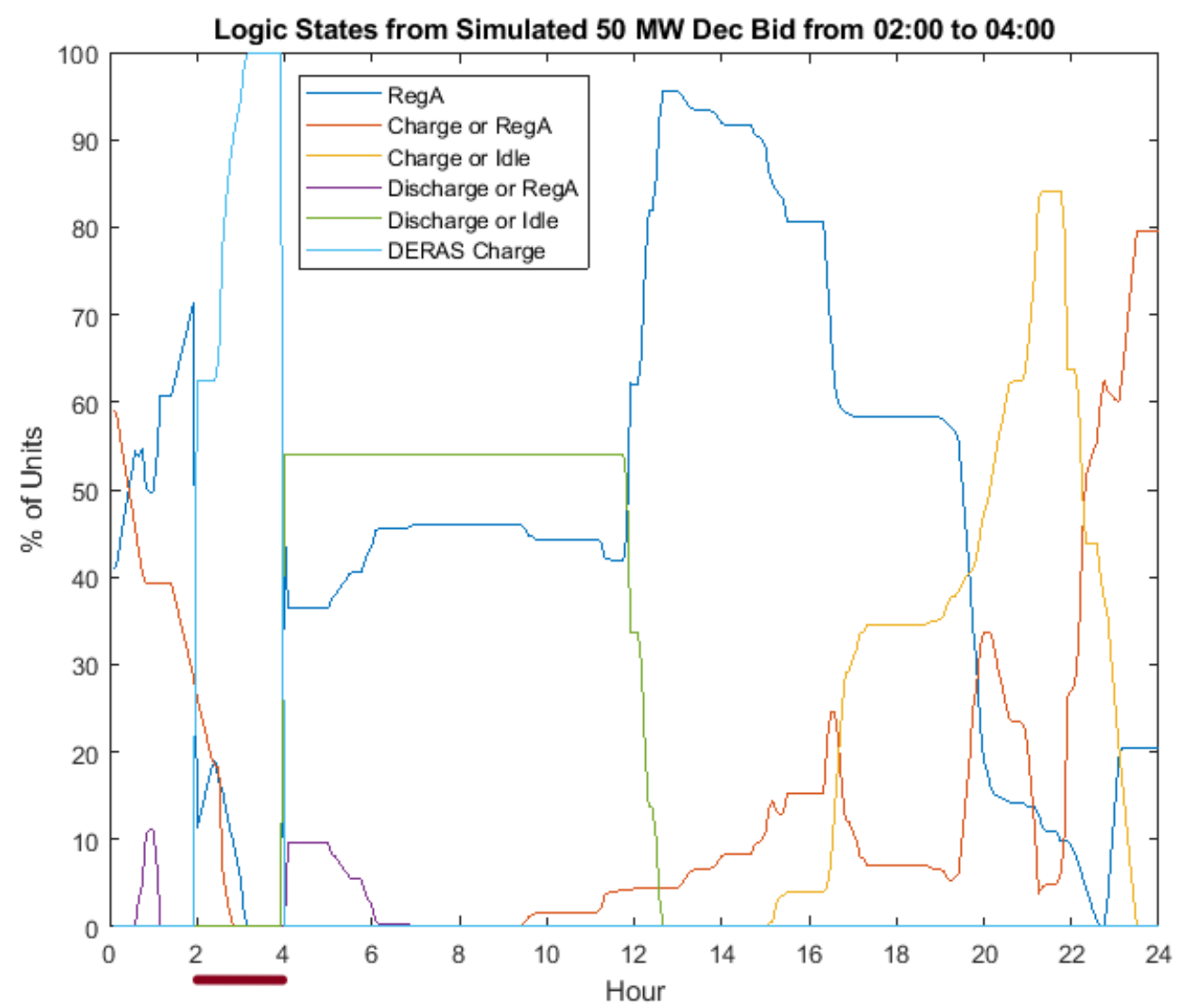

Figure 3.33: Logic states of batteries after a $50 \mathrm{MW}$ bid from 02:00 to 04:00. 


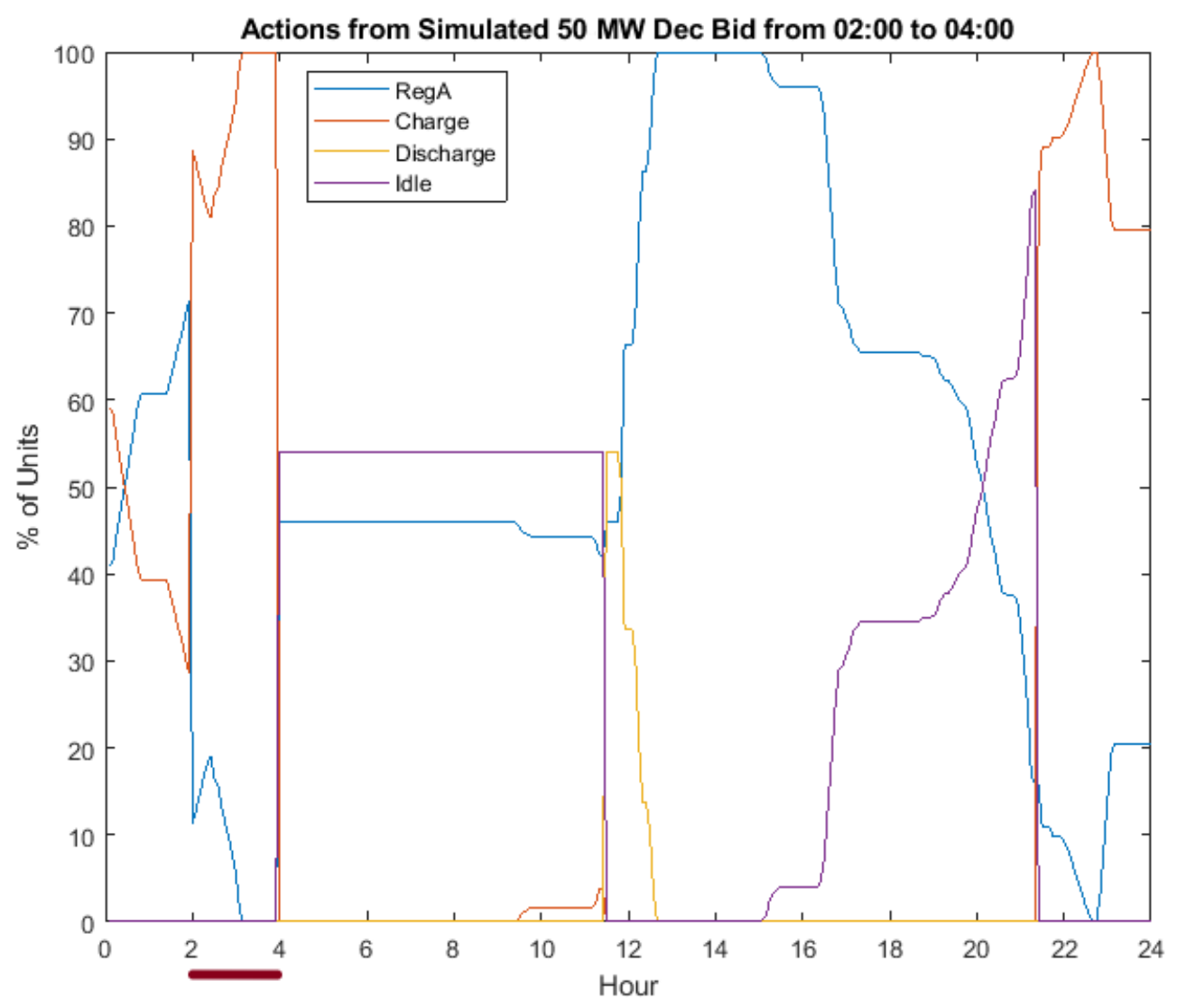

Figure 3.34: BIS actions after a $50 \mathrm{MW}$ bid from 02:00 to 04:00.

Figure 3.35 shows the power charged by the BIS aggregation for bids ranging from 20 to $80 \mathrm{MW}$. As batteries become fully charged, DERAS loses its ability to offer power. Incidentally, the $80 \mathrm{MW}$ is the absolute maximum power of the battery aggregation based on 10,000 batteries each providing a maximum of 8,000 watts. 


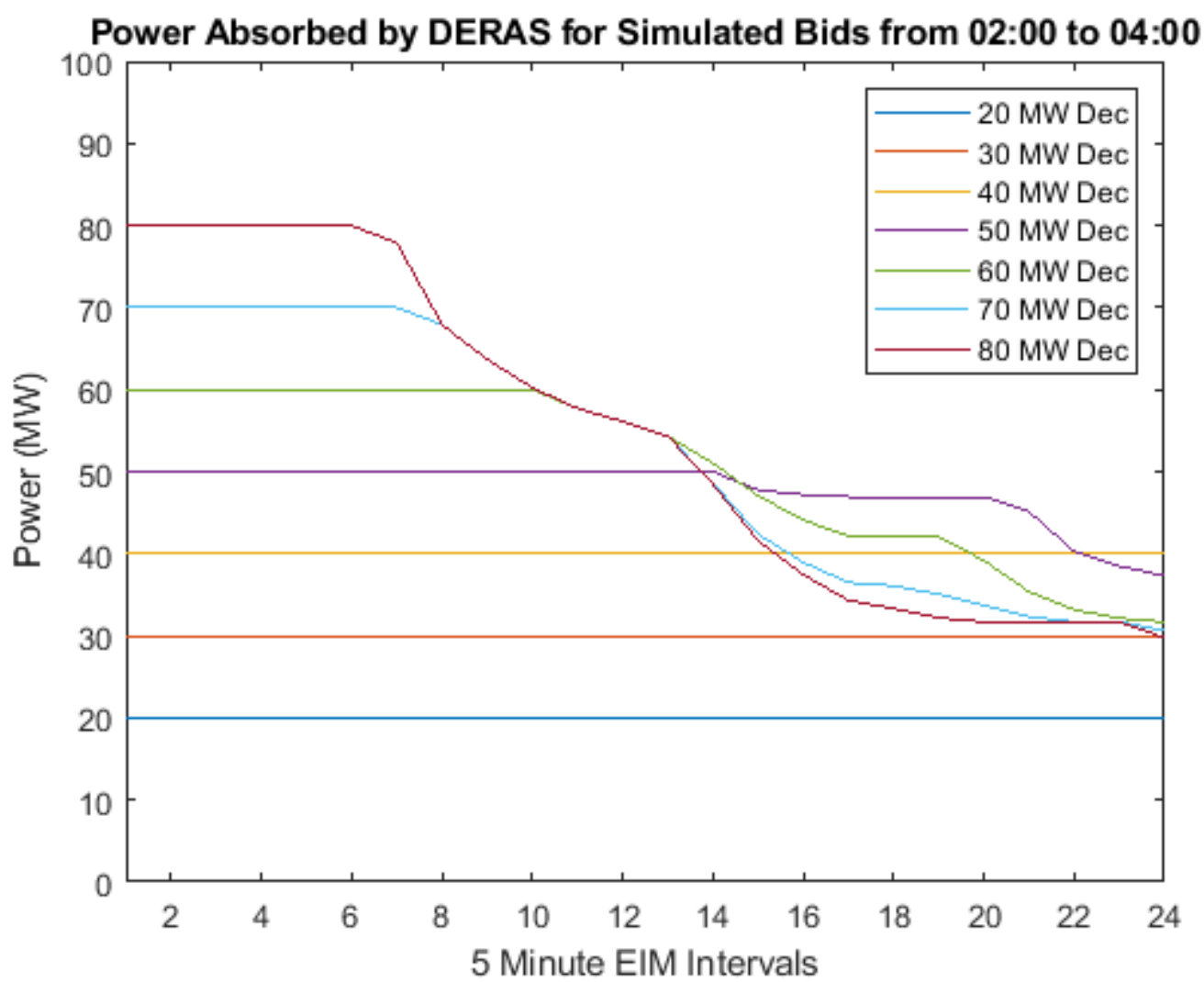

Figure 3.35: Power drawn by the aggregator in response to various decrement bids from 02:00 to 04:00.

I also performed a simulation using a much longer 18 hour time frame for a bid. In this case, I bid $15 \mathrm{MW}$ across 216 EIM 5 minute intervals (270 MWh). Figure 3.36 shows the energy across the start to approach maximum charge. Figure 3.37 and Figure 3.38 show the battery logic states and actions respectively. At the final intervals, almost $100 \%$ of the battery aggregation is charging. 


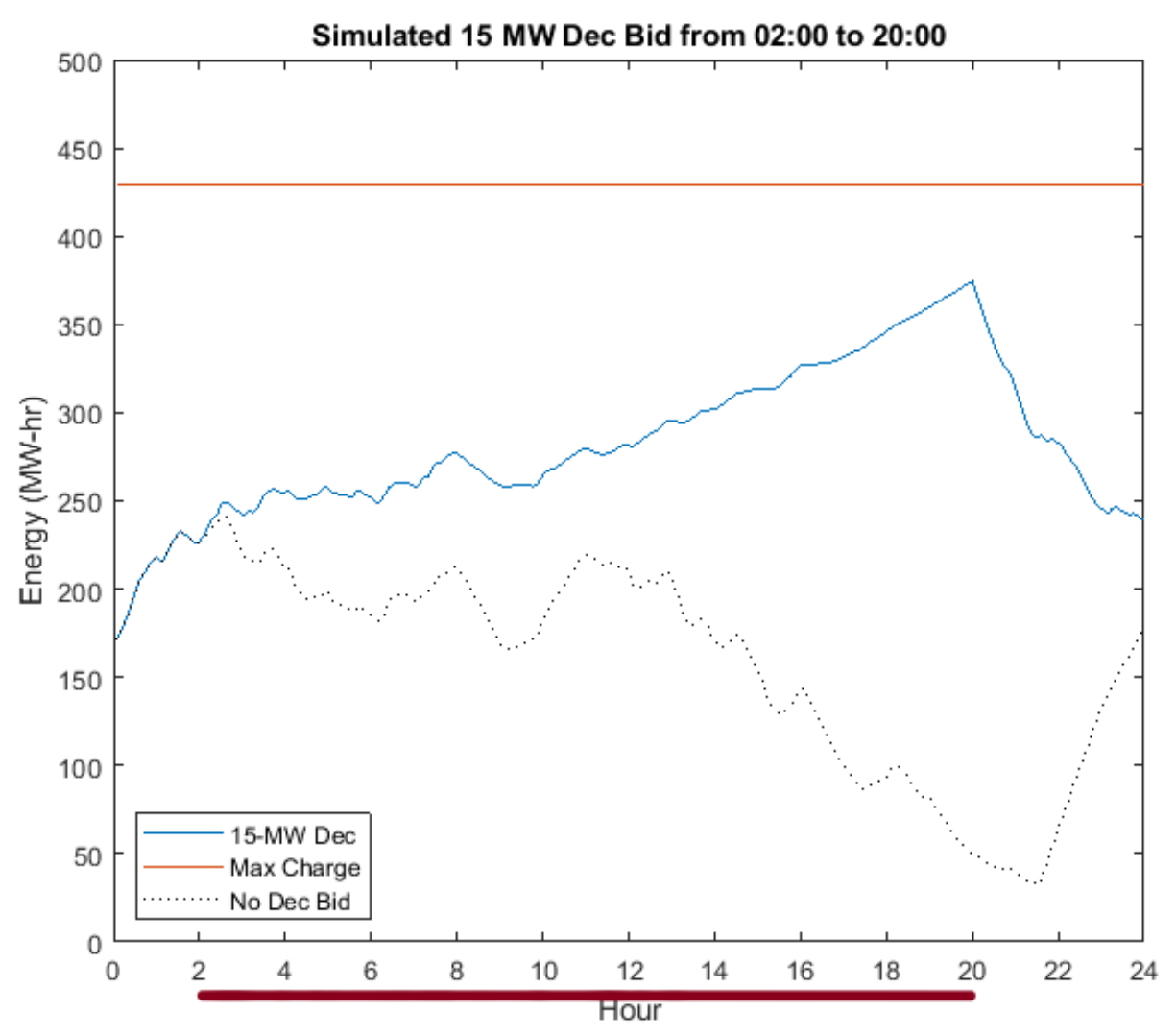

Figure 3.36: State of charge profile after a $15 \mathrm{MW}$ bid from 02:00 to 20:00. 


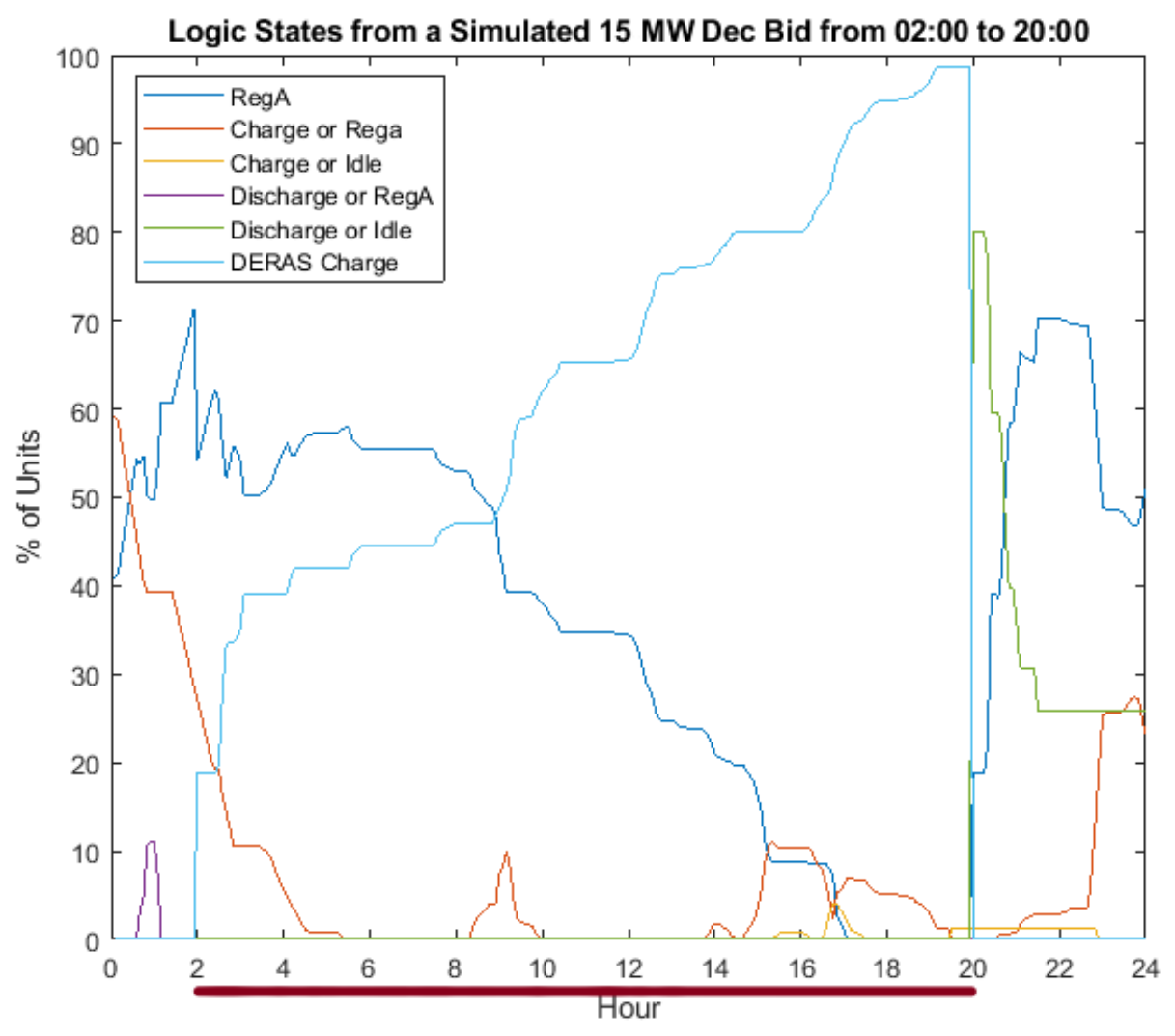

Figure 3.37: Logic states of batteries after a $15 \mathrm{MW}$ bid from 02:00 to 20:00. 


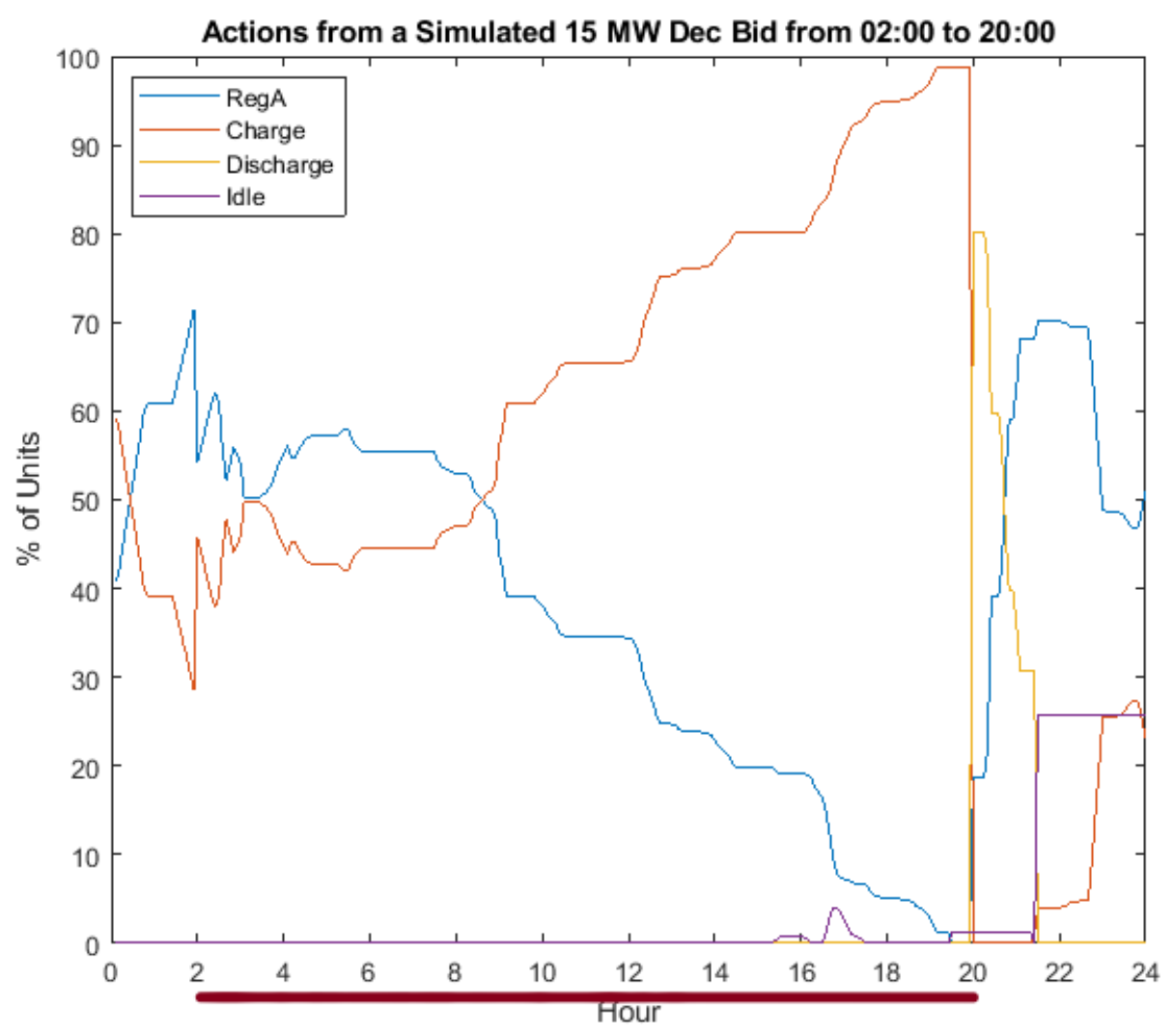

Figure 3.38: Battery actions after a $15 \mathrm{MW}$ bid from 02:00 to 20:00.

When I simulate a $20 \mathrm{MW}$ overbid across 18 hours (360 MWh), DERAS maxes out both its energy availability and power. Figure 3.39 shows the battery states of charge for the aggregation. Between the hours of 17:00 and 20:00, the battery aggregation reaches its maximum charge. 


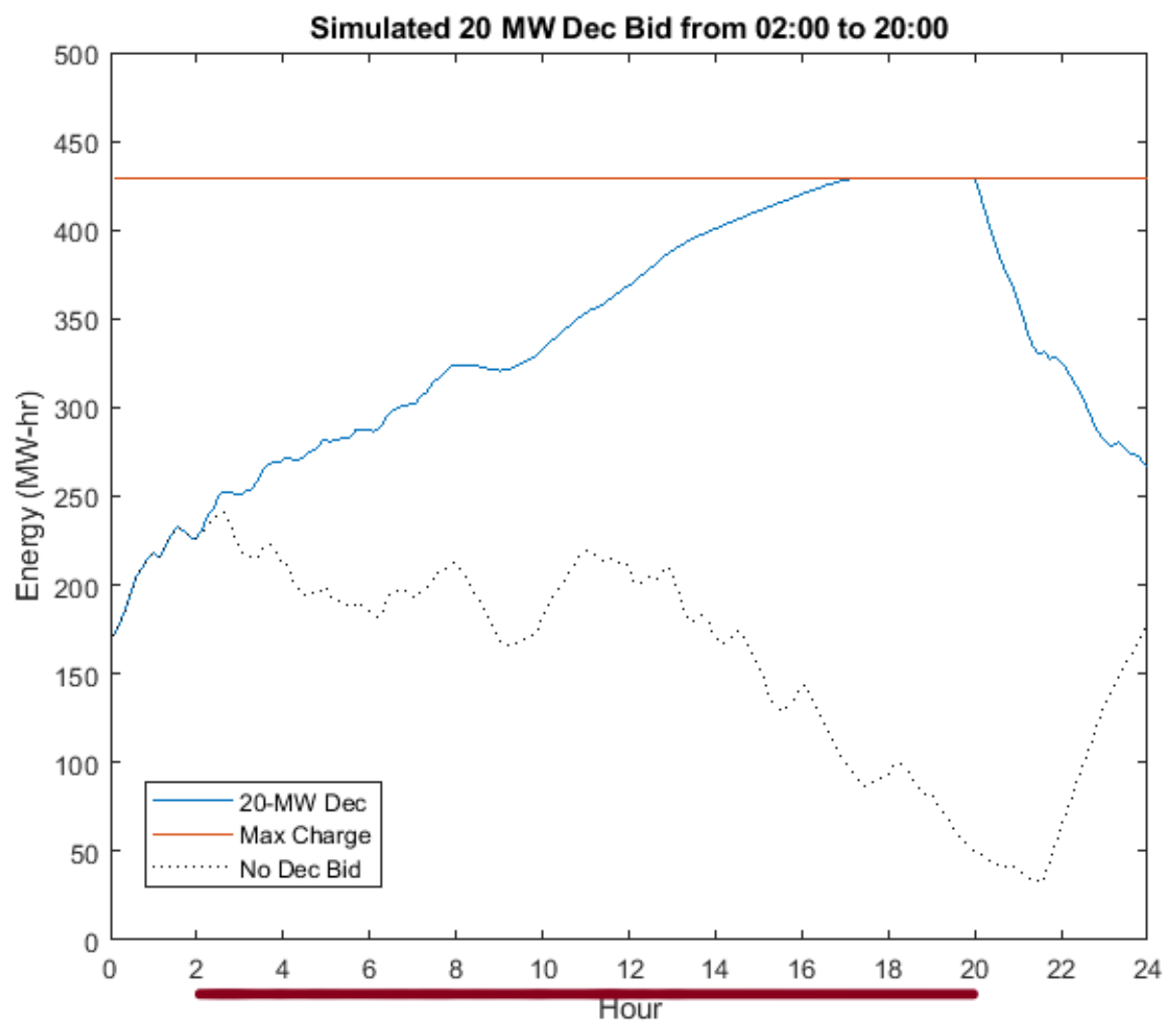

Figure 3.39: State of charge profile after a $20 \mathrm{MW}$ bid from 02:00 to 20:00. The aggregation becomes 100\% fully charged. 


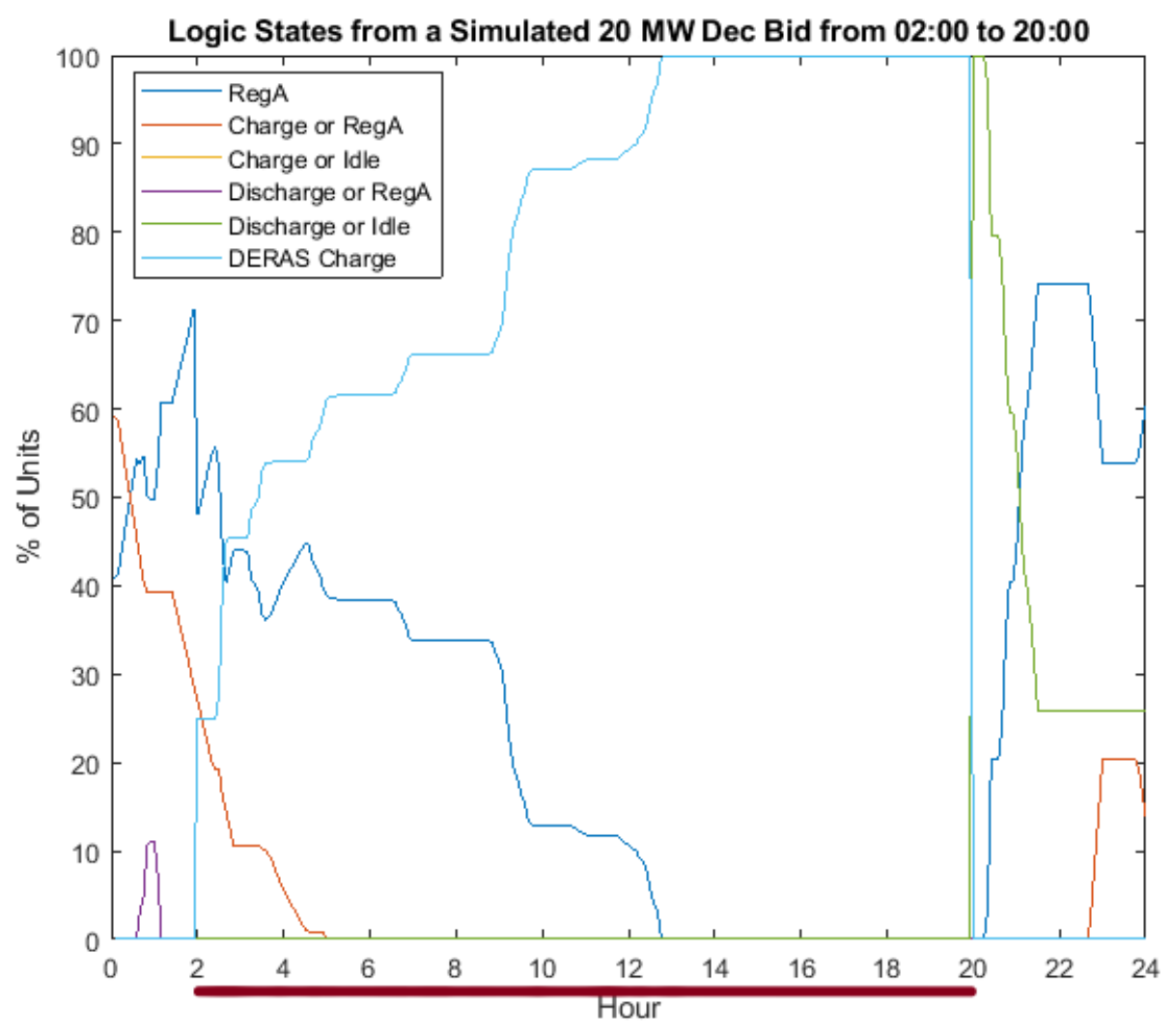

Figure 3.40: Logic states of batteries after a 20 MW bid from 02:00 to 20:00.

The logic states and battery actions are shown on figure 3.40 and figure 3.41 respectively. These show that the $100 \%$ of the units are called on starting at 13:00. This again demonstrates a power limited bid, in that it fails due to lack of power before it fails due to lack of energy. 


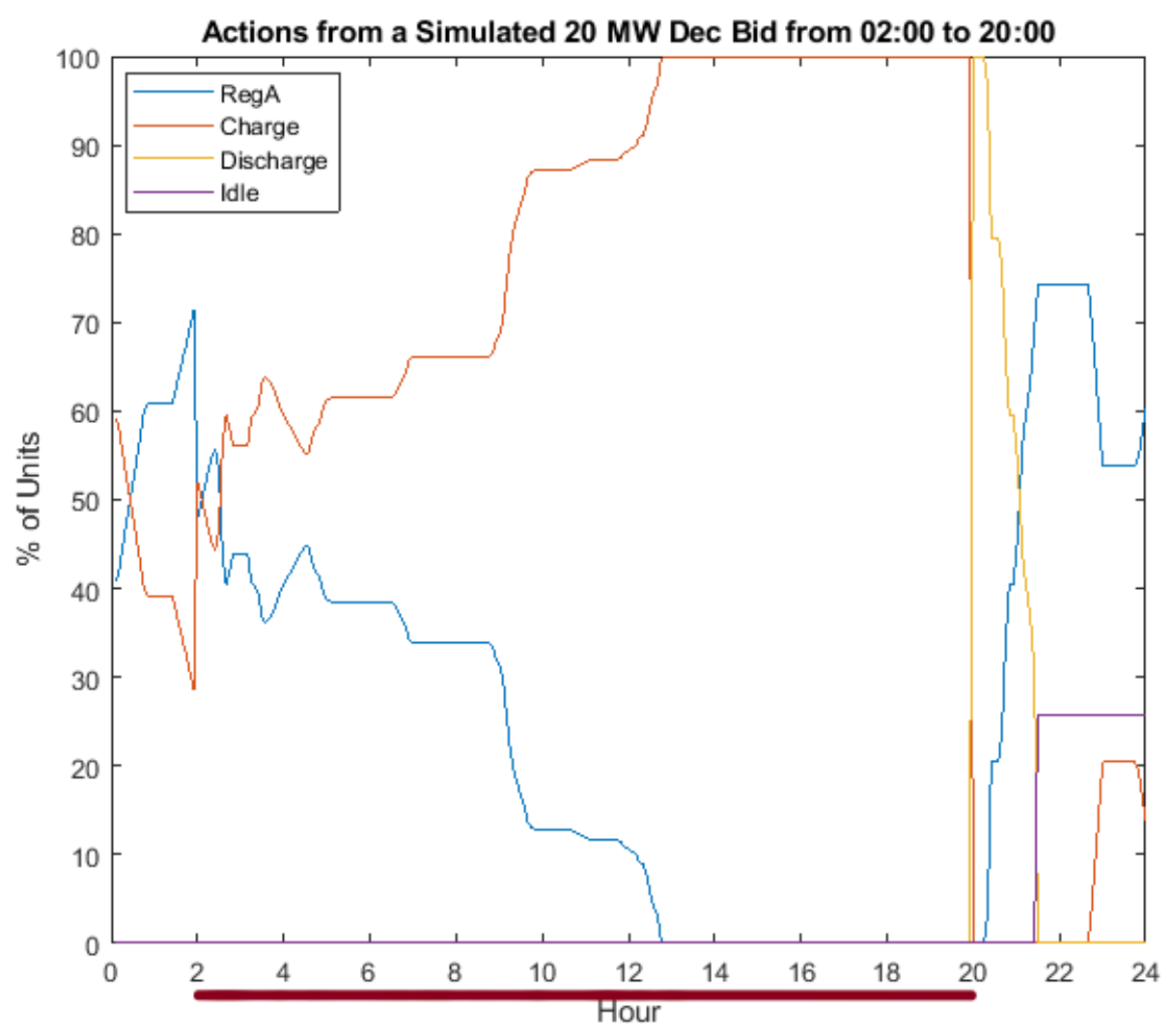

Figure 3.41: Battery actions after a $20 \mathrm{MW}$ bid from 02:00 to 20:00.

The power absorption by DERAS for 18 hour bids ranging from 15 to $30 \mathrm{MW}$ is shown in Figure 3.42. For higher bids, the power absorption loses momentum and quickly crashes to zero. 


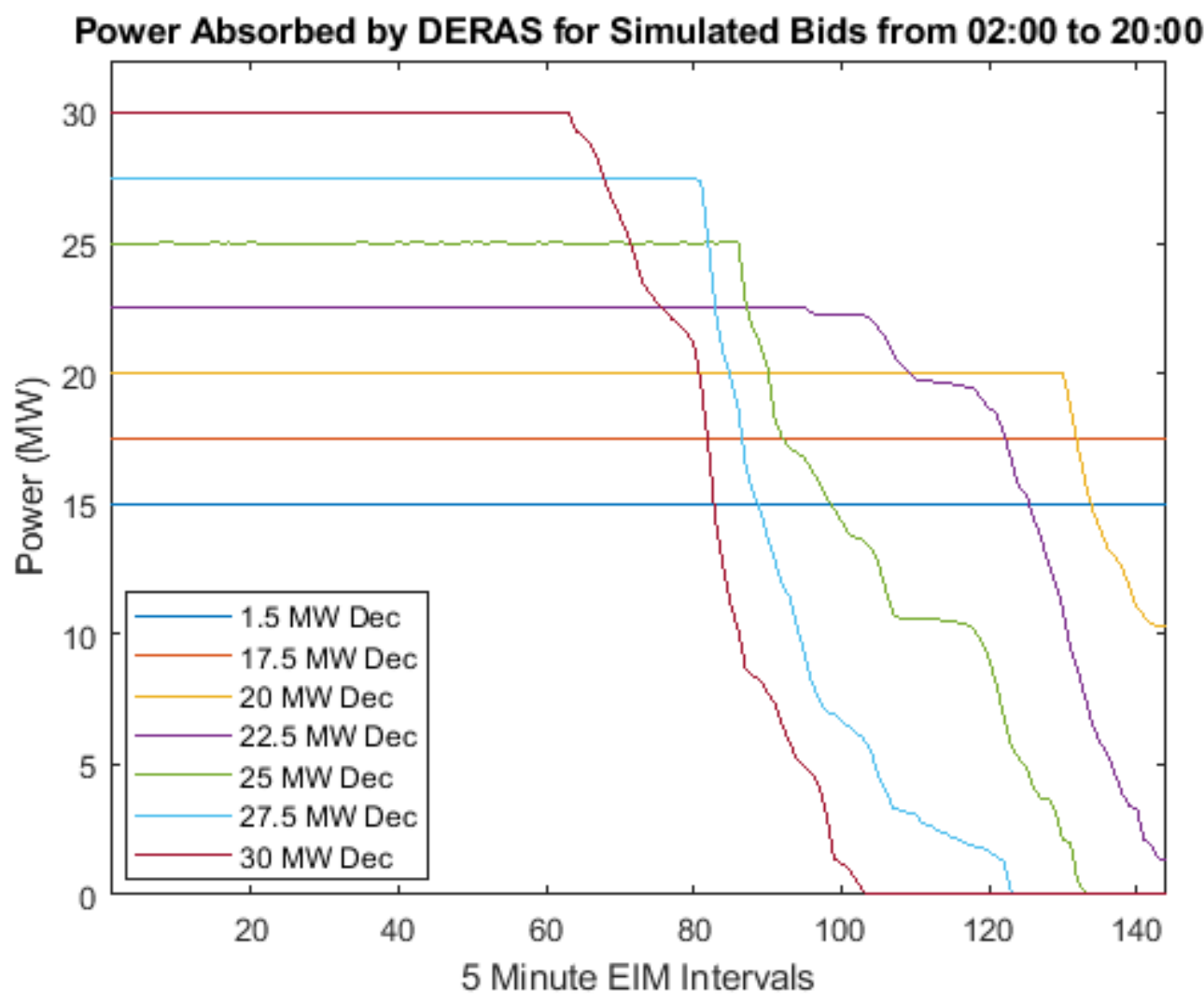

Figure 3.42: DERAS power absorption for $18 \mathrm{hr}$ decrement bids.

Additionally I simulated the maximum decrement bids available across for a given number of 5 minute intervals. Figure 3.43 shows the maximum available bids for anywhere from 1 interval ( 5 minutes) to 36 intervals ( 3 hours). For short stints, the battery aggregation can supply $80 \mathrm{MW}$ continuously, but as the number of intervals increases, the 2 hour batteries (16 kWhs) and the 4 hour batteries ( $24 \mathrm{kWhs)} \mathrm{start} \mathrm{filling} \mathrm{to} \mathrm{capacity.} \mathrm{Once} \mathrm{a} \mathrm{battery} \mathrm{is} \mathrm{filled}$ to capacity, it can no longer charge so the power from its inverter becomes unavailable. 


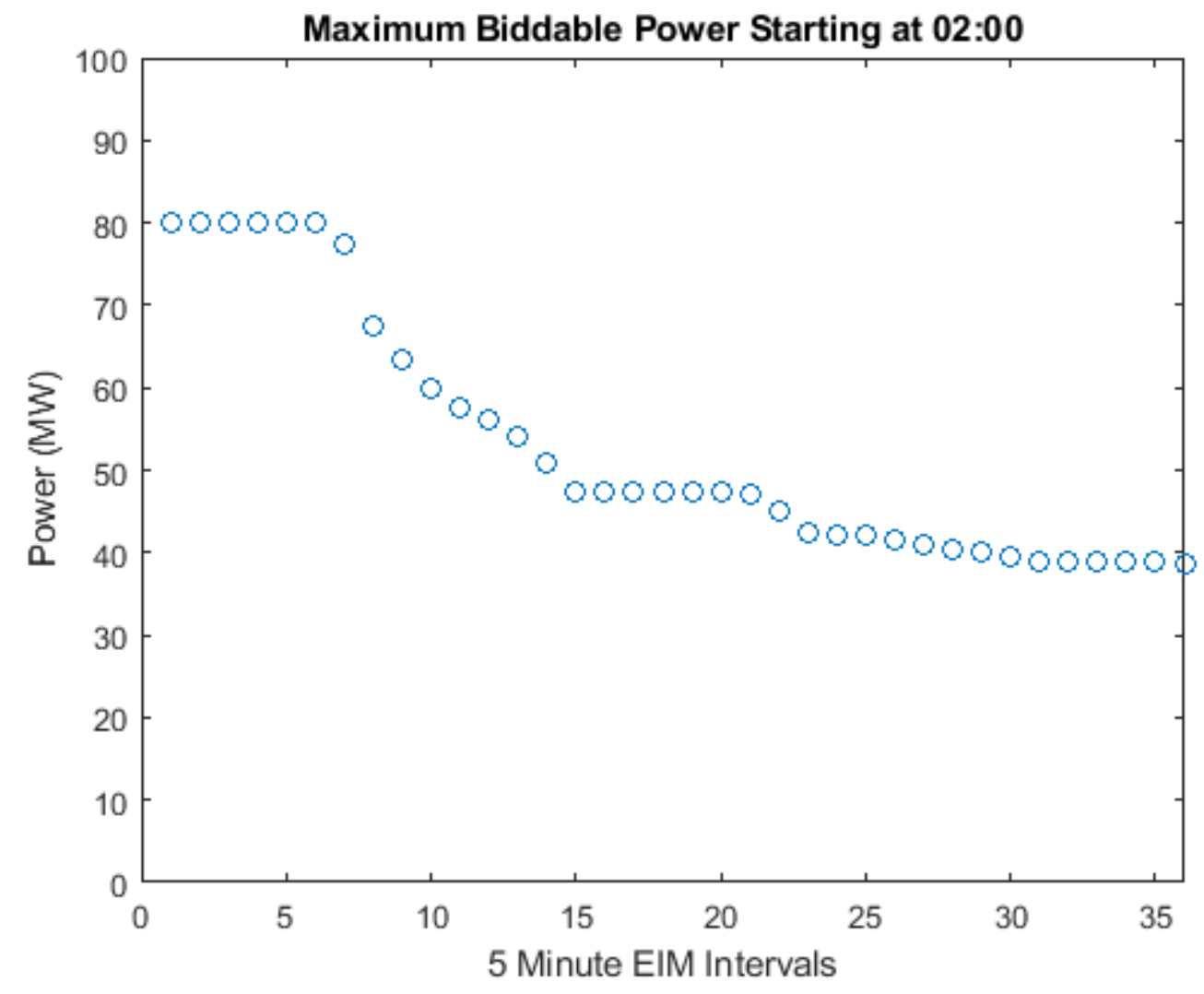

Figure 3.43: Power output from aggregation drops as batteries become fully charged. 


\section{Discussion}

The results of these simulated bids show how aggregations of EWHs and aggregations of BISs can bid into an EIM through decrement bids.

\subsection{EWH Aggregations}

EWHs have a primary purpose to provide hot water to their owners. An EWH aggregation could take advantage of a grid use, but this would be secondary to their providing hot water. The model I used assumed that the EWH would be available for hot water at all times and that any grid functionality came secondary at lower priority.

The simulations of the 10,000 EWH aggregation demonstrated the ability of an aggregator to follow EIM decrement bids. The model used 39.5\% of the households with 40 gallon units, $39.6 \%$ with 50 gallon units, and $20.9 \%$ with 80 gallon units. The model assumes that an aggregator would find approximately this makeup of CTA-2045 assets among its EWHs. The model also assumed assets that had turned on before the bid or would turn on due to ambient heat losses could not be used to supply power as part of the aggregation, as these assets could be considered part of the load forecast. The model additionally assumed that the power availability of the units was 4500 Watts, which is not an unreasonable assumption as most water heaters have power ratings around this value. 
With these assumptions in mind, a 10,000 unit EWH aggregation would have around 5 or $6 \mathrm{MWh}$ of energy available at any given time. The available power would be related to the units that were not heating or forecasted to be heating. The maximum available power would be the sum of all the power in each unit, or $45 \mathrm{MW}$. However, since some of these would already be heating, this could be down rated as much of $20 \%$, or around $36 \mathrm{MW}$.

The EWH aggregations could provide high power bids over short time periods or lower power bids across longer intervals. I found bids of $43 \mathrm{MW}$ would be successful over a 5 minute period. I found that bids of $5 \mathrm{MW}$ would be successful over a period of an hour. I found that 1.5 MW bids would be successful over periods of 18 hours. In each of these cases, when bids exceeded the available energy or power the bids would fail to provide the correct amounts of megawatts over the given bid periods. I found that bids were limited by energy across all numbers of five minute intervals except the first five minute interval. Across the first 5 minute interval energy levels with the ability to provide roughly $60 \mathrm{MW}$ across 5 minutes was limited by a maximum power of $45 \mathrm{MW}$ by the electric coils. After that first interval, the EWH aggregation was limited by the energy take of the system. These details are summarized in Table 3.1.

When overbidding occurred, the aggregation was unable to deliver the necessary power over the required time period. This led to the power drawn by the aggregation diminishing in the later intervals. For short, high power, bids, the system did not recover, and the power diminished to about $0.5 \mathrm{MW}$, or the continuous power coming from the hot water draws as in Figure 3.8. However, when fewer megawatts were bid across longer intervals, the hot 
water draws could allow the system to recover back to full power, except for a few bad 5 minute intervals as shown in Figure 3.17.

While overbidding would result in insufficient power over certain intervals, the DERAS dispatch algorithm could be questioned. I dispatched units to cover bids until the bids could no longer be covered and the system started to fail. An alternative way would be to recognize first that DERAS could not cover the bid, and then even out deficiencies in the bid over the entire time interval. For short bids, like a 1 hour, $6 \mathrm{MW} \mathrm{bid,} \mathrm{the} \mathrm{solution} \mathrm{is} \mathrm{to} \mathrm{simply}$ offer 5.2 MW over the entire hour. This can be solved simply using the maximum power algorithm as shown in Table 3.1. However for longer intervals like the 18 hour, $2 \mathrm{MW}$ bid, a dispatch that minimizes disturbances might be better than a dispatch that tries to assign units to cover every single interval until failure.

After nearly depleting themselves, EWHs took roughly 7 hours to recover back to their non-bid states. Here there are two settling times, the energy settling time for when energy takes recover to within $2 \%$ of the non-bid levels and the power settling time for when the number of units heating returns to within $2 \%$ of the non-bid levels. After these settling times, the aggregate system effectively returns to its normal energy state as if no bid had occurred.

\subsection{BIS Aggregations}

BIS for the most part have a primary purpose of making transactions on the electric grid. Certain customers may have a BIS to provide backup power, but failures tend to be rare on the modern electric grid. For this reason, grid transactions can be viewed as the primary 
purpose of the BIS aggregation.

Since the batteries can be providing other services, the question then becomes what those services should be. The action I chose for the battery aggregation was to follow a frequency regulation signal first, and secondarily play economic arbitrage when needing to discharge or recharge. The important take away of this model is, the BIS are performing some task, and I am going to take control of part of the BIS aggregation and have it perform another task. In this case, the task I am having them perform is a decrement to an EIM.

The BIS aggregation was able to make a $40 \mathrm{MW}$ bid over the course of two hours without losing power across any of its 5 minute intervals. The BIS aggregation was also able to supply $15 \mathrm{MW}$ of power across 18 hours, while still maintaining sufficient power draw. As bids increased, the power absorption from the aggregation of batteries would fail. The aggregation would not be able to absorb enough power across the later intervals.

The aggregate response to an overbid might be improved by the dispatch algorithm. The current dispatch algorithm dispatches enough BIS units to cover each bid interval until the system runs out of units. A smarter algorithm might be designed to provide a smaller insufficient amount of energy across each of the bid intervals to minimize the shock to the the system once the aggregator could no longer absorb power. With BIS, where the primary grid function is serving the grid, a better strategy might be to bid the maximum amount of power based on the maximum bid algorithm.

The BIS aggregated bids were entirely power limited. Over a 24 hour period, bids failed due to lack of power rather than lack of energy. This is perhaps due to the DERAS dispatch 
algorithm, which finds units to cover the bid, and then operates them at $100 \%$ of full power. As the batteries start charging, they reach their maximum state of charge. At this point, the battery can no longer charge, so the overall power available to the system diminishes. An algorithm that utilized batteries at less than full power could more efficiently access its energy take. The highest available maximum bid would theoretically fail by both power and energy take at the same time.

The battery model used a very generic control logic. Batteries took grid actions based on a logic state that was based upon their state of charge. These led to results where a decrement bid increased the short term charge of the system, while decreasing the charge later on due to changes in logic states from the base system. Figure 3.29 demonstrates this. The battery aggregation charges between 02:00 and 04:00, but then around 09:30 to 11:30, the battery aggregations follow the RegA signal because they have a relatively high charge. The battery aggregation that did not charge between 02:00 and 04:00 became so depleted, that many of its BIS charged between 09:30 and 11:30 rather than follow the RegA signal. This resulted in the system that fulfilled the decrement bid by charging from 02:00 to 04:00, having a lower state of charge around 20:00 than the system that did not make a decrement bid.

This is a result of the BIS logic model. On the one hand, the aggregator could judge that income it makes from the decrement bid, and the subsequent regulation following, justifies this decision over the no-bid situation. Alternatively, an aggregator could choose to control the system differently and simply tell the BIS aggregation to charge between 09:30 and 
11:30.

The decisions on how to model the control and dispatch algorithms for the BIS aggregations are more flexible than the EWHs, because the BIS aggregation is primarily transaction with the electric grid. This leaves more flexibility in deciding how to decide when to charge or discharge, and when to make EIM bids. 


\section{Conclusion}

This research shows the potential for aggregated EWH assets and BIS assets for providing energy to an EIM. A 10,000 unit aggregation EWH was able to provide roughly $43 \mathrm{MW}$ of instantaneous power over a single 5 minute interval and roughly 5 to $6 \mathrm{MW}$ over an hour, depending on time of day. This research shows that aggregations of EWHs can be used to provide significant decrementing power to an EIM market while still maintaining their primary function of providing hot water.

This research also examined the ability of aggregated BISs to offer decrementing bids to an EIM while also providing frequency regulation and performing economic arbitrage. To this end, the simulated BIS aggregations provided significant decrementing support, as much as $40 \mathrm{MW}$ in a 2 hour period and $15 \mathrm{MW}$ in an 18 hour period.

Further research may focus on a smarter dispatch algorithm. The water heater algorithm of picking the assets with highest energy takes and forcing them to heat is a simple straight forward model, which could be adapted for short intervals by simply reducing power in the case of an overbid. However, the longer running bids might be better dispatched to increase the number of insufficient intervals while reducing the insufficiency across these intervals. For batteries, figuring out the use case is most important. Batteries following an economic arbitrage model will necessarily want to follow different strategies than those following a 
regulation signal with EIM as a secondary purpose. Dispatch algorithms can be tailored to the purpose of the BIS aggregation.

Further research could also focus on better modeling data. As DERAS grows larger and can control tens of thousands of DER assets, the ability to track real assets and build digital twins of these assets for forecasting decisions would allow for a model that can predict power availability of real assets in real time. This is the goal of a fully mature DER aggregation. 


\section{Bibliography}

[1] Georgia E. Asimakopoulou and Nikos D. Hatziargyriou. Evaluation of economic benefits of DER aggregation. Energy, 9:499-510, Apr 2018.

[2] C.F. Calvillo, A. Sancherz-Miralles, J. Villar, and F. Martin. Optimal planning and operation of aggregated distributed energy resources with market participation. Applied Energy, 182:340-357, 2016.

[3] Western Electrical Coordinating Council. Base schedules foundational concepts computer based training.

[4] Western Electrical Coordinating Council. The basics of the real-time market - computer based training.

[5] Western Electrical Coordinating Council. Map of Western Interconnect Balancing Authorities. Jan 2017.

[6] Western Electrical Coordinating Council. Western EIM active and pending participants. 2019.

[7] Energymag. Daily Demand for Florida Utilities. Wordpress, Feb 2014.

[8] Tasnimun Faika, Taesic Kim, and Maleq Khan. An Internet of Things (IoT)-based network for dispersed and decentralized wireless battery management systems. 2018 
IEEE Transportation Electrification Conference and Expo, pages 1060-1064, June 2018.

[9] Niall Fitzgerald, Aoife M. Foley, and Eamon McKeogh. Integrating wind power using intelligent electric water heating. Energy, 48:135-143, 2012.

[10] Robert Hendron. DHW event schedule generator. U.S. Department of Energy, March 2011.

[11] S.J. Humes. Supreme court walks energy policy tightrope as it addresses federalism and states' rights. Trends: ABA Section of Environment, Energy and Resources Newsletter, 4:7-9, Apr/May 2016.

[12] Pennsylvania-New-Jersey-Maryland Interconnect. Regulation a data. Data Miner 2, 2018.

[13] Vassilis Kapsalis and Loukas Hadellis. Optimal operation scheduling of electric water heaters underdynamic pricing. Sustainable Cities and Societies, 31:109-121, 2017.

[14] Vassilis Kapsalis, Georgia Safouri, and Loukas Hadellis. Cost/comfort-oriented optimization algorithm for operation scheduling of electric water heaters under dynamic pricing. Journal of Cleaner Production, 198:1053-1065, 2018.

[15] Peter Kepplinger, Gerhard Huber, and Jorg Petrasch. Autonomous optimal control for demand side management with resistive domestic hot water heaters using linerar optimization. Energy and Buildings, 100:50-55, 2015. 
[16] M. Khalid and A.V. Savkin. Minimization and control of battery energy storage for wind power smoothing: Aggregated, distributed, and semi-distributed storage. Renewable Energy, 44:78-86, 2018.

[17] L. Schwartz, M. Wei, W. Morrow, J. Deason, S.R. Schiller, G. Leventis, et al. Electricity end uses, energy efficiency, and distributed energy resources baseline, January 2017. Report Prepared for the U.S. Department of Energy.

[18] J.C. Laurent, G Desaulniers, R.P. Malhame, and F. Soumis. A column generation method for optimal load management via control of electric water heaters. IEEE Transactions on Power Systems, 10:1389-1400, Aug 1995.

[19] J.C. Laurent and R.P. Malhame. A physcially-based computer model of aggregate electric water heating loads. IEEE Transactions on Power Systems, 9:1209-1217, Aug 1994.

[20] Jianing Li, Zhi Wu, Suyang Zhou, Hao Fu, and Xiao-Ping Zhang. Aggretator service for PV and battery energy storage systems of residential building. CSEE Journal of POWER and Energy Systems, 44:78-86, 2018.

[21] U.S. Beureau of the Census. U.S. residential household data. American FactFinder, 2018.

[22] Y. Parag. Beyond energy efficiency: A 'prosumer market' as an integrated platform for consumer engagement with the energy system. ECEEE Summer Study on Energy Efficiency, June 2015. 
[23] Jay Burch Robert Hendron and Greg Barker. Tool for generating realistic residential hot water event schedules. SimBuild Conference, August 2010.

[24] Mushfiqur R. Sarker, Yury Dvorkin, and Miguel A. Ortega-Vazquez. Optimal participation of an electric vehicle aggregator in day-ahead energy and reserve markets. IEEE Transactions on Power Systems, 31(5):3506-3515, September 2016.

[25] Setiawan and Eko Adhi. Concept and Controllability of Virtual Power Plant. Kassel University Press, Kassel, Germany, 2007.

[26] Tylor Slay. Adoption of an Internet of Things Framework for Distributed Energy Resource Coordination and Control. Portland State University, 2018. Masters thesis.

[27] Mike Turner and Jamal Batakji. Business practices manual for the energy imbalance market. California Independent System Operator, 2018.

[28] Stylianos I. Vagropoulos and Anastasios G. Bakirtzis. Optimal bidding strategy for electric vehicle aggregators in electricity markets. IEEE Transactions on Power Systems, 28(4):4031-4041, November 2013.

[29] Marina Gonzalez Vaya and Goran Andersson. Electric vehicle aggregator/system operator coordination for charging scheduling and services procurement. IEEE Transactions on Power Systems, 30(5):2375-2385, September 2015. 
Appendix A: MATLAB Scripts 


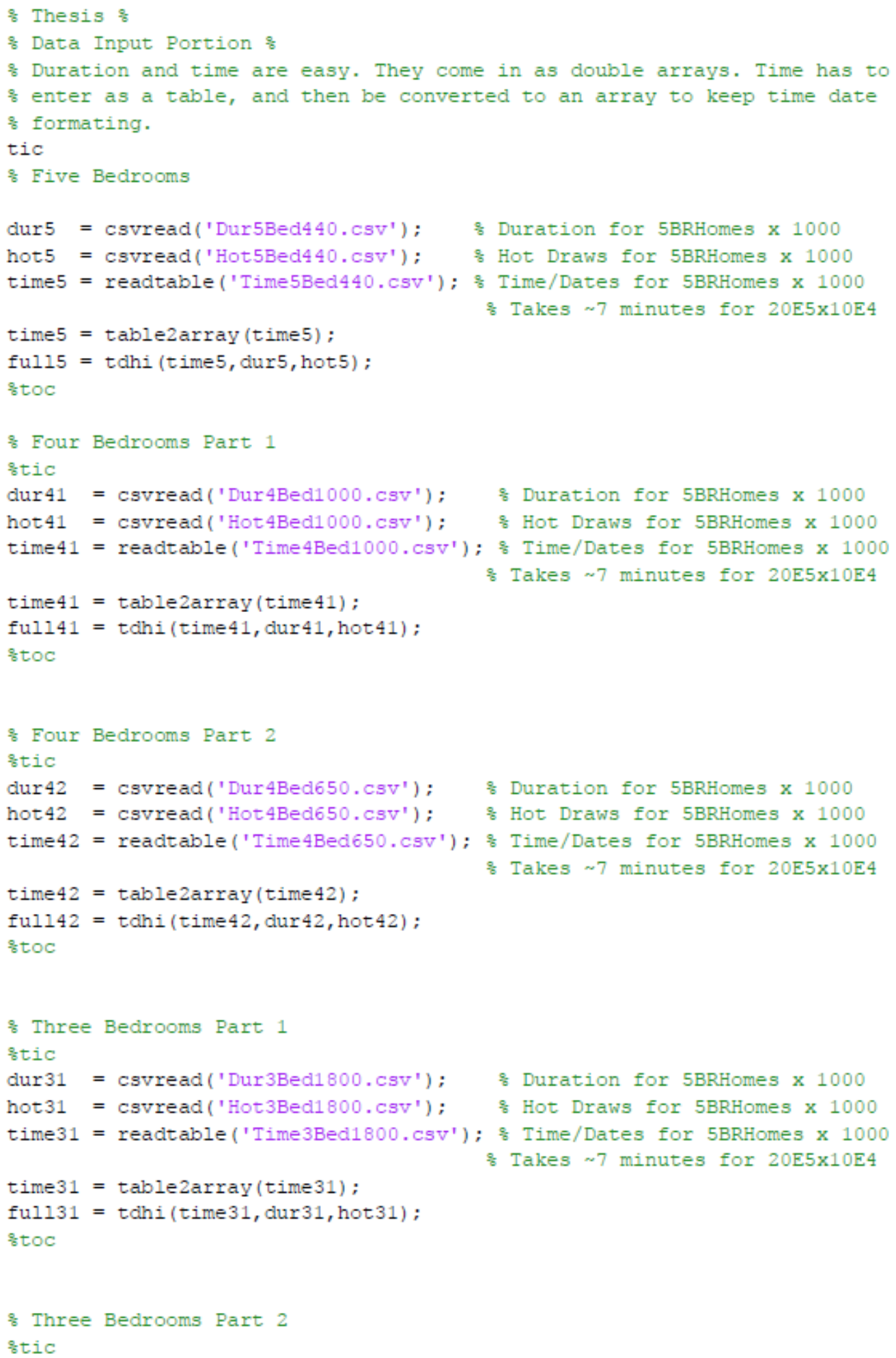




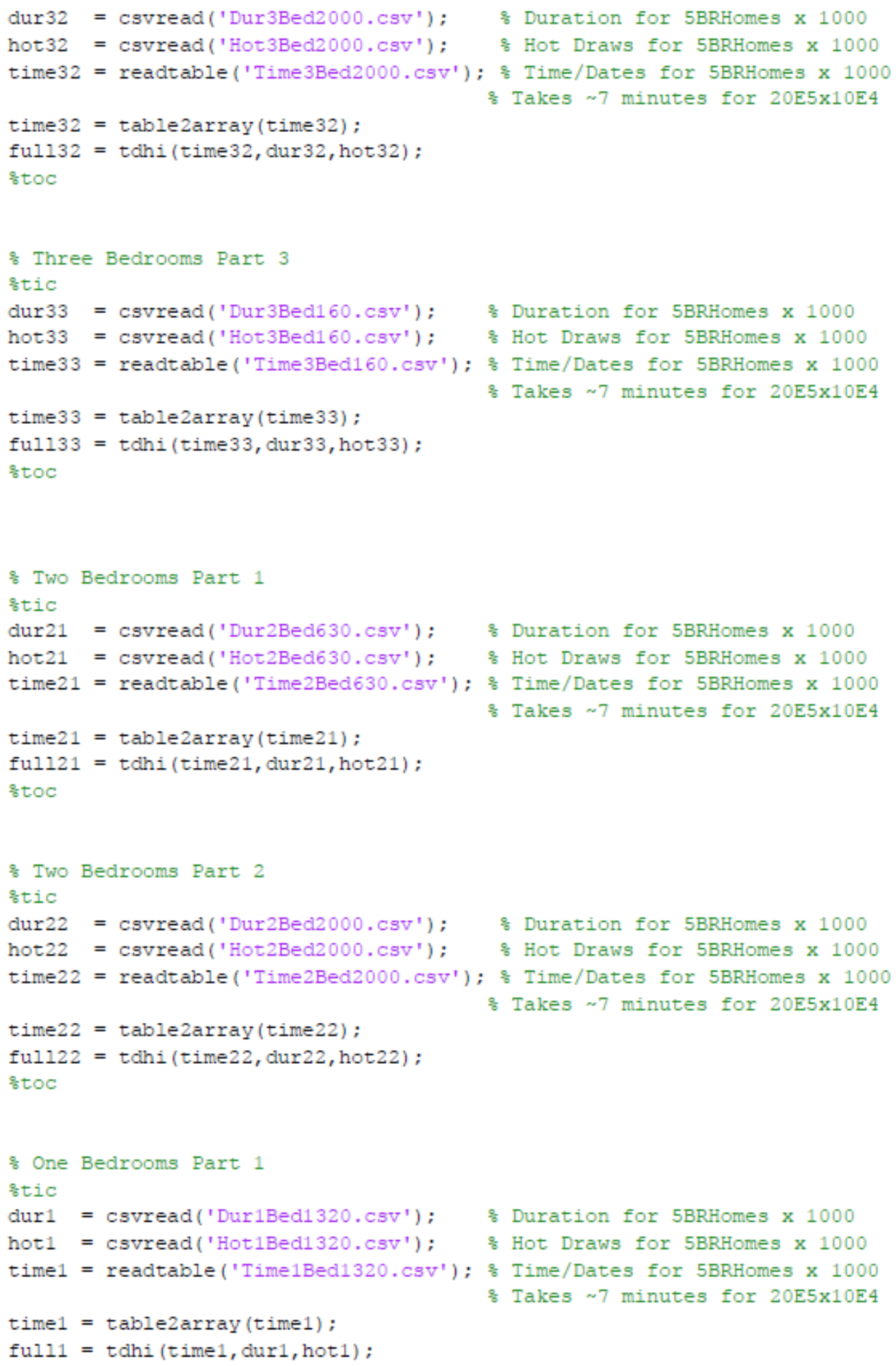




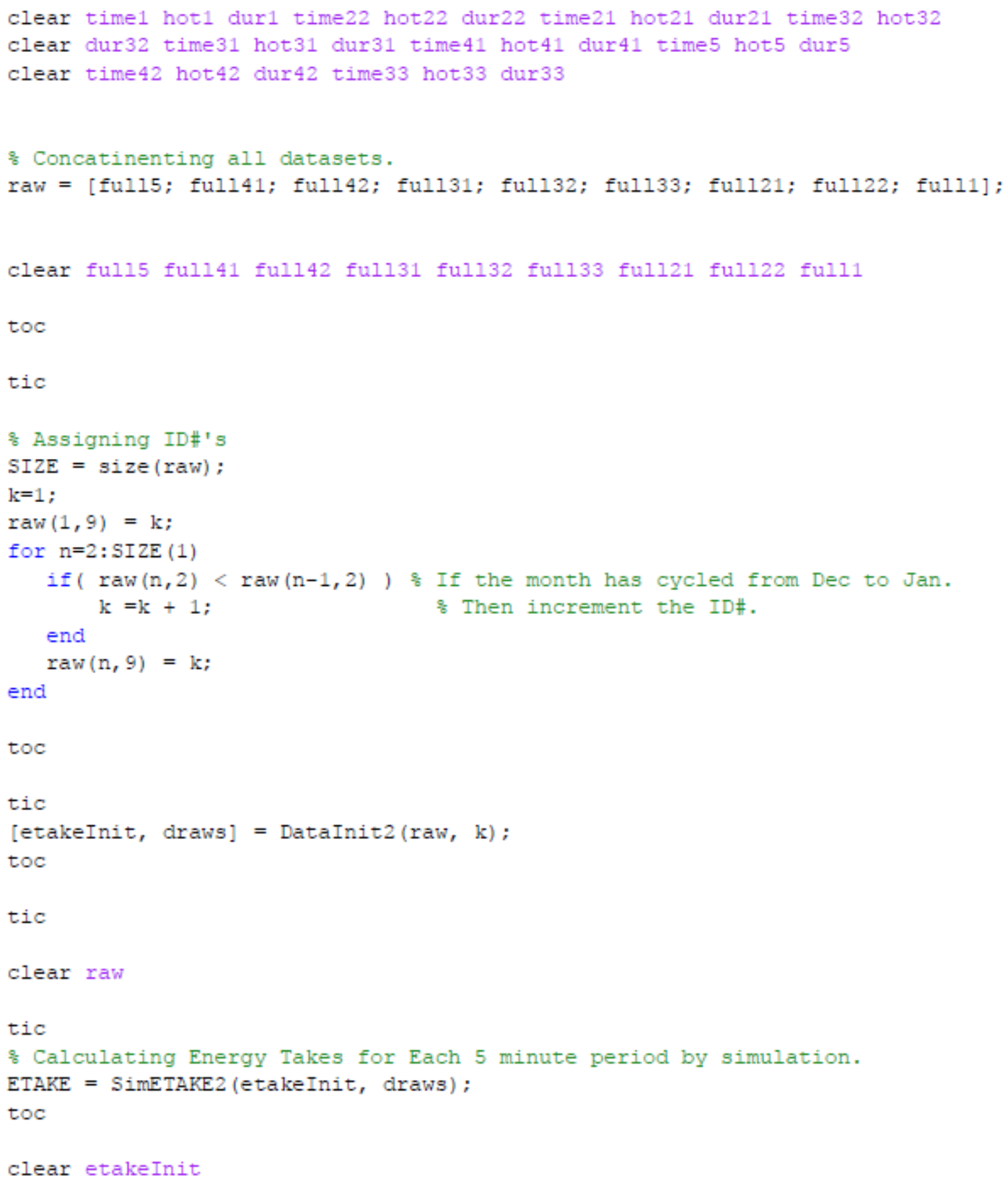




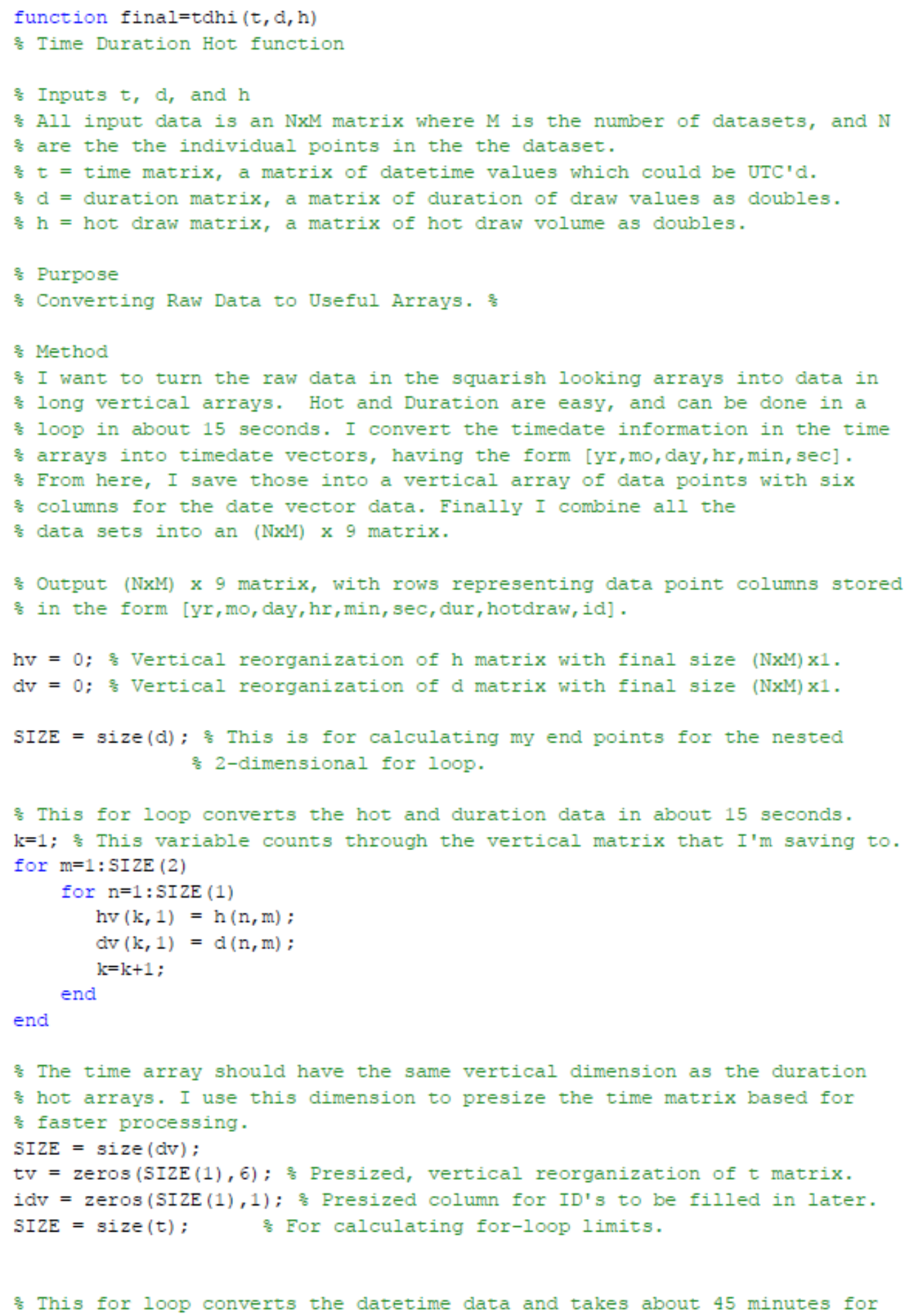


옹 a $20000 \times 1000$ input matrix of datetime entries.

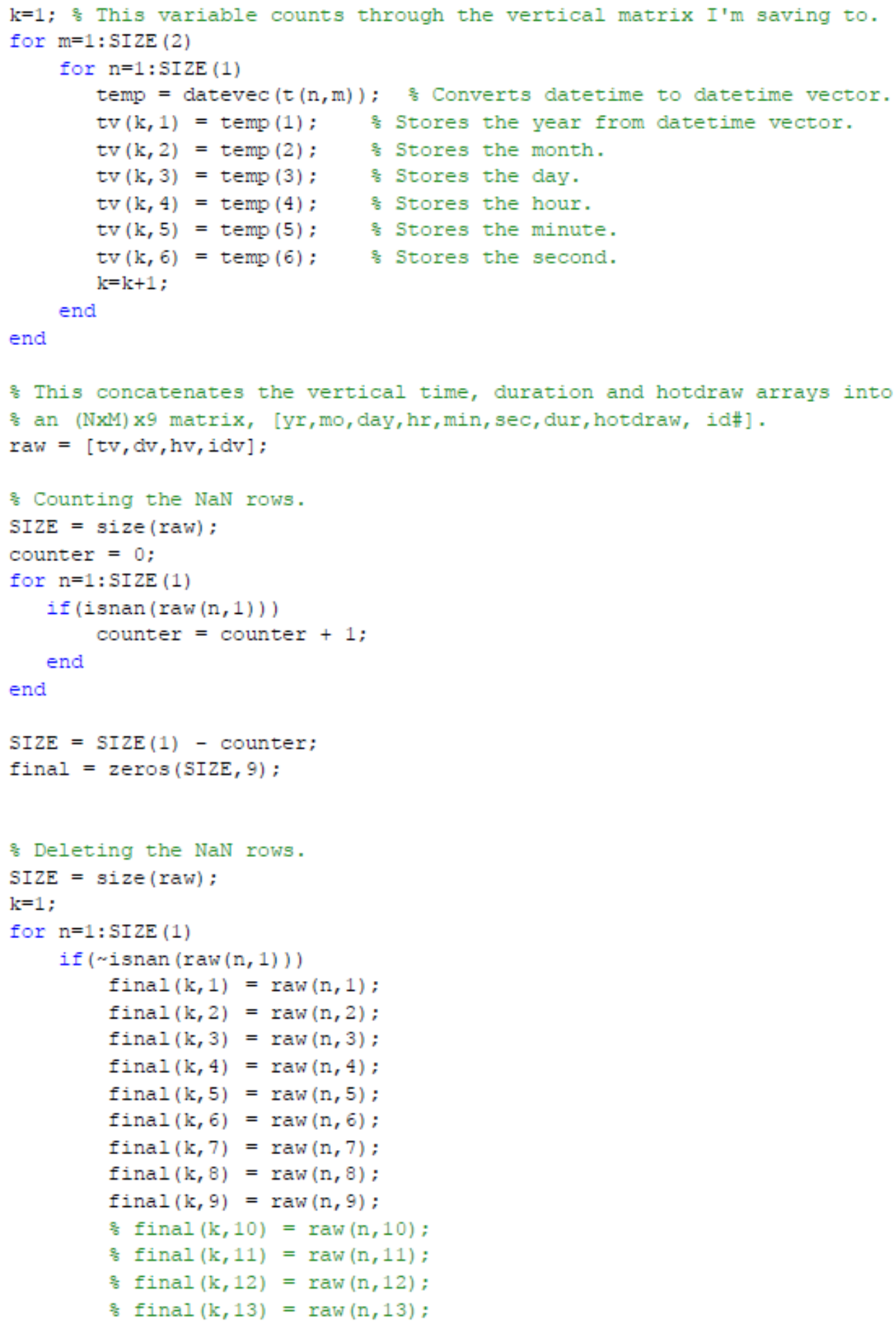




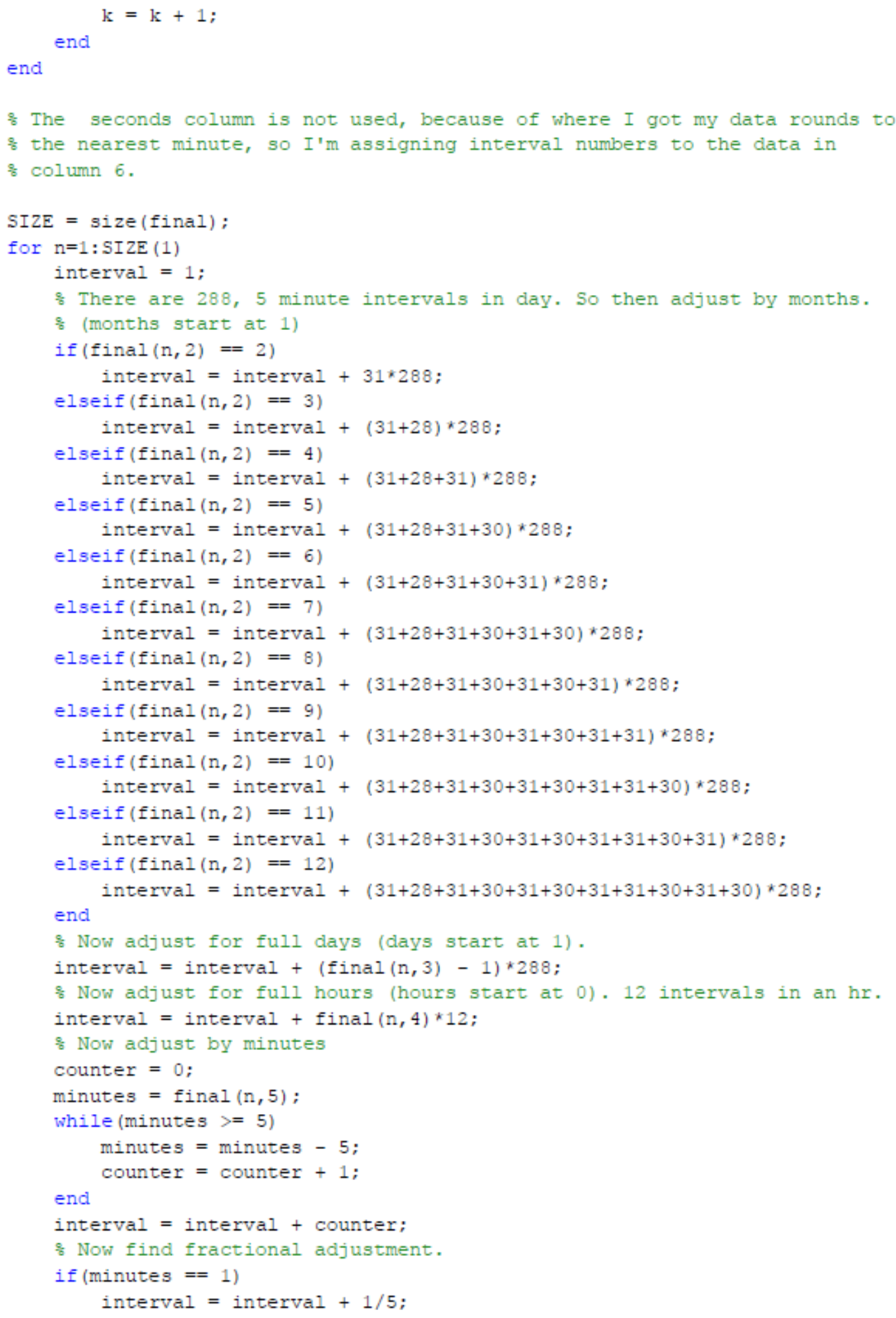




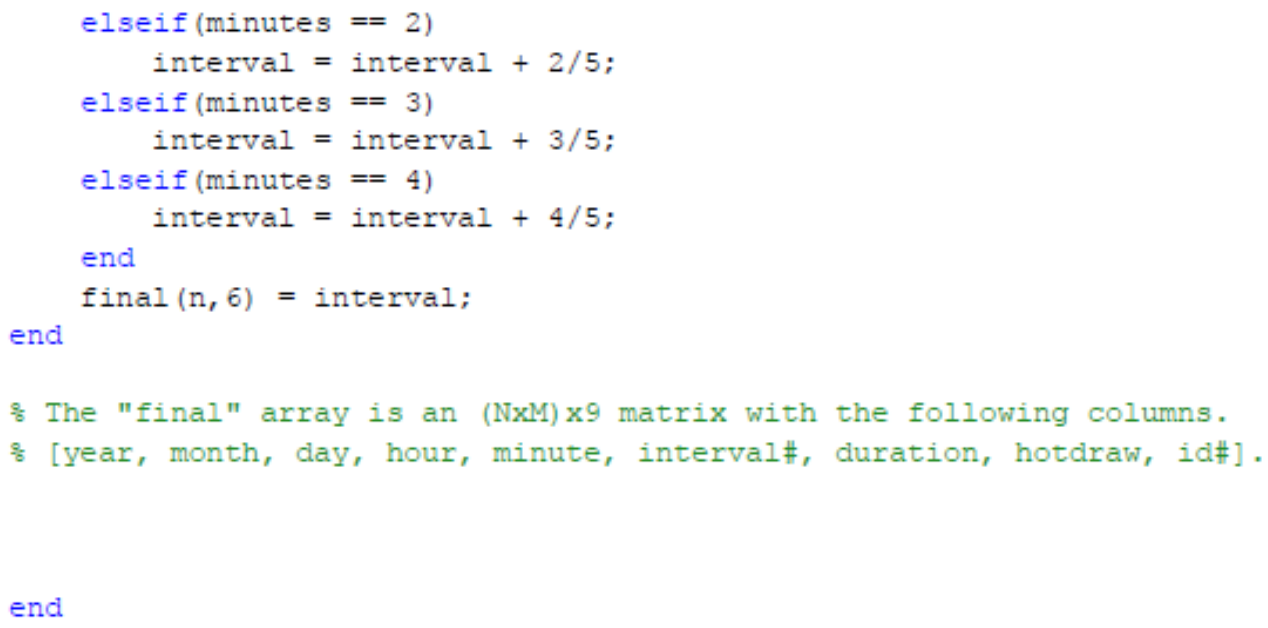




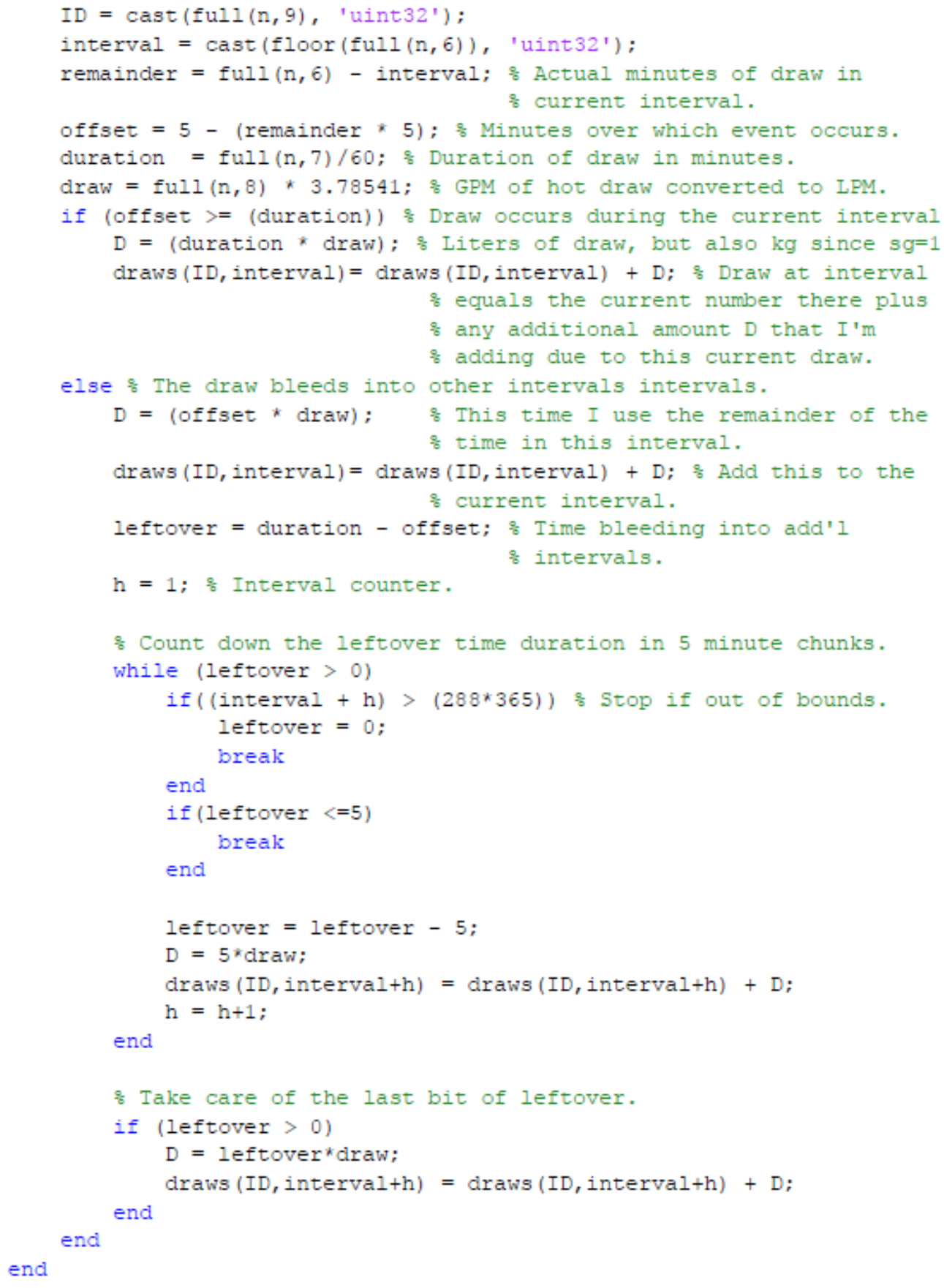

end 


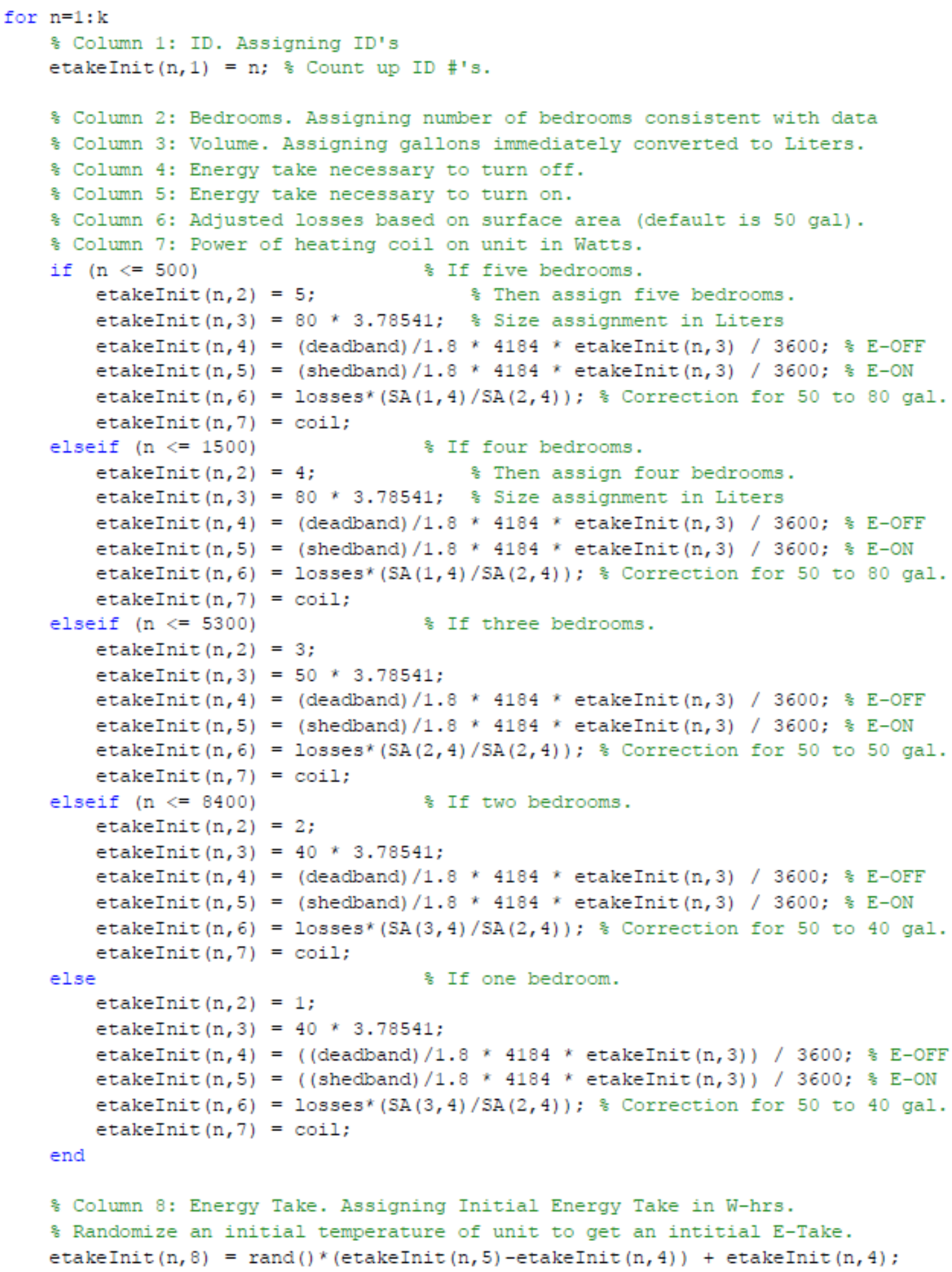




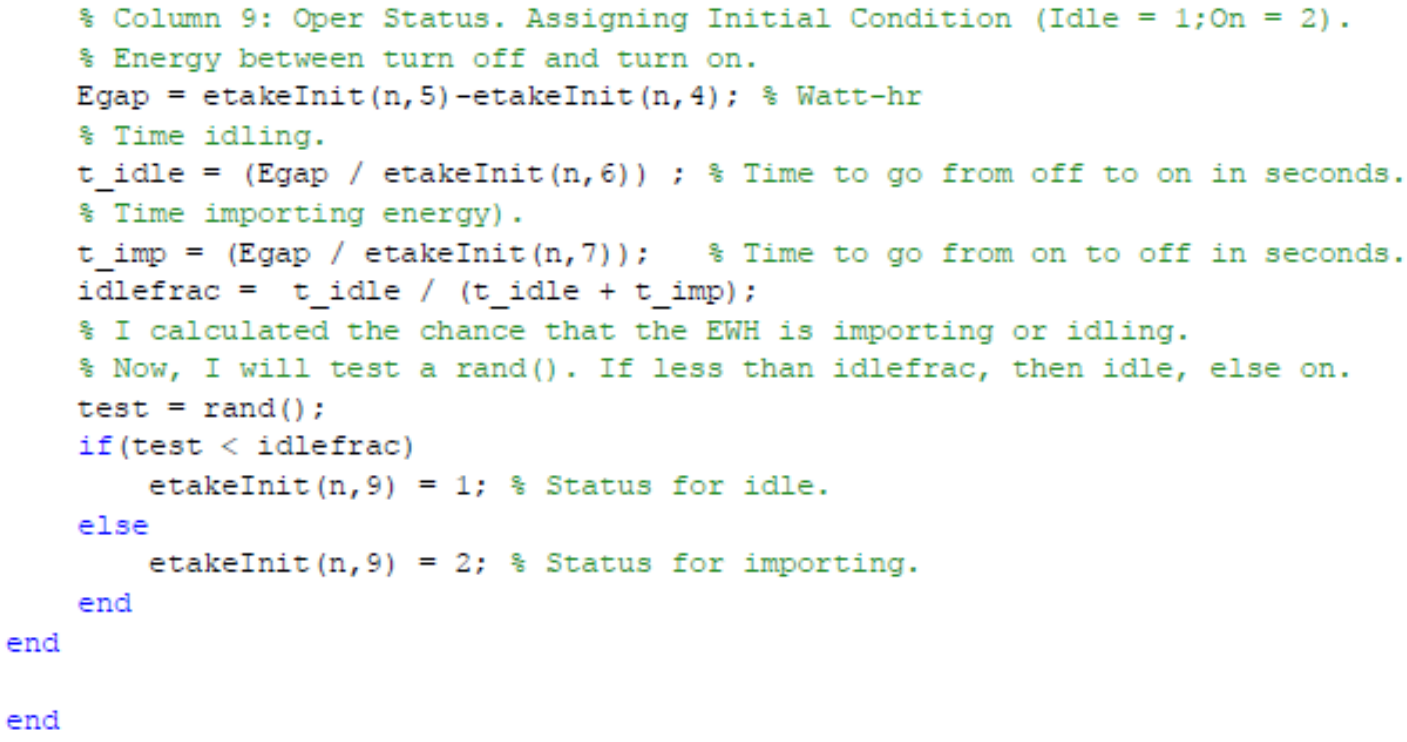




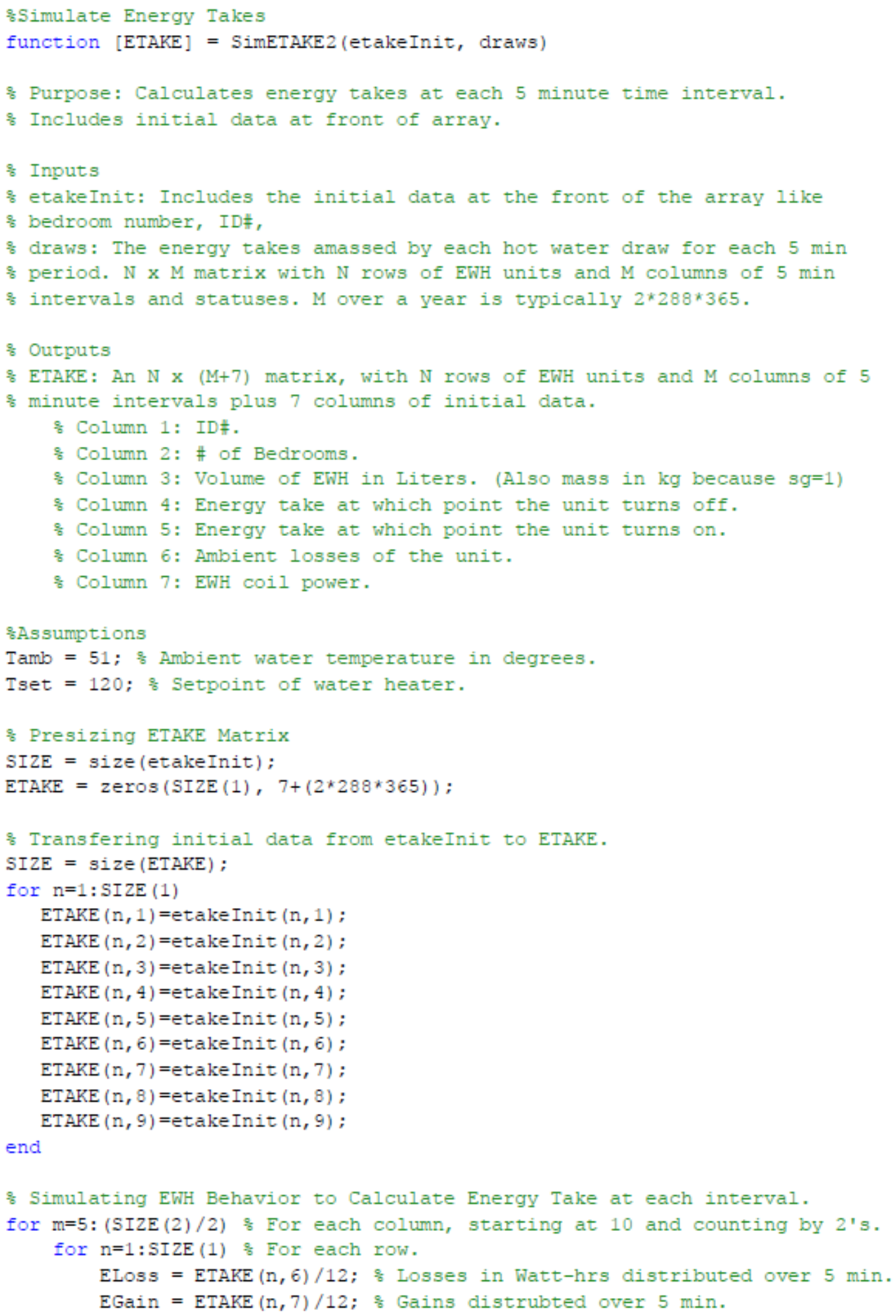




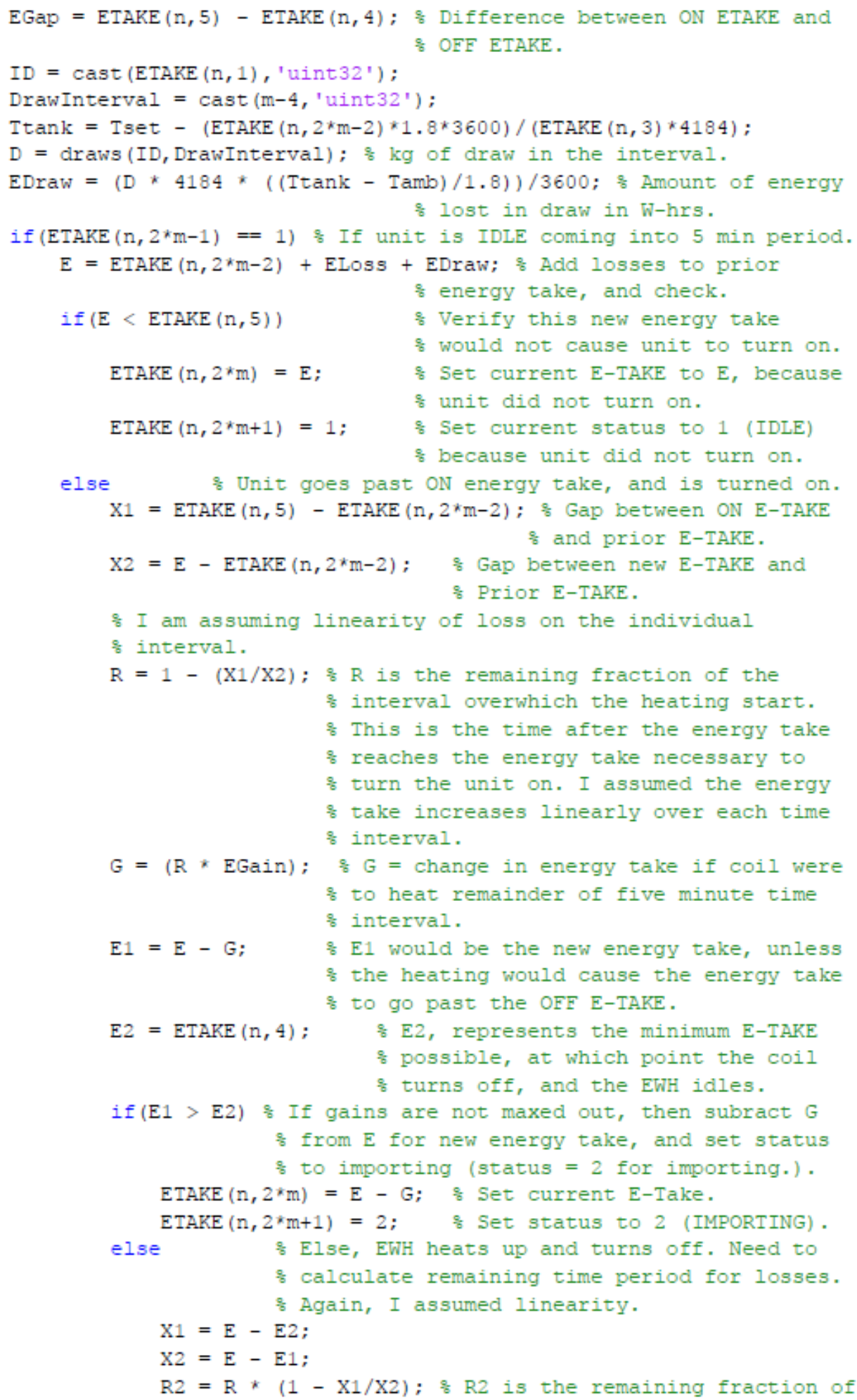




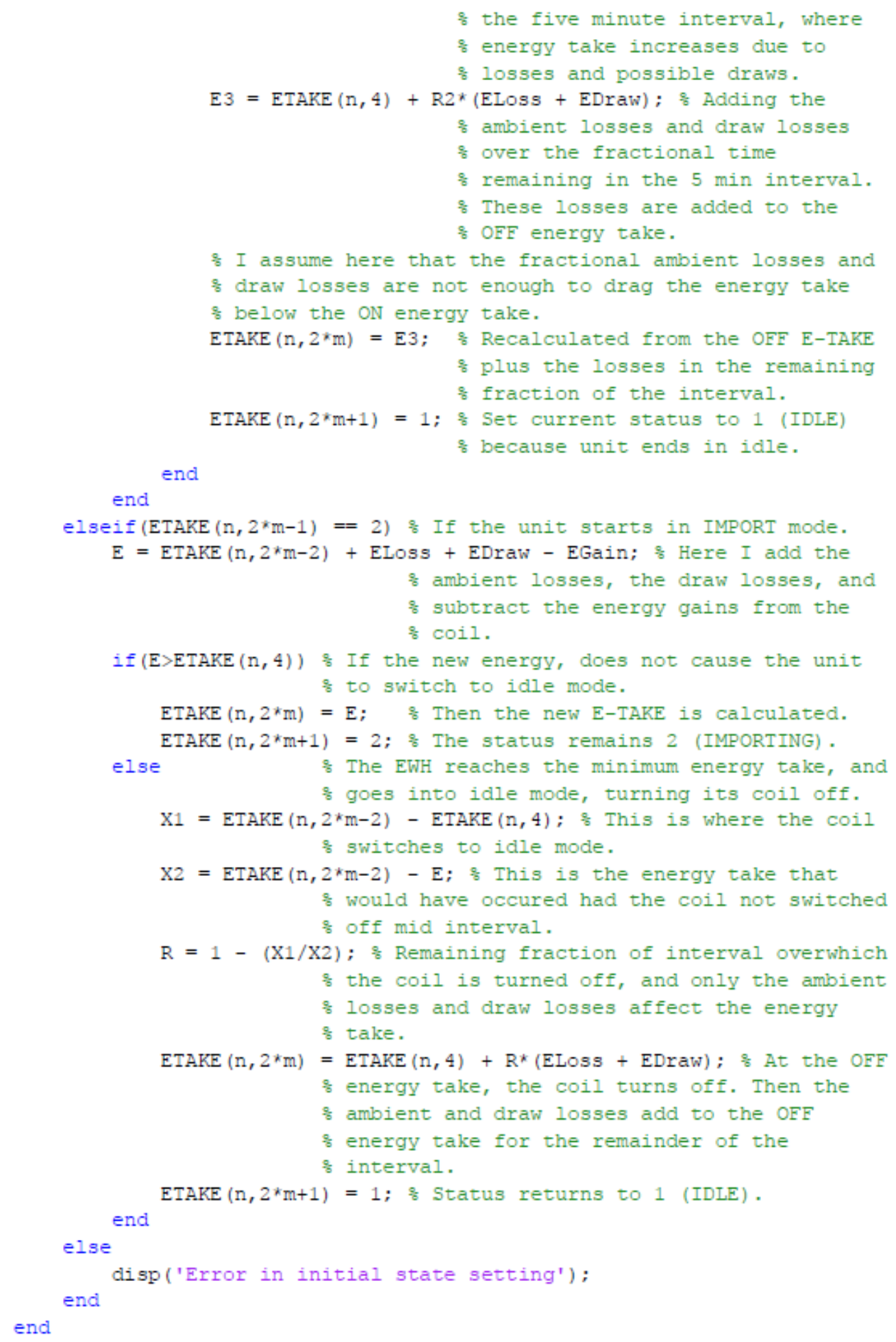




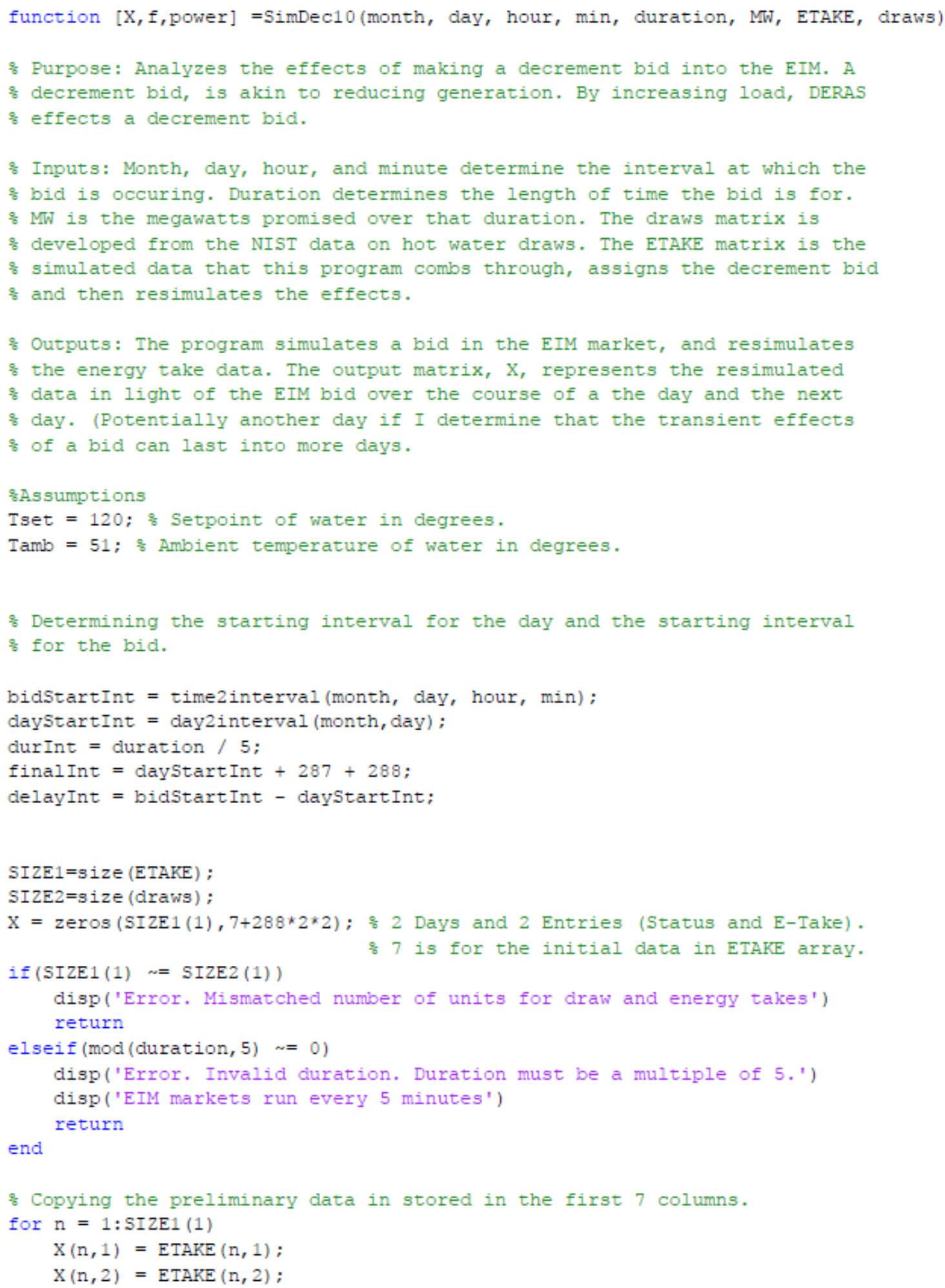




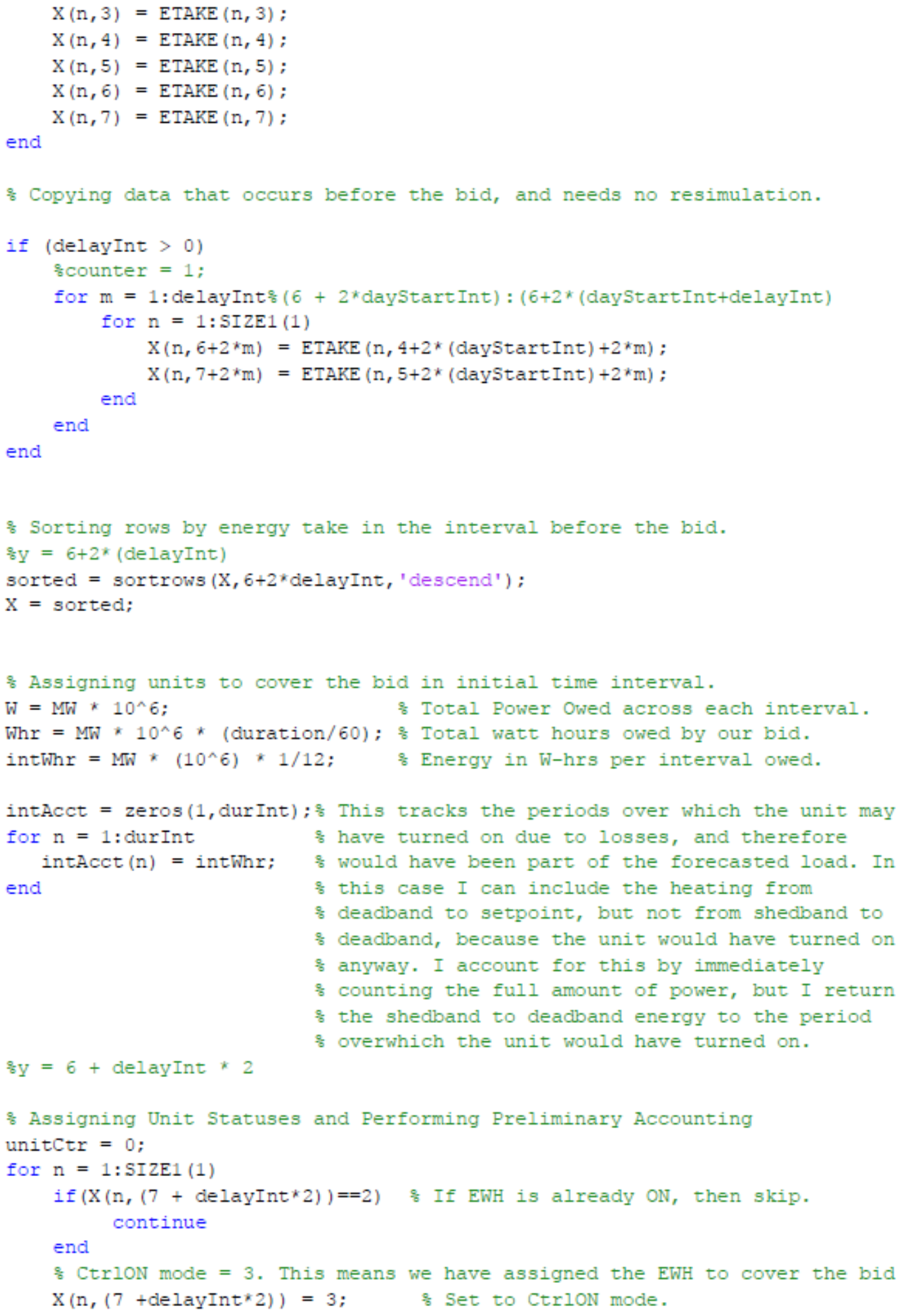




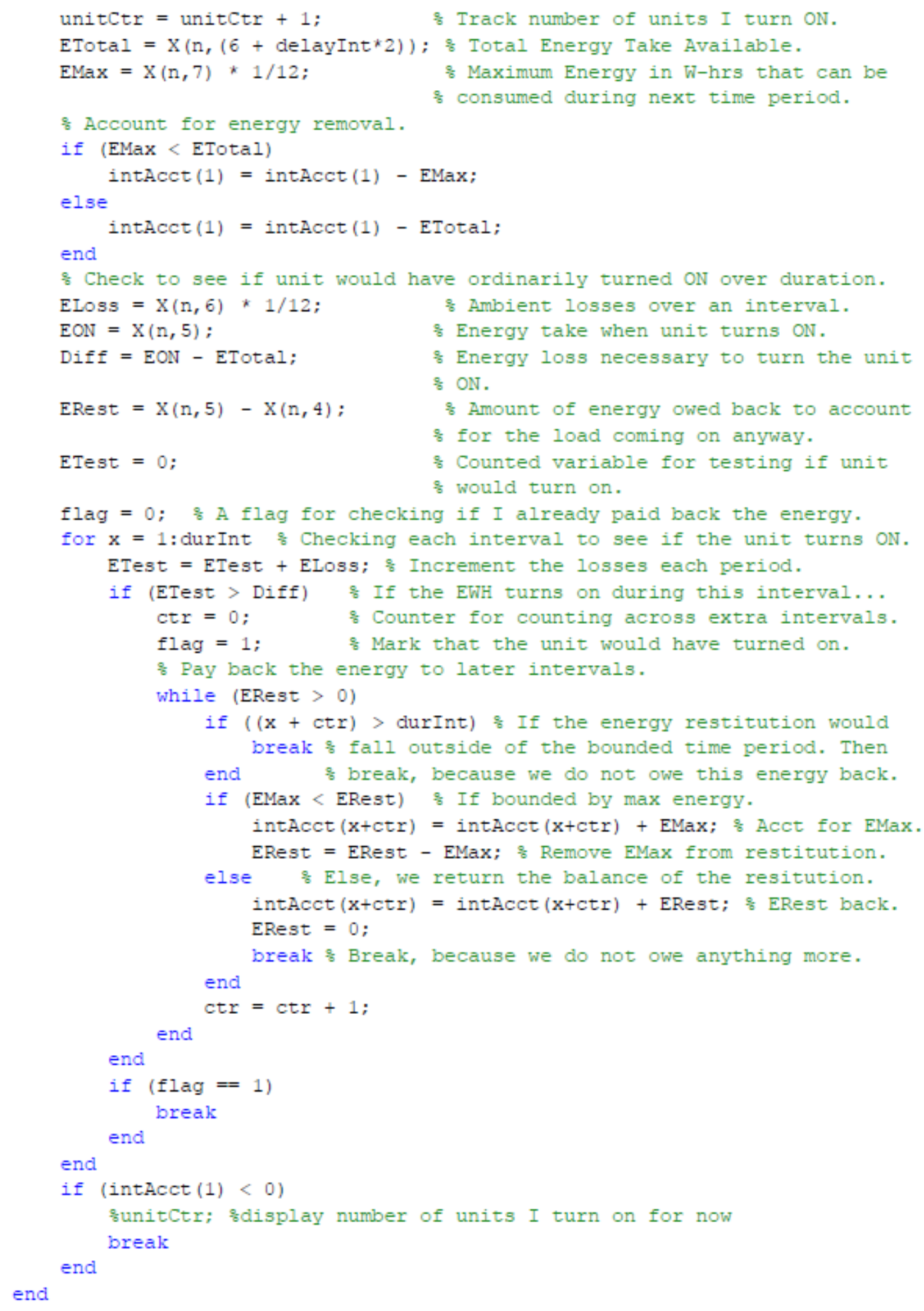




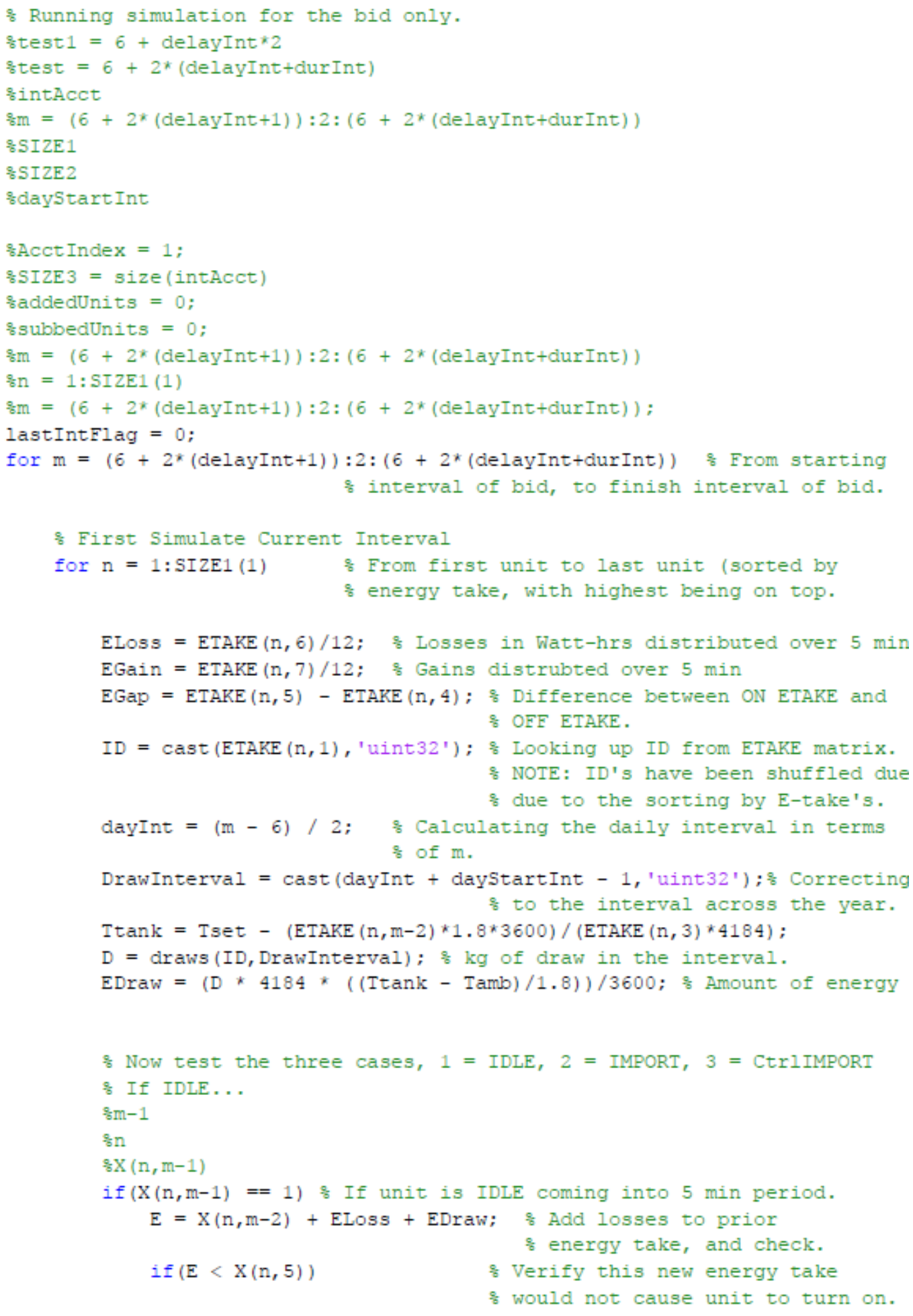




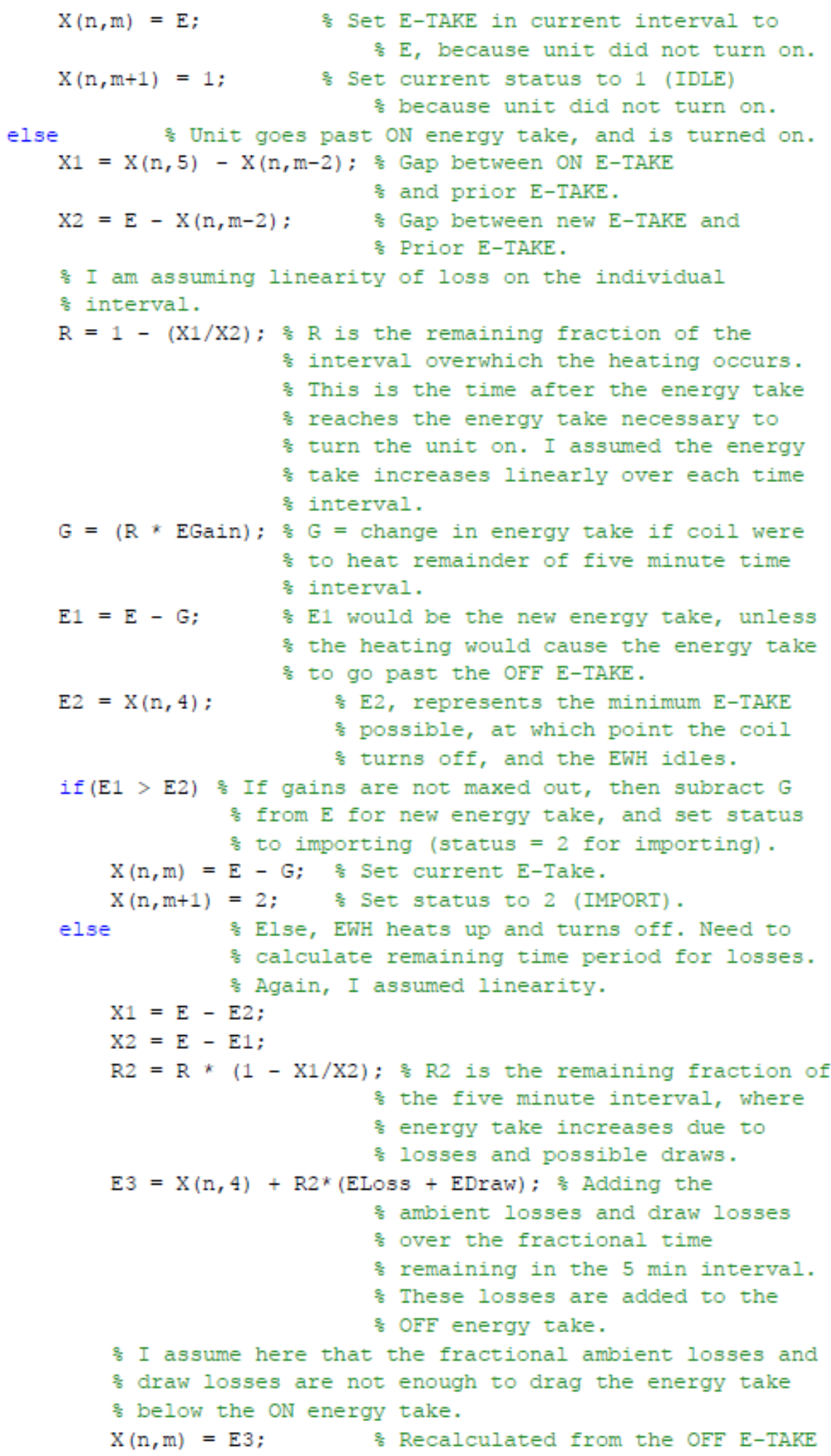




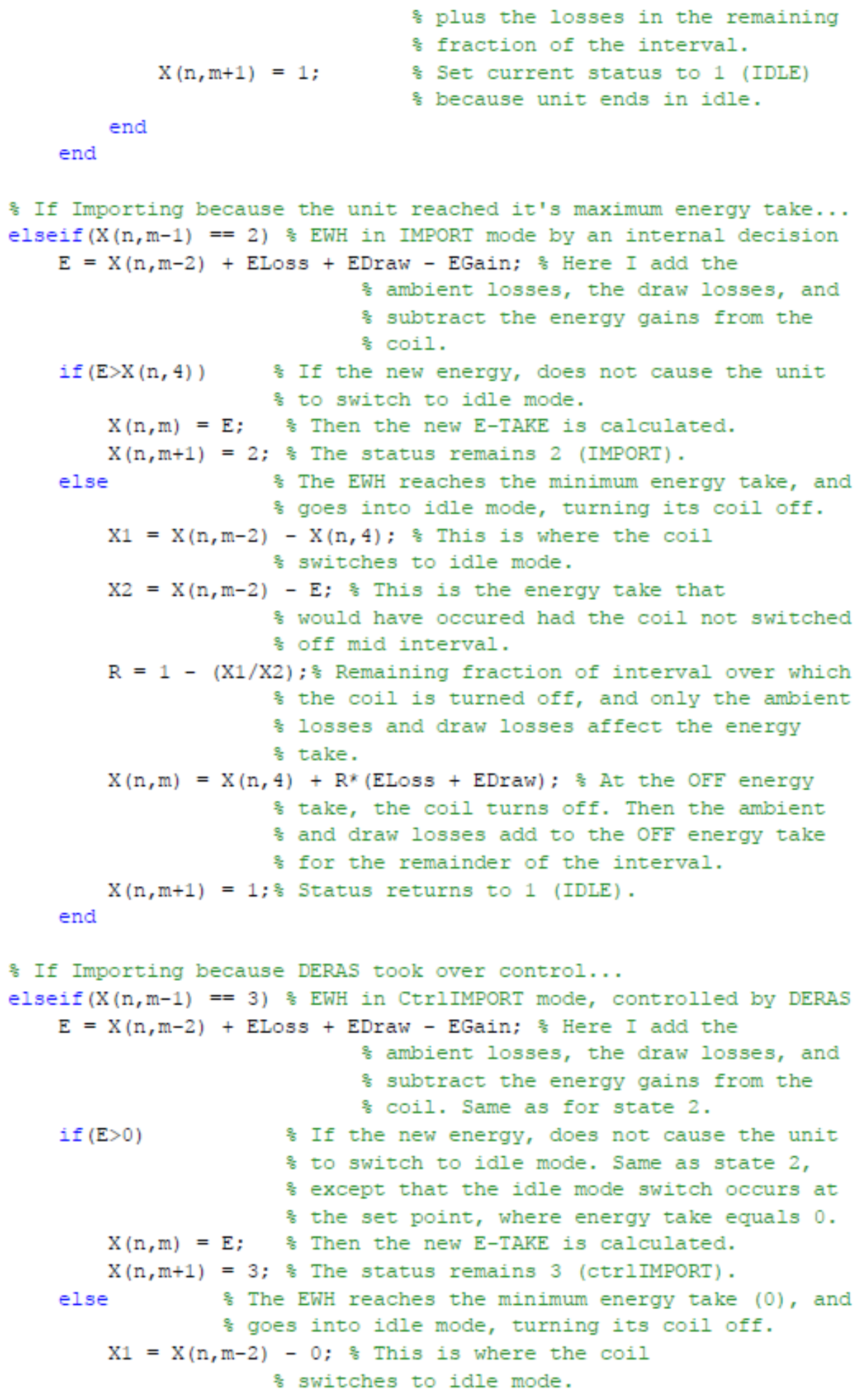




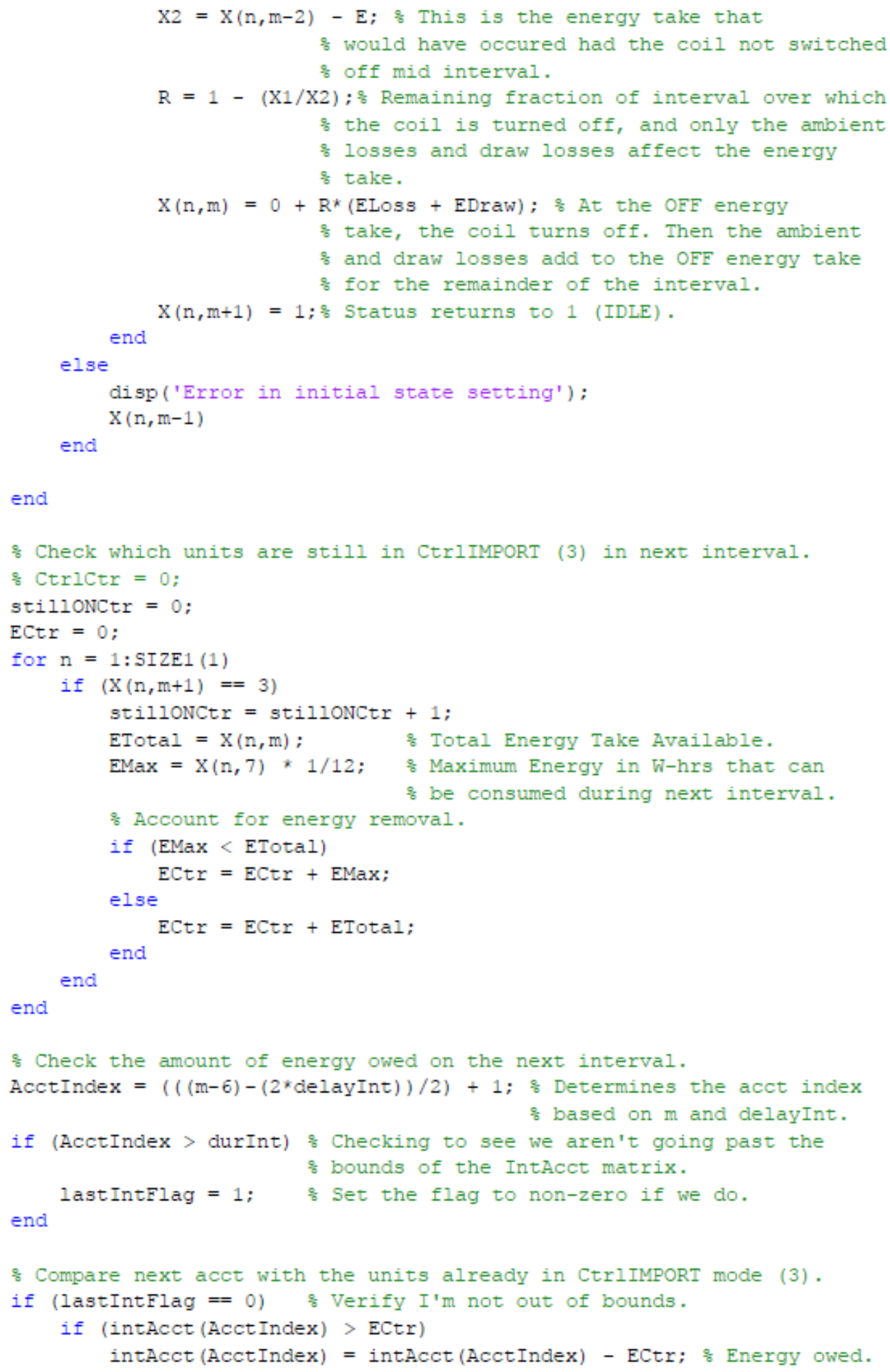




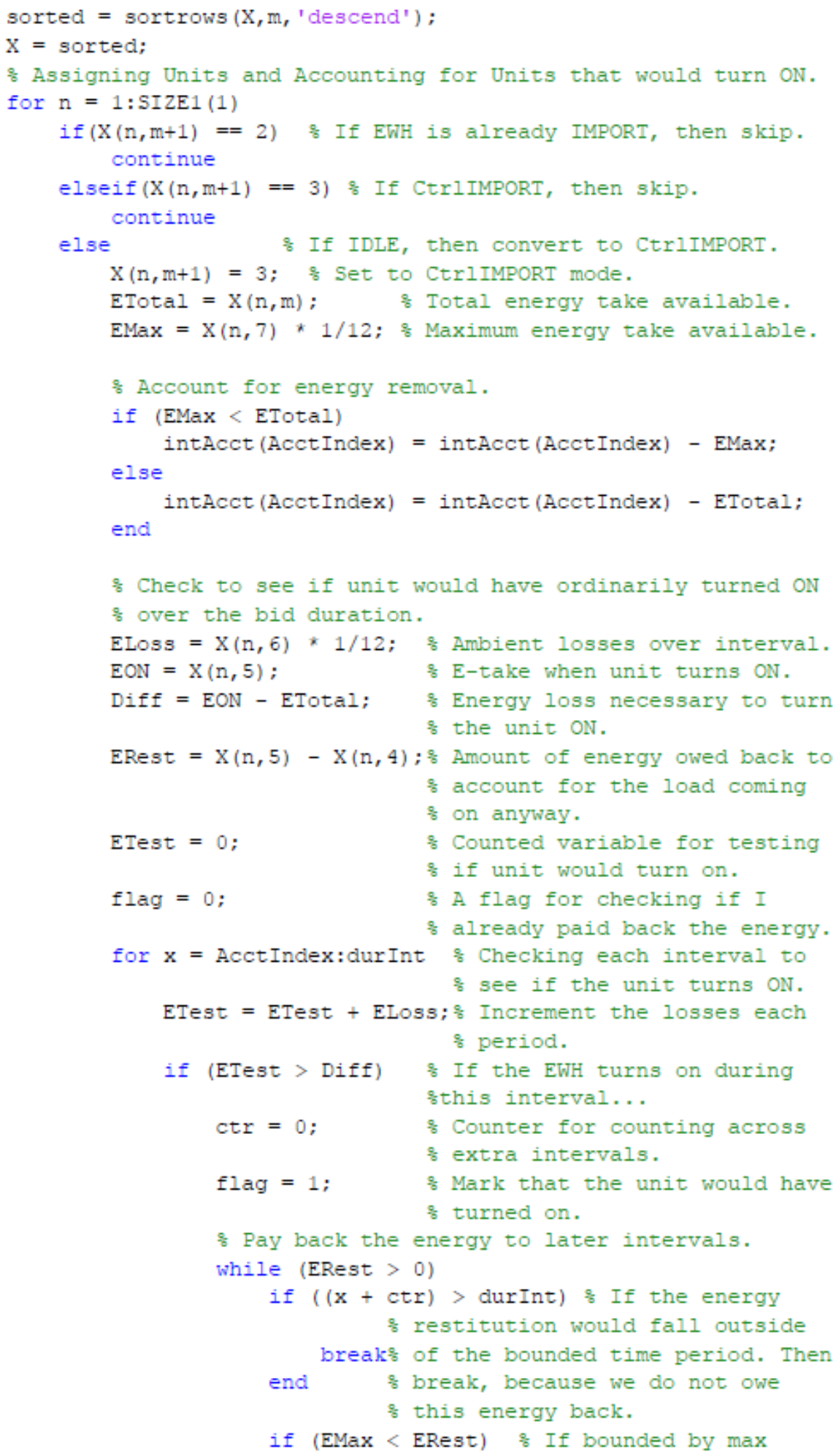




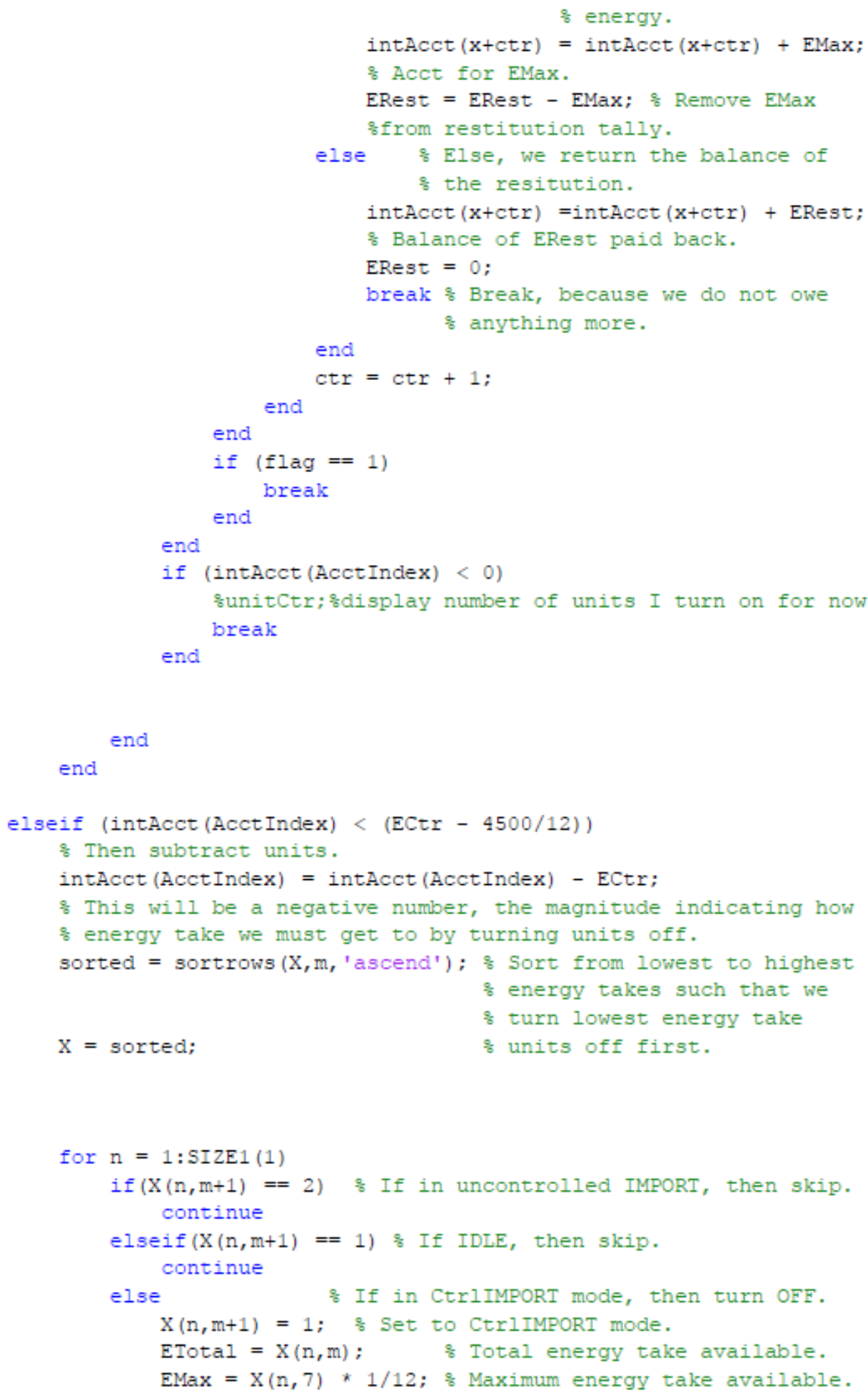




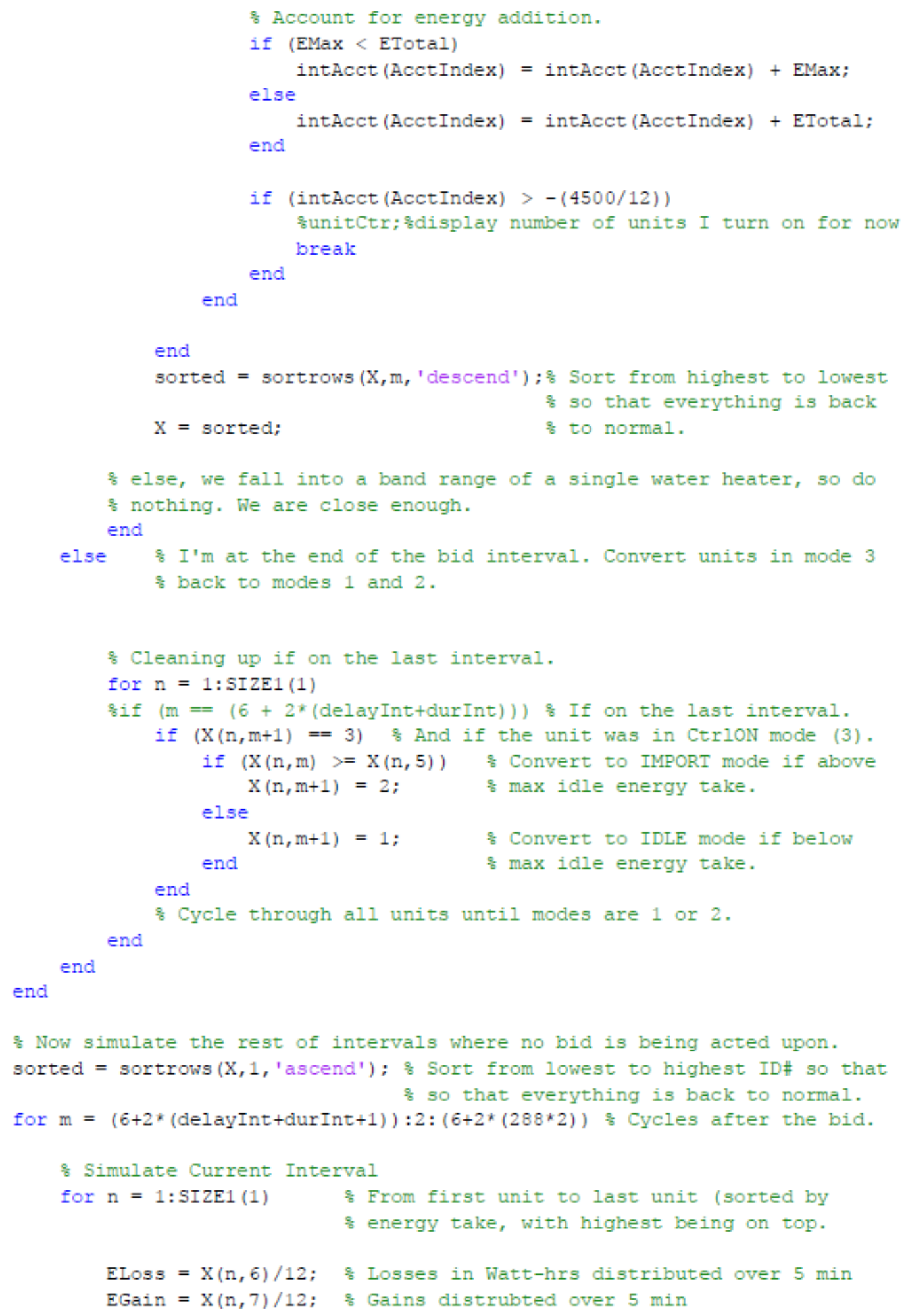




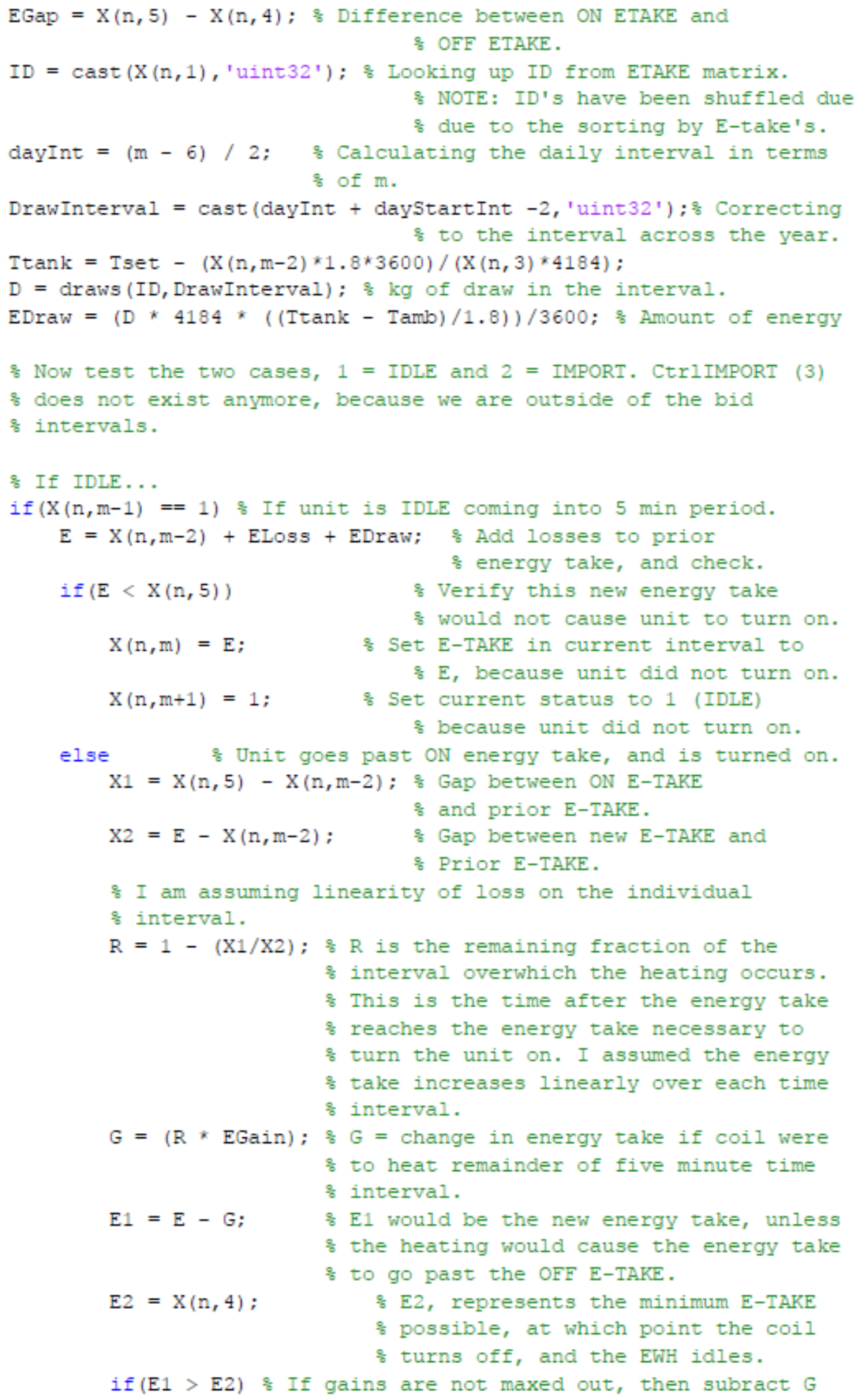




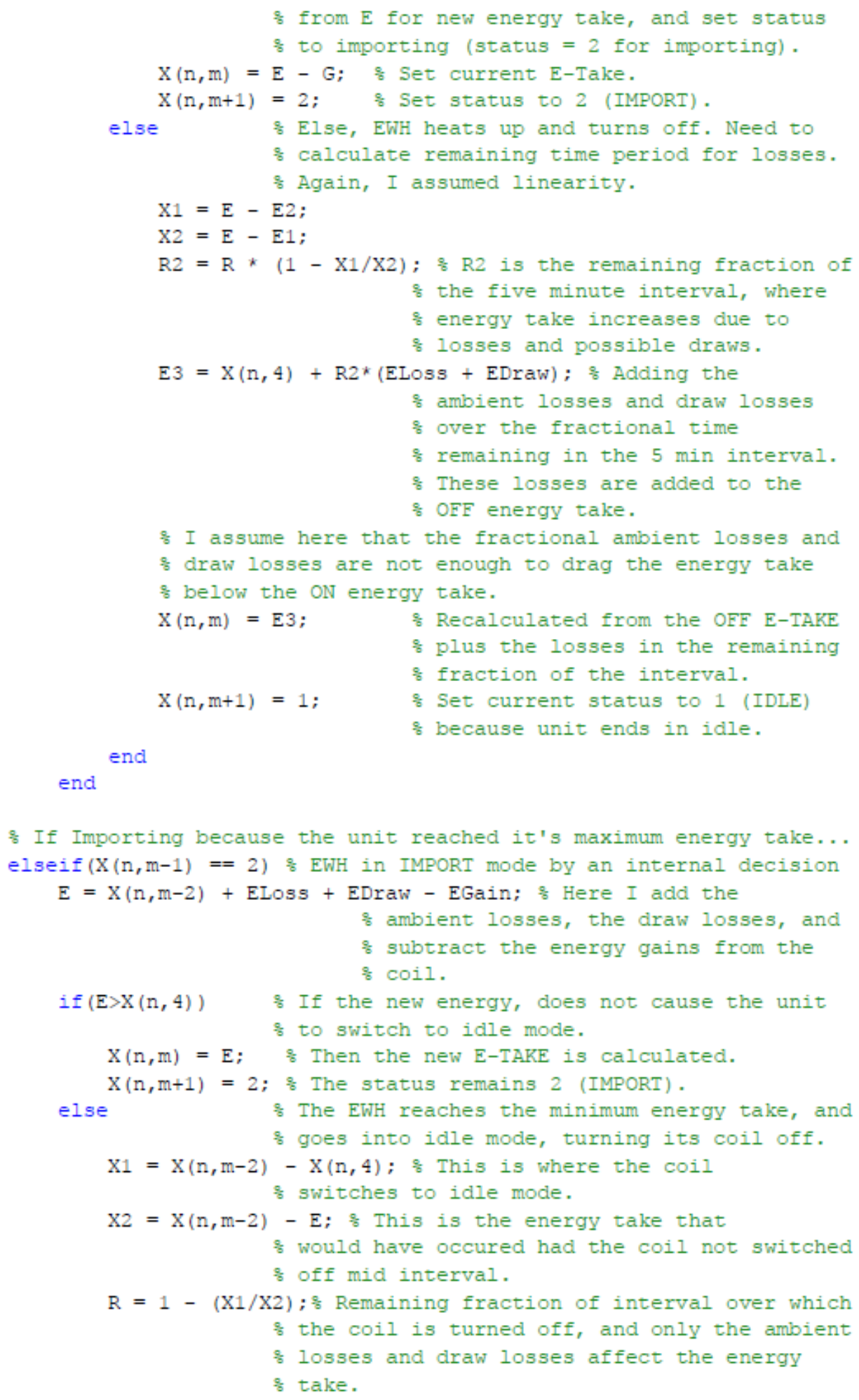




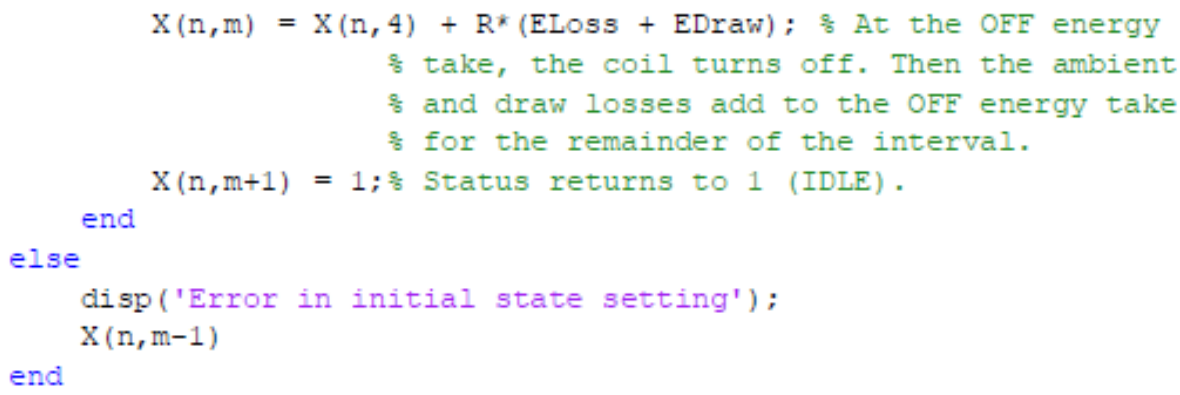




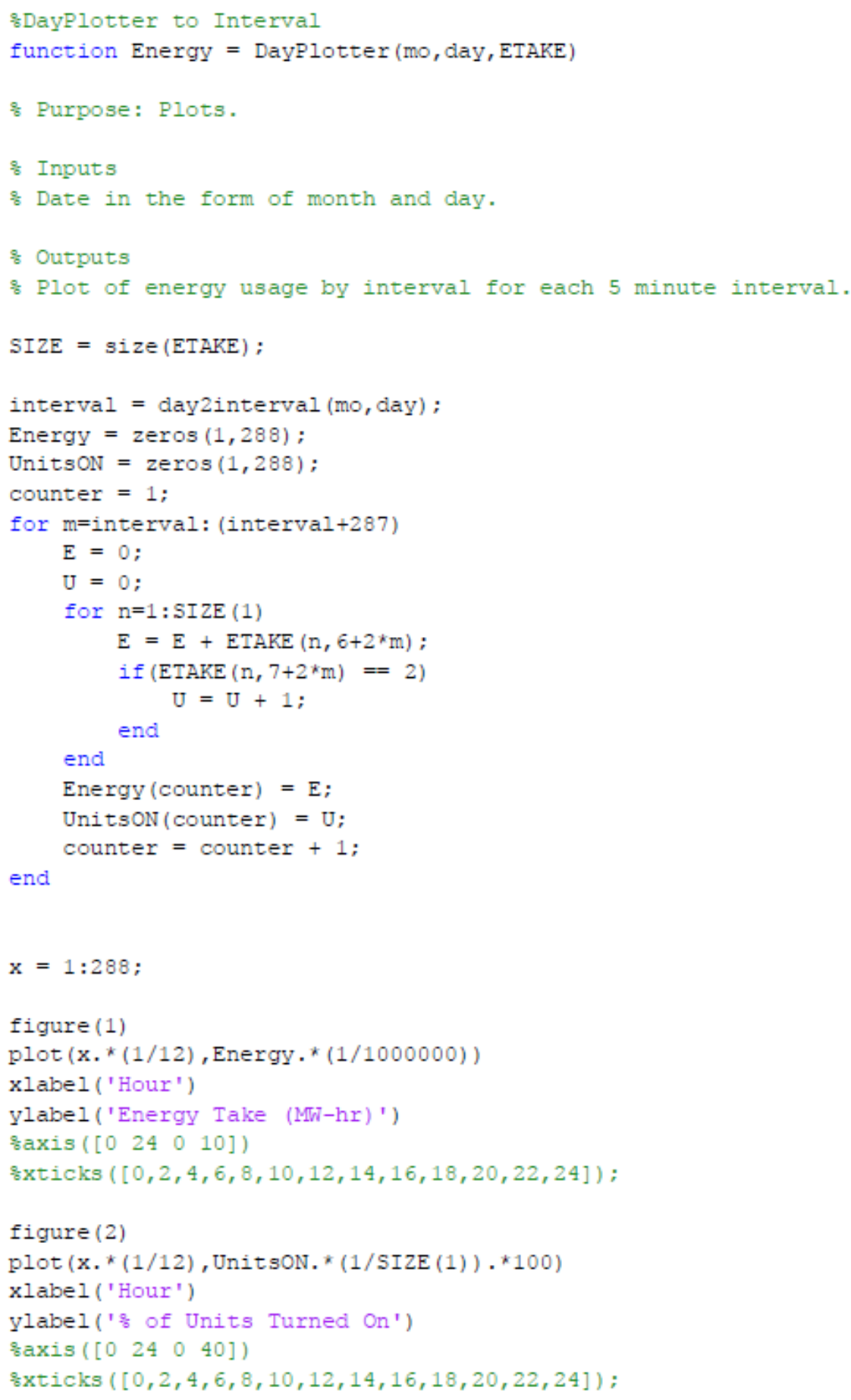




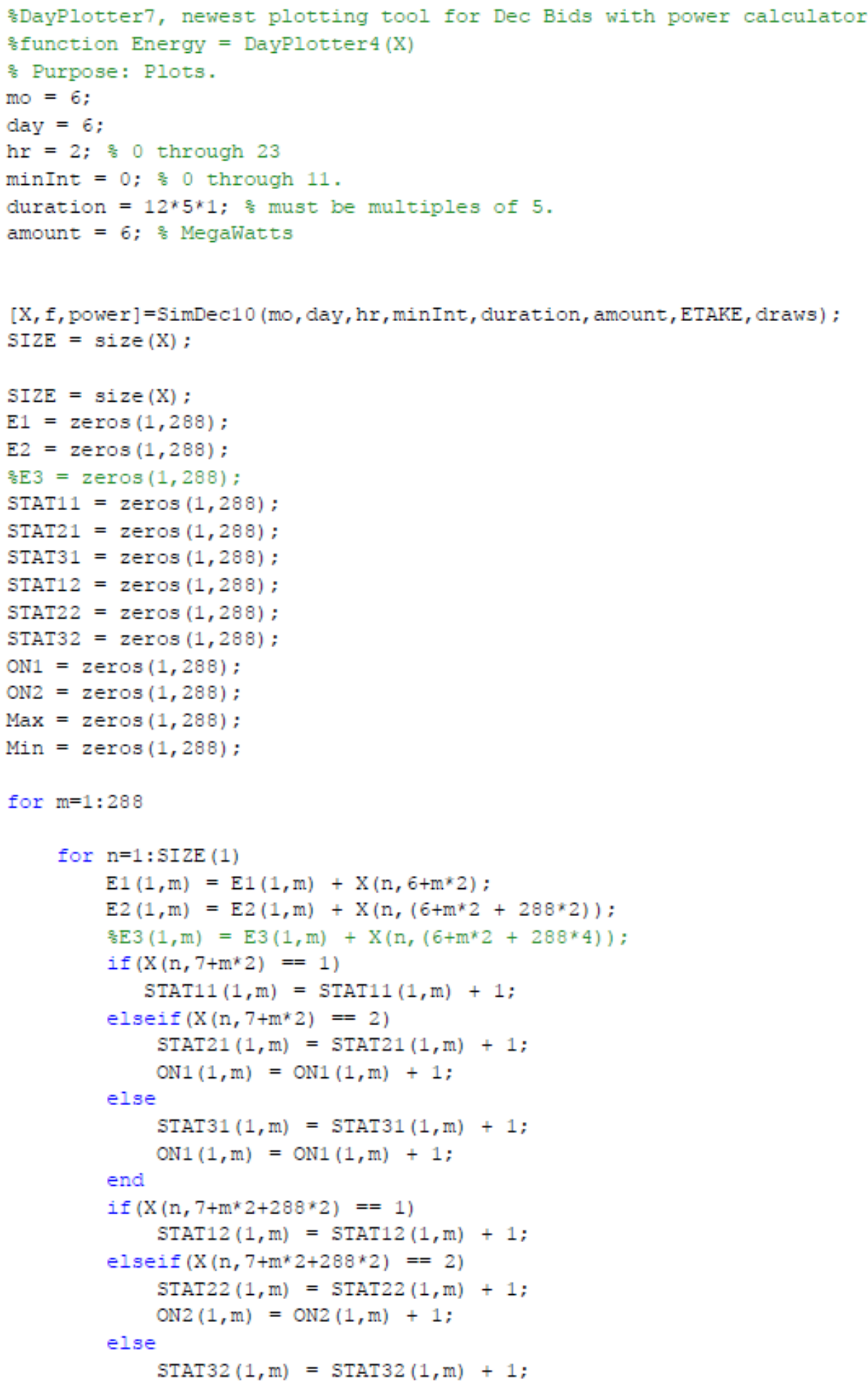




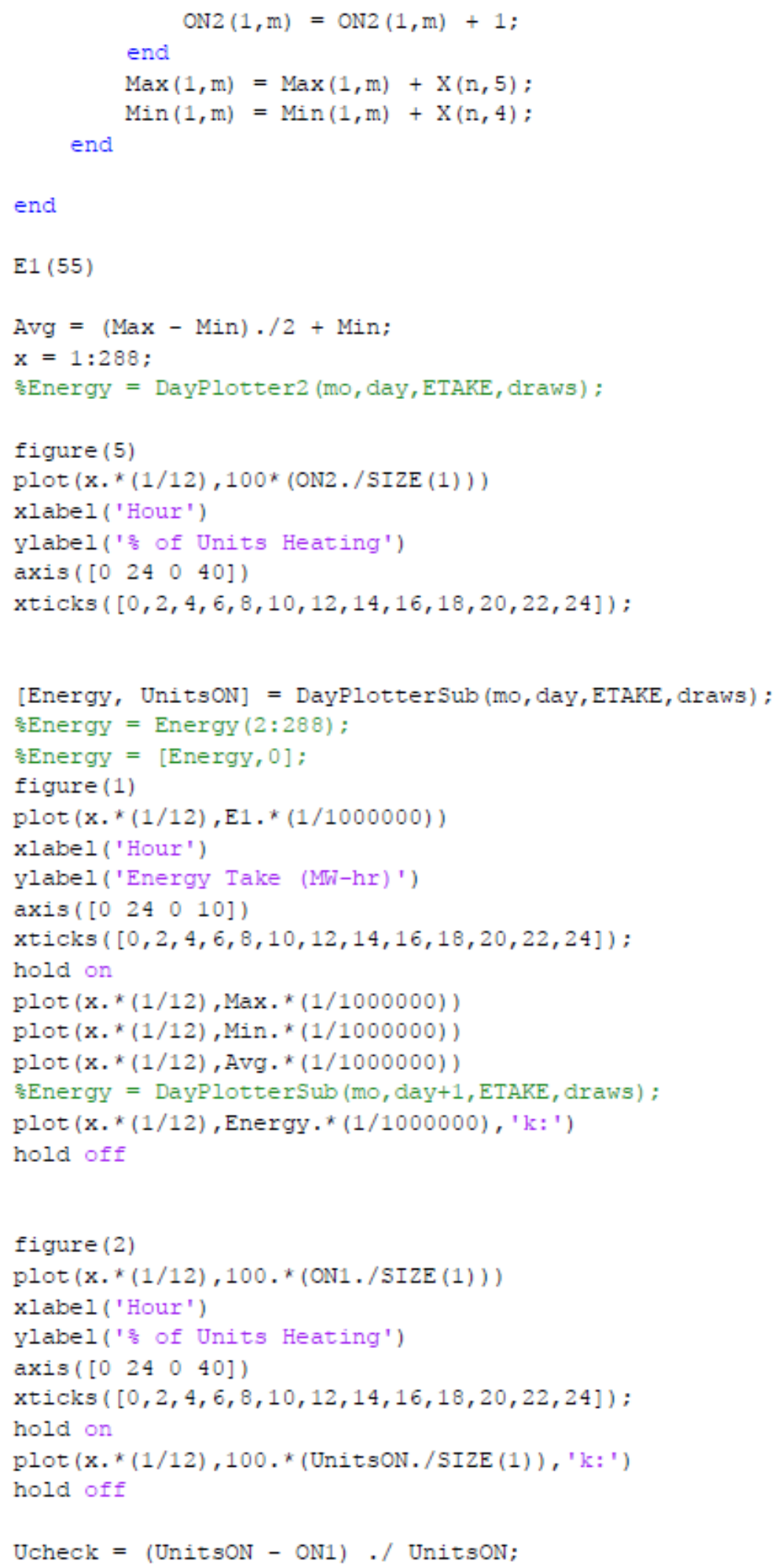




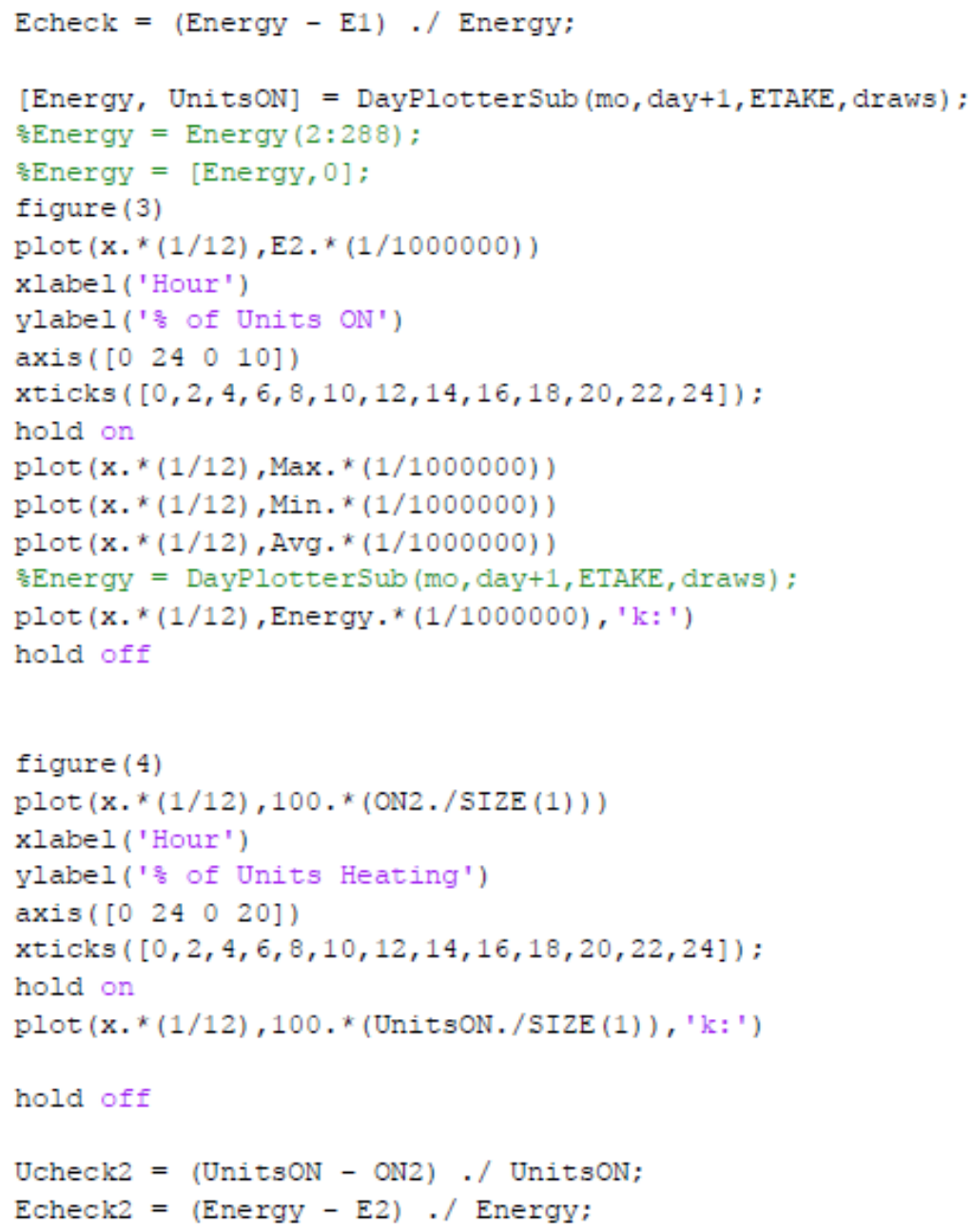




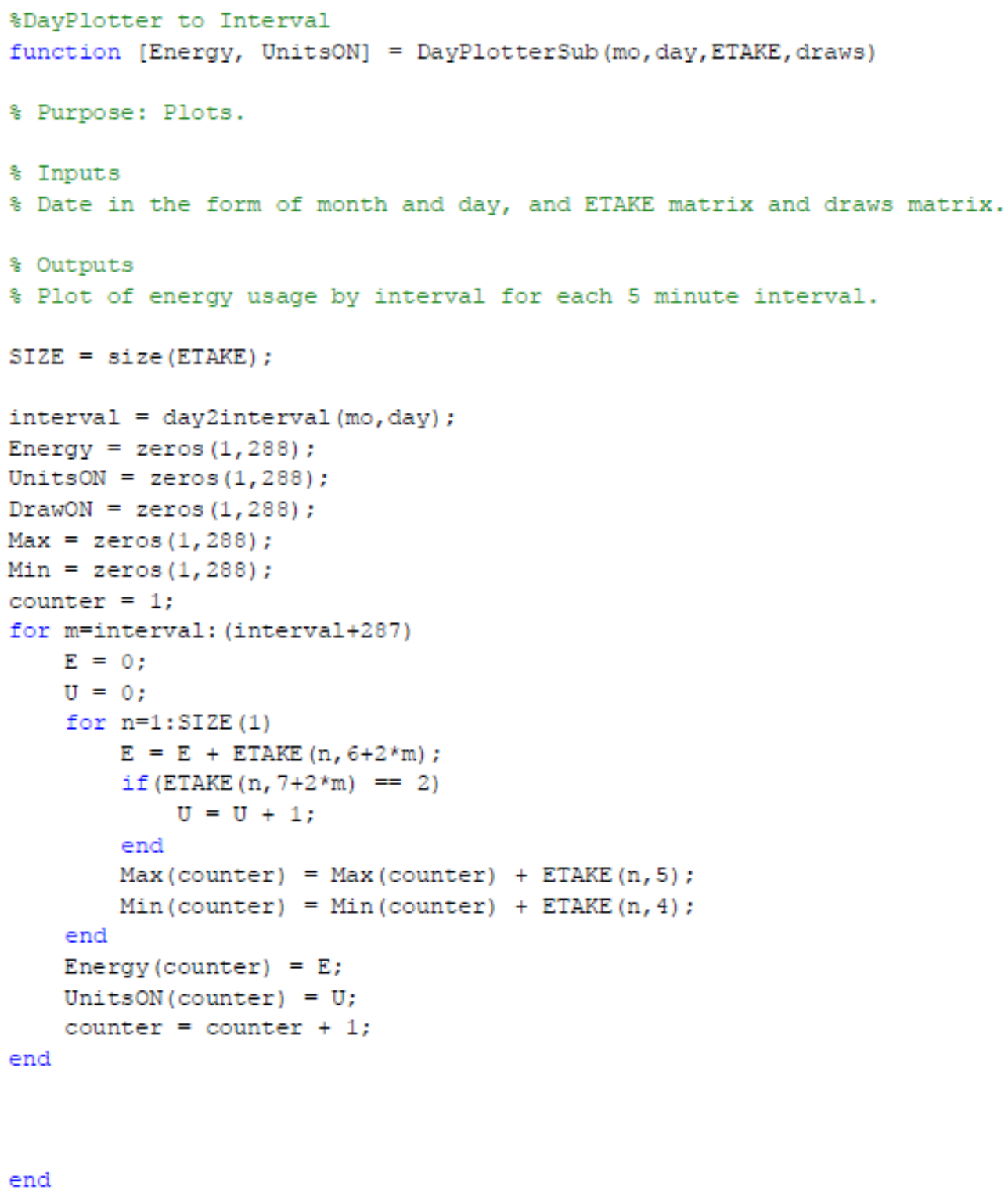




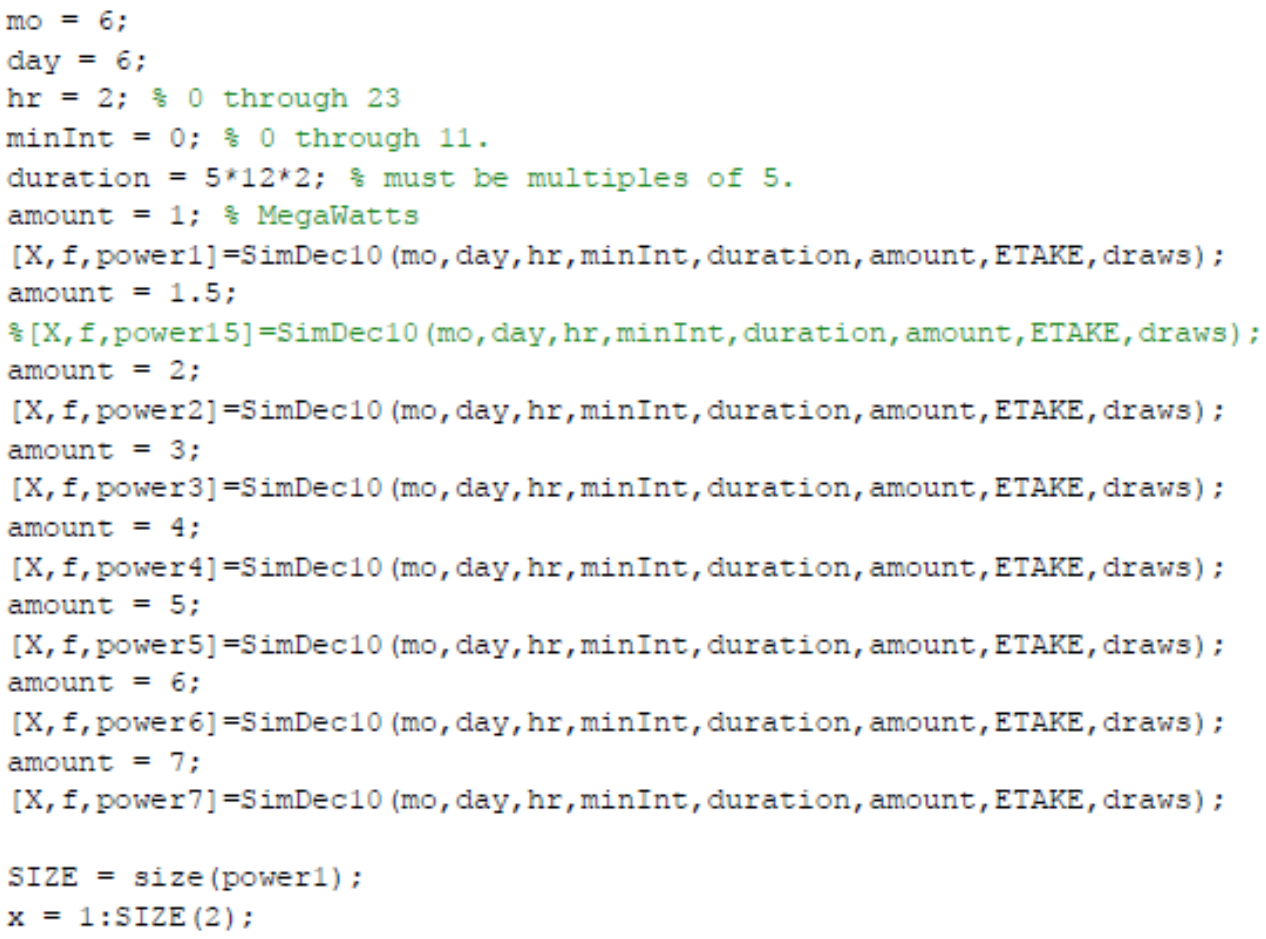




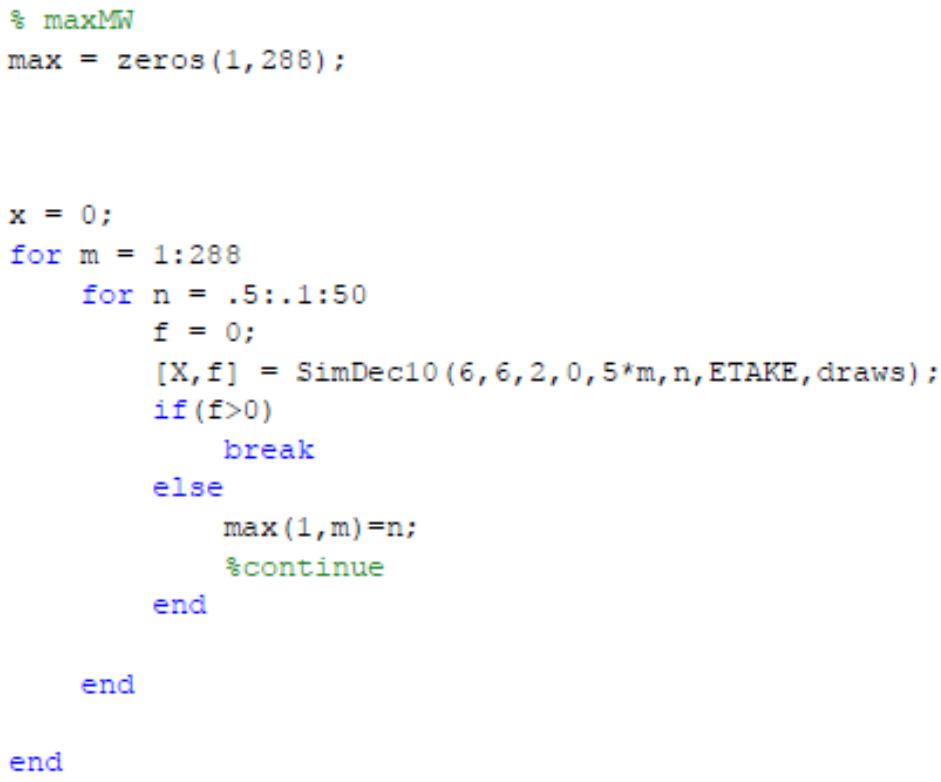




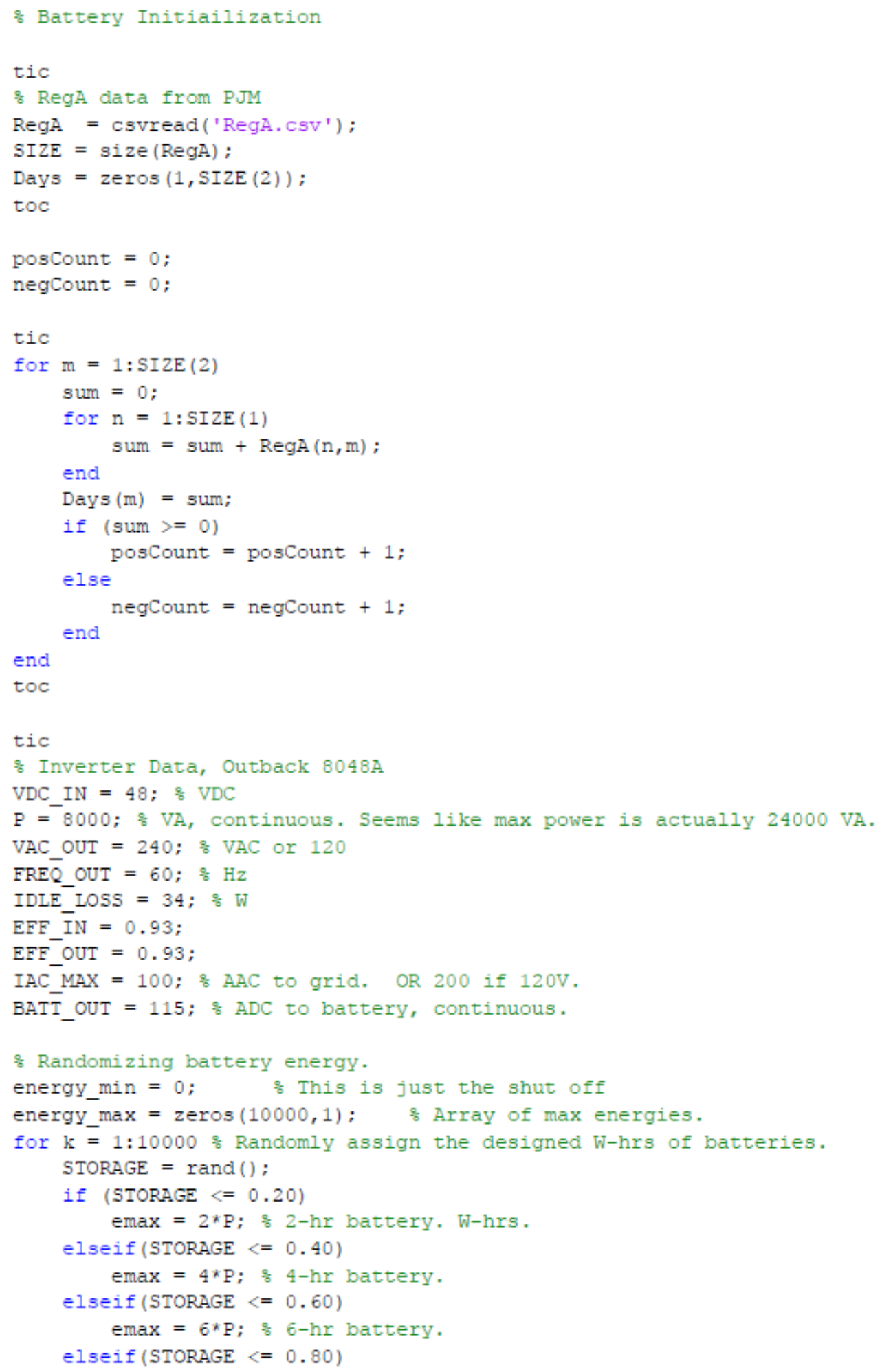




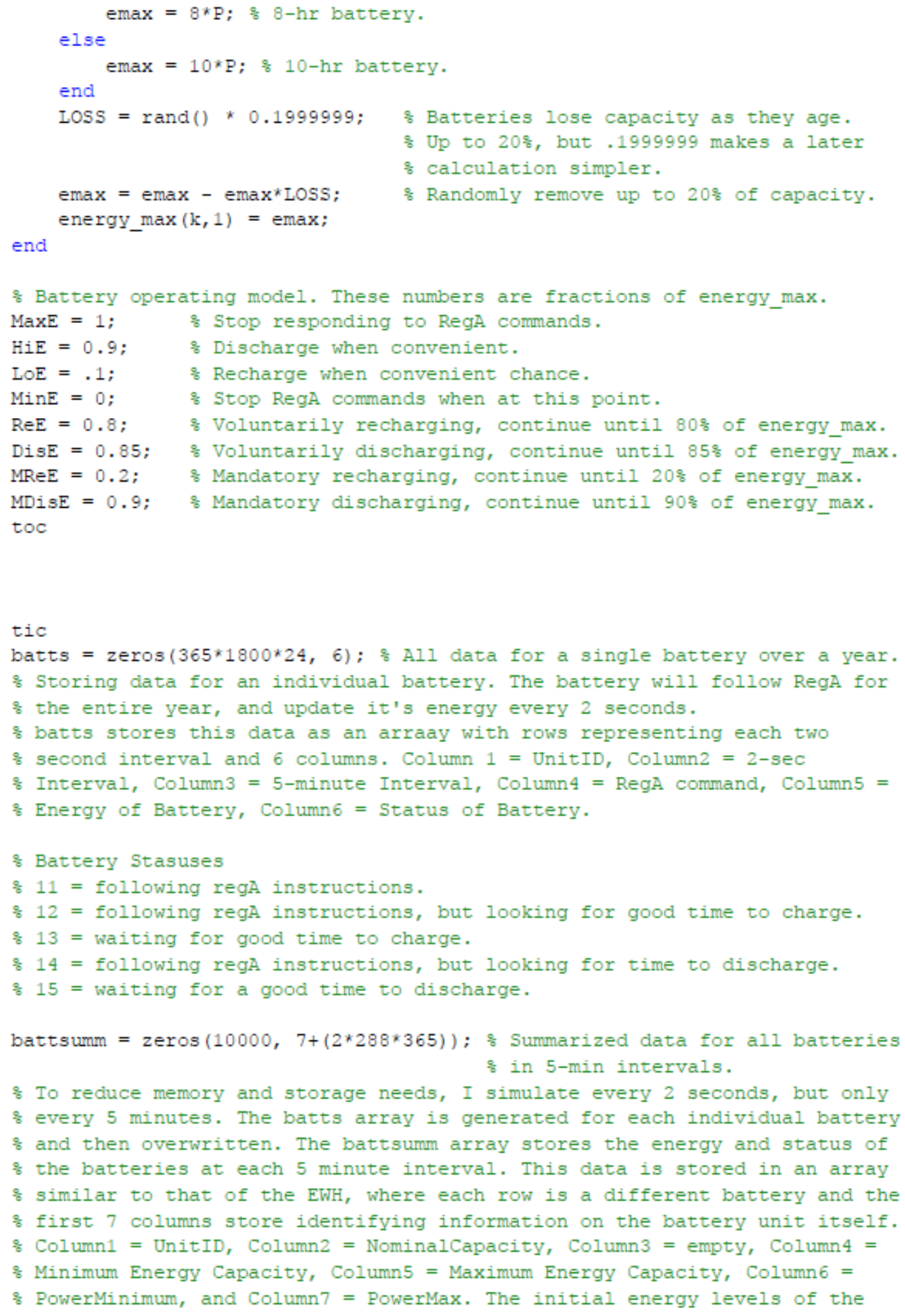




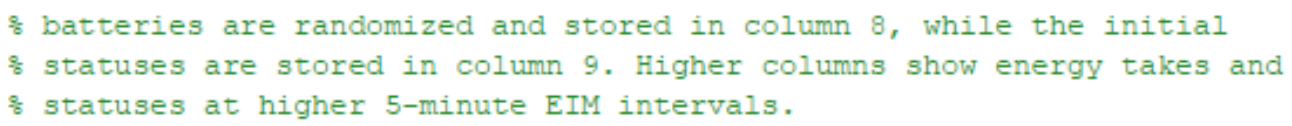




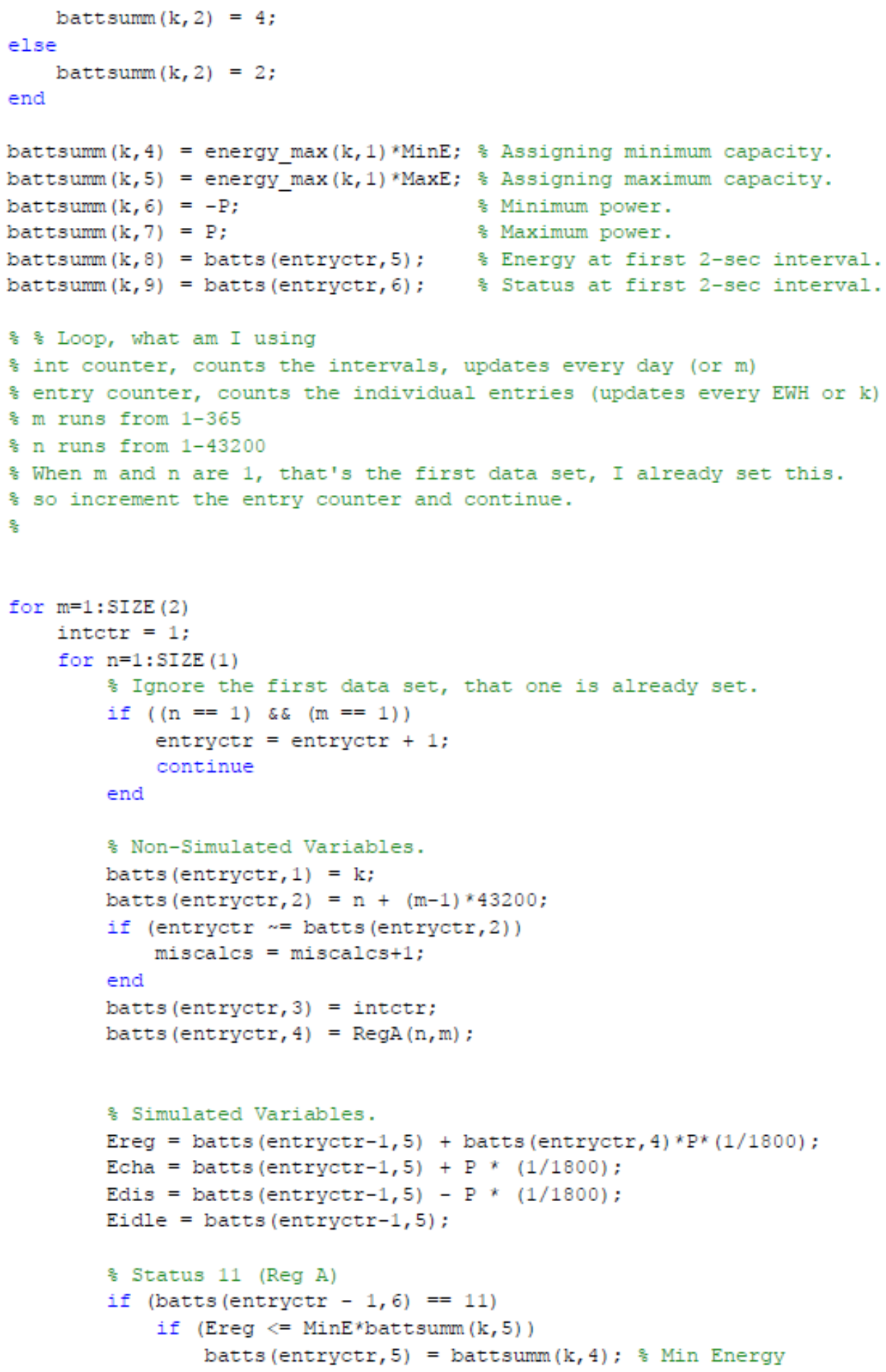




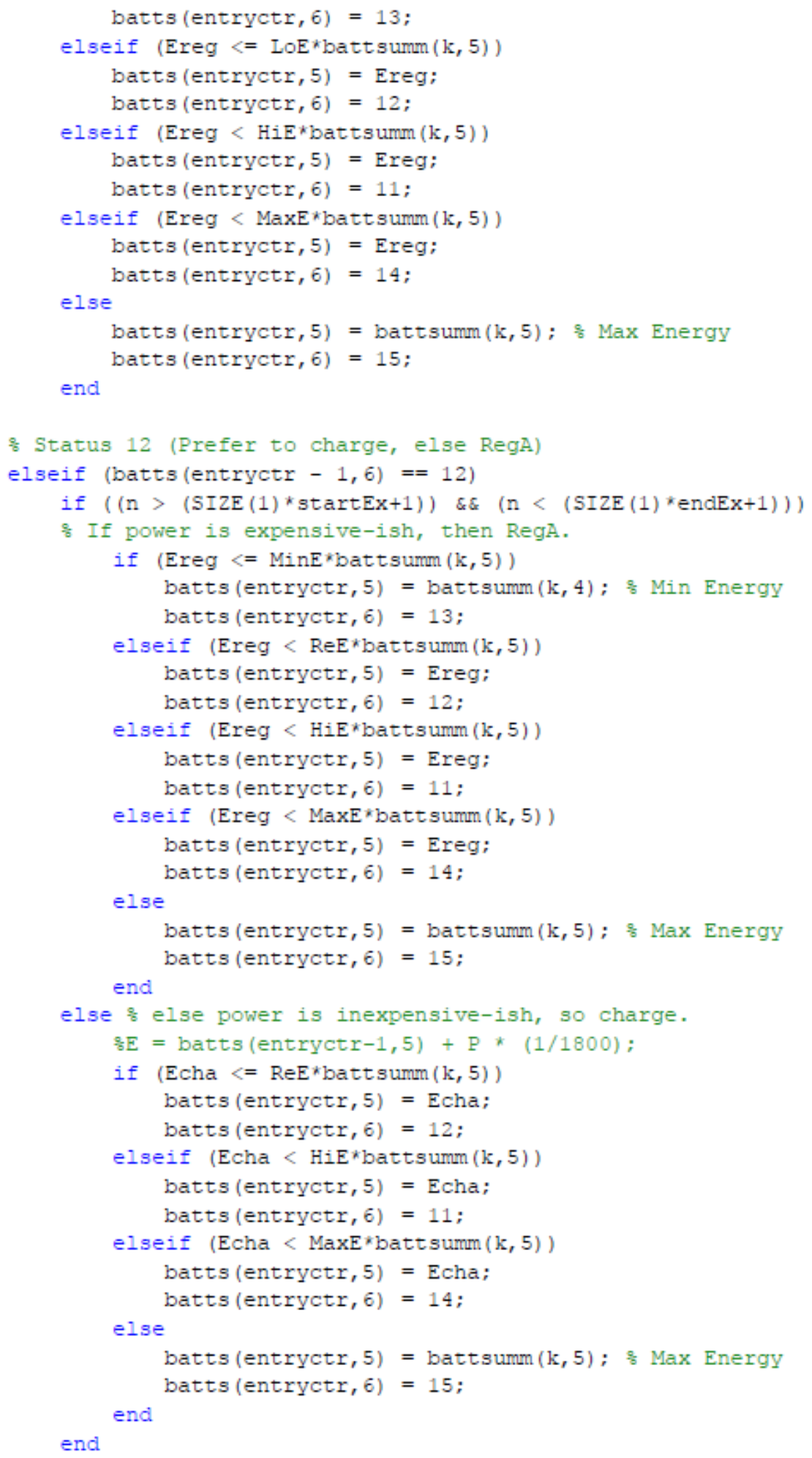




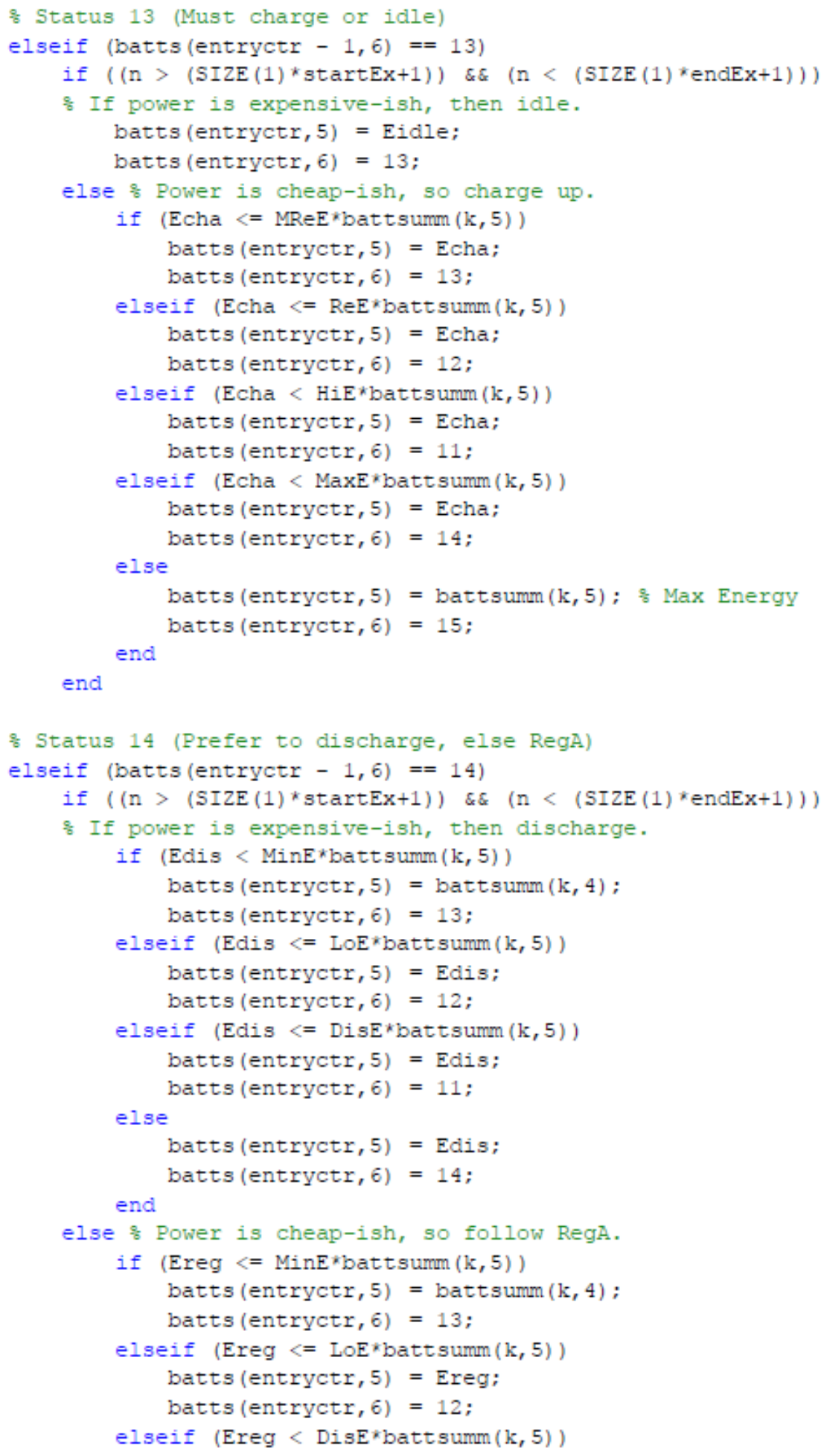




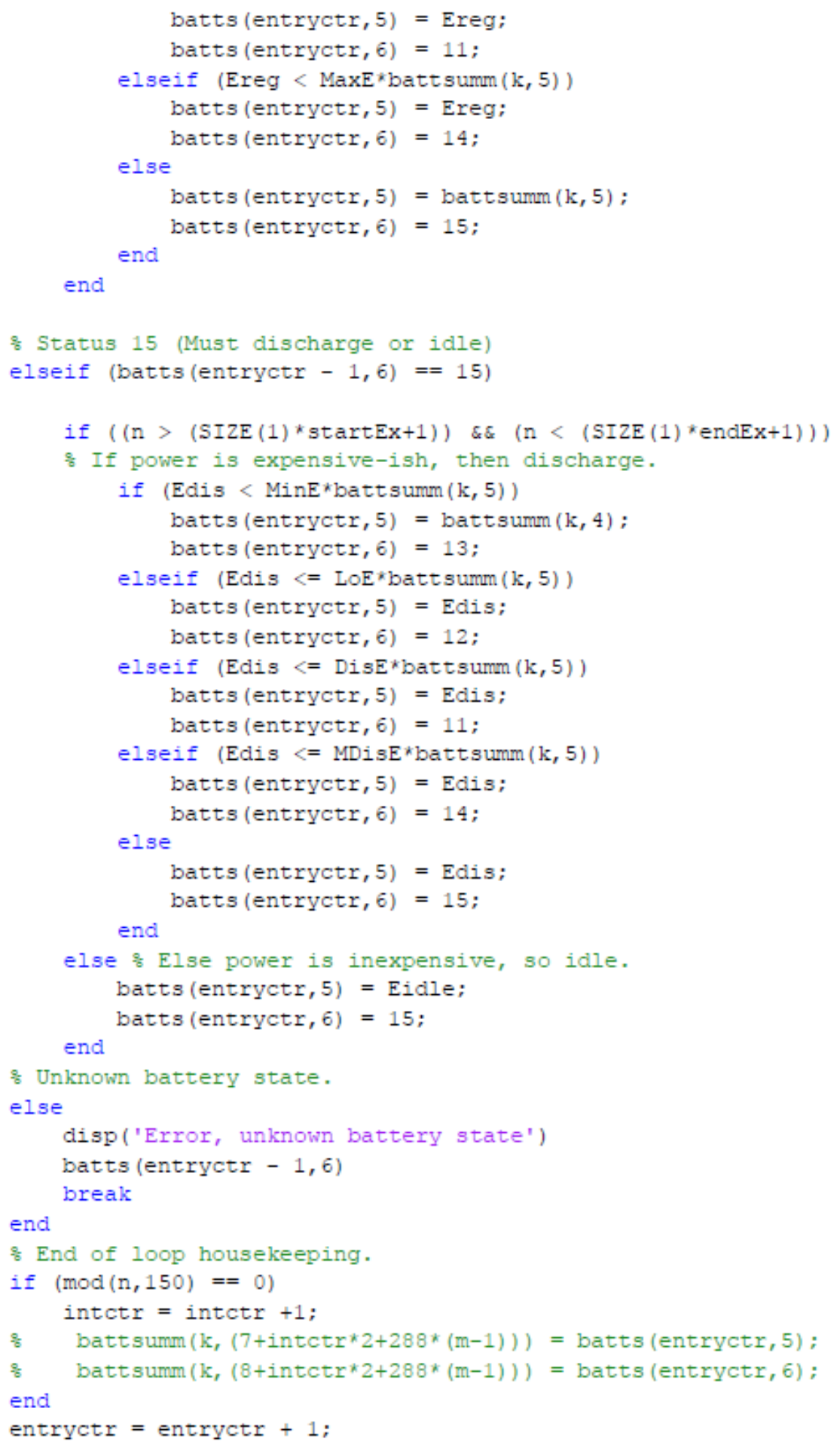




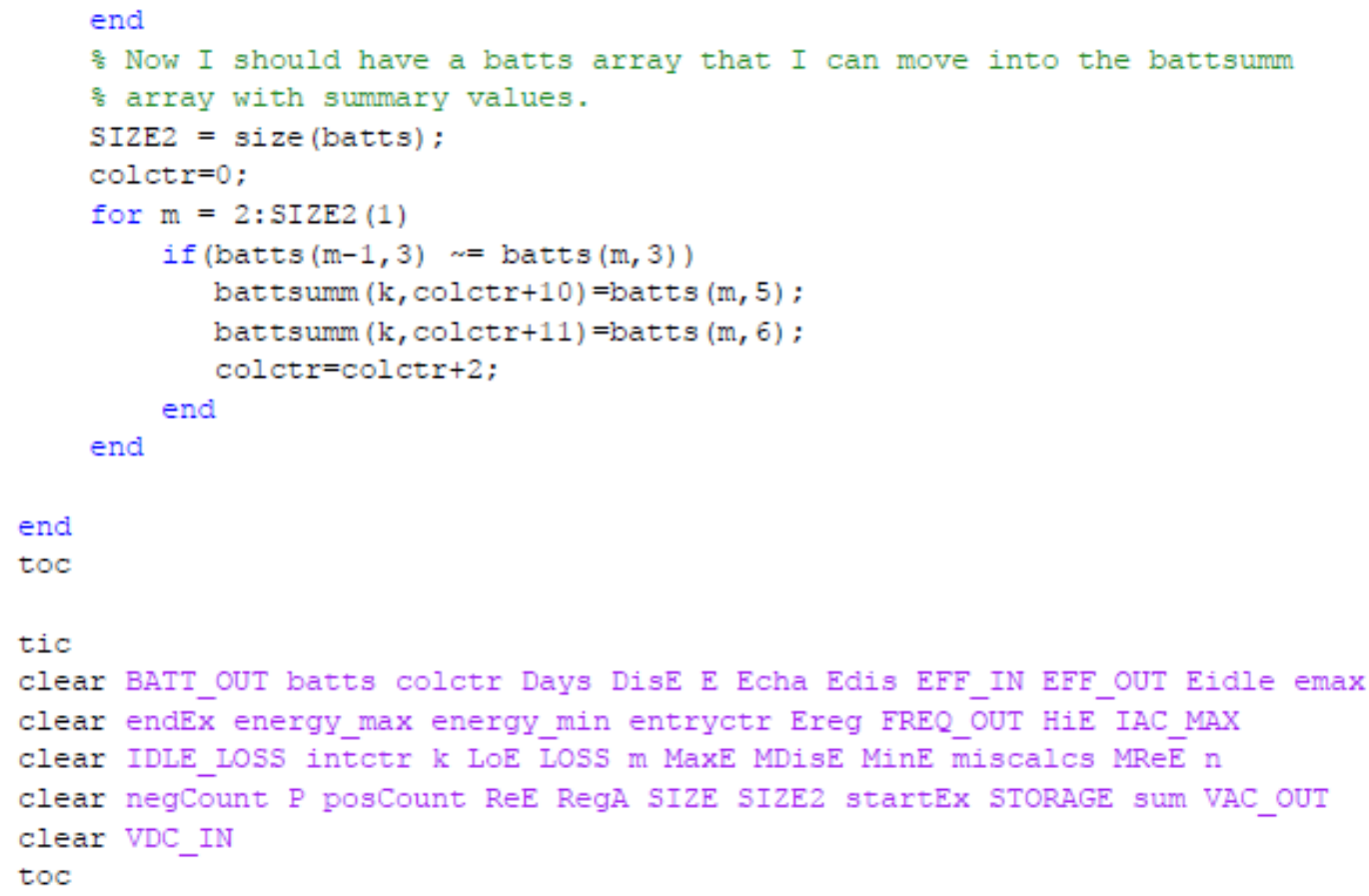




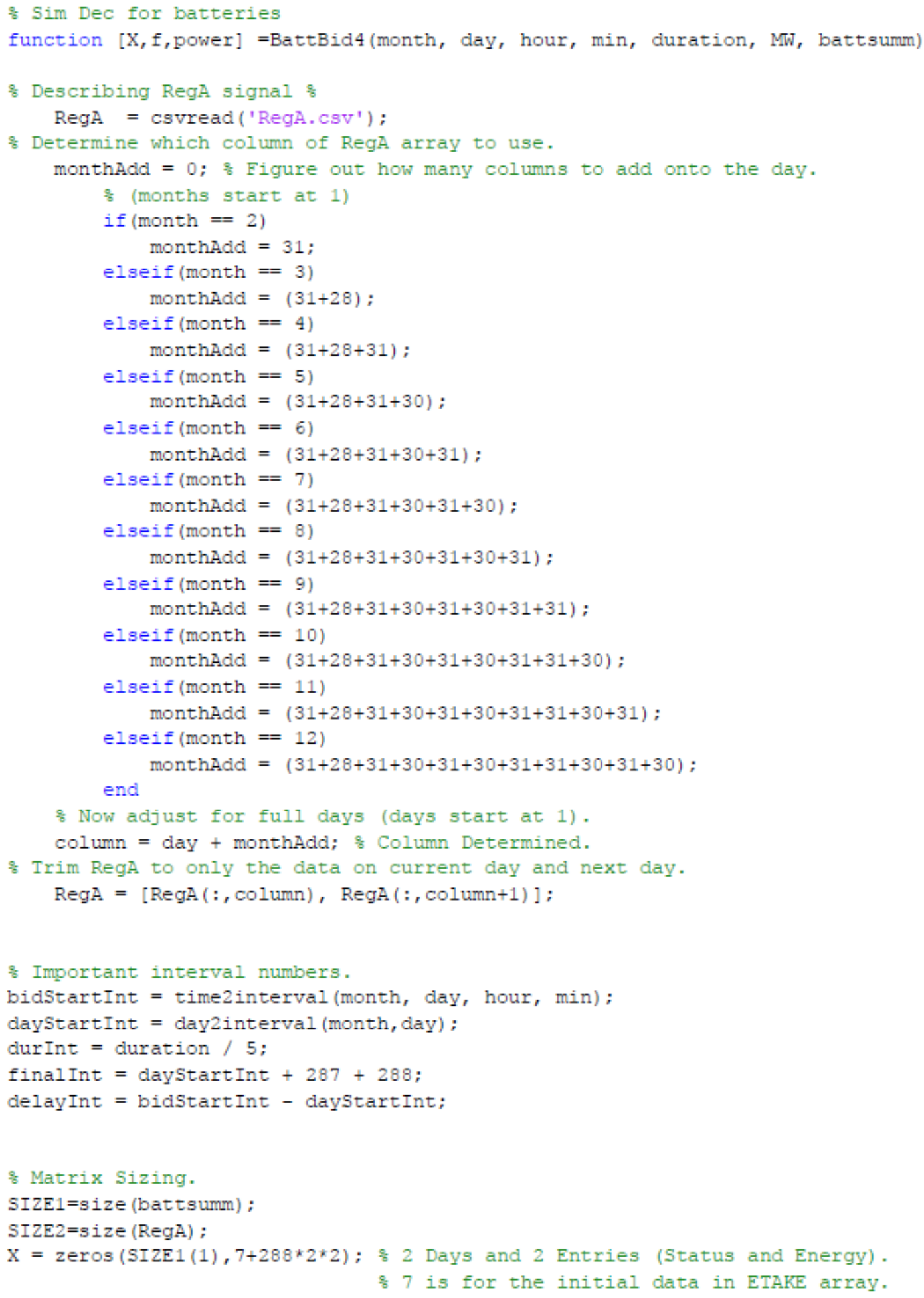




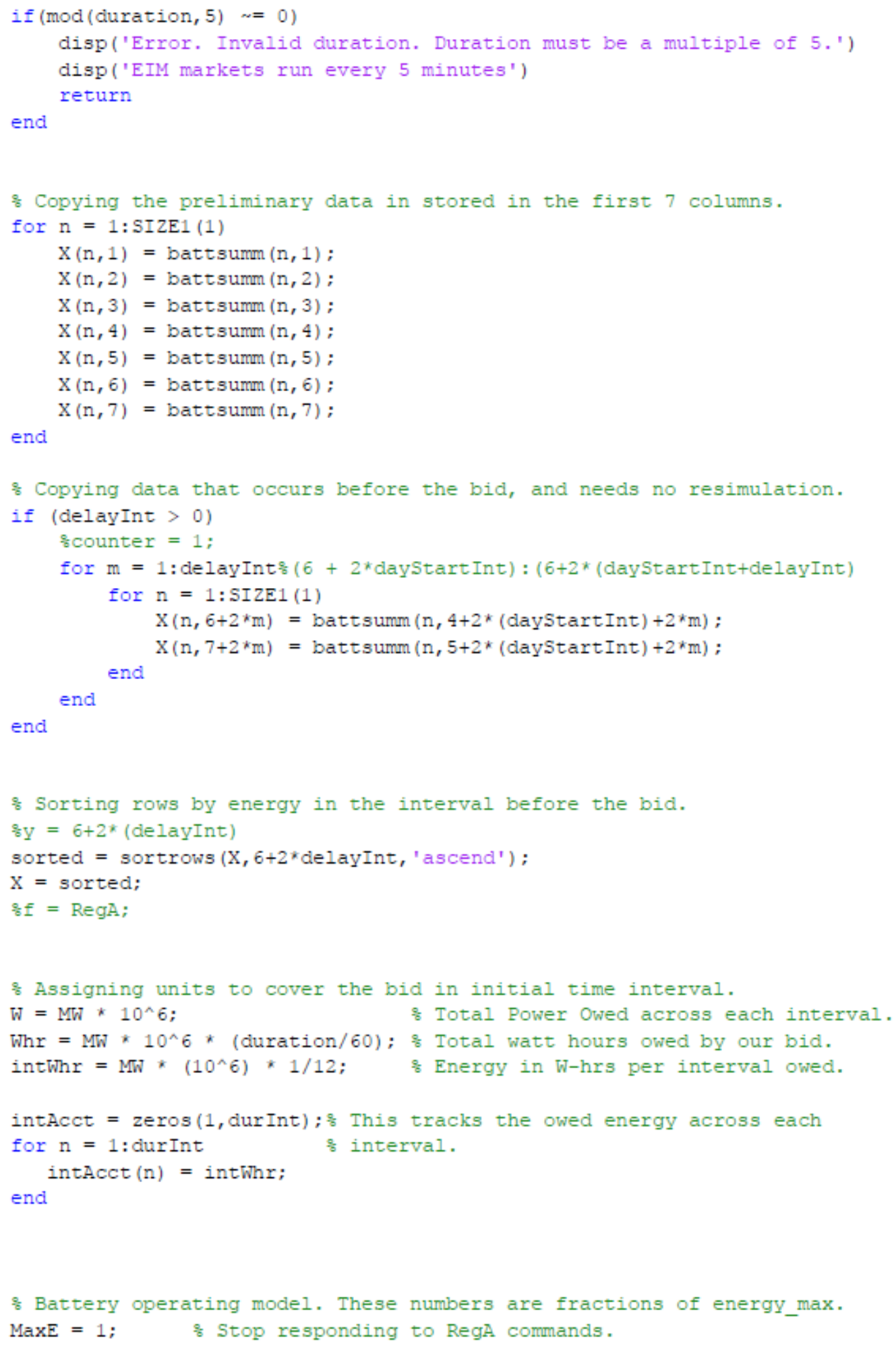




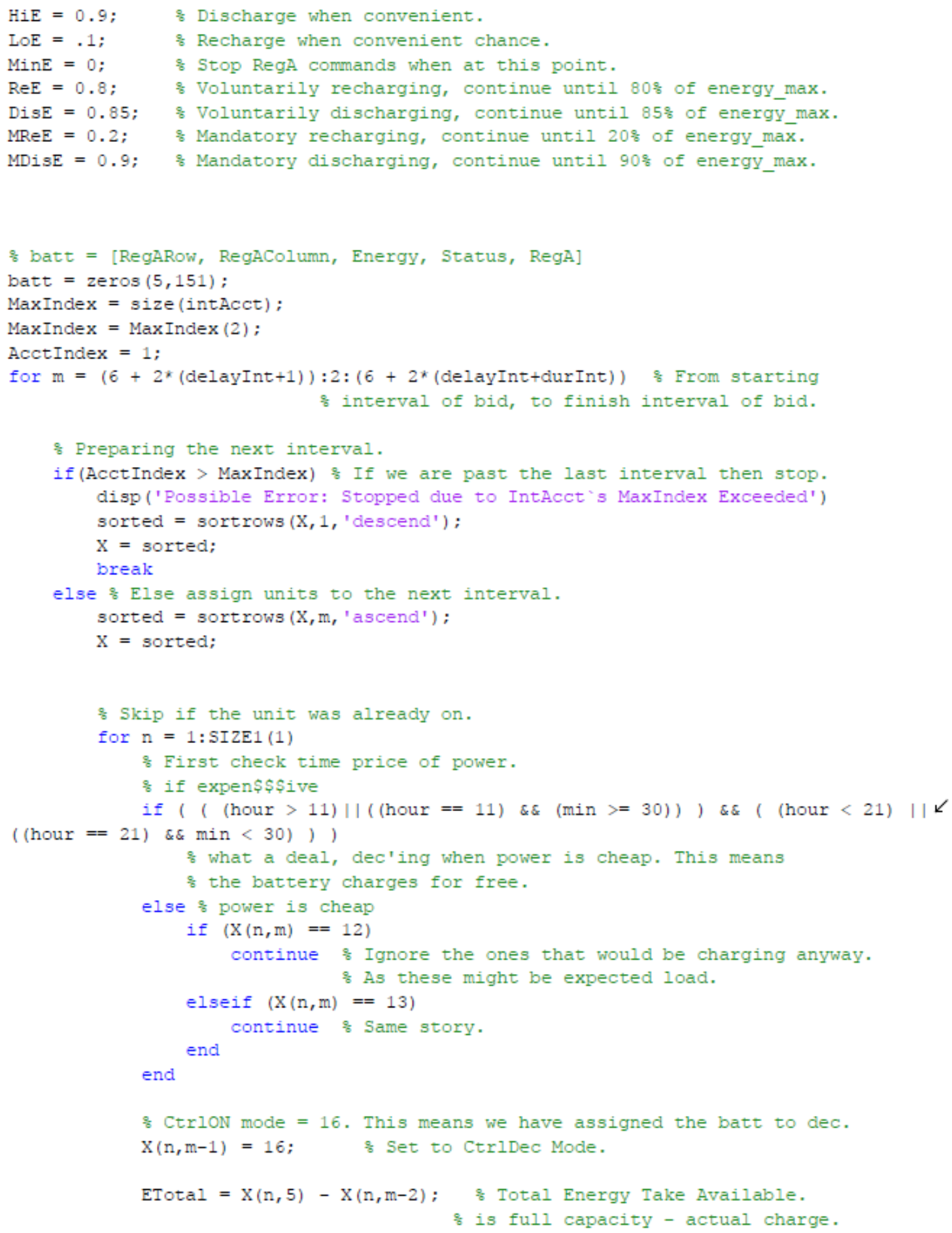




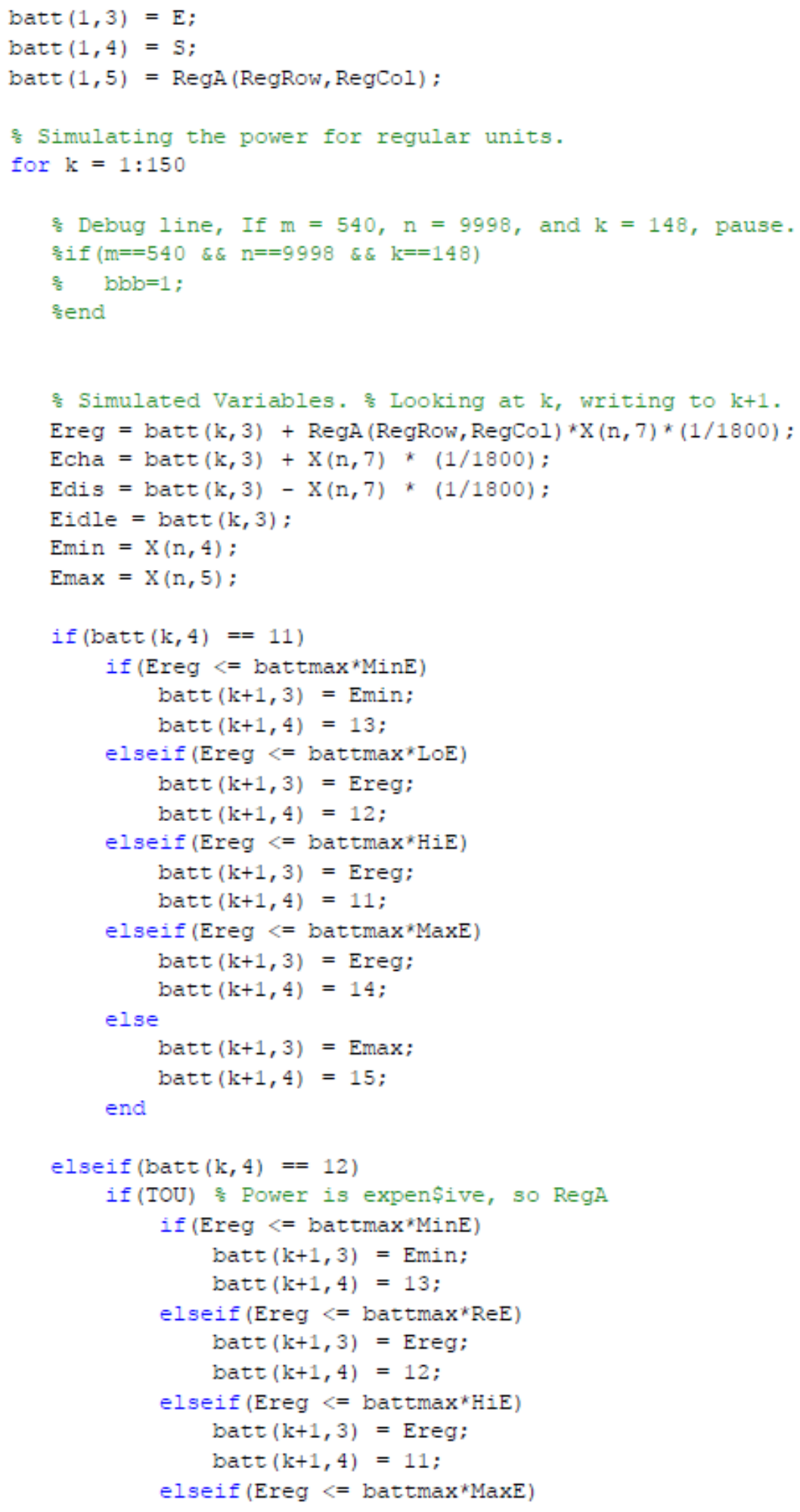




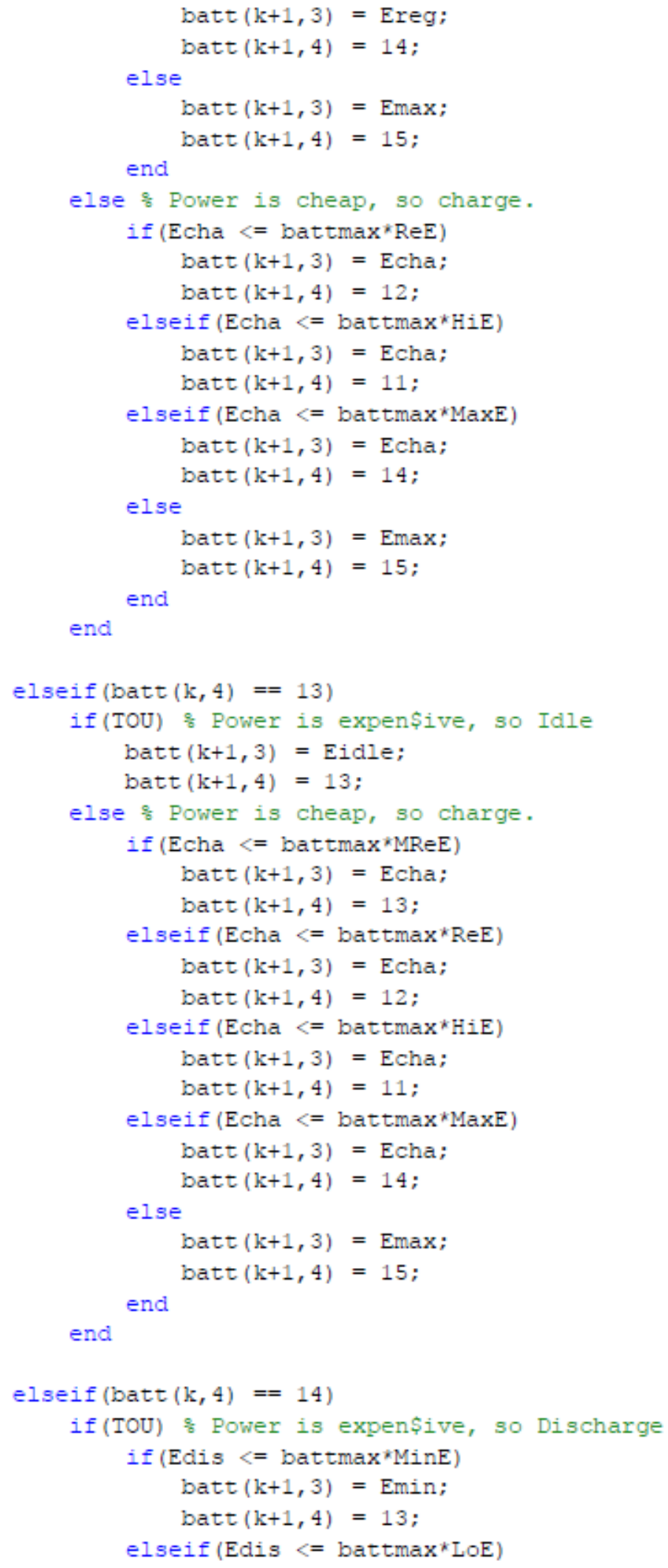




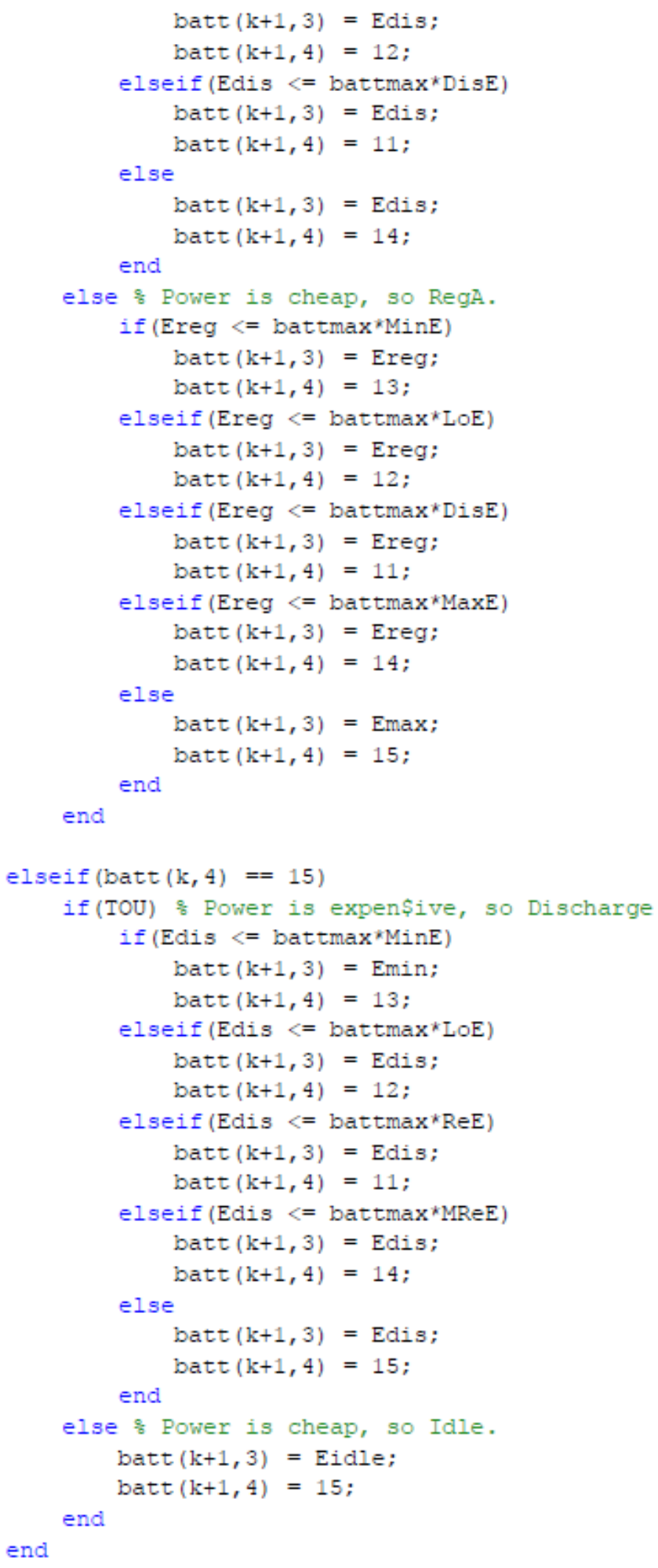




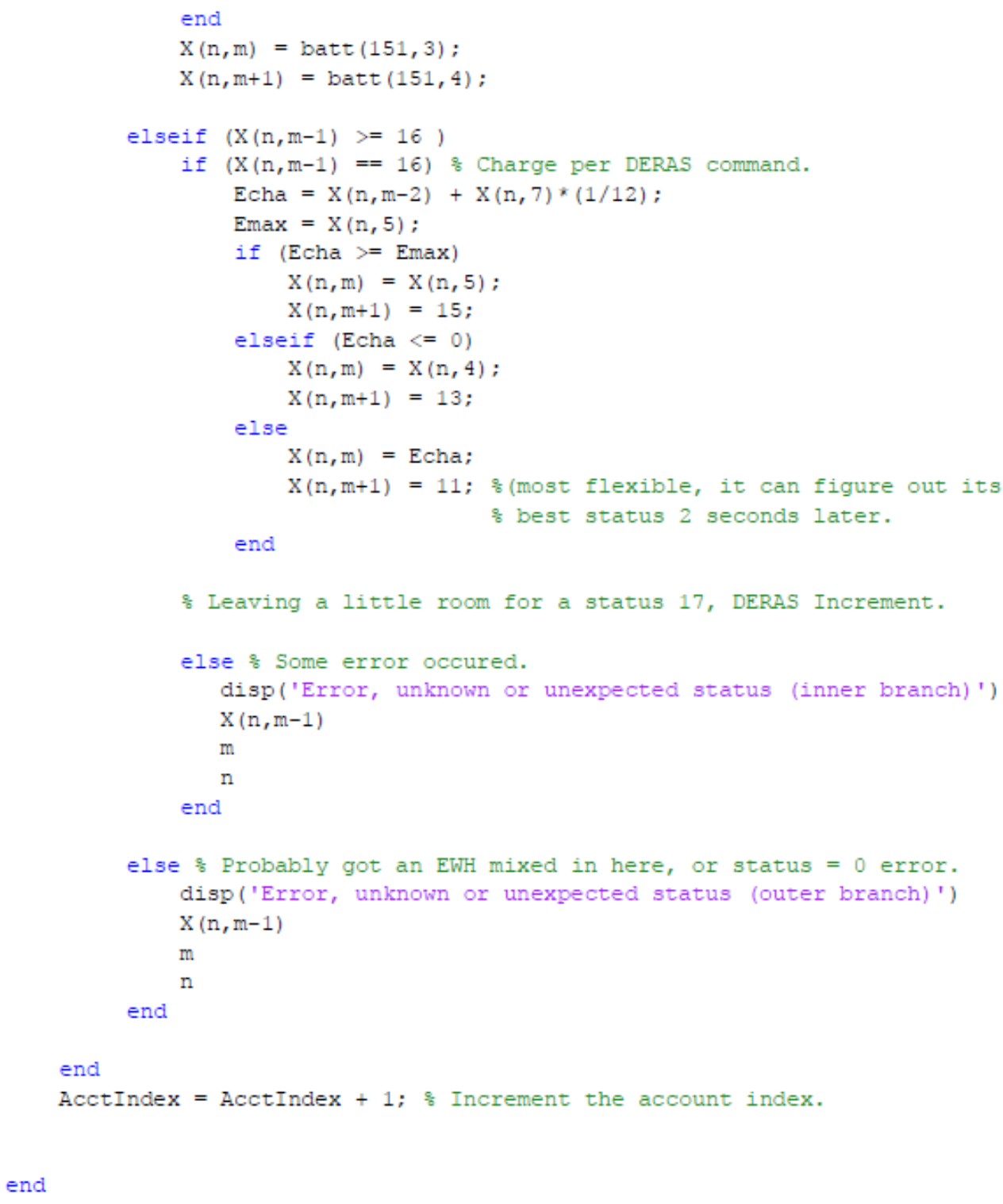




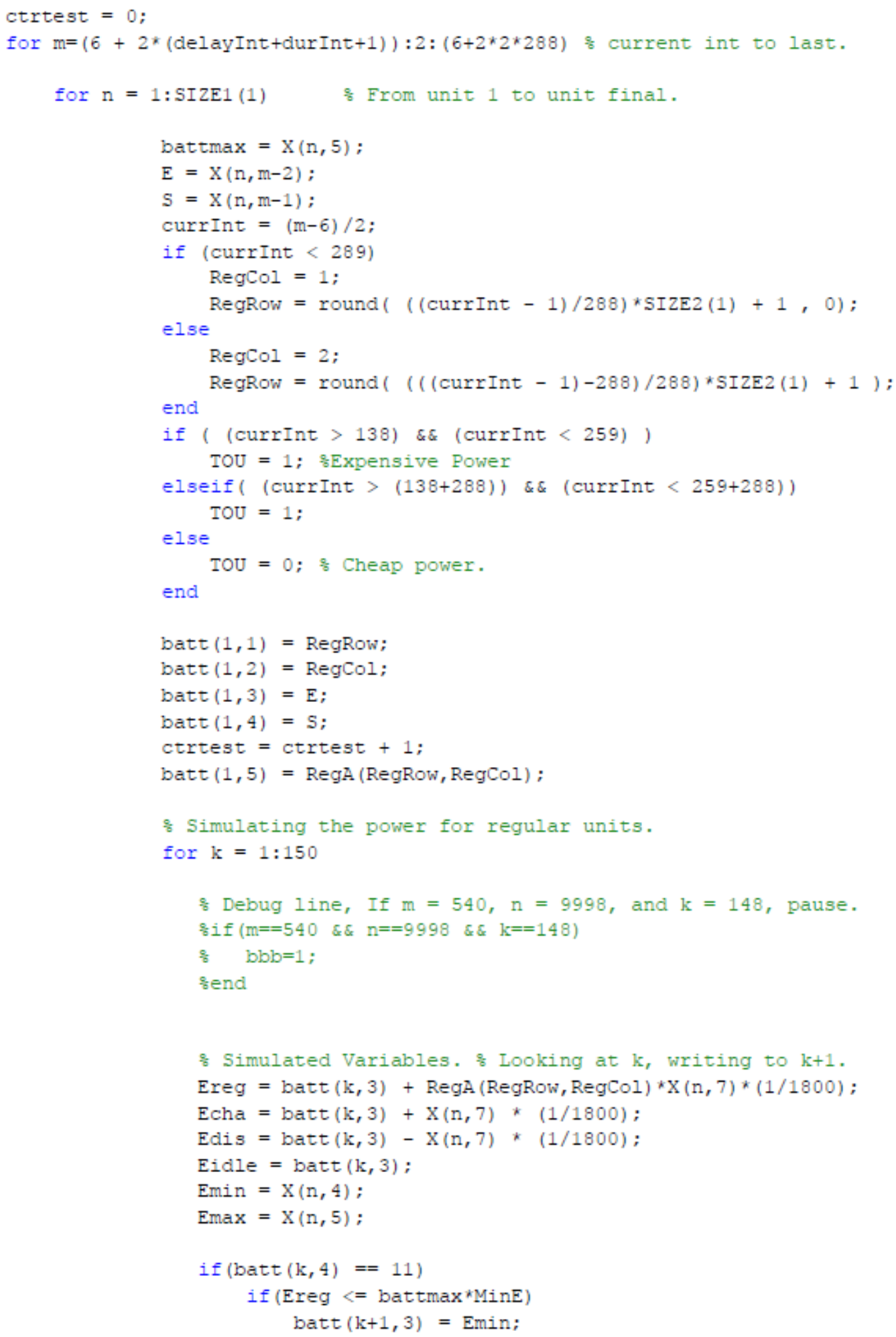




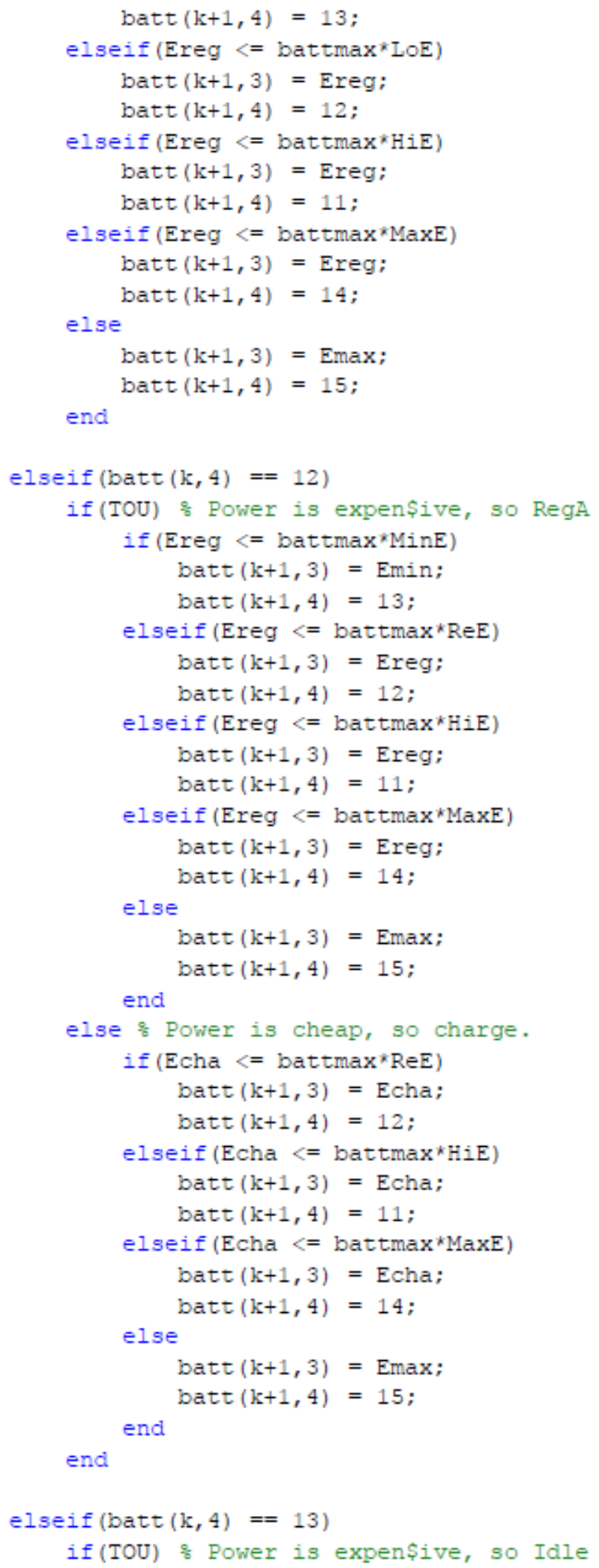




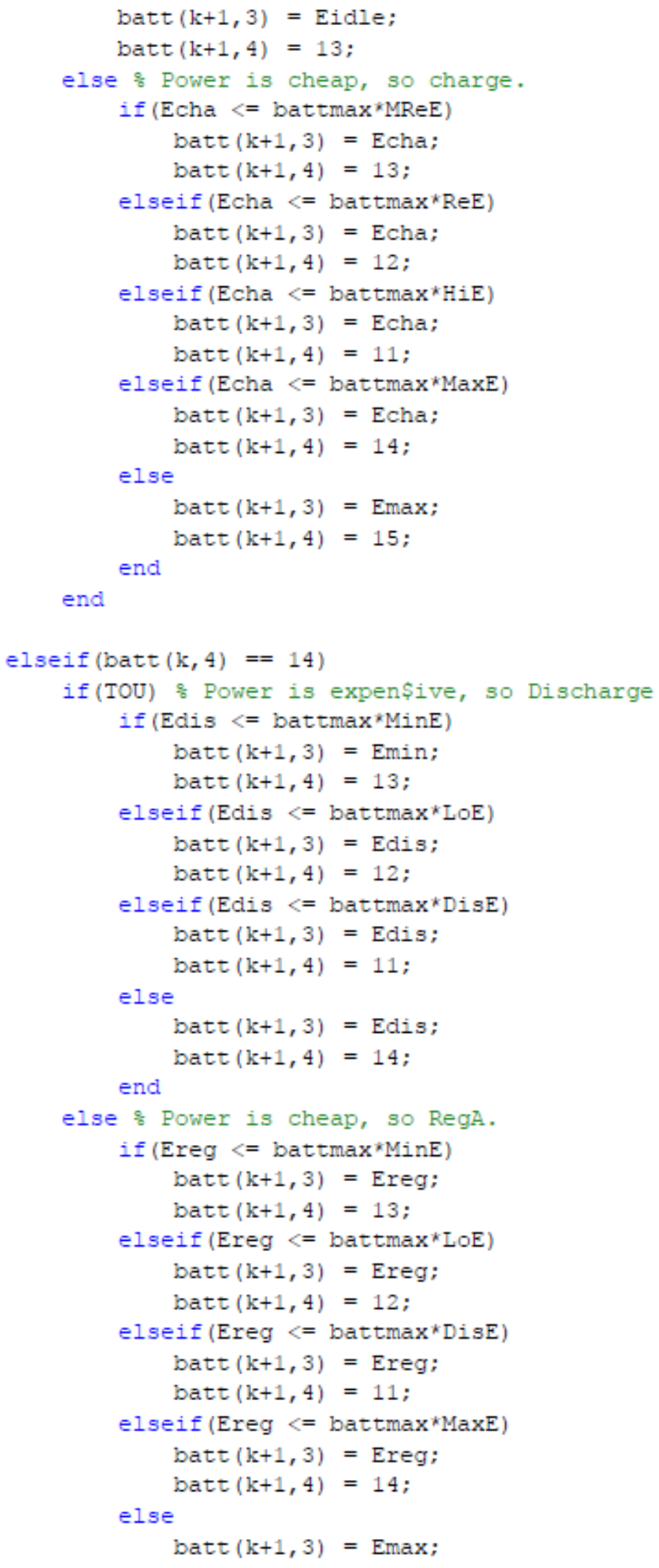




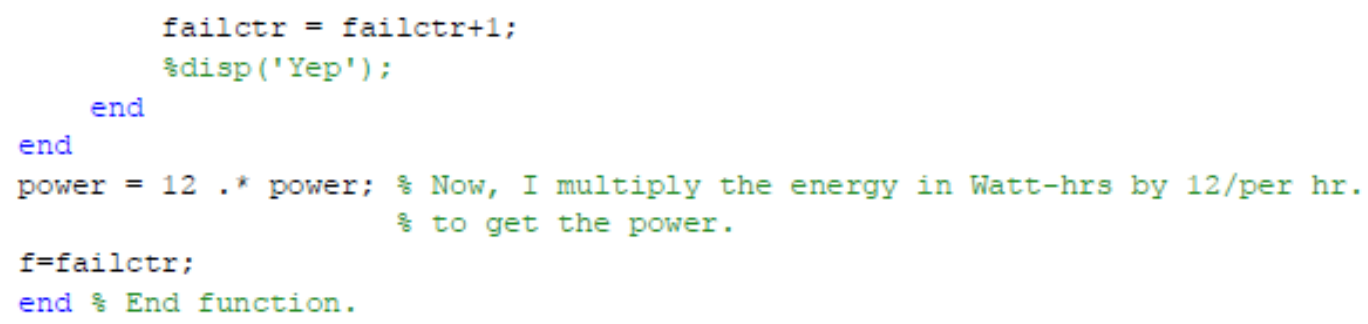




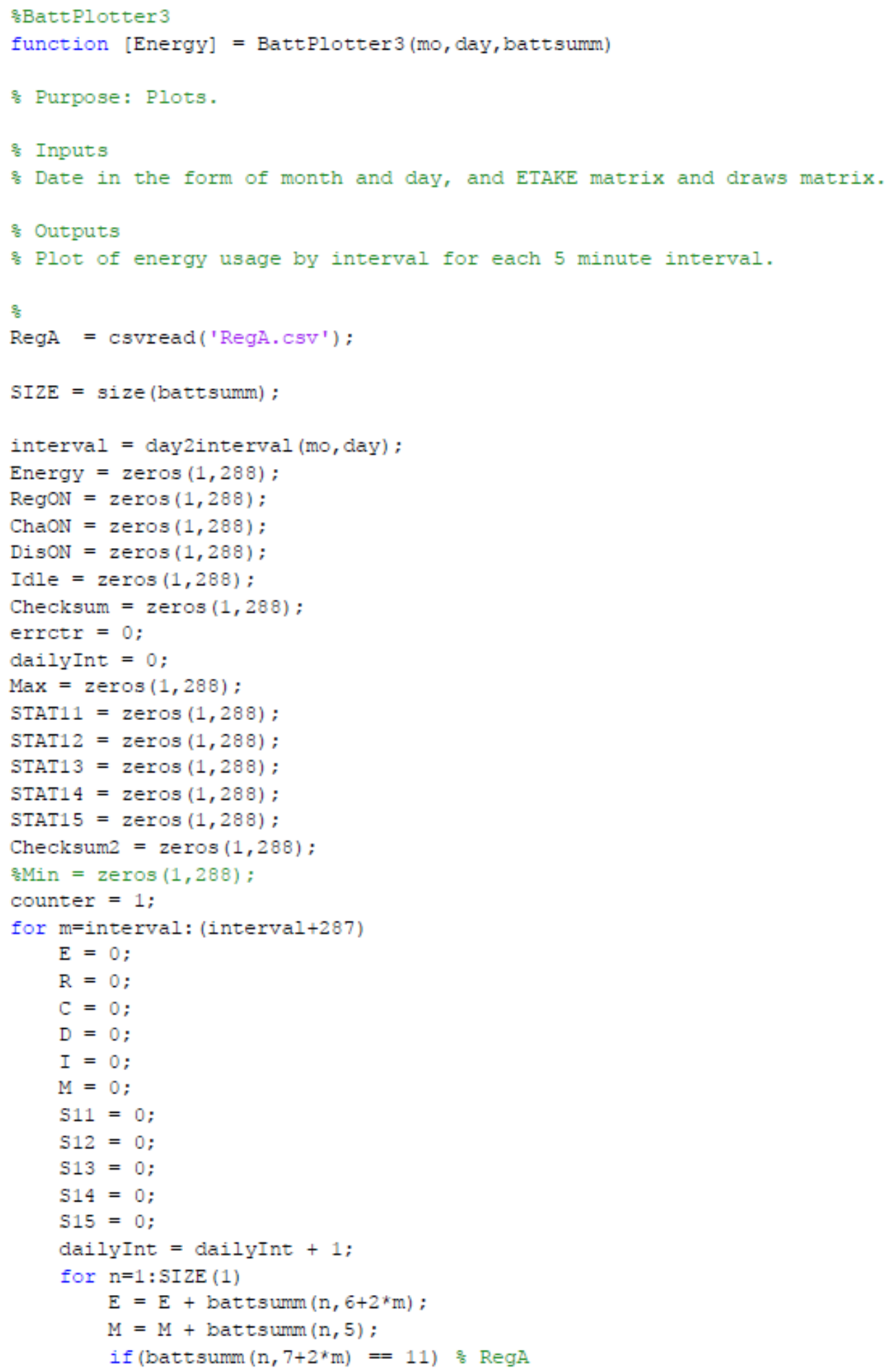




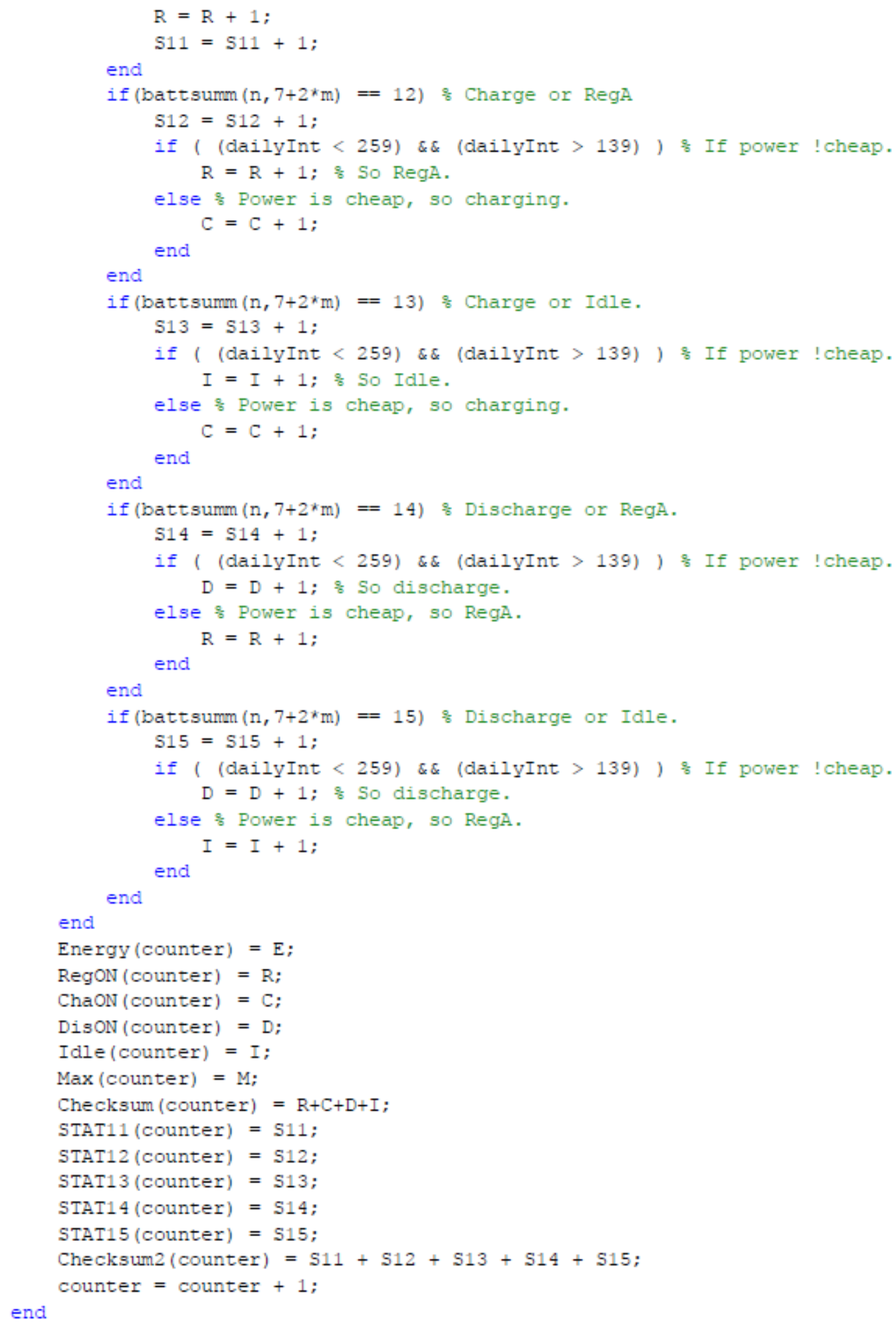




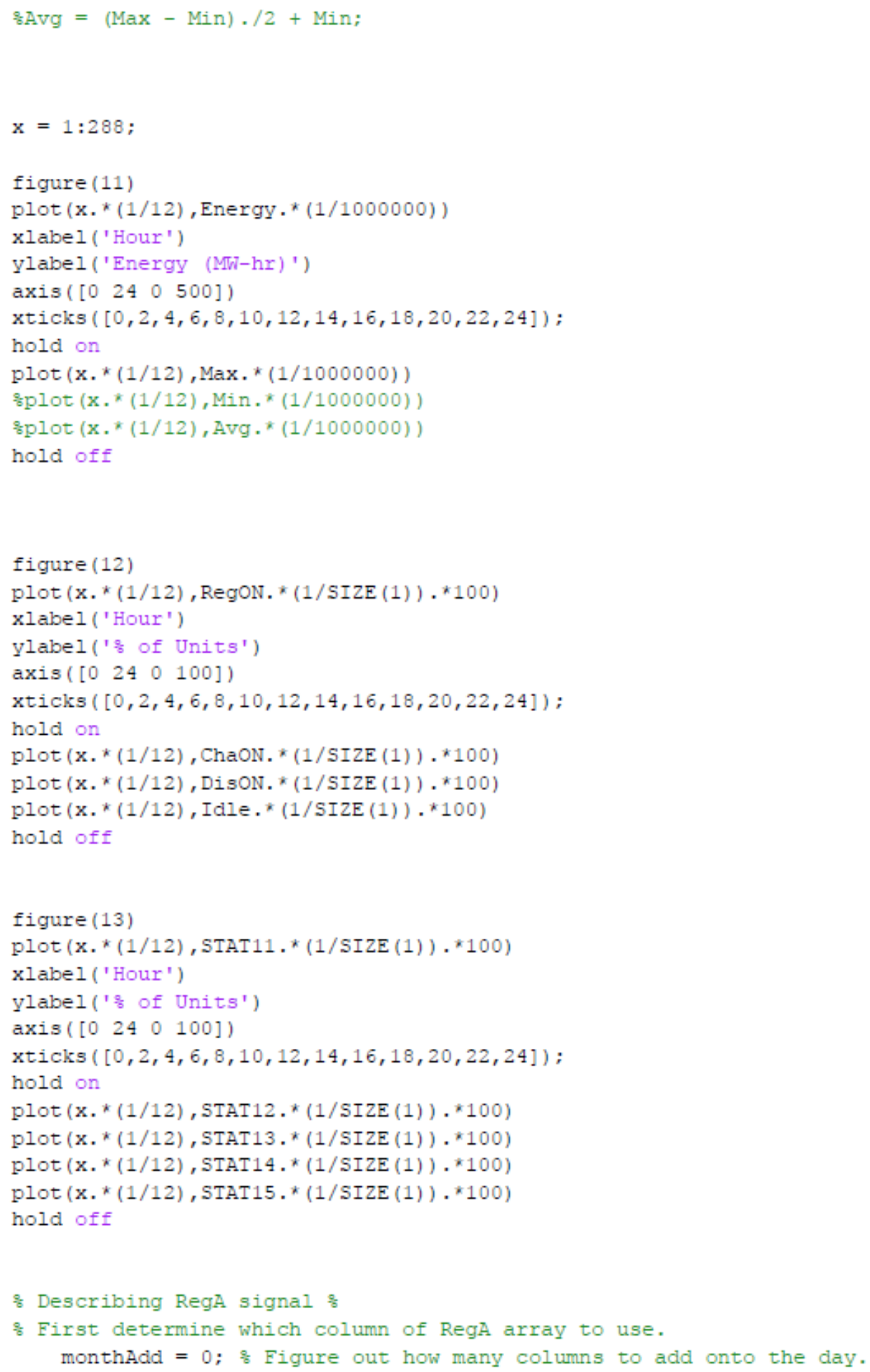




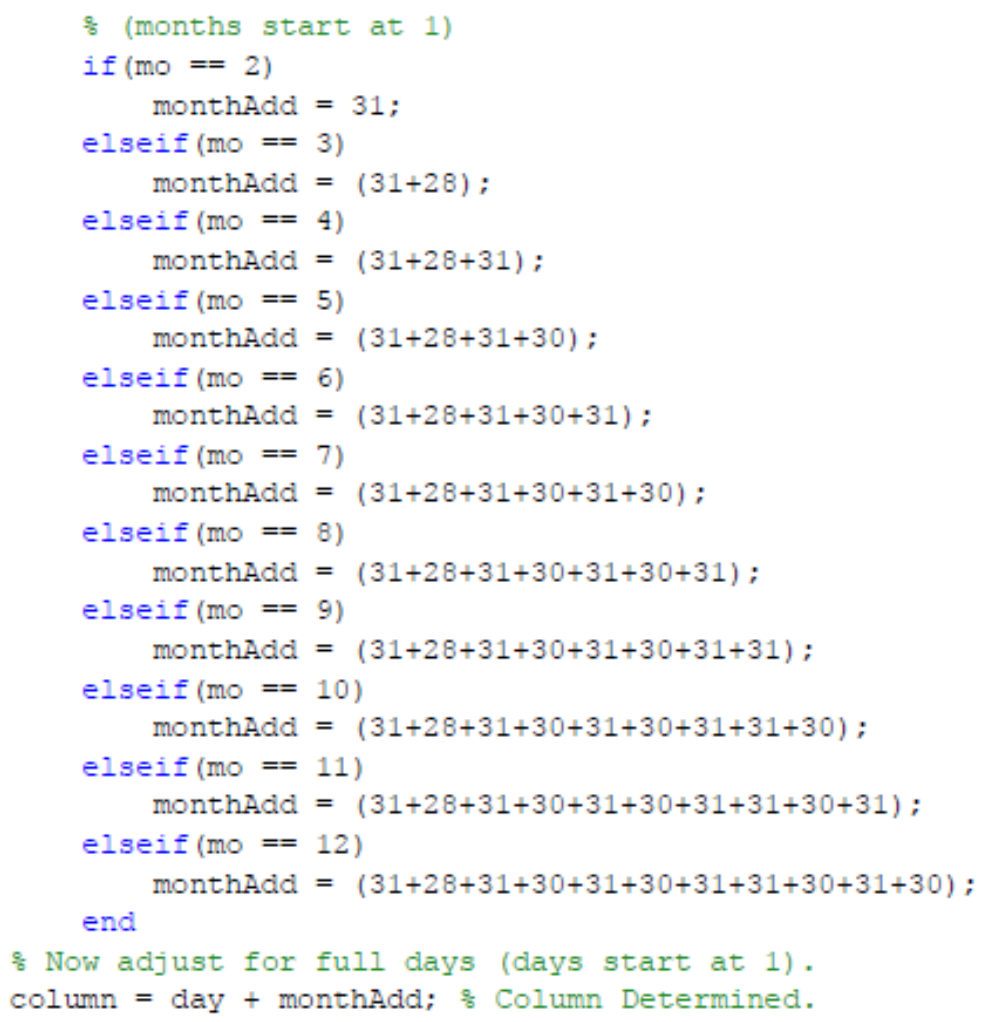




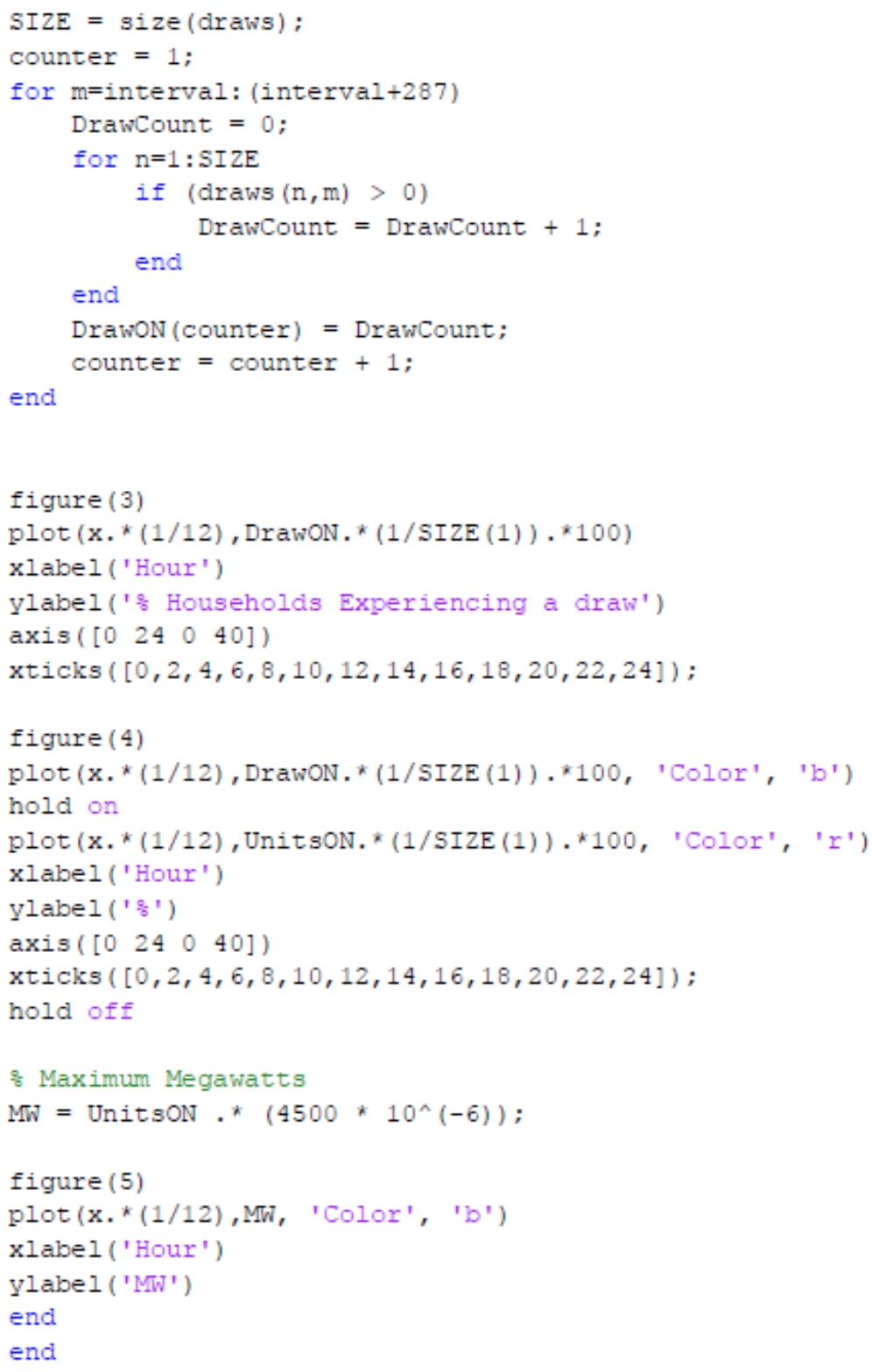




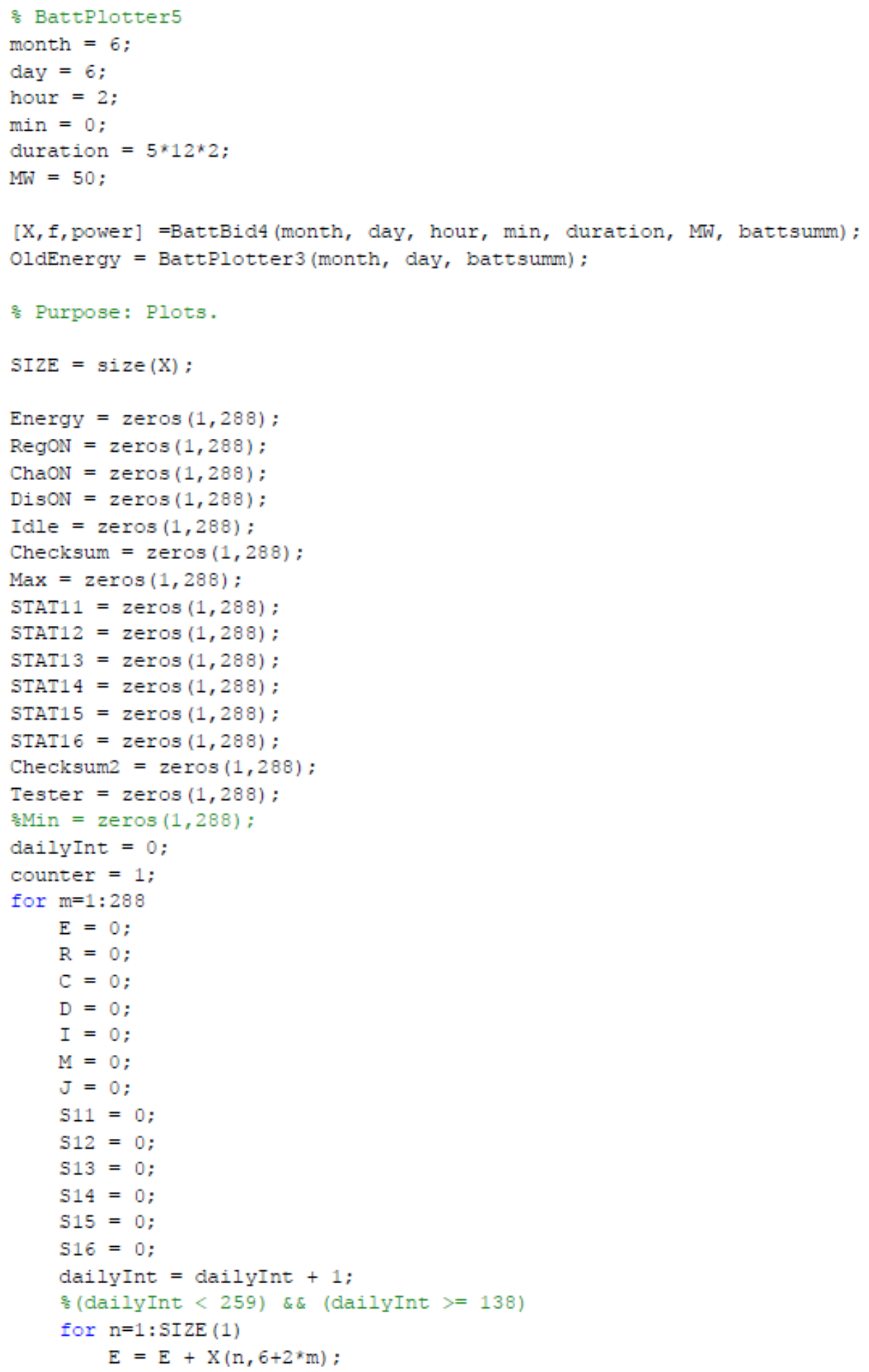




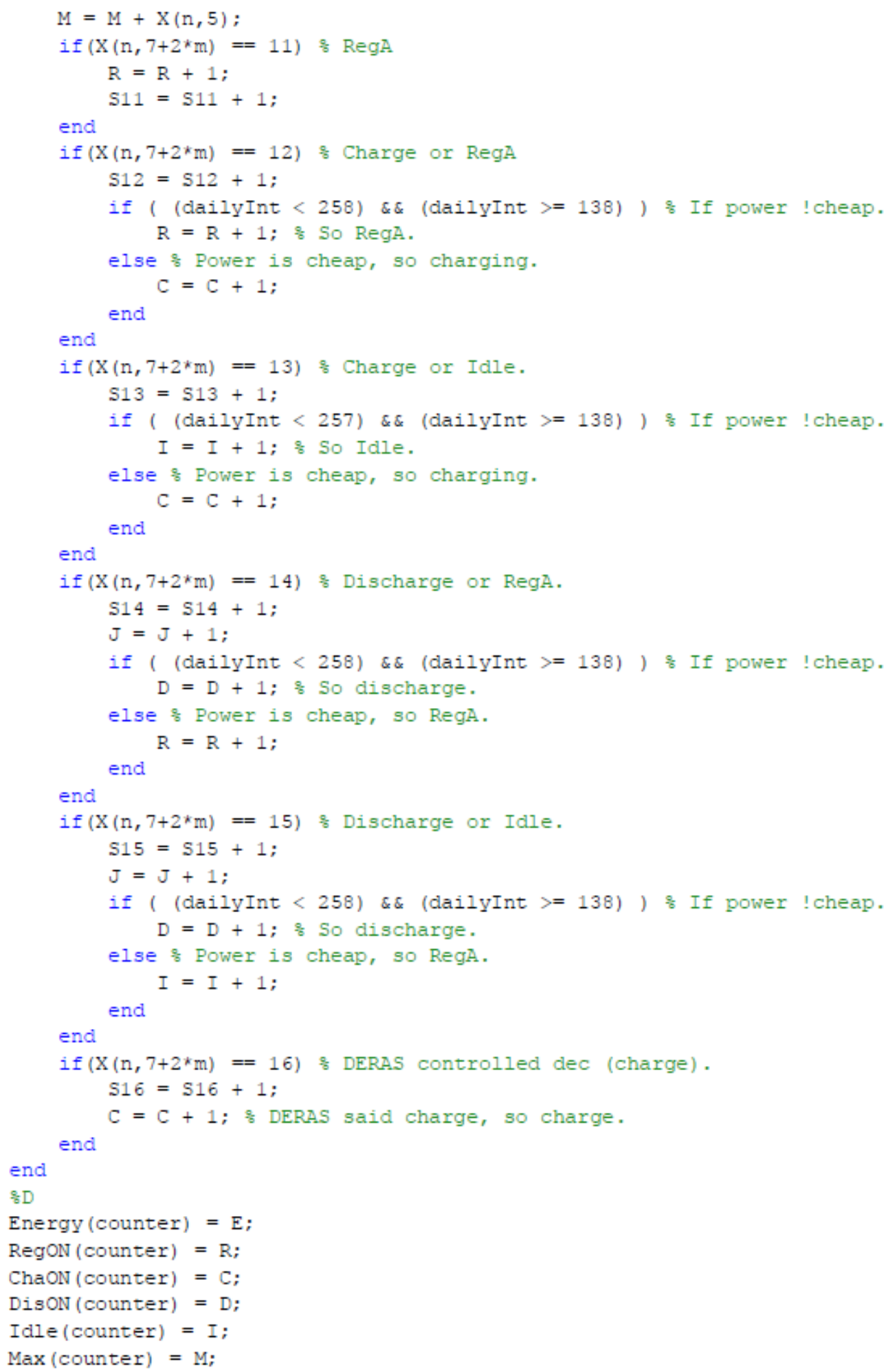




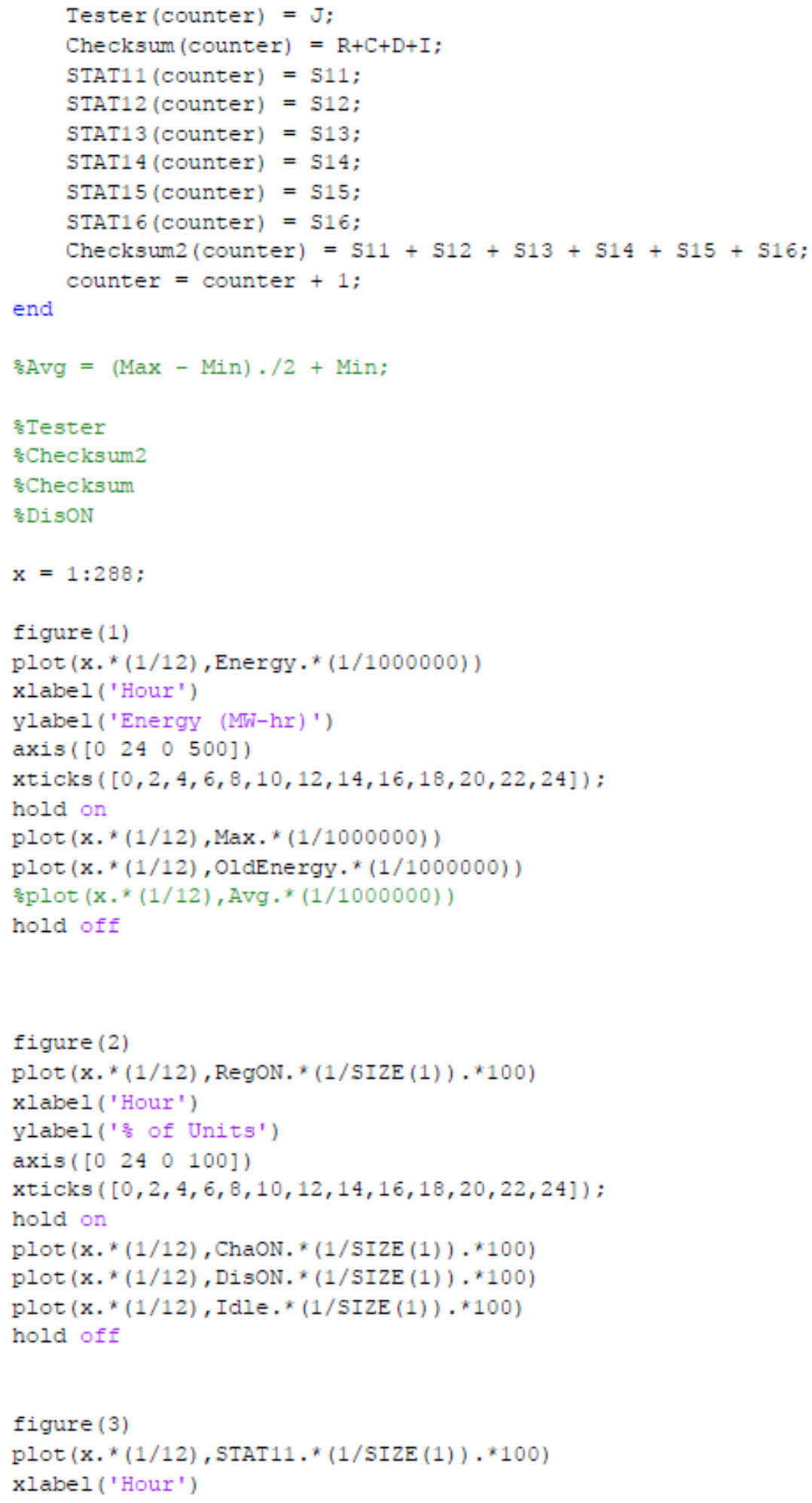




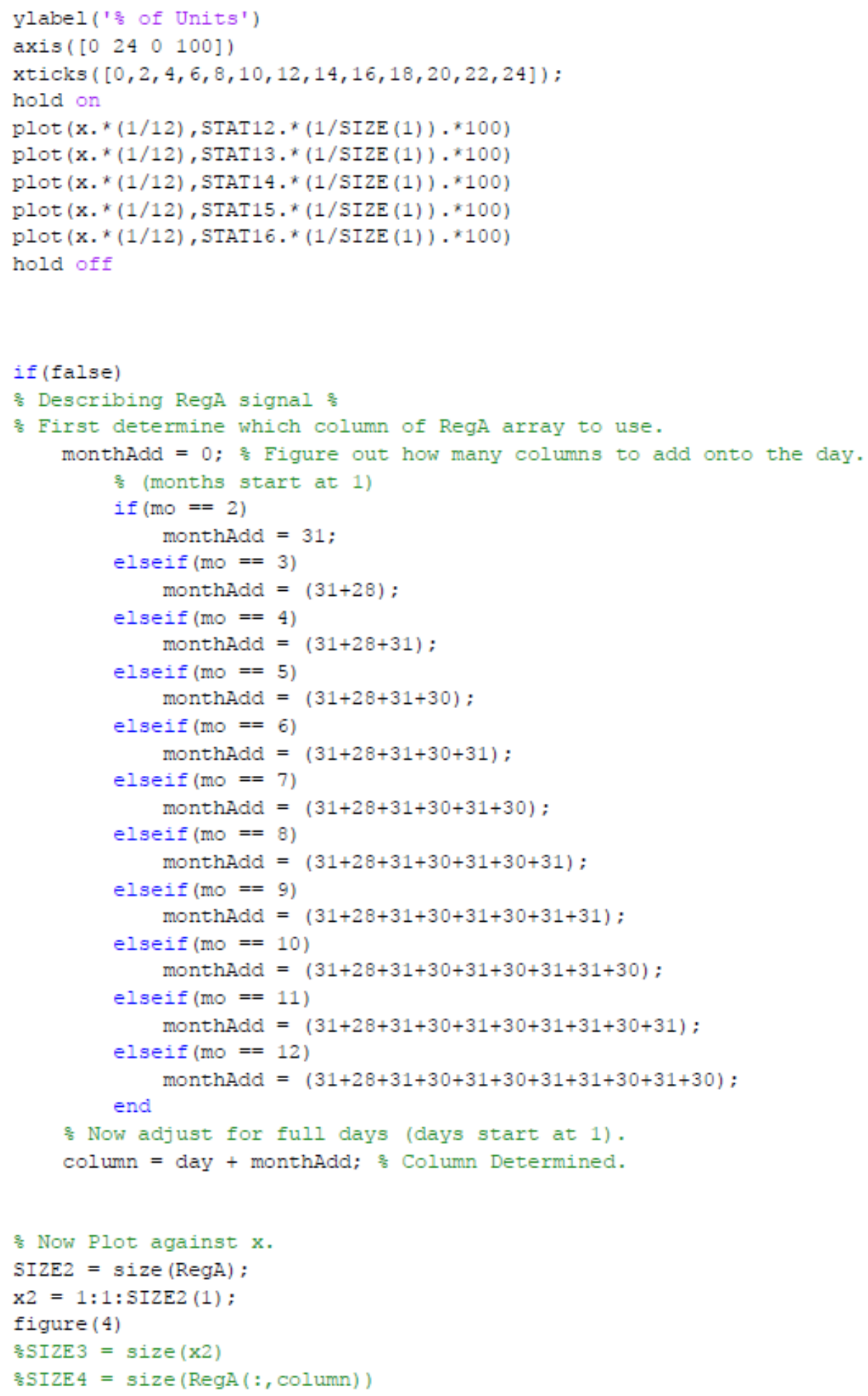




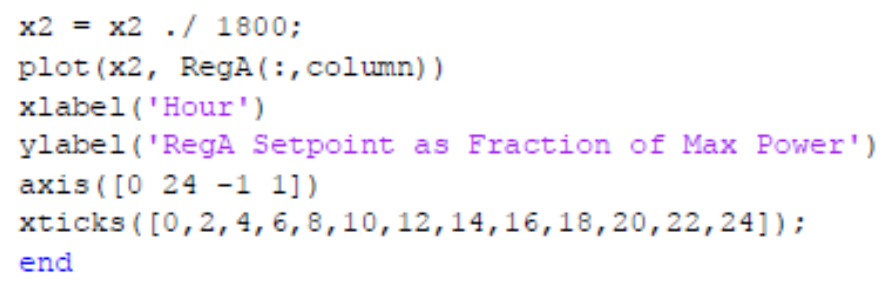




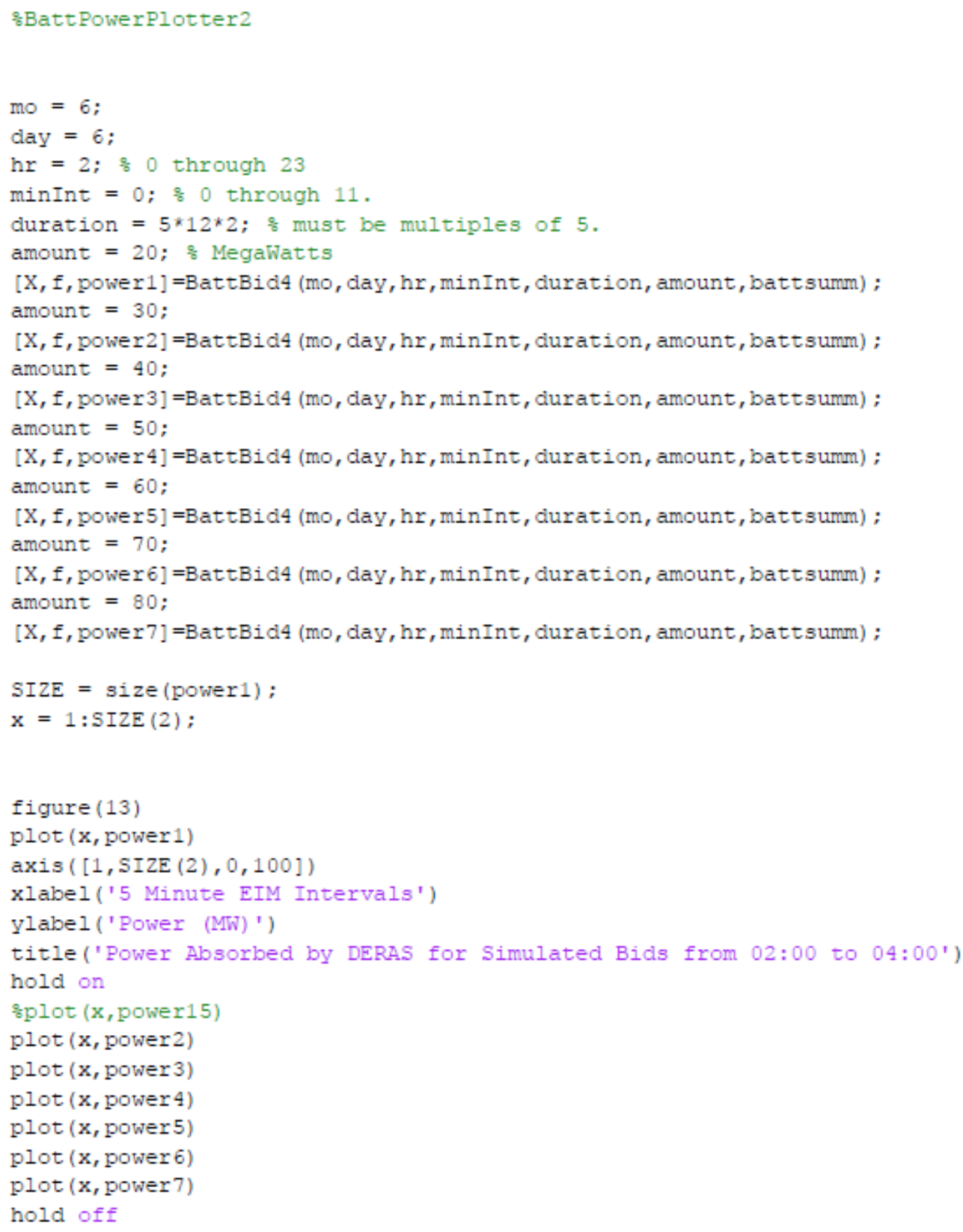




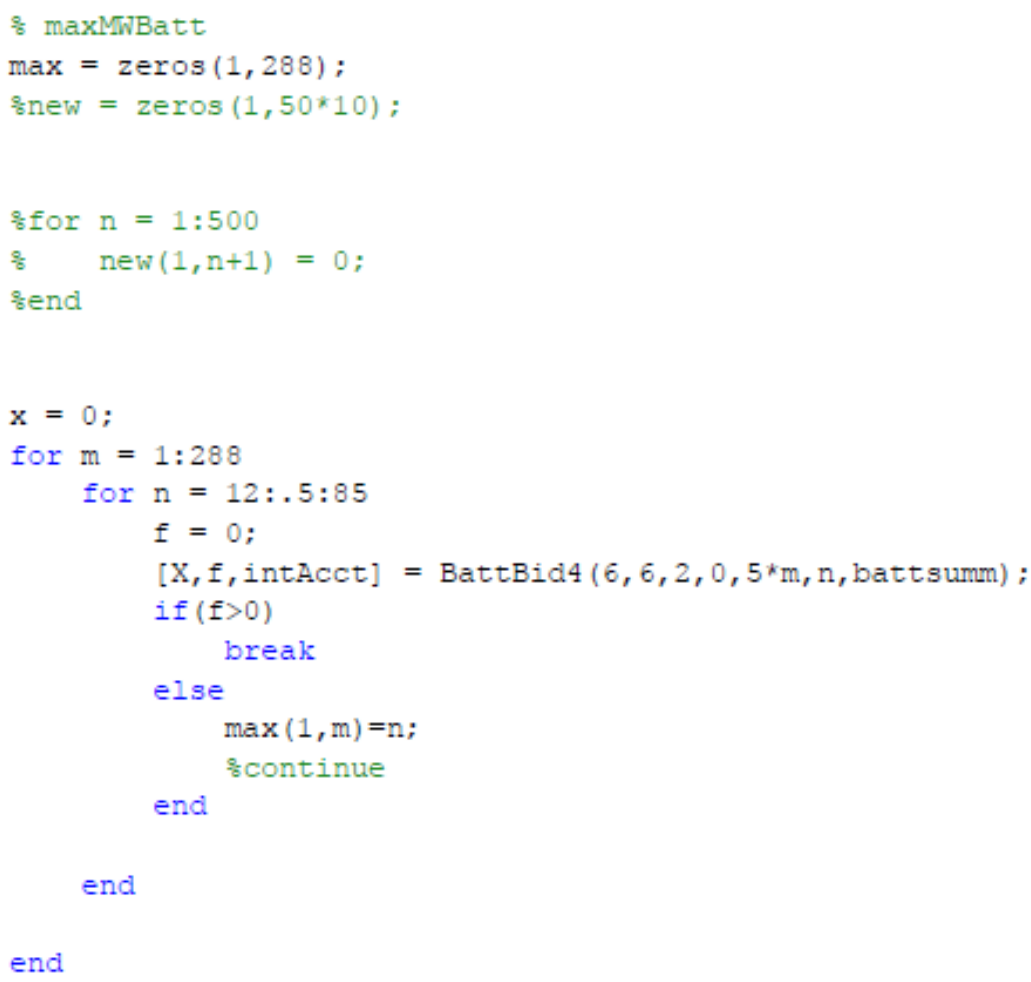

